\title{
Fetal alcohol spectrum disorders in South Africa
}

Citation for published version (APA):

Olivier, L. (2017). Fetal alcohol spectrum disorders in South Africa: A 20-year journey. [Doctoral Thesis, Maastricht University]. Datawyse / Universitaire Pers Maastricht. https://doi.org/10.26481/dis.20171212lo

Document status and date:

Published: 01/01/2017

DOI:

10.26481/dis.20171212lo

Document Version:

Publisher's PDF, also known as Version of record

\section{Please check the document version of this publication:}

- A submitted manuscript is the version of the article upon submission and before peer-review. There can be important differences between the submitted version and the official published version of record.

People interested in the research are advised to contact the author for the final version of the publication, or visit the DOI to the publisher's website.

- The final author version and the galley proof are versions of the publication after peer review.

- The final published version features the final layout of the paper including the volume, issue and page numbers.

Link to publication

\footnotetext{
General rights rights.

- You may freely distribute the URL identifying the publication in the public portal. please follow below link for the End User Agreement:

www.umlib.nl/taverne-license

Take down policy

If you believe that this document breaches copyright please contact us at:

repository@maastrichtuniversity.nl

providing details and we will investigate your claim.
}

Copyright and moral rights for the publications made accessible in the public portal are retained by the authors and/or other copyright owners and it is a condition of accessing publications that users recognise and abide by the legal requirements associated with these

- Users may download and print one copy of any publication from the public portal for the purpose of private study or research.

- You may not further distribute the material or use it for any profit-making activity or commercial gain

If the publication is distributed under the terms of Article $25 \mathrm{fa}$ of the Dutch Copyright Act, indicated by the "Taverne" license above, 
Fetal

Alcohol

Spectrum

Disorders in

South Africa

Leann Olivier

A 20-year journey 
The studies presented in this thesis were performed at the Foundation of Alcohol Related Research (FARR), South Africa among others in collaboration with the Governor Kremers Centre, Maastricht University, The Netherlands.

\section{farr}

Maastricht UMC+

GKC

(C) Copyright Leana Olivier, Cape Town-Maastricht 2017

Printing: Datawyse | Universitaire Pers Maastricht 


\title{
Fetal Alcohol Spectrum Disorders in South Africa
}

\author{
-A 20-year journey-
}

\begin{abstract}
DISSERTATION
to obtain the degree of Doctor at Maastricht University,

on the authority of the Rector Magnificus, Prof. dr. Rianne M. Letschert

in accordance with the decision of the Board of Deans,

to be defended in public on Tuesday 12 December 2017 at 16:00 hours
\end{abstract}

by

Leana Olivier 


\section{Supervisors}

Prof. dr. L.M.G. Curfs

Prof. dr. D.L. Viljoen (University of Stellenbosch and FARR, Cape Town, South Africa)

Prof. dr. G.J. Kok

\section{Assessment Committee:}

Prof. dr. J.G. Nijhuis (Chair)

Dr. D.M. Black (University of Groningen)

Prof. dr. E.P. Riley (San Diego State University)

Prof. dr. R.A.C. Ruiter

Prof. dr. L.J.I. Zimmermann 
This dissertation is dedicated with gratitude and respect to those who have walked this journey with me and to those who are devoted to the prevention of FASD. 



\section{Contents}

List of Abbreviations and Explanations of Terminology 9

List of Figures 12

List of Tables $\quad 12$

$\begin{array}{lll}\text { Chapter } 1 & \text { Introduction } & 13\end{array}$

$\begin{array}{lll}\text { Chapter } 2 \text { Alcohol Consumption } & 17\end{array}$

Chapter 3 History of Fetal Alcohol Spectrum Disorders 27

Chapter 4 The Prevalence of Fetal Alcohol Spectrum Disorders in South Africa $\quad 37$

Chapter 5 Fetal Alcohol Spectrum Disorders Determinants 53

Chapter 6 The Individual with a Fetal Alcohol Spectrum Disorder 69

Chapter 7 Fetal Alcohol Spectrum Disorders Intervention Opportunities in South Africa

Chapter 8 Discussion: Lessons Learnt from the Past 20 Years

Article 1 Fetal alcohol spectrum disorders: Prevalence rates in

South Africa

Article 2 Burden of fetal alcohol syndrome in the rural West Coast of South Africa

Article 3 Prevalence of Fetal Alcohol Syndrome in a South African City with a Predominantly Black African population

Article 4 Changes in drinking patterns during and after pregnancy among mothers of children with fetal alcohol syndrome: A study in three districts of South Africa

Article 5 Nocturnal incontinence in children with fetal alcohol spectrum disorders (FASD) in a South African cohort

Article 6 Effects of consumption of biscuits baked with Red Palm Oil (RPO) shortening on the vitamin A, $\alpha$ - and $\beta$-Carotene and vitamin $E$ status of pre-school children attending an informal crèche in Bethelsdorp, Eastern Cape. Part 1. Baseline Study. Nutritional and Health Status. 
Article 7 Effects of consumption of biscuits baked with Red Palm Oil (RPO) shortening on the vitamin $A, \alpha$ - and $\beta$-Carotene status of pre-school children attending an informal crèche in Bethelsdorp, Eastern Cape. Part 2. Intervention Study. Nutritional and Health Status.

Article 8 Effects of biscuits baked with Red Palm Oil (RPO) shortening on the vitamin $E$ and inflammatory status of pre-school children attending an informal crèche in Bethelsdorp, Eastern Cape. Part 3. Intervention Study. Nutritional and Health Status.

Summary

Samevatting

Valorization

Acknowledgements

Curriculum Vitae

Addendum 1 Informed Consent Form for FASD Prevalence Study

Addendum 2 Dysmorphology Checklist

Addendum 3 Cape Argus, 5 April 2016

Addendum 4 Healthy Mother Healthy Baby Programme: Audit Screening Tool

Addendum 5 Healthy Mother Healthy Baby Programme: My Special Booklet

Addendum 6 Do yo have 3 minutes? Card for Health Professional

Addendum 7 Do you have 3 minutes? Card for Educators

Addendum 8 Do you have 3 minutes? Card for Community Workers

301 


\section{List of Abbreviations and Explanations of Terminology}

Binge drinking is the most common pattern of excessive alcohol use. It typically occurs after a period of abstinence (e.g. week days) when a person then consumes 5 or more standard drinks (in the case of men) and 4 or more standard drinks (in the case of women), in about 2 hours. This raises the person's blood alcohol concentration (BAC) to 0,05 gram percent (legal alcohol limit) or more. (See the definitions of 'legal alcohol limit' and 'a standard drink' below.)

Birth defect or congenital disorder is a condition which arises before birth, adversely affecting the body structure or function.

Birth or biological mothers refer to the woman who gave birth to a child.

Black people refers to an ethnic classification in South Africa including all the black ethnic groups for example the Zulu, Xhosa, Tswane, Pedi, Suthu and other groups.

Coloured people (or "Coloureds") refers to a minority population group (9\%) in South Africa, derived from mixed ancestral origins.

Community Workers (CWs) in the text refers to lay people who were recruited by the Research Group from the project site. After employment they received extensive training in terms of FASD awareness, prevention and research. This included interviewing and counselling skills and techniques, data collection and electronic capturing, recordkeeping and public speaking.

Foundation for Alcohol Related Research (FARR) - referred to in the text as the 'Research Group', is a South African based non-governmental organization (NGO) focusing on research, awareness, prevention and training relating to Fetal Alcohol Spectrum Disorders (FASD). It was established in 1997 and the first to raise concern regarding FASD in the country.

Fetal Alcohol Spectrum Disorders (FASD) is the umbrella term to describe a group of conditions affecting the unborn baby resulting from prenatal alcohol exposure. There are four main conditions on the continuum of the spectrum, namely Fetal Alcohol Syndrome (FAS), Partial Fetal Alcohol Syndrome (pFAS), Alcohol Related Birth Defects (ARBD) and Alcohol Related Neurodevelopmental Disorder (ARND):

- Fetal Alcohol Syndrome (FAS) is the most severe form of FASD. It is characterized by prenatal and/or postnatal growth retardation (head, weight and height), characteristic facial anomalies and evidence of deficient brain growth and struc- 
tural abnormalities. It is not essential to have a confirmed prenatal alcohol consumption history to make this diagnosis.

- Partial Fetal Alcohol Syndrome (pFAS) is a diagnosis based on several key characteristic facial features, prenatal and/or postnatal growth retardation (head, weight and height), deficient brain growth and/or structural problems, and behavioural and cognitive abnormalities. A confirmed history of prenatal alcohol consumption is not mandatory to make this diagnosis.

- Alcohol Related Birth Defects requires the presence of characteristic facial abnormalities, the presence of structural defects of the heart, eye, skeleton and other major organs and a confirmed history of prenatal alcohol consumption.

- Alcohol Related Neurodevelopmental Disorders are diagnosed based on the evidence of deficient brain growth or structural abnormalities, behavioural and cognitive deficits and a confirmed history of prenatal alcohol exposure.

Imbizo is a gathering or meeting called by a traditional or community leader. The meeting is attended by community leaders and members. It provides them with the opportunity to gain information and to participate in the decision-making process.

Joe Public is a term used for a hypothetical person or member of the general public. It therefore represents ordinary people in the community.

Legal alcohol limit in South Africa is a breath alcohol content of $0.24 \mathrm{mg}$ per $1,000 \mathrm{ml}$, or a blood alcohol limit of $0.05 \mathrm{~g}$ per $100 \mathrm{ml}$. (https://www.drivesouthafrica.co.za/blog/ drunk-driving-in-south)

Millennium Development Goals (MDGs) are the world's time-bound and quantified targets for addressing extreme poverty in its many dimensions such as income, poverty, hunger, disease, lack of adequate shelter, while promoting gender equality, education, and environmental sustainability (https://www.unmillenniumproject.org/goals).

Millennium Development Goals (MDGs) for South Africa (2015):

- Eradicate extreme hunger and poverty;

- Achieve universal primary education;

- Promote gender equality and empower women;

- Reduce child mortality;

- Improve maternal health;

- Combat HIV/AIDS, malaria and other diseases;

- Ensure environmental sustainability;

- Develop a global partnership for development.

Primary Health Care (PHC) in South Africa is provided by the private or public sector. Citizens in middle and higher income groups, often with access to health insurance, use private health practitioners of their choice and private clinics, hospitals and pharmacies. 
The majority of the population (approximately 84\%) rely on health care services provided by the state such as clinics, day hospitals (open during office hours only) and district/provincial/tertiary hospitals. In remote rural areas health services are rendered from mobile units (trucks equipped to render a health care service).

Primary Health Care (PHC) Nurse in South Africa is defined as an Advanced Nurse Practitioner (ANP), who focuses on primary care, health assessment, diagnosis and treatment. In South Africa, these PHC nurses might specialize in midwifery, psychiatry and paediatrics and work outside of the formal hospital environment in community health care centre, clinics or mobile units (clinics in trucks) in rural areas or in the non-government sector.

Priority health programmes refer to the main service delivery areas identified for PHC services. In South Africa these are:

- Communicable Diseases (especially HIV/AIDS and Tuberculosis);

- Non-communicable (or chronic) diseases (e.g. cardio-vascular conditions and diabetes);

- Maternal, Child and Woman's Health;

- Injuries and Violence

Project Managers in the text, refers to professionals, such as registered nurses, social workers, educators, occupational therapists, psychologists, psychometrists, genetic counsellors, etc., recruited from project sites and appointed to manage the respective FASD research, awareness, prevention and training projects. These Project Managers received extensive training to equip them for their tasks. A number of them are currently doing post graduate studies on FASD issues.

A Standard drink refers to $10 \mathrm{ml}$ to $15 \mathrm{ml}$ of absolute alcohol (AA). The calculations differ from country to country. In South Africa $10 \mathrm{ml}$ of AA is classified as standard drink.

Ubuntu is a Nguni term which means "humanity". It is often used in describing humanity towards others. It also means that a human being cannot function in isolation, but needs others to succeed, thereby making the collective effort bigger than the individual outcome.

Umqombothi is the Xhosa word for homebrewed beer. The beer is made from maize (corn), malt, sorghum, salt and water. It has a low alcohol content, usually less than $3 \%$ and is rich in Vitamin B. It is light in colour, with a thick and creamy texture. The beer has a sour smell and often appears frothy. It is commonly found in South Africa and very popular in especially the rural areas.

WHO or World Health Organization was established in 1948 as a specialized agency of the United Nations focusing on international public health. It has its headquarters in Geneva, Switzerland. The WHO Constitution was signed by 61 countries in 1948. 


\section{List of Figures}

Figure 1: Drink of choice per percentage in South Africa 22

Figure 2: William Hogarth's Gin Lane (1751) 31

Figure 3: Three-tiered approach used during FASD prevalence studies 42

Figure 4: Alcohol burden in South Africa 48

Figure 5: Reasons for the gap in understanding FASD stigmatisation 62

Figure 6: Common cognitive and behavioural problems in children with FASD $\quad 74$

Figure 7: The cycle caused by the underestimation of congenital disorders, such as FASD 84

Figure 8: FASD stakeholders $\quad 85$

Figure 9: The Research Group's main focus areas 97

Figure 10: PAth project logo 98

Figure 11: The 3-phased approach of the Comprehensive FASD Projects 100

Figure 12: The Research Group's prevalence study sites and rates 101

Figure 13: Flyer for the LoveChild industrial theatre show and workshop 103

Figure 14: One of the LoveChild actors in action 103

Figure 15: FAStrap Course Modules 105

Figure 16: Healthy Mother Healthy Baby Programme: Risk Groups 106

Figure 17: Summary of brief interviewing sessions in HMHB Programme 107

Figure 18: A group of high-risk clients who completed the HMHB Programme with their healthy infants

108

\section{List of Tables}

Table 1: South African FASD prevalence rates

Table 2: Overview of possible links and opportunities with FASD stakeholders

Table 3: Intervention Mapping Model used to develop the HMHB Programme as part of the Comprehensive FASD research, awareness, prevention and training project 
Chapter

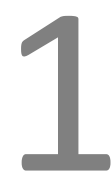

Introduction 



\section{Introduction}

The South African story of Fetal Alcohol Spectrum Disorders (FASD) is complex and deeply imbedded in the country's history. Exploring this journey, takes one back to interesting, but also dark places, in the country's history, exposes continuous misunderstandings and marginalization, and fortunately, at the same time, also provides promising opportunities for future management.

The past and, sometimes, present-day, often makes it difficult for some South Africans to understand FASD as the public health problem that it is, and therefore, a psycho-social and economic threat to the well-being of the country and all its citizens. Together with HIV/AIDS, Tuberculosis (TB), Malaria, Malnutrition and other Substances of Abuse, including the influx of immigrants from neighbouring countries, FASD is constantly competing for access to scarce resources in this under-resourced, developing country. It is therefore vital for government departments, the public sector, civil society and Joe Public to take collective responsibility and action to prevent this problem and to take adequate care of fellow citizens already affected by FASD and their families.

\section{Thesis outline and research questions}

In this thesis the author briefly explores the history of alcohol use and abuse in South Africa. She outlines the history of FASD internationally and nationally, and reports on studies focusing on the prevalence of FASD in different communities in five of the nine provinces in South Africa since 1997 (no prevalence studies have been done in the other provinces to date). An overview of some of the determinants for prenatal alcohol use are provided and factors pertaining to individuals affected with FASD are evaluated. FASD prevention strategies and opportunities in the current South African context are discussed. The author furthermore shares awareness, prevention and training interventions implemented over the past 20 years by the leading FASD non-governmental organization in South Africa, the Foundation for Alcohol Related Research (FARR). Existing gaps and challenges are highlighted. Information from the authors research and published peer reviewed journal articles are included. Finally, recommendations on how to address the problem more effectively are discussed and also questions to guide this process are identified.

The publications indicated with an asterisk $(*)$ are part of this thesis (see list of publications page 113). Each chapter of this thesis ends with one or more references of author's publications relevant to the chapter. 

Chapter

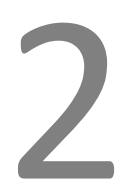

Alcohol Consumption 



\section{A brief history of alcohol consumption in South Africa}

Like the rest of the world, many indigenous groups in South Africa brewed and consumed alcohol for pleasure, medicinal purposes, during times of conflict and wars, to strengthen warriors, to celebrate victories and for trading. People did not drink on a daily basis or did not drink alone just for the sake of 'drinking' (Parry, 2000).

In South Africa the well-known traditional beer, Umqombothi (Xhosa word for beer), was brewed from maize (corn), sorghum malt, yeast and water. It is rich in Vitamin B and has a low alcohol content (usually less than 3\%). The Umqombothi ingredients, were cooked in a cast-iron pot, fermented for a few days, strained and consumed to celebrate events such as the home-coming of young men from initiation, receptions for warriors, weddings, funerals or at imbizos (traditional meetings). The drinking was moderate and very strict social and tribal guidelines existed as to when, why, how much and who should drink. Although the women were responsible for the brewing of the beer, they were mostly excluded from the use thereof (Olivier, Curfs \& Viljoen, 2016; Setlalentoa, Pisa, Thekisho, Ryke \& Loots, 2010).

With the arrival of the Dutch Settlers in 1652 and later, the French Huguenots, wine farms were established in the Western Cape. Indigenous South Africans, mostly people from Khoisan and Hottentot origin, as well as slaves, were employed as farm workers. During the colonial times (1652 to 1948), settlers introduced the practice of partially paying their farm workers with bread, tobacco and wine for their labour (Olivier et al., 2016; Scully, 1992). The system, known as the 'dop' system, soon became entrenched in the lives of farm workers and their families (Setlalentoa et al., 2010). The 'dop' system was outlawed in 1961 and became an illegal practice in 2003 with fines as high as ZAR1million for any contravention of this act. Unfortunately, the effects of the system still linger and in many ways created the legacy of alcohol abuse and dependency in these areas, especially in the form of binge drinking (Croxford \& Viljoen, 1999).

The introduction to Western practices also acquainted local people to European liquor, initially called 'Cape Smoke'. High levels of intoxication led to absenteeism, productivity and unruly behaviour and resulted in the Prohibition Act of 1897 which made it illegal for black people to drink alcohol (Setlalentoa et al., 2010).

In the northern part of South Africa, with the discovery of gold and diamonds, the mining industry provided job opportunities for mostly Black African male migrant workers who lived in compounds (dormitories or shared living spaces) whilst their wives stayed at home to tend to their children, cattle and crops. The life of these migrant workers centred on work, sleep and leisure. Drinking provided comfort and often led to alcohol dependence and addiction. Beer was brewed by the miners or women who stayed in the areas around the mines. The women sold the beer to miners as an additional income. In 'Brewers, Beerhalls and Boycotts', Paul la Hausse (1988) describes how the mine authorities turned a blind eye to these practices, but society in general became increasing concerned about the alcohol abuse and resulting consequences such as 
prostitution and loitering. To control the drinking, town councils stepped in and established beer halls. The first was built in the KwaZulu Natal Province in 1909. The Native Beer Act of 1908 allowed the municipalities to use the profits from their beer sales to build houses, hospitals and "other facilities for Africans" (Lester, Menguele, KaruriSebina \& Kruger, 2009).

Beer hall protests erupted in the late 1920's, mainly because women whose men were working on the mines, complained that their menfolk were spending too much of their wages on beer and sent too little home (La Hausse, 1988). By the 1960s more than 60 municipalities operated legal beer halls whilst black African women sold their beer in shebeens (informal bars) (Lester et al., 2009). Home-brewing was illegal and often resulted in 'beer hall raids' by 'beer police'. Black musicians, like Miriam Makeba, ("Miriam Makeba", n.d.) wrote striking songs about the beer raids such as 'Khwela Khwela' as a reminder to these times.

Today, licenced shebeens serve mostly commercial beers and other alcoholic drinks, along with some traditional beers. In rural areas the shebeens take the form of mobile distributors who travel by car or truck to sell their products to consumers who might not have access to transport. In many ways the shebeen-system has replaced the 'dop' system and by doing so facilitates the easy access to alcohol and continues to feed the cycle of poverty and alcohol dependence (London, 1999).

The above-mentioned record gives some background information regarding the drinking practices in some of the cultural groups in South Africa. Unfortunately, little is known about the drinking practices of the Settlers, Voortrekkers (citizens who moved from the south to the northern parts of South Africa during the 1800's to escape the British regime) and other groups.

\section{Current alcohol consumption in South Africa}

In local tribal mores, beer-brewing and consumption thereof were socially controlled by the traditional regulations. Social and economic changes resulting from westernization and urbanization brought about new patterns of drinking. The easy access to alcohol, the higher alcohol content and enticing advertising contributed to the changes in the drinking patterns. Alcohol use among women, previously socially frowned upon, has also become normalized and largely accepted (Morojele, Kachiengá, Mokoko, Nkoko, Parry, Nkowane \& Saxena, 2006; Setlalentoa et al., 2010). Previously where individuals drank until the 'beer ran out', people now started drinking until 'the money runs out' (Jernigan, Monteiro, Room \& Saxena, 2000).

It is estimated that in 2012 alcohol contributed to 5,9\% (3,3 million) of deaths in the world and 5,1\% (139 million) to disability adjusted life years. South Africa is also listed as the country with the 31st highest level of alcohol consumption with 11 litres of absolute alcohol consumed per capita (World Health Organization [WHO], 2014). 
In exploring the reasons for the high levels of alcohol consumption in South Africa, stress is frequently listed as a possible causative factor. (Bezuidenhout, 2004). Alcohol is also seen as a social lubricant which helps people relax, reduces stress and dulls the pain of hardship. It is used by some as a ritual and sign of macho behaviour and some users succumb to peer pressure. For others it provides a form of social sharing and is abused due to alcohol dependence and addiction (Freeman \& Parry, 2006).

Not all South Africans drink. In 2002 there were fewer 'current drinkers' than in other developing countries, such as Mexico and Namibia (Room, Jernigan, Carini-Marlatt, Gureje, Mäkelä, Marshall \& Saxena, 2002). In the South African Demographic and Health Survey of 1998 (SADHS), just under half of men (45\%) and 17\% of women, older than 15 years, reported that they were using alcohol (Freeman \& Parry, 2006). In the same survey white males (71\%) reported the highest consumption levels, followed by white females (51\%) and Coloured males (45\%). African (12\%) and Asian (9\%) females reported the lowest levels. For females the highest levels (23-25\%) were recorded in the Free State, Western Cape and Northern Cape Provinces (Freeman et al., 2006; Olivier, et al., 2016).

Unfortunately, it seems as if the national alcohol consumption rates in South Africa are on the increase. The WHO reports that $56,3 \%$ of men and $26,3 \%$ of women, older than 15 years, consumed alcohol during the past year (WHO, 2014). In countries with a high level of abstention it is highly likely that the per capita consumption rate will be understated (Olivier et al., 2016). Coupled with the underreporting, it possibly provides some of the reasons why there is often inconsistency in reports on the absolute alcohol (AA) per capita consumption rates in South Africa. Estimates of the average per capita consumption in South Africa vary from 11 litres of absolute alcohol/AA (WHO, 2014) to 10,3 - 12,4 litres of AA (Peltzer \& Ramlagan, 2009). Compared to the global average of 6,2 litres it shows that South Africa has one of the highest rates of consumption in the world (Peltzer et al., 2009).

South African males and females are equally likely to engage in risky drinking (Room et al., 2002). This is contrary to what has been found in developed countries (Babor, Caetona, Casswell, Edwards, Giesbrecht, Graham, ... \& Rossow, 2003). Binge drinking practices ( $\geq 4$ drinks per occasion for women and $\geq 5$ drinks for men), as defined by the National Institute on Alcohol Abuse and Alcoholism (2015), are very similar for males and females with a 4-5 times greater frequency during weekends. This is especially prevalent in rural areas and amongst people with a lower level of education (Grade 1 to Grade 7). The prevalence is most frequent amongst Africans and Coloureds, with the highest levels reported amongst females in the Northern Cape Province (Freeman et al., 2006).

According to Freeman and Parry (2006) commercial beer is by far the drink of choice, followed by traditional beer (home-brewed beer) and wine, as illustrated in Figure 1 below. 




Figure 1: Drink of choice per percentage in South Africa (Freeman, et al., 2006)

Although the 'dop' system is illegal, there are media and word-of-mouth reports that it might still be practiced in isolated cases. Based on a study which specifically investigated alcohol use, working conditions, job benefits and the legacy of the 'dop' system amongst farm workers in the first FASD prevalence study site in the Western Cape Province, there is currently 'zero tolerance for coming to work intoxicated'. Farm owners encourage their workers to use alcohol responsibly and also assist those with dependency problems to obtain the necessary treatment (Gossage et al., 2014). Despite of this, the study found that the legacy of the 'dop' system contributed to the current use of alcohol by these workers (Gossage, Snell, Parry, Marais, Barnard, De Vries, ... \& May, 2014). In research studies elsewhere in the country it became apparent that the easy availability of alcohol (e.g. by shebeens) and the acceptability of alcohol use by both men and women are important contributors not only to the high levels of alcohol abuse, but also FASD in South Africa (Olivier et al., 2016).

\section{Government's most recent response}

Since 1994 several new alcohol policies, regulations on alcohol advertising, the by-laws on retail alcohol sales, control of alcohol packaging and increased alcohol taxation have been put into place in an attempt to address the high alcohol consumption rate and to reduce alcohol-related harm in South Africa. The most recent attempt is the Draft Liquor Amendment Bill (2016) which was released by the National Department of Trade and Industry for public comment on 3 October 2016. The Bill proposes a raise in the legal age for alcohol consumption from 18 to 21 years of age, restrictions on the num- 
ber and location of liquor outlets, stricter licensing procedures and reporting of irregularities. (Department of Trade and Industry, 2016).

\section{Conclusion}

Alcohol abuse has a long history of many detrimental outcomes, such as harmful health and psycho-social effects, risky behaviour, FASD, family disruption, negative work performance, economic cost and injuries, increased violence and criminal activities and, ultimately, even disability or death. Deeply imbedded in the country's history are historical reasons and tribal practices which perpetuated alcohol use and abuse. Exploitation and oppression further aggravated some of the problems. For the country to adequately address alcohol abuse and its related problems, all of these factors have to be acknowledged and taken into consideration.

\section{Author's Publications Relevant to Chapter 2}

* Olivier, L., Curfs, L.M.G. \& Viljoen, D.L. (2016). Fetal alcohol spectrum disorders: Prevalence rates in South Africa. South African Medical Journal 106(6) Supplement 1: S103S106. http://doi.org/10.7196/samj.2016.v106i6.11009 


\section{References}

Barbor, T., Caetano, R., Casswell, S., Edwards, G., Giesbrecht, N., Graham, K., Grube, J., Gruenewald, P., Hill, L., Holder, H., Homel, R., Ősterberg, E., Rehm, J., Room, R., \& Rossow, I. (2003). Alcohol no ordinary commodity: Research and public policy. New York: Oxford University Press

Bezuidenhout, F. J. (2004). Substance Abuse and addiction: Drugs and alcohol. In F. J. Bezuidenhout (Ed.), A reader on selected social issues (3rd ed., pp. 15-30). Pretoria: Van Schaik Publishers

Croxford, J., \& Viljoen, D. (1999). Alcohol consumption by pregnant women in the Western Cape. South African Medical Journal, 89(9), 962-965

Department of Trade and Industry. (2016). Draft Liquor amendment bill. Government Gazette, (40319), 4-27. Retrieved from http://www.gov.za/sites/www.gov.za/files/40319_gon1206.pdf

Freeman, M., \& Parry, C. (2006). Alcohol use literature review. Retrieved from http://saapa.net/research-andresources/research/alcohol-use-literature-review.pdf

Gossage, J.P., Snell, C.L., Parry, C.D.H., Marais, A-S., Barnard, P., De Vries, M., Blankenship, J., Seedat, S., Hasken, J.M., \& May, P.A. (2014). Alcohol use, working conditions, job benefits, and the legacy of the "Dop" system among farm workers in the Western Cape Province, South Africa: Hope despite high levels of risky drinking. International Journal of Environmental Research and Public Health 11(7): 7406-7424, http://do.org/10.3390/ijerph110707406

Jernigan, D. H., Monteiro, M., Room, R., \& Saxena, S. (2000). Towards a global alcohol policy: Alcohol, public health and the role of WHO. Bulletin of the World Health Organization, 78(4), 491-499. http://doi.org/10.1590/S0042-96862000000400011

La Hausse, P. (1988). Brewers beerhalls and boycotts: A history of liquor in South Africa. Johannesburg: Raven Press.

Lester, N., Menguele, F., Karuri-Sebina, G., \& Kruger, M. (Eds.) (2009). Township Transformation Timeline. Department of Co-Operative Governance and Traditional Affairs in collaboration with the European Commission, 2009

London, L. (1999). The "dop" system, alcohol abuse and social control amongst farm workers in South Africa: a public health challenge. Social Science \& Medicine, 48(10), 1407-1414. http://doi.org/10.1016/s02779536(98)00445-6

Miriam Makeba. (n.d.). Retrieved August 18, 2017, from http://www.allmusic.com/artist/miriam-makebamn0000496097

Morojele, N. K., Kachieng'a, M. A., Mokoko, E., Nkoko, M. A., Parry, C. D. H., Nkowane, A. M., \& Saxena, S. (2006). Alcohol use and sexual behaviour among risky drinkers and bar and shebeen patrons in Gauteng province, South Africa. Social Science and Medicine, 62(1), 217-227. http://doi.org/10.1016/j.socscimed. 2005.05.031

National Institute on Alcohol Abuse and Alcoholism. (2015). Women and Alcohol. Retrieved from https://pubs.niaaa.nih.gov/publications/womensfact/womensFact.pdf

Olivier, L., Curfs, L. M. G., \& Viljoen, D. L. (2016). Fetal alcohol spectrum disorders: Prevalence rates in South Africa. South African Medical Journal, 106(6 Suppl. 1), S103-S106. http://doi.org/10.7196/SAMJ.2016. v106i6.11009

Parry, C. D. H. (2000). Alcohol problems in developing countries: Challenges for the new millennium. Suchtmed, 2(4), 216-220.

Parry, C. D. H., Plüddemann, A., Steyn, K., Bradshaw, D., Norman, R., \& Laubshcer, R. (2005). Alcohol use in South Africa: findings from the first Demographic and Health Survey (1998). Journal of Studies on Alcohol, 66(1), 91-97.

Peltzer, K., \& Ramlagan, S. (2009). Alcohol use trends in South Africa. Journal of Social Sciences, 18(1), 1-12.

Room, R., Jernigan, J., Carlni-Marlatt, B., Gureje, O., Mäkelä, K., Marshall, M., .... \& Saxena, S. (2002). Alcohol and the developing world: A public health perspective. Helsinki: Finnish Foundation for Alcohol Studies in collaboration with the World Health Organization, 2002. 
Scully, P. (1992). Liquor and labour in the Western Cape, 1870-1900. In J. Crush \& C. Ambler (Eds.), Liquor and labour in Southern Africa (pp. 56-77). Athens: Ohio University Press.

Setlalentoa, B. M. P., Pisa, P. T., Thekisho, G. N., Ryke, E. H., \& Loots Du, T. (2010). The social aspects of alcohol misuse/abuse in South Africa. South African Journal of Clinical Nutrition, 23(Suppl. 1), S11-S15. http://doi.org/10.1080/16070658.2010.11734296

World Health Organization. (2014). Global status report on alcohol and health-2014. World Health Organization. Retrieved from http://www.who.int/substance_abuse/publications/global_alcohol_report/msbgsru profiles.pdf 

Chapter



History of Fetal Alcohol Spectrum Disorders 



\section{Fetal Alcohol Spectrum Disorders (FASD): a snapshot}

Alcohol consumption during pregnancy might lead to a myriad of adverse pregnancy outcomes such as spontaneous abortions, preterm labour, low birth weight, stillbirths, postnatal growth retardation, neonatal and infant deaths, such as Sudden Infant Death Syndrome (SIDS) (Grinfeld, 2009; Odendaal, Steyn, Elliot \& Burd, 2009; Ornoy \& Ergaz, 2010) and Fetal Alcohol Spectrum Disorders (Jones \& Smith, 1973; Jones, Smith, Ulleland \& Streissguth, 1973).

The term Fetal Alcohol Spectrum Disorders (FASD) describes a wide range of birth disorders or disabilities resulting from prenatal alcohol exposure. The most severe form of this group is Fetal Alcohol Syndrome (FAS). Other conditions on the spectrum of disorders include Partial Fetal Alcohol Syndrome (pFAS), Alcohol Related Neurodevelopmental Disorders (ARND) and Alcohol Related Birth Defects (ARBD) (Hoyme, Kalberg, Elliot, Blankenship, Buckley, Marias \& May, 2016). There is also a diagnostic category, separate from FASD in the field of psychology, namely neurobehavioral disorderprenatal alcohol exposed (ND-PAE) (Harris, 2014).

Individuals with FASD, especially FAS and pFAS, might present with characteristic facial features (Hoyme et al., 2016) and, due to the permanent brain damage, experience learning disabilities and behavioural anomalies. Meaningful relationships are difficult to establish, risky behaviours become the norm and inappropriate decision-making is common (Davis, Gagnier, Moore \& Todorow, 2013). Depending on the level of injury, an individual can be so severely affected that he/she becomes a dependent for life, placing a considerable economic and psycho-social burden on the family, community and society at large (Lupton, Burd \& Harwood, 2004: Thanh \& Johnsson, 2009). In a developing country like South Africa this burden has severe societal and fiscal consequences (Credé, Sinanovic, Adnams \& London, 2011).

\section{FASD: A new condition or not?}

Alcohol has been consumed and abused since antiquity with many references in historical scriptures and publications about the harmful effects of alcohol. It is therefore difficult to understand why Fetal Alcohol Syndrome (FAS) was only described as a clinical result of maternal alcohol use in the $20^{\text {th }}$ century. Many researchers have attempted to find historical and religious references to the syndrome or to alcohol related birth defects. There are references in the Quran forbidding all Muslims to use any form of alcohol (Quran 5: $90-91 \&$ 35:6), but no reference is made to possible birth defects due to alcohol use. The Biblical reference of an angel visiting Samson's mother and forbidding her to use alcohol whilst she is pregnant, is another example that is frequently used (Judges 13: 3 - 4). Unfortunately, this Biblical reference has nothing to do with the pre- 
vention of birth defects, but rather refers to the practices of Nazirites who were expected to abstain from any alcohol use (Judges 13: 15; Abel, 1997).

In his report on the studies of ancient times, Abel (1997) states that although the Talmud mentions a number of birth defects, it does not warn against alcohol related birth defects. However, on the contrary, it recommends that pregnant women should drink wine to ensure that they bear strong, good-looking and healthy children (Ketub 60b-61a). It was also believed that breastfeeding mothers could increase their milk production by drinking wine (Ketub 65b; Abel, 1997).

Some authors quoted Aristotle as stating in the 'Problamata' that "... foolish, drunken and hare-brained women [for the] most part bring forth children like unto themselves, morose and languid". But recent research could not confirm that Aristotle was in fact the creator of this damning message (Abel, 1999). Some researchers furthermore claim that the ancient Carthaginian custom whereby newly married couples were forbidden to use alcohol on their wedding night resulted from a believe that alcohol consumption pre-conception will lead to the birth of children with birth defects (Jones \& Smith, 1973). Abel believes that alcohol use, even by pregnant women, was generally perceived as part of a 'healthy lifestyle' (Abel, 1997).

In modern times, alcohol has often been used for medicinal purposes. British colonists used gin and tonic as a way of warding off malaria, due to the anti-malarial effect of the quinine in the tonic. This trend was also applied by British hunters in Africa and has led to the current day practice of the ultimate way to end a day on safari.

In 1747 a Scottish surgeon, James Lind, discovered that scurvy, one of the most common illnesses amongst sailors, could be prevented by consuming citrus fruit. In 1867 the Merchant Shipping Act made it compulsory for all British ships to provide lime juice to its crew. In 1879 Rear- Admiral Sir Thomas Gimlette, a surgeon in the Royal Navy, prescribed gin and lime cordials as part of sailors' regular daily ration. Apart from its anti-scurvy function the lime juice also masked the bitterness of the gin and ensured that the sailors consumed their medicine. (Hence the 'gimlet cocktail'.) (http://www.diffordguide.com/about). The association with the health benefits helped to popularise gin in 'polite society', but it soon threatened to cause ruin as it affected so many of the population, especially in London. As early as 1750 William Hogarth painted his notorious depiction of London life, entitled Gin Lane, centred around a baby falling from its gin-drinking mother's arms (Figure 2). Calling on society's moral conscious, gin soon got the unflattering name of 'Mother's Ruin.' (http://www.historicuk.com/CultureUK/Mothers-Ruin/). 




Figure 2: William Hogarth's Gin Lane (1751)

The first recorded medical warnings regarding the possible harmful effects of prenatal alcohol consumption described infant outcomes during the 'gin epidemic' when the British Royal College of Physicians (1752) reported that 'weak, feeble and distempered children' might be born after been exposed to gin in utero. Of interest is that during this time (1697-1764) the gin tax was reduced, making gin very cheap. At the same time physicians reported an increase in infant mortality and epilepsy (Hoyme, May, Kalberg, Kodituwakku, Gossage, Trujillo, ... \& Robinson, 2005)

In 1834 the House of Commons (England) issued a parliamentary report on the 'Effects of Drunkenness on the Nation'. This report remarked on the phenomenon that infants of maternal alcoholics are 'born starved, shrivelled and imperfect in form'. After the British College of Physicians encouraged the Parliament to increase gin taxation, infant mortality and epilepsy decreased (Warren \& Foudin, 2001).

The recording of the possible harmful effects of prenatal alcohol exposure continued with the Deputy Medical Officer of the Convict Prison in Parkhurst, England reporting in 1899 that pregnant inmates, known to be alcoholics, were at a higher risk of miscarriages and that their babies were often born with birth defects (Warren, et al. 2001). In 1900 Sullivan reported a higher rate of pregnancy losses, stillbirths, and epilepsy amongst children of chronic alcohol abusing mothers (Barry, Caetano, Chang, DeJoseph, Miller, O’Çonnor, ... \& Leeks, 2009). 
In 1968 Lemoine published the first journal article on the teratogenic effects of prenatal alcohol use in his article 'The children of alcoholic parents: anomalies observed in 127 cases'. (Calhoun \& Warren, 2007; Lemoine, Harousseau, Borteyru, \& Menuet, 2003). Lemoine described a common pattern of birth defects, as well as growth retardation, low IQ, psychomotor delays and atypical EEG (Bertrand, Floyd, Weber, O'Connor, Riley, Johnson, ...\& National Task Force on Fetal Alcohol Syndrome and Fetal Alcohol Effects, 2009), but unfortunately did not provide any further information on the affected children. Five years later Jones and Smith described a number of case studies where they found a generic pattern of physical and developmental anomalies in babies and children prenatally exposed to alcohol and coined the condition 'Fetal Alcohol Syndrome' or FAS (Jones, et al., 1973; Smith \& Smith, 1973). At the same time, they also laid the foundation for the first diagnostic criteria.

When Fetal Alcohol Syndrome (FAS) was initially described, the diagnosis was largely based on physical parameters, such as pre and/or postnatal growth retardation and a unique cluster of facial anomalies. Research has since determined that FAS lies towards the extreme end of the continuum of alcohol related birth disorders. Over the years it has become apparent that the most profound effects of FASD are on the developing brain, as well as the life-long cognitive and behavioural effects. This resulted in the term Fetal Alcohol Spectrum Disorders (FASD) (Riley, Infante \& Warren, 2011). Various internationally accredited guidelines to facilitate the diagnosis of FASD have been developed since 1997 and include the physical features of the patient, as well as the Central Nervous System deficiencies (Astley \& Clarren, 2000; Chudley, Conry, Cook, Loock, Rosales \& Leblanc, 2005; Hoyme, et al., 2005; Hoyme, et al., 2016). Although there is no international consensus on the use of these diagnostic criteria the Institute of Medicine guidelines are currently most widely used, which is also the case in South Africa (Hoyme, et al., 2005).

A vast number of FAS, and later FASD-related prevalence studies have been conducted in many countries resulting in two recent systematic reviews and meta-analyses. Popova, Lange, Probst, Gmel, \& Rehm (2017) estimated the global FAS prevalence rate as 14,6 per 10000 (9,4-23,3). Roozen, Peters, Kok, Townend, Nijhuis \& Curfs (2016) estimated the global FAS prevalence between 0 and 39.55 per 10000 livebirths (point estimate to be 2.89). FAS has also been acknowledged as the leading cause of preventable mental disabilities in the world (Astley, 2013).

\section{The start of the FASD jouney in South Africa}

In South Africa the earliest references to FAS dates back to 1978 when two clinicians, Beyers and Palmer, reported on infants with FAS in their clinics (Beyers \& Moosa,1978; Palmer, 1978). In 1985 Palmer conducted a 12-month survey amongst newborns in a 
Cape Town hospital and reported a prevalence of 1 per 281 live births (Marais, Jordaan, Olivier \& Viljoen, 2012).

Until the first research study in 1997, funded by the USA's National Institute of Health (NIH) and the National Institute for Alcohol Abuse and Alcoholism (NIAAA), through the Foundation for Alcohol Related Research (FARR), FASD was a totally underreported condition in South Africa. The first official report raising concern about FAS in South Africa was published in 1999 (Viljoen, 1999). Since then, FASD rates ranging from 27 per 1000 (Viljoen \& Craig, 2001) to 259 per 1000 (May, De Vries, Marais, Kalberg, Adnams, Hasken, ... \& Hoyme, 2015; Olivier, et al., 2016) and 280 per 1000 (Olivier, 2017) have been reported in South Africa in rural and urban communities.

The true scale of the FASD problem in South Africa is most probably considerably higher than reported in the above studies. Due to difficulties in diagnosing participants with the full spectrum of the disorder, specifically Alcohol Related Birth Defects (ARBD) and Alcohol Related Neurodevelopmental Deficits (ARND) in a community prevalence study in a rural area, the researchers are the first to acknowledge that these conditions are surely under-diagnosed and reported (Olivier, Urban, Chersich, Temmerman \& Viljoen, 2013).

Commenting on the high FASD rates Olivier and colleagues (2016), state that South Africa has some of the highest reported rates in the world. With HIV/AIDS, tuberculosis, malnutrition and malaria listed as the top health priorities in the country, the bulk of the public health resources are allocated to these conditions. Despite the fact that the prevalence of FASD is higher than HIV/AIDS or tuberculosis in some of the researched areas, FASD is yet to be acknowledged as a public health priority by the National Department of Health. Government prevention, awareness and management programmes are limited to a few high-risk areas in the Northern Cape and Western Cape Provinces. Little or no training is provided to service providers within the government sector, leading to gross under-diagnosis and reporting. This is costing families, communities and the country dearly (Olivier, et al, 2016).

Sampson and colleagues (1997) state that 'FAS is the most common preventable cause of mental retardation in the world'. Research in South Africa indicate that this country is especially hard hit. The potentially crippling effect of the FASD-related disabilities necessitates further research, as well as practical and cost-effective interventions to address this preventable condition.

\section{Conclusion}

Despite claims of religious and historical scriptures' reference to the dangers coned of prenatal alcohol abuse and possibly FASD, the first recorded description of the condition was by Lemoine and colleagues in 1968 (Lemoine, et al., 2003). Smith and Jones were the first to name the condition and raised awareness regarding Fetal Alcohol Syn- 


\section{Chapter 3}

drome (Smith, et al. 1973). In South Africa concern regarding FAS was already voiced in a publication in 1978 (Beyers, et al., 1978), but it was only after the publication of information about the first FAS prevalence study that the journey regarding Fetal Alcohol Spectrum Disorder research, awareness and prevention began in earnest (Viljoen, 1999). Since then alarmingly high rates have been reported in rural and urban communities in the country, raising the concern that South Africa has some of the highest rates reported in the world.

\section{Author's Publications Relevant to the Chapter 3}

* Olivier, L., Curfs, L.M.G. \& Viljoen, D.L. (2016). Fetal alcohol spectrum disorders: Prevalence rates in South Africa. South African Medical Journal 106(6) Supplement 1: S103-S106. http://doi.org/10.7196/samj.2016.v106i6.11009

* Olivier, L., Urban, M.F., Chersich, M.F., Temmerman, M., \& Viljoen, D.L. (2013). Burden of fetal alcohol syndrome in a rural West Coast area of South Africa. South African Medical Journal 103(6): 402-405. http://doi.org/10.7196/samj.6249

Marais, S., Jordaan, E., Olivier, L., \& Viljoen, D. (2012). Fetal Alcohol Spectrum Disorders. In A. Van Niekerk, S. Suffla, \& M. Seedat (Eds.), Crime, Violence and Injury in South Africa, $21^{\text {st }}$ Century Solutions for Child Safety (pp.214-228). [Adobe PDF version]. Retrieved from http://www.mrc.ac.za/crime/Chapter15.pdf 


\section{References}

Abel, E.L. (1997). Was the Fetal Alcohol Syndrome recognized in the Ancient Near East? Alcohol \& Alcoholism, 32(1), 3-7

Abel, E.L. (1999). Was the Fetal Alcohol Syndrome recognized by the Greeks and Romans? Alcohol Alcohol, 34(6), 868-872

Astley S., \& Clarren, S. (2000). Diagnosing the Full Spectrum of Fetal Alcohol-Exposed Individuals: Introducing the 4-Digit Diagnostic Code. Alcohol Alcoholism, 35(4):400-410. http://doi.org/10.1093/alcalc/35.4.400

Astley, J. Validation of the Fetal Alcohol Spectrum Disorder (FASD) 4-Digit Diagnostic Code. (2013). Journal of Population Therapeutics and Clinical Pharmacology, 20(3), e416-e467

Barry, K.L., Caetano, R., Chang, G., DeJoseph, M.C., Miller, L.A., O'Connor, M.J., Olson, H.C., Floyd, R.L., Weber, M.K., DeStefano, F., Dolina, S., \& Leeks, K. (2009). Reducing Alcohol-Exposed Pregnancies: A report of the national task force on fetal alcohol syndrome and fetal alcohol effect. Atlanta, GA, Centers for Disease Control and Prevention. Retrieved from http://www.cdc.gov/ncbddd/fasd/documents/redalcohpreg.pdf

Bertrand, J., Floyd, R.L., Weber, M.K., O'Connor, M., Riley, E.P., Johnson, K.A., Cohen, D.E. and National Task Force on Fetal Alcohol Syndrome and Fetal Alcohol Effect (2004). Fetal Alcohol Syndrome: Guidelines for Referral and Diagnosis. Centers for Disease Control and Prevention, Atlanta GA, pp. 1-62

Bingham, R.J. (2015). Latest evidence on alcohol and pregnancy. Nursing for Women's Health. 19(4), 338-344

Beyers, N., \& Moosa, A. (1978). The fetal alcohol syndrome. South African Medical Journal, 54(14), 575-578

Calhoun, F., \& Warren, K. (2007). Fetal alcohol syndrome: historical perspectives. Neuroscience \& Biobehavioral Reviews, 31(2), 168-171. http://doi.org/10.1016/j.neubiorev.2006.06.023

Chudley, A.E., Conry, J., Cook, J.L., Loock, C., Rosales, T., \& Leblanc, N. (2005). Fetal alcohol spectrum disorder: Canadian guidelines for diagnosis. Canadian Medical Association Journal, 172(Suppl. 5), S1-21 http:/doi.org/10.1503/cmaj.1040302

Credé, S., Sinanovic, E., Adnams, C., \& London, L. (2011). The utilization of health care services by children with Foetal Alcohol Syndrome in the Western Cape, South Africa. Drug and Alcohol Dependence, 115(3), 175-182. http://doi.org/10.1016/j.drugalcdep.2010.10.019

Davis, K.M., Gagnier, K.R., Moore, T.E., \& Todorow, M. (2013). Cognitive aspects of fetal alcohol spectrum disorder. Wiley Interdisciplinary Reviews: Cognitive Science, 4(1), 81-92. http://doi.org/10.1002/wcs.1202

Grinfeld, H. (2009). Alcohol use in pregnancy. In De Andrade, A.G., Anthony, J.C., \& Silveira, M. (Eds.), Alcohol and its consequences: dealing with multiple concepts (pp.179 - 200). [Adobe PDF version]. Retrieved from http://orig.cisa.org.br/UserFiles/File/alcoolesuasconsequencias-en-cap9.pdf

Harris, J.C. (2014). New classifications for neurodevelopmental disorders in DSM-5. Current Opinion in Psychiatry, 27(2), 95- 97. http://doi.org/10.1542/peds.2015-4256

Hoyme, H.E., Kalberg, W.O., Elliott, A.J., Blankenship, J., Buckley, D., Marais, A.-S., \& May, P.A. (2016). Updated Clinical Guidelines for Diagnosing Fetal Alcohol Spectrum Disorders. Paediatrics, 138(2), e20154256e20154256. http://doi.org/10.1542/peds.2015-4256

Hoyme, H.E., May, P.A., Kalberg, W.O., Kodituwakku, P., Gossage, J.P., Trujillo, P.M., Buckley, D.G., Miller, J.H., Aragon, A.S. Khaole, N., Viljoen, D.L., Jones, K.L., \& Robinson, L.K. (2005). A Practical Clinical Approach to Diagnosis of Fetal Alcohol Spectrum Disorders: Clarification of the 1996 Institute of Medicine Criteria. Paediatrics 115(1): 39-47. DOI: 10.5142/peds.2004-0259

Jones, K.L., \& Smith, D.W. (1973). Recognition of the Fetal Alcohol Syndrome in Early Infancy. The Lancet, 302(7836), 999-1001. http://doi.org/10.1016/So140-6736(73)91092-1

Jones, K.L., Smith, D.W., Ulleland, C.N., \& Streissguth, P. (1973). Pattern of malformation in offspring of chronic 121 Prenatal Alcohol Exposure, FAS, and FASD: An Introduction alcoholic mothers. The Lancet, 1(7815), 1267-1271

Lemoine, P., Harousseau, H., Borteyru, J. P., \& Menuet, J. C. (2003). Children of alcoholic parents--observed anomalies: discussion of 127 cases. Therapeutic Drug Monitoring, (25), 132-136

Lupton, C., Burd, L. \& Harwood, R. (2004). Cost of fetal alcohol spectrum disorders. American Journal of Medical Genetics. Part C, Seminars in Medical Genetics, 127C(1), 45-50. http://doi.org/10.1002/1mjmg.c.30015 
Marais, S., Jordaan, E., Olivier, L., \& Viljoen, D. (2012). Fetal Alcohol Spectrum Disorders. In A. Van Niekerk, S. Suffla, \& M. Seedat (Eds.), Crime, Violence and Injury in South Africa, $21^{\text {st }}$ Century Solutions for Child Safety (pp.214-228). [Adobe PDF version]. Retrieved from http://www.mrc.ac.za/crime/Chapter15.pdf

May, P.A., De Vries, M.M., Marais, A-S., Kalberg, W.O., Adnams, C.M., Hasken, J.M., Tabachnick, B., Robinson, L.K., Manning, M.A., Jones, K.L., Hoyme, D., Seedat, S., Parry, C.D.H., \& Hoyme, E. (2015) The continuum of fetal alcohol spectrum disorders in four rural communities in South Africa: Prevalence and Characteristics. Drug and Alcohol Dependence, 159, 207-218. http://dx.doi.org/doi:10.1016/j.drugalcdep. 2015.12.023

Odendaal, H.J., Steyn, D.W., Elloitt, A., \& Burd, L. (2006). Combined effects of cigarette smoking and alcohol consumption on perinatal outcome. Gynecologic and Obstetric Investigation, 67(1), 1-8. http://doi.org/10.1159/000150597

Olivier, L., Curfs, L.M.G. \& Viljoen, D.L. (2016). Fetal alcohol spectrum disorders: Prevalence rates in South Africa. South African Medical Journal 106(6) Supplement 1: S103-S106. http://doi.org/10.7196/samj. 2016.v106i6.11009

Olivier, L., Urban, M.F., Chersich, M.F., Temmerman, M., \& Viljoen, D.L. (2013). Burden of fetal alcohol syndrome in a rural West Coast area of South Africa. South African Medical Journal 103(6): 402-405. http://doi.org/10.7196/samj.6249

Olivier, L. (2017) [Fetal Alcohol Spectrum Disorder prevalence data for Renosterberg study]. Unpublished raw data

Ornoy, A., \& Ergaz, Z. (2010). Alcohol abuse in pregnant women: effects on the fetus and newborn, moede of action and maternal treatment. International Journal of Environmental Research and Public Health, 7(2), 364-379. http://doi.org/10.3390/ijerph7020364

Palmer, C. (1978). Fetal alcohol effects - incidence and understanding in the Cape. South African Medical Journal, 68(11),779-780. Retrieved from http://www.ncbi.nlm.nih.gov/pubmed/3840921

Papova, S., Lange, S., Probst, C., Gmel, G., \& Rehm, J. (2017). Estimation of national, regional, and global prevalence of alcohol use during pregnancy and fetal alcohol syndrome: a systematic review and metaanalysis. The Lancet Global Health, 5(3), e290-e299. http://dx.doi.org/10.1016/S2214-109X(17)30021-9

Riley, E. P., Infante, M. A., \& Warren, K. R. (2011). Fetal Alcohol Spectrum Disorders: An Overview. Neuropsychology Review, 21(2), 73-80. http://doi.org/10.1007/s11065-011-9166-x

Roozen, S., Peters, G-J.Y., Kok, G., Townend, D, Nijhuis, \& J., Curfs, L. (2016). Worldwide prevalence of fetal alcohol spectrum disorders: a systematic literature review including meta-analysis. Alcohol Clinical and Experimental Research, 40(1),18-32. http://doi.org/10.1111/1cer.12939

Sampson, P.D., Streissguth, A.P., Bookstein, F.L., Little, R.E., Clarren, S.K., Dehaene, P., Hanson, J.W., \& Graham, J.M. (1997). Incidence of fetal alcohol syndrome and prevalence of alcohol-related neurodevelopmental disorder. Teratology, 56(5), 317-326. http://doi.org/10.1002/(SICI)1096-9926(199711)56:5<317: AID-TERA5>3.0.CO;2-U

Smith, K.L., \& Smith, D.W. (1973). Recognition of the fetal alcohol syndrome in early infancy. The Lancet, 302(7836), 999-1001

Thanh, N.X., \& Johnsson, E. (2009). Cost of fetal alcohol spectrum disorder in Alberta, Canada. The Canadian Journal of Clinical Pharmacology, 16(1), e80-90. Retrieved from htpp://www.ncbi.nlm.nih.gov/pubmed/ 19151424

Viljoen, D. (1999). Fetal Alcohol Syndrome. South African Medical Journal 89(9): 958 - 960

Viljoen, D. \& Craig, P. (2001). Epidemiological studies for fetal alcohol syndrome in four Gauteng communities. Report prepared for National Department of Health, Directorate Mental Health and Substance Abuse, Pretoria, South Africa

Warren, K.R. \& Foudin, L.L. (2001). Alcohol-related birth defects - the past, present, and future. Alcohol Research \& Health: The Journal of the National Institute on Alcohol Abuse and Alcoholism, 25(3), 153158. Retrieved from http://www.ncbi.nlm.nih.gov/pubmed/1181095 
Chapter

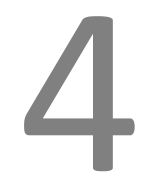

The Prevalence of Fetal Alcohol Spectrum
Disorders in South Africa 



\section{Introduction}

The first three Fetal Alcohol Spectrum Disorders (FASD) prevalence studies in South Africa (1997 - 2001) were undertaken in the same community in a rural, viticulture area located about 70km from Cape Town (Croxford, et al., 1999, May, Brooke, Gossage, Adnams, Jones \& Viljoen, 2000). This is where the first Settlers established wine-farms and introduced the 'dop' system (described in Chapter 3 ). The research results of these first studies were widely published in the lay media and it took some time before results of new studies, elsewhere in South Africa and in other population groups, were published (Viljoen, et al., 2001).

This fuelled the belief that people at risk for having children with FASD are predominantly Coloureds and from the 'Winelands' (the specific wine-producing area). The conclusion was also made that the high FASD prevalence in the area is a direct cause of the 'dop' system. These misconceptions and beliefs were soon challenged when FASD prevalence studies of other cultural groups and communities, where the 'dop' system was never practiced, became known. Unfortunately, the bias remains a constant challenge and often perpetuates the myth that people of other cultural groups and higher socio-economic status are not at risk of having alcohol exposed pregnancies and children with FASD (Olivier, 2016).

\section{Main research groups in South Africa}

In South Africa two main groups are currently doing FASD prevalence studies in South Africa:

Fetal Alcohol Syndrome Epidemiological Research - South Africa/FASER-SA

FASER-SA, under the leadership of the Principle Investigator, Prof Philip A. May, was established as a collaborative endeavour between the University of North Carolina (UNC, USA), the University of New Mexico (UNM, USA), the Faculty of Medicine and Health Sciences of Stellenbosch University (SU), and the Medical Research Council of South Africa (MRC). The group's research is funded by grants from the USA National Institute on Alcohol Abuse and Alcoholism (NIAAA). It focusses mainly on communities in two districts in the Western Cape Province. One of these communities includes the area (Wellington) where the first FASD Prevalence studies (1997 - 2001) took place. Ongoing research in these areas has provided the FASER-SA group with the opportunity to study these communities over a 20-year period and to do in-depth research into the aetiology of FASD, refine active case ascertainment methods, investigate general population patterns and improve the general understanding of the phenomenon. It has pro- 
vided a wealth of information used in FASD prevention and management interventions in South Africa and elsewhere.

Foundation for Alcohol Related Research/FARR (in text referred to as the Research Group)

The Foundation for Alcohol Related Research (FARR), a non-profit, non-governmental organization (NGO) was founded by Prof Denis L. Viljoen in 1997. Viljoen is still the main Principle Investigator of this group, as well as the Chairperson of the organization's Board of Directors. FARR is responsible for FASD research, community awareness and prevention projects in the Free State, Western, Northern and Eastern Cape provinces and training of professionals and community workers nationally. A study in Gauteng province was completed in 2001.

Viljoen and May were the Principle Investigators of the first three FASD Prevalence Studies in South Africa (1997 - 2001) and in many ways brought the FASD-problem in the country under the attention of the world.

\section{FASD prevalence studies in South Africa}

\section{Disclaimer}

For the sake of this thesis and in-line with the author's publications, this section will focus on the unique strategy and procedures developed by FARR (further referred to as 'the Research Group'). It will outline how internationally accredited criteria (Hoyme et al, 2016) and awareness and prevention models (Springer \& Phillips, 2007) are being incorporated in the research and accompanying community projects.

\section{Permission, funding and reporting on FASD projects}

\section{Research ethical and community approval}

Prevalence studies conducted by the Research Group are undertaken on invitation only and include 3-year comprehensive FASD community awareness, prevention, management and training projects in all the study areas. The invitations for these FASD projects come from authorities such as government departments, local authorities or community leaders in the study area.

Community support and approval are obtained by consultative meetings and imbizos (traditional meetings) involving political leaders, community leaders, church/religious groups, non-governmental organizations, employers, corporates and community mem- 
bers. It usually requires up to two years to receive authorization and endorsement from all these authorities. Research ethical approval is obtained from a Research Ethical Committee (REC), based at one of the universities in South Africa, as well as the respective REC's of the Provincial Departments of Health, Education and Social Development, including the National Health Research Database (www.hst.org.za/projects/nationalhealth-research-database-nhrd). This is an unique process set up by the Research Group in collaboration with the governmental departments as it facilitates buy-in, increased awareness and collaboration. It also provides the Research Group with unrestricted access to these departmental facilities and authorities in the project areas, at local and provincial levels.

\section{Funding}

Funding is sourced from the public sector (government), private sector (corporates) and philanthropists.

Four comprehensive projects (including FASD prevalence studies) have been commissioned and funded by government departments to date (2017). In two studies government departments have partnered with the liquor industry to provide funding.

\section{Monitoring and evaluation}

A rigorous monitoring and evaluation process is followed by the Research Group. A formal reporting system forms part of the research ethical committees' and funders' agreements and contracts. This requires monthly, quarterly, 6-monthly and annual reports, as well as meetings, site visits and regular presentations at various forums. Feedback is also given to local stakeholder groups in the research areas, including the parents/guardians of the children participating in the prevalence studies.

\section{Methods}

\section{Sampling and recruitment}

FASD prevalence studies in South Africa are done on Grade One learners (school-entry children) who are usually between the ages of 6 and 9 years. If possible, all the primary schools in the study area (e.g. town) are invited to participate (with the support of the Department of Education), or in a larger population, a random selection of the schools is done (e.g. a district comprising a number of towns, or a city). The engagements with these learners and their parents are arranged via the schools as no direct access to the participants and their legal guardians is allowed at this stage (Urban, Olivier, Viljoen, Lombard, Louw, Drotsky, ... \& Chersich, 2015). 
Written informed consent for participation is obtained from the parents. If parents are absent or deceased consent is obtained from their guardians (Addendum 1). Children without informed consent or children whose parents/guardians declined participation are excluded from the study. Children may be withdrawn from the study at any stage by a parent or guardian (Olivier, 2013).

\section{Study process}

An active case ascertainment, three-tiered process of screening, data collection and diagnosis is used (Figure 3), in line with the updated and revised Institute of Medicine model (Hoyme et al., 2016). The process has been validated and extensively used in previous studies in South Africa (May, Brooke Gossage, Adnams, Jones \& Viljoen, 2000; Olivier et al., 2016; Urban, Chersich, Fourie, Chettty, Olivier \& Viljoen, 2008; Urban et al., 2015; Viljoen, Gossage, Brooke, Adnams, Jones, Robinson, ... \& May, 2005).

\section{Tier 1:}

Anthropometric

Screening \& Clinical Assessment
- No stunting or health problems: No further intervention needed

- No stunting, but health/psycho-social problems: Referral and management

- Yes stunted: Refer for Dysmorphology Assessment
Tier 2:

Neuro-cognitive

Assessment
- Griffiths Mental Developmental Scales - Extended Revised (GMDS-ER)

- NEPSY ॥

\section{Tier 3:}

Maternal

interview
- Interview with biological mother or guardian/caregiver, if mother is not available or deceased

Figure 3: Three-tiered approach used during FASD prevalence studies

\section{Anthropometric screening}

All the participating children (child participants) receive an anthropometric and basic paediatric health screen done by trained Primary Health Care (PHC) nurses employed by the Research Group. During the screening process, the participating child's head circumference, height and weight are compared to clinical growth charts (Centers for 
Disease Control and Prevention [CDC] \& the National Center for Health Statistics [NCHS], 2000; Rollins, Collines \& Holden, 2010). Children with a head circumference $\leq$ the $10^{\text {th }}$ centile of the clinical growth charts for weight, height and/or head circumference (CDC \& NCHS, 2000; Rollins et al., 2010) are referred for a standardised, blinded clinical assessments by a dysmorphologist ( $1^{\text {st }}$ Tier) (Olivier, et al., 2016; Urban et al., 2015).

\section{Clinical assessment}

The above-mentioned 'screen positive' participants are assessed by a dysmorphologist for any dysmorphic features of FASD, major organ system anomalies and overt neurological signs. For standardization purposes a checklist was developed with a maximum 'dysmorphology score' of 50 (Olivier et al., 2013; Urban et al., 2015). This dysmorphology checklist was adapted from the criteria described by Hoyme et.al. and forms the basis for the clinical assessments (Hoyme, Kalberg, Elliot, Blankenship, Buckley, Marais, ... \& May, 2016). The Research Group also uses it as a training tool for new clinicians (Addendum 2).

\section{Neurocognitive assessment}

The neurocognitive assessments $\left(2^{\text {nd }}\right.$ Tier) are conducted by psychometrists using the Griffiths Mental Developmental Scales - Extended Revised (GMDS-ER) (Griffiths, 1970; Luiz, Faragher, Barnard, Knoesen, Kotras, Burns \& Challis, 2006; Preston, 2006). With the GMDS-ER, suitable for children up to 8 years of age, six developmental domains, namely locomotor (gross motor skills), eye-hand (fine motor coordination), personalsocial (adaptive functioning), hearing-speech (verbal ability), performance (pattern construction and speed of performance) and practical reasoning (numerical, time and spatial concepts), are assessed. For each domain raw scores are converted to z-scores and ultimately a GQ (general quotation as an aggregated scored based on all 6 subdomains on which the child has been tested), is calculated (Olivier et al., 2016). Two or more standard deviations below the mean of the GMDS-ER are indicative of a significant delay (Luiz et al., 2006).

Concerns have been raised about the suitability of the GMDS-ER for use on South African populations (Van Heerden, 2007). Since the NEPSY II (Brooks et al., 2010) has already been identified as a suitable test for the neurobehavioural deficits of FASD internationally (Clarren, Randels, Sanderson, \& Fineman, 2009), the Research Group is using this as an additional assessment tool since 2016.

The NEPSY-II comprises a comprehensive neurodevelopmental assessment tool, suitable for children between $3-16$ years of age. It is used for its ability to test the primary shortfalls of children due to impaired performance in the functional domains, but also across the aforesaid domains. It focusses on the following domains: attention 
and executive functioning, language, memory and learning, sensorimotor, social perception and visuospatial processing (Davis \& Matthews, 2010).

The use of both tools enables the Research Group to determine the suitability of the NEPSY II as part of its diagnostic process. Once more data has been gathered, a decision will be made on the abilities to clearly define aspects of cognitive functioning affected by prenatal alcohol exposure, the suitability of the tool in the South African scenario and which method the Research Group will use in future.

\section{Maternal interviews}

Community workers, appointed from the study areas, are trained to use standardised questionnaires to interview biological mothers or guardians of the child participants $\left(3^{\text {rd }}\right.$ Tier). The questionnaire was developed and refined during previous prevalence studies (May et al., 2005, 2008; Viljoen et al., 2002) and later shortened and updated to the current version (Breytenbach, 2014; Olivier et al., 2016).

Information is gathered to determine maternal risk factors before, during and after the gestation of the index child. Data pertaining to the mother's nutritional and health status, her prenatal alcohol and drug consumption, socio-economic status and educational level is recorded. The index child's birth weight and health status immediately post-birth and during the neonatal period are also obtained (Olivier et al., 2016). During the interview both the mother/guardian and the interviewer are blinded to the FASD status of the child.

\section{Case conference}

To make a final diagnosis the findings of the clinical examination, neurocognitive assessment and the maternal interview of each child are discussed. Based on relevant criteria, the child is diagnosed with FAS, pFAS, ARBD, ARND or 'not FASD' (Hoyme et al., 2016). The children with a 'not FASD' diagnosis might receive a diagnosis of mild to severe neurodevelopmental delay or other problems (Olivier et al., 2016).

\section{Referrals}

In South Africa pre-school children tend to have a relatively high Primary Health Care (PHC) clinic attendance until they have completed their immunizations at approximately 2 years of age. After that, especially in rural areas, they attend health care facilities only when they are ill. As a result of this, unidentified and untreated health problems may exist.

During the anthropometric screening and clinical assessments of the Grade One learners, the clinical team often detects a variety of health and psycho-social conditions which need management. These conditions range from minor ailments such as skin 
conditions (e.g. rashes, allergies) to birth defects associated with FASD (e.g. strabismus, heart defects), genetic conditions, health disorders (e.g. respiratory/urinary tract or other infections), undiagnosed chronic conditions (e.g. epilepsy, diabetes), developmental and learning problems unrelated to FASD (e.g. autism), nutritional deficits, oral hygiene and dental defects. Social problems such as child neglect, abuse and exploitation are regularly identified.

Children with any of the above-mentioned maladies are referred to the appropriate health and social services. In many study areas, such as in deep rural areas, these services are either far from the study area or not available (e.g. school psychologists). For these children, the Research Group has to provide the transport and means to access the referral services and, in cases where no service is available, provide the necessary support. The referral of every participating child is tracked and recorded to ensure service delivery and adequate care.

\section{Feedback and counselling}

After the case conference counsellors of the Research Group meet with the biological mother/parents or guardian of each participating child. This is to provide feedback on the child's diagnosis and to discuss the individual report provided for every participating child. Parents/guardians of children who were referred for other conditions (as discussed above) also receive reports. If needed, on-going counselling is provided, as well as a referral for additional social services support provided by local service providers (such as a non-governmental or church group) or the Department of Social Development.

\section{Training of professional service providers}

To ensure transfer of knowledge and capacity development, local service providers such as health care professionals, social workers, educators (teachers), community workers and employees of other NGO's in the project sites receive training. The training sessions and workshops focus on FASD awareness and prevention, as well as the management of children with FASD and their families. In the sessions with the social workers and health care professionals, interventions and opportunities within the existing government programmes (e.g. the Department of Health's Basic Antenatal Care Programme/BANC) are explored (Buchmann, 2015; Hofmeyr \& Mentrop, 2015).

The Research Group also provides training to the Foundation Phase (Grade 1 to 3) educators (teachers) of all the participating schools. The training aims to provide the educators with the necessary knowledge and skills to manage learners with FASD in the school setting. If the parents/guardians consent, their children's reports are also discussed with their educators. 


\section{Knowledge and capacity development}

The Institute of Medicine (IOM) model of prevention comprising universal, selective and indicated interventions, are used to guide this process (Springer et al., 2007). Community educational sessions include industrial theatre productions (LoveChild drama), storytelling, lifeskills courses (FAStrap course) and community events such as awareness walks (e.g. on International FASD day). These events aim to increase awareness and to develop the necessary capacity in the community to prevent FASD. (See Chapter 8 for more information.)

\section{Publication of findings}

The research findings, prevalence rates and recommendations are reported to the Departments of Education, Health and Social Development and funders by means of meetings and regular reports (monthly/quarterly/annual). A final project report is provided. As to ensure that the correct information is shared with the communities in the project site and to facilitate responsible media reporting, the relevant Minister of Social Development (or the Premier of the Province) hosts a press conference involving the Research Group. The Research Group prepares the press release on behalf of the Minister or Premier (Addendum 3).

\section{FASD prevalence rates in South Africa}

To date (2017) eleven FASD prevalence studies have been undertaken in 19 towns and 3 cities in 4 of the 9 provinces in South Africa (Olivier et al., 2016). However, with rates reported between 20 - 282 per 1000 Grade One (School entry) Learners, South Africa ranks amongst the countries with the highest reported rates in the world. It is important to note that due to limitations in diagnosing conditions such as ARND and ARBD within a FASD prevalence study, the focus of the studies is primarily on the diagnosis of FAS. The FASD rates in the researched sites therefore reflect minimum prevalence rates (Olivier et al., 2016). 
Table 1: South African FASD prevalence rates

\begin{tabular}{|c|c|c|c|}
\hline Province & Community & $\begin{array}{l}\text { Prevalence Rate } \\
\text { per } 1000 \text { Grade } \\
\text { One Learners }\end{array}$ & Reference \\
\hline \multirow[t]{5}{*}{ Western Cape } & Wellington (town) & 89,2 & $\begin{array}{l}\text { (Viljoen, Gossage, Brooke, } \\
\text { Adnams, Jones, Robinson, ... \& } \\
\text { May, 2005) }\end{array}$ \\
\hline & Aurora (town) & 100 & (Olivier et al., 2013) \\
\hline & Witzenberg Sub-district & 9,6 & (Olivier et al., 2016) \\
\hline & Saldanha Municipality & 6,7 & (Olivier et al., 2016) \\
\hline & $\begin{array}{l}\text { Wellington, Montagu, Ashton, } \\
\text { Robertson }\end{array}$ & $135-208$ & (May et al., 2015) \\
\hline Gauteng & Soweto, Diepsloot, Lenasia (towns) & 26 & (Viljoen, 2001) \\
\hline \multirow[t]{6}{*}{ Northern Cape } & De Aar 1 (town) & 119,4 & (Urban et al., 2008) \\
\hline & De Aar 2 (post intervention) & 112,8 & $\begin{array}{l}\text { (Chersich, Urban, Olivier, Davies, } \\
\text { Chetty \& Viljoen, 2012) }\end{array}$ \\
\hline & Upington 1 (town) & 7,4 & (Urban et al., 2008) \\
\hline & Upington 2 (post intervention) & 65,9 & (Chersich et al., 2012) \\
\hline & Kimberley (city) & 64 & (Urban et al., 2015) \\
\hline & Renosterberg Municipality & 282 & (Olivier et al., 2017b) \\
\hline Eastern Cape & Bethelsdorp, Port Elizabeth (city) & 130 & (Olivier et al., 2017a) \\
\hline
\end{tabular}

The rates reported in Table 1 undoubtedly indicate that high rates are prevalent in both urban and rural communities. At the time of the studies in the cities (Kimberley and Port Elizabeth) it was believed that the disorder is more rampant in rural communities, especially amongst Coloured women, working and/or living on farms. The research findings in the Kimberley study were therefore met with surprize as this was the first study to raise concern about high levels of prenatal alcohol use amongst young Black women (Urban, 2015). Since the study was done in a well-resourced city it challenged the previous belief of FASD being a predominantly rural problem, specifically prevalent amongst women with lower educational qualifications, with limited access to information and resources (Croxford et al, 1999; May et al. 2000; Viljoen et al., 2005). These concerns were further amplified when an even higher rate was reported in Port Elizabeth, a city in another province (Olivier et al., 2017a).

The study in Aurora involved all the learners in the only primary school (Grades 1 7) in the town. Differences in the prevalence between the grades clearly indicated that psycho-social, economic and other factors are at play prior and during the conception of the children. FASD rates are therefore not stable and can fluctuate due to changes in the environment, living conditions and access to resources (Olivier, et al., 2013).

In all the studies were common determinants indicating that whether women are residing in an urban or rural setting, abstinence from alcohol use during pregnancy remains a problem for a variety of reasons that will be discussed in more detail in Chapter 5. 
Since no FASD studies have been conducted in 5 provinces of the country, the national FASD prevalence rate for South Africa is still unknown. Since there are considerable differences between the rates in the respective study areas, the Research Group is of the opinion that it is of more importance to identify high-risk areas for focussed interventions and resources by government and other service providers.

In 2008 the Department of Health used the published rates and announced an estimated national FASD Prevalence Rate of 60/1000 live births, as depicted in the diagram in Figure 4 (presentation Dr J Corrigal, 2008). Estimates have however put the national FASD rate of South Africa at 58,5 per 1000 (Popova, Lange, Probst, Gmel \& Rehm, 2017 Supplementary Appendix).

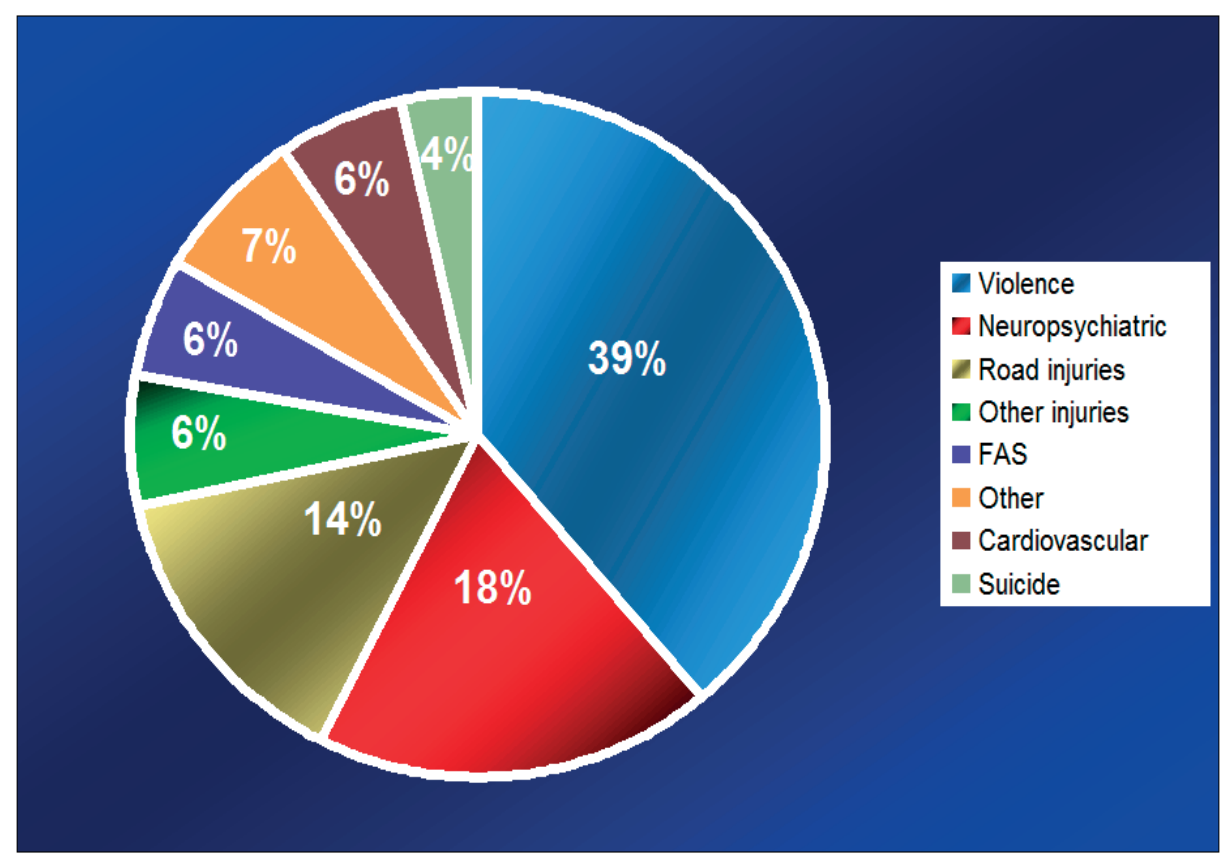

Figure 4: Alcohol burden in South Africa

\section{Conclusion}

Since 1997 two research groups have conducted a number of FASD prevalence studies in South Africa. Using internationally acknowledged methods and tools, rates between 26 to 282/1000 have been reported. Recent studies in two cities in two different provinces unequivocally indicate that FASD is a widespread problem in the country and not only limited to rural areas where there is inadequate access to education, resources and 
work. The research findings increase the concern about the impact of this condition and intensifies the urgency for FASD prevention and support to those at risk.

\section{Author's Publications Relevant to the Chapter 4}

* Olivier, L., Curfs, L.M.G. \& Viljoen, D.L. (2016). Fetal alcohol spectrum disorders: Prevalence rates in South Africa. South African Medical Journal 106(6) Supplement 1: S103S106. http://doi.org/10.7196/samj.2016.v106i6.11009

* Olivier, L., Urban, M.F., Chersich, M.F., Temmerman, M., \& Viljoen, D.L. (2013). Burden of fetal alcohol syndrome in a rural West Coast area of South Africa. South African Medical Journal 103(6): 402-405. http://doi.org/10.7196/samj.6249

* Urban, M.F., Olivier, L., Viljoen, D.L., Lombard, C., Louw, J.G., Drotsky, L-M., Temmerman, M., \& Chersich, M.F. (2015). Prevalence of fetal alcohol syndrome in a South African city with a predominantly Black African population. Alcohol Clinical and Experimental Research 39(6), 1016-1026. http://doi.org/10.1111/ acer.12726

Chersich, M.F., Urban, M.F., Olivier, L., Davies, L-A., Chetty, C., \& Viljoen, D. (2012). Universal Prevention is Associated with Lower Prevalence of Fetal Alcohol Spectrum Disorder in Northern Cape, South Africa: A Multi-centre Before-After Study. Alcohol and Alcoholism, 47(1):66-74. http://doi.org/10.1093/alcalc/agr145 


\section{References}

Breytenbach, B. (2014). A revision of a maternal interview questionnaire used in fetal alcohol spectrum disorder prevention programmes in South Africa. [Adobe PDF version]

Brooks, B.L, Sherman, E.M.S., \& Strauss, E. (2010). NEPSY-II: A Developmental Neuropsychological Assessment, Second Edition. Child Neuropsychology: A Journal on Normal and Abnormal Development in Childhood and Adolescence, 16(1), 80-101. http://doi.org/10.1080/09297040903146966

Buchmann, E. (Ed). (2015). Guidelines for Maternity Care in South Africa. A manual for clinics, community health centres and district hospitals. (Fourth Edition). Pretoria: National Department of Health

Centers for Disease Control and Prevention, \& National Center for Health Statistics. (2000). CDC clinical growth charts: United States. Retrieved from htpp://www.cdc.gov/growthcharts/charts.htm

Chersich, M.F., Urban, M.F., Olivier, L., Davies, L-A., Chetty, C., \& Viljoen, D. (2012). Universal Prevention is Associated with Lower Prevalence of Fetal Alcohol Spectrum Disorder in Northern Cape, South Africa: A Multicentre Before-After Study. Alcohol and Alcoholism, 47(1):66-74. http://doi.org/10.1093/alcalc/agr145

Clarren, S.K., Randels, S.P., Sanderson, M. \& Fineman, R.M. (2001). Screening for fetal alcohol syndrome in primary schools: a feasibility study. Teratology, 63(1), 3-10

Croxford, J. \& Viljoen, D. (1999). Alcohol consumption by pregnant women in the Western Cape. South African Medical Journal, 89(9), 962-965

Davis, J.L., \& Matthews, R.N. (2010). Nepsy-II Review: Korkman, M., Kirk, U., \& Kemp, S. (2007). NEPSY-Second Edition (NEPSY II). San Antonio, Texas: Harcourt Assessment. Journal of Psychoeducational Assessment, 28(2), 175-182. http://doi.org/10.1177/0734282909346716

Griffiths, R. (1970). The Ability of Young Children: A Comprehensive System of Mental Measurement for the first eight years of life. (Association for Research in Infant and Child Development). England: The Test Agency Ltd

Hofmeyer, G.J. \& Mentrop, L. (2015). Time for 'basic antenatal care plus' in South Africa? South African Medical Journal, 105(11), 902-904

Hoyme, H.E., Kalberg, W.O., Elliott, A.J., Blankenship, J., Buckley, D., Marais, A.-S., Robinson, L.K., \& May, P.A. (2016). Updated Clinical Guidelines for Diagnosing Fetal Alcohol Spectrum Disorders. Pediatrics, 138(2). http://doi.org/10.1542/peds.2015-4256

Luiz, D., Faragher, B., Barnard A, Knoesen, N., Kotras, N., Burns, L.E., \& Challis, D. (2006). Griffiths Mental Developmental Scales-Extended Revised - Two to Eight Year. Analysis Manual. Oxford: Hogrefe

May, P.A., Brooke, L., Gossage, J.P., Adnams, C., Jones, K.L., \& Viljoen, D. (2000). Epidemiology of fetal alcohol syndrome in a South African community in the Western Cape Province. American Journal of Public Health, 90(12), 1905-1912. http://doi.org/10.2105/1jph.90.12.1905

May, P.A., Gossage, J.P., Brooke, L.E, Snell, C.L., Marais, A-S., Hendricks, L.S., Croxford, J.A., \& Viljoen, D.L. (2005). Maternal risk factors for fetal alcohol in the Western Cape Province of South Africa: A population-based study. American Journal for Public Health 95(7):1190-1199. http://doi.org/:10.2105/ ajph.2003.037093

May, P.A., Gossage, J.P. Marais, A-S, Hendricks, L.S., Snell, C.L. Tabachnick, B.G., Stellayato, C., Buckley, D.G., Brooke, L., \& Viljoen, D.L. (2008). Maternal risk factors for fetal alcohol syndrome and partial fetal alcohol syndrome in South Africa: A third study. Alcoholism: Clinical and Experimental Research 32(5):736753. http://doi.org/10.1111/j.1530-0277.2008.00634.x

Olivier, L. (2017a). [Fetal Alcohol Spectrum Disorder prevalence data for Bethelsdorp study]. Unpublished raw data

Olivier, L. (2017b). [Fetal Alcohol Spectrum Disorder prevalence data for Renosterberrg study]. Unpublished raw data

Olivier, L., Curfs, L.M.G. \& Viljoen, D.L. (2016). Fetal alcohol spectrum disorders: Prevalence rates in South Africa. South African Medical Journal 106(6) Supplement 1: S103-S106. http://doi.org/10.7196/samj.2016. v106i6.11009 
Olivier, L., Urban, M.F., Chersich, M.F., Temmerman, M., \& Viljoen, D.L. (2013). Burden of fetal alcohol syndrome in a rural West Coast area of South Africa. South African Medical Journal 103(6): 402-405. http://doi.org/10.7196/samj.6249

Olivier, L., Curfs, L.M.G., \& Viljoen, D.L. (2016). Fetal alcohol spectrum disorders: Prevalence rates in South Africa. South African Medical Journal 106(6) Supplement 1: S103-S106

Preston, P. (2006). Testing Children - A Practitioner's Guide to the Assessment of Mental Development in Infants and Young Children. Oxford: Hogrefe

Rollins, J.D., Collins, J.S., \& Holden, K.R. (2010). United States head circumference growth reference charts: birth to 21 years. The Journal of Pediatrics, 156(6), 907-913, 913-2. http://doi.org/10.1016/j.jpeds. 2010.01.009

Springer, F. \& Phillips, J. (2007). The Institute of Medicine Framework and its implication for Advancement of Prevention Policy, Programs and Practice. [Adobe PDF version]. Retrived from http://ca-sdfsc.org/docs/ resources/SDFSC_IOM_Policy.pdf

Urban, M.F., Chersich, M.F., Fourie, L-A., Chetty, C., Olivier, L., \& Viljoen, D.L. (2008) Fetal alcohol syndrome among Grade 1 school children in Northern Cape Province: Prevalene and risk factors. South African Medical Journal 98(1), 877-882. Retrieved from http://www.ncbi.nlm.nih.gov/pubmed/19177895

Urban, M.F., Olivier, L., Viljoen, D.L., Lombard, C., Louw, J.G., Drotsky, L-M., Temmerman, M., \& Chersich, M.F. (2015). Prevalence of fetal alcohol syndrome in a South African city with a predominantly Black African population. Alcohol Clinical and Experimental Research 39(6), 1016-1026. http://doi.org/10.1111/ acer. 12726

Van Heerden, R. (2007). Exploring normal South African and British children: A comparative study utilizing the Griffiths mental development Scales - extended revised. Nelson Mandela Metropolitan University. Retrieved from https://www.nmmu.ac.za/documents/theses/RIVCA VAN HEERDEN.pdf

Viljoen, D. \& Craig, P. (2001). Epidemiological studies for fetal alcohol syndrome in four Gauteng communities. Report prepared for National Department of Health, Directorate Mental Health and Substance Abuse, Pretoria, South Africa

Viljoen, D.L., Croxford, J., Gossage, J.P., Kodituwakka, P.W., \& May, P.A. (2002). Characteristics of mothers of children with fetal alcohol syndrome in the Western Cape Province of South Africa: A case control study. Journal of Studies on Alcohol, 63(1), 6-17. Retrieved from http://www.ncbi.nih.gov/pubmed/11925060

Viljoen, D.L., Gossage, J.P., Brooke, L., Adnams, C.M., Jones, K.I., Robinson, L.K., Hoyme, H.E., Snell, C., Khaole, N.C. Kodituwakku, P.W., Asante, K.O. Findlay, R., Quintion, B. Marais, A.S., Kalberg, W.O. \& May, P.A. (2005) Fetal alcohol syndrome epidemiology in a South African community: A second study of a very high prevalence area. Journal on Studies on Alcohol, 66(5), 593-604. Retrieved from http://www.pubmedcentral.nih.gov/articlerender.fcgi?artid=1414648\&tool=pmcentrz\&rendertyper=abs tract 

Chapter

Fetal Alcohol Spectrum Disorders

Determinants 



\section{Introduction}

Heavy or even light to moderate maternal consumption of alcohol during pregnancy have been globally linked to developmental delays and FASD (Henderson et al., 2007; O'Keeffe et al., 2014). Animal and human studies report on the teratogenic effects on the developing central nervous system and organs of the fetus. This has led to strong statements such as the recent American Academy of Paediatrics' message, as paraphrased by Elizabeth Cohen (Senior Medical Correspondent for CNN): "Don't do it. Ever. At all. Not even a tiny bit. No amount of alcohol should be considered safe to drink during any trimester of pregnancy" (2015).

A very clear message, with simple advice? Unfortunately, this is an exceptionally difficult goal to attain.

Biological mothers have carried the bulk of the blame for having children with birth defects due to alcohol use during pregnancy. Clearly the causative factors indicate a much more complex network of determinants which require to be understood before appropriate management guidelines and services can be developed. One of the aspects that is totally under-explored is the role of the biological father and/or partner. Also, it is in the best interest of all to have an empathetic and supportive approach to all involved, rather than a 'blame and shame' attitude.

\section{Global concern}

In a systematic review and meta-analysis done by Popova et al. (2017), it is estimated that globally about $10 \%$ of women use alcohol during pregnancy and that approximately 1 in 67 women will eventually give birth to a child with FAS. This translates to about 15 children out of every 10000 livebirths being born with FAS (Popova et al., 2017).

Alarmingly, reports indicate that rates of alcohol use, binge drinking and drinking during pregnancy appear to be on the increase in many countries. Coupled with the high number of unplanned pregnancies, the risk of alcohol exposed pregnancies is escalating (Popova et al., 2017). Of concern is that pregnant women receive mixed messages about the acceptability and risk of drinking during pregnancy from the researchers, media, liquor industry, health care providers, family and friends. A recent example is the review published in the International Alliance for Responsible Drinking (IARD, 2017) commenting on the Popova systematic review and meta-analysis (Popova et al., 2017). The IARD report focusses on mainly the limitations in the article, making statements such as "currently there is little scientific data on the prevalence of fetal disorders associated with alcohol" and "light to moderate drinking has not been clearly linked to FAS" (IARD, 2017). 


\section{Factors associated with FASD in South Africa}

Due to the high FASD prevalence rates in South Africa, a number of studies have been undertaken in an attempt to understand the determinants of drinking during pregnancy and to identify the maternal risk factors. All of these studies mention demographic, cultural, lifestyle, psycho-social and economic factors (Coxford et al., 1999; Hay., Jacobson, Molteno, Viljoen, , \& Jacobson,, 2004; May et al., 2000; 2015; Viljoen, 2002; Urban et al., 2016; Viljoen et al., 2002). Increasingly concern is raised about the effects of poor nutritional status of pregnant women (May, 2015), pharmakinetics (Khaole, Ramchandani, Viljoen, \& Li, (2004) and epigenetics influencing the development of FASD (Masemola, van der Merwe, Lombard, Viljoen, \& Ramsay, 2015). Researchers have also raised concerns pertaining to the father's alcohol use on the epigenetic mechanism pertaining to their offsprings (Ramsay, Masemola, Pitamber, Patel, Lombard, \& Viljoen, 2010).

\section{Psycho-social factors}

Jacobs and Jacobs investigated alcohol dependence in the family in the post-apartheid South Africa and concluded that individuals often drink to get drunk so as to reduce negative and painful experiences (Jacobs \& Jacobs, 2013). In alcohol dependent family systems or communities, the void is commonly filled with alcohol. Children growing up in these families/communities learn by observation that alcohol consumption can be used as a coping mechanism. As the family is the primary circle of association and learning, the example set by the mother and father sends a very strong social message to the children in the family.

In families and communities faced with alcoholism there is a "concerted silence" and collective agreement to 'keep up the appearance' to ensure that it appears from the outside as if nothing is wrong (Jacobs et al., 2013). This code of silence and alcohol abuse in families/communities might have led to the belief that some communities have 'a culture of drinking'.

Cloete and Ramugondo (2015) postulate that with the information available there is still little understanding of how culture, economy and politics contribute to the marginalization of women who drink during pregnancy. They further state that personal deficiencies in some cultures and the link between individuals and their respective cultures, and the context in which they live, work and interact in society, need more investigation. In their studies in the rural areas in the Western Cape Province they have found the main reasons for the continuation of drinking in pregnant women are based on the women's fear of losing friends, losing control over their drinking and the difficulty they experience in abstaining from drinking, especially if drinking is the norm in the community. With futures bleak as a result of limitations due to their circumstances, low educational levels, a lack of future planning and inability to break out of the cycle, the women 
in the study group have given up hope. Excessive alcohol use, daily hardships of life and loss of hope are part of their daily existence (Cloete \& Ramugondo, 2015). The researchers are of the opinion that some women might experience the scars of oppression (e.g. due to the Apartheid system or submissive role of woman in some cultures) which presents as subjectivity, suppressed emotional expression, dysfunctional interpersonal relationships, a higher prevalence of mental health problems and substance abuse (Cloete et al., 2015).

\section{Demographic factors}

Earlier publications reported that rural women drink more than urban women. In a 2009 study $41,3 \%$ of rural versus 20,1\% of urban women reported regular alcohol consumption (Morojele, London, Olorunju, Matjila, Davids, \& Rendall-Mkosi, 2009). There is evidence in recent reports that the gap might be closing. Two recent South African studies support this notion in cities in the Northern Cape (Urban et al., 2015) and the Eastern Cape (Olivier, 2017). Both of the studies were undertaken in cities with high unemployment and poverty rates. The research participants reported that $77-83 \%$ of women used alcohol during the past year. Binge drinking ( $\geq 4$ drinks per occasion for women and $\geq 5$ drinks for men) remains the preferred form of alcohol use (Urban et al., 2015; Olivier, 2017).

In the past it was believed that Coloured women are more at risk of having children with FASD, but a study by Urban and colleagues in the Northern Cape Province revealed that the rates were more or less the same amongst Coloured and Black women (Urban et al., 2015).

\section{Maternal drinking behaviour}

As stated before (Chapter 2), not all South Africans drink, but those who do consume alcohol, drink at high levels. Women drink in pregnancy for many reasons such as social and lifestyle issues, addiction and mental health problems (May \& Gossage, 2011). Studies have shown that women with higher educational qualifications tend to drink more than those with a lower educational status, but a higher proportion of the latter group are binge drinkers. Gossage and colleagues report that $66 \%$ of females in an area with a high FASD prevalence rate in the Western Cape Province, were current drinkers and 49\% practiced binge drinking during the past 7 days. Binge drinking in groups is common (Gossage, Snell, Parry, Marais, Barnard, De Vries, ...\& May, 2014), with $14 \%$ of all South African women reporting binge-drinking (Urban et al., 2016). This is also practiced during pregnancy and is a well-documented determinant of FASD in South Africa (Morojele et al., 2009; Olivier et al., 2017; Te Water Naude, London, Pitt, \& Mahomed, 1998; Viljoen et al., 2002,). Mothers of children with FASD in a 2012 study reported that they drank on average 13 drinks per week, compared to 5,6 drinks per week in the control 
group (May et al., 2013). The more often a pregnant woman drinks, especially bingetype drinking and if the drinking continues throughout pregnancy, the more likely her child is to have FASD (Ernhart, Sokol, Martier, Moron, Nadler, Ager, \& Wolf, 1987).

Older women who drink frequently, especially in larger quantities and those with a low Body Mass Index (BMI) and/or poor nutritional status, are at a higher risk of having children with FASD. This is further exacerbated by more frequent pregnancies (gravidity $\geq 3$ ), more children (parity $\geq 3$ ), lower educational status, unemployment, being unmarried/single and residing in a rural area (Abel, 1995; Jacobson, 1998; Viljoen, 2002; Olivier, 2013; Urban, 2016).

Research findings indicate that low and moderate drinking also lead to significant developmental delays, learning problems, inattentiveness and distractibility, hyperactivity, memory deficits, impulsivity and psychiatric problems of which mood disorders are the most common (Sokol, Delaney-Black, \& Nordstrom, 2003).

\section{Maternal nutritional factors}

In a first of its kind study in South Africa conducted by May and colleagues (2016) the nutritional status of a cohort of South African biological mothers were compared to control mothers. Both groups' dietary intake for macro- and micronutrients, as well as fat, were analysed in terms of the estimated average requirements and adequate intakes for pregnant women. Nearly all the participants in both groups had deficient estimated required intakes of most of the micronutrients. Biological mothers of children with FASD had a lower BMI than the control mothers. Despite the fact that some of the biological mothers consumed more micronutrients, the study found that the teratogenic effect of the alcohol was stronger and it was concluded that it significantly determined FASD (May et al., 2016).

May and colleagues (2016) state that shorter women with a low BMI are 'overrepresented among women who have children with FASD'. (Since the observation is made based on studies in high-risk populations, the author of this dissertation speculates that some of these women might be people with FASD themselves.) Alcohol metabolism is positively influenced by body size and nutrition. The women with a higher BMI are therefore favoured with this protective factor (May et al., 2016).

All the studies conducted thus far in South Africa are in consensus that women with unplanned pregnancies, low BMI, low education, single/unmarried and unemployed, are at a higher risk of abusing alcohol during pregnancy and therefore at risk of giving birth to a child with FASD (Olivier et al., 2017; Urban et al., 2015, 2016).

In a study involving 61 pre-school children ( $3-5$ years of age) in the Eastern Cape Province, low levels of Vitamin A and $E$ were found and raised the question about the blood plasma levels of their mothers. (See Chapter 6 for more information.) In general, both vitamins are associated with better cognitive development and plays an important role in immune functioning. Low levels of Vitamin $\mathrm{E}$ are associated with increased infec- 
tion, growth stunting and poor outcomes during pregnancy for infants and mothers (Benade, Olivier \& Bukasa, 2017). The FASD-status of the participants is unknown, but since the study took place in an area with a high FASD prevalence rate (130/1000), it raises questions regarding the possibility that children of women with low levels of these vitamins might be more susceptible to the harmful effects of alcohol (Olivier, 2017).

\section{Role of the father, other family members and friends}

Maternal alcohol use can be influenced by the perceptions and behaviour of others, especially those who play a significant role in their lives (Watt, Eaton, Dennis, Choi, Kalichman, Skinner, \& Sikkeman, 2016). The role of the father, partner, family members and friends are therefore of the utmost importance in terms of FASD prevention.

Peer alcohol use was a strong predictor of binge drinking, especially amongst young pregnant women in a South African study conducted on one of the Research Group's study sites. Participants in the study indicated that they drink with their friends, especially over weekends, because they are tired and want to relax. Friendship, a sense of community and heavy drinking seem to be intertwined and form part of 'having a good time' (Kelly \& Ward, 2017). By not drinking, a woman might isolate herself in society. The role of significant other and their influence on the drinking behaviour of pregnant women is a repeated issue in most of the studies undertaken by the Research Group and others (Cloete et al., 2015; Croxford, et al., 1999; May et al., 2011; Viljoen et al., 2002; Olivier et al., 2013).

The quality of the relationship between the biological parents also has an influence on the biological mothers' drinking behaviour. High levels of conflict and unhappiness in relationships are associated with high levels of stress and alcohol consumption (Bakhireva, Wilsnack, Kristjanson, Yevtushok, Onishenko, Wertelecki, \& Chambers, 2011).

Alcohol use is often a way of coping with difficult relationships and domestic problems. In a South African cohort, pregnant women reported that due to emotional pain, they drink until they 'pass out and forget for the moment'. Participants turned to alcohol as a form of self-medication in order to manage their inner tensions, emotional pain and every-day stressors (Kelly et al., 2017). The hardship experienced by pregnant women in the study areas might be further exasperated by the fact that participants often report that they are single, unmarried or divorced/separated (Croxford et al., 1999; May et al., 2011; Olivier, 2017; Urban et al., 2015).

In a systematic review McBride and Johnson (2016) analysed the results of 12 studies which explored the effects of paternal alcohol consumption on sperm health, impacts on fetal and infant health and maternal drinking. According to these studies the biological father plays a significant role in determining and/or influencing his pregnant partner's drinking behaviour. Social determinants such as paternal and maternal drink- 
ing, recent maternal drug use, high life stress and exposure to violence are some of the factors mentioned in studies from Australia, Hungary, England, the Netherlands and the United States of America (USA) (McBride \& Johnson, 2016).

High levels of paternal drinking, especially one week before donating sperm for infertility treatment such as GIFT (gamete intra-fallopian transfer) and IVF (in vitro fertilization), resulted in an increase in spontaneous abortions (2 - 5 times higher risk). The review concluded that results pertaining to other possible pregnancy outcomes, such as low birth weight, gestation and infant health, were inconclusive and need further investigation (McBride et al., 2016).

In South Africa birth mothers repeatedly report drinking with partners, family and friends and often experience group pressure in this regard (Croxford et al., 1999; Kelly \& Ward, 2017; Olivier et al., 2013, 2017; Urban et al., 2015).

In an investigation into the drinking practices of pregnant women enrolled in the Research Group's studies, a number of participants mentioned that they stopped drinking on the insistence of their partners and friends. Others mentioned that they tried to abstain from alcohol use, but found it tempting when their significant others used alcohol and some even had to avoid their partners, friends and/or family during pregnancy so as to not succumb to the need to drink (Kelly et al., 2017).

It is alarming to note that in South Africa the role of the father in FASD prevention receives very little attention and therefore many opportunities in terms of support to the biological mother are missed.

\section{Knowledge and attitudes of pregnant women}

In a study for a master's dissertation, undertaken by one of the Research Group's researchers, the perceptions and knowledge of alcohol-related harm and FASD among women attending private antenatal services versus public (state) facilities were compared. The study found that both groups had limited knowledge of the harm caused by alcohol during pregnancy and that there were serious misconceptions about prenatal alcohol consumption and FASD (Le Roux, 2013). Alarmingly statements made by some of the women include:

"Pregnant women are not educated enough about dangers of alcohol because we turn to it during rejection during pregnancy." (Le Roux, 2013: p. 50)

"I believe that it is all related to amount consumed and the odd drink shouldn't be a problem." (Le Roux, 2013: p. 51)

"I have heard that the body needs alcohol, but not sure how much does it still need when you are pregnant." (Le Roux, 2013: p. 51)

"Milk stout is good every now and then and can be good for breast milk." (Le Roux, 2013: p. 51) 
Of concern is that all of these women were attending antenatal care services (Le Roux, 2013).

\section{Risk perception}

To change drinking behaviour a woman needs an accurate perception of her risks during an alcohol exposed pregnancy. A major challenge is that some women present with unrealistic optimism which leads to them believing that they are less at risk of having children with FASD (Louw, Tomlinson \& Olivier, 2017).

In South Africa this phenomenon manifests in different forms such as individuals quoting the FASD risk factors pertaining to "others" that they have learnt through health promotion messages, media and research reports. In doing so they often exclude the risk factors pertaining to themselves or over emphasise risk factors that do not pertain to them, e.g. ethnicity, educational level, socio-economic status and location (e.g. rural versus urban).

\section{Stigma}

The stigma associated with problematic alcohol use, especially prenatal alcohol use, presents a significant barrier to the prevention and management of FASD. Not only the people affected by FASD and their mothers, but also their siblings, other family members and, in some cases, even the caregivers experience stigma (Green, Cook, Racine, \& Bell, 2014).

Stigma is defined as a 'negative stereotype' and a person being 'stigmatized' means that the individual is unfairly regarded by many as being bad or having something to be ashamed of. (Link \& Phelan, 2006). People who are stigmatized, such as pregnant women using alcohol, find it difficult to acknowledge that they might practice a stigmatized behaviour which might have an effect on their help-seeking behaviour. This may be one of the reasons why some researchers report challenges pertaining to self-reporting behaviour.

Green and colleagues (2014) state that people often judge those who seem to be unable to address their own problematic drinking. In the case of FASD this judgement might be even more severe as some perceive the women as causing (preventable) harm to her unborn child and "life-long irreversible damage". This term is regularly used in publications, presentations, health promotion messages and in prevention programmes. Women who drink are often perceived as bad mothers and incapable of caring for themselves and their children.

In a recent study 395 participants were asked to rate levels of difference, disdain, and responsibility on four conditions, namely: serious mental illness, substance use disorders, jail experience, and FASD. The research participants rated biological mothers of children with FASD as more different, disdained and irresponsible than women with 
serious mental illness, substance abuse disorders and previous incarceration (Corrigan et al., 2017). Women are often more heavily judged and stigmatized than men, especially poor women and women who are abusing substances (Green et al., 2014; Chersich et al., 2016).

In South Africa it has led to the belief that some women in low socio-economic areas might intentionally drink to harm their unborn children. Hence the label the so-called "grabbing culture" amongst the poor (Chersich et al., 2016). By giving birth to children with FASD it is postulated that they might plan to get access to Care Dependency Grants which has a threefold monetary value compared to the generic Child Support Grant. This allegation has led to the Department of Trade and Industry's commission for research in an area where this behaviour was apparently practiced. In a study involving biological mothers and guardians of 1928 children, of whom 251 were diagnosed with FASD, the Research Group could find no evidence to substantiate this claim. None of the children in the study received the Care Dependency Grant or received a FASDdiagnosis prior to the study (Olivier et al., 2017).

Feeling judged by others affects the self-esteem of the individual, resulting in feelings of shame, depression and even the fear of possibly losing custody of their children. Adding to the feelings of loss and hopelessness, this loss of self-esteem is something that at risk women in South Africa can ill afford. The stigma associated with drinking during pregnancy and having a child with FASD might dissuade people affected with FASD, biological mothers and families from seeking treatment services and disclosing drinking habits (Eggertson, 2013; Green et al., 2014). As stated before, stigma might be fuelled by negative messaging in health promotion campaigns projecting biological mothers as the cause of FASD which is " $100 \%$ preventable, but a life-long condition".

In a CanFASD Webinar (February 22, 2016) Dr E Bell (Psychiatrist, Alberta University) lists the following reasons for the gap in our understanding of FASD stigmatization (Figure 5):

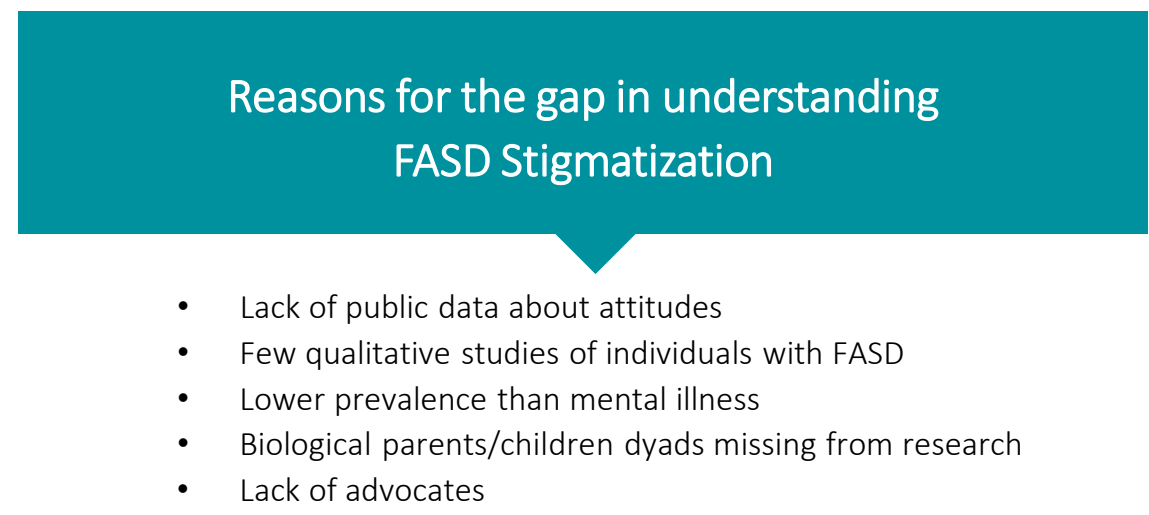

Figure 5: Reasons for the gap in understanding FASD stigmatization (Bell, 2016) 
Bell (2016) expresses the need for people affected with FASD, biological mothers and families to speak up about their experiences and needs. She believes that 'breaking the silence' will alleviate the misconceptions and societal judgement against those affected and will raise the collective responsibility towards FASD management and prevention in general.

In South Africa concern has been raised about poor attendance at health care facilities, resulting in low contraceptive use, high levels of teenage and unplanned pregnancies and also late confirmation of pregnancy, as well as attitudes towards marginalized women and teenagers (Morojele et al., 2010; Wood \& Jewkes, 2006). According to an Amnesty International Report (2014) more than half of pregnant women and teenagers attend antenatal care after 20 weeks' gestation (Amnesty International, 2014). In cases of unplanned and unconfirmed pregnancies, women are at greater risk of having alcohol exposed pregnancies.

Very little, if any information regarding substance abuse, FASD awareness, prevention and management is included in undergraduate studies of health care providers. There is at present (2017) no national or provincial policy or management guidelines for prenatal substance abuse in health care facilities. Women at risk and in need therefore face significant challenges in obtaining appropriate medical and obstetrical care and support. In some cases, they encounter negative attitudes of staff and even receive misinformation (Le Roux, 2013; Wood et al., 2006).

\section{Conclusion}

Considering the vast number of challenges, peer group pressure and misinformation, it is evident that women do not 'choose' to deliberately drink during pregnancy. Alcohol use by pregnant women is deeply imbedded in their particular context and is influenced by a variety of social and structural issues, which do not occur in isolation. Aspects such as demographic and psycho-social factors, the support system of women and pressure from significant others in the decision-making process are crucial behavioural determinants. Some pregnant women find themselves at a disadvantage due to limited access to education, poor nutrition and stigmatization. All of these aspects influence their perception of their own risk in having a child with FASD. The role of the father of the child is often ignored or understated in prevention and education programmes, placing an even greater burden on the women and making them more vulnerable to stigmatization.

Early identification of at risk women by means of public education, screening programmes and awareness campaigns is essential to reduce the incidence of FASD. It is vital to strike a balance between awareness programmes and interventions whereby at risk women and families are identified. To ensure an universal understanding of the 
complexity and to adequate manage the problem, society has to take collective responsibility rather than to 'blame and shame'.

\section{Author's Publications Relevant to the Chapter 5}

* Benade, A.J.S., Olivier, L. \& Bukasa, L. (2017). Effects of biscuits baked with Red Palm Oil (RPO) on the vitamin E and inflammatory status of pre-school children attending an informal crèche in Bethelsdorp, Eastern Cape. Part 3. Intervention study. Nutritional and Health Status. South African Nutritional Journal, 2017 (in publication)

* Olivier, L., Urban, M., Chersich, M., Temmerman, M., \& Viljoen, D. (2013). Burden of fetal alcohol syndrome in a rural West Coast area of South Africa. South African Medical Journal 103(6):402-405. http://doi.org/10.7196/samj.6249

* Urban, M.F., Olivier, L., Viljoen, D.L., Lombard, C., Louw, J.G., Drotsky, L-M., Temmerman, M., \& Chersich, M.F. (2015). Prevalence of fetal alcohol syndrome in a South African city with a predominantly Black African population. Alcohol Clinical and Experimental Research 39(6), 1016-1026. http://doi.org/10.1111/acer.12726

* Urban, M.F., Olivier, L., Louw, J.G., Lombard, C., Viljoen, D.L., Scorgie, F., \& Chersich, M.F. (2016) Changes in drinking patterns during and after pregnancy among mothers of children with fetal alcohol syndrome: A study in three districts of South Africa. Drug and Alcohol Dependence, 168, 13-21. http://doi.org/10.1016/j.drugalcdep.2016.08.629

Louw, J.G., Tomlinson, M., \& Olivier, L. (2017). Unrealistic optimism with regard to drinking during pregnancy among women of childbearing age in a South African community. South African Journal of Psychology 1-11. http://doi.org/10.1177/0081246317717105 


\section{References}

Abel, E.L. (1995). An update on the incidence of FAS: FAS is not an equal opportunity birth defect. Neurotoxicology and Teratology, 17(4), 437-443. http://doi.org/10.106/0892-0362(95)00005-C

Amnesty International. (2014). Struggle for Maternal Health Barriers to Antenatal Care in South Africa. [Adobe PDF version]. Retrieved from http://www.amnesty.ca/sites/default/files/southafricanmaternalhealthreport 9october14.pdf

Benade, A.J.S., Olivier, L. \& Bukasa, L. (2017). Effects of biscuits baked with Red Palm Oil (RPO) on the vitamin $E$ and inflammatory status of pre-school children attending an informal crèche in Bethelsdorp, Eastern Cape. Part 3. Intervention study. Nutritional and Health Status. South African Nutritional Journal, 2017 (in publication)

Bakhireva, L.N., Wilsnack, S.C., Kristjanson, A., Yevtushok, L., Onishenko, S., Wertelecki, W., \& Chambers, C.D. (2011). Paternal drinking, intimate relationship quality, and alcohol consumption in pregnant Ukrainian women. Journal of Studies on Alcohol and Drugs, 72(4), 536-544. http://doi.org/10.15288/jsad.2011.72.536

Bell, E. (2016). Webinar, February 22, 2016 Canada FASD Research Network. Retrieved from https://canfasd.ca/wp-content/uploads/sites/

Benade, A.J.S., Olivier, L. \& Bukasa, L. (2017). Effects of biscuits baked with Red Palm Oil (RPO) shortening on the vitamin $E$ and Inflammatory status of pre-school children attending an informal crèche in Bethelsdorp, Eastern Cape. Part 3. Intervention study. Nutritional and Health Status. South African Nutritional Journal, 2017 (in publication)

Chersich, M.F., Luchters, S., Blaauw, D., Scorgie, F., Kern, F., Van den Heever, A., Rees, H., Peach, E., Kharadi, S., \& Fonn, S. (2016). Safeguarding maternal and child health in South Africa by starting the Child Support Grant before birth: Design lessons from pregnancy support programmes in 27 countries. South African Medical Journal 106(12), 1192-1210. http://doi.org/10.7196/samj.2016.v106i12.12011

Cloete, L.G., \& Ramugondo, E.L. (2015). "I drink." Mothers' alcohol consumption as both individualized and imposed occupation. South African Journal of Occupational Therapy 45(1), 34-40. http://doi.org/10.17159/2310-3833/2015/v45no1a6

Cohen, E. (2015). No alcohol during pregnancy -ever-plead USA paediatrician. Retrieved August 3, 2017, from http://edition.cnn.com/2015/10/21/health/aap-no-alcohol-during-pegnancy/

Corrigan, P.W., Lara, J.L., Shah, B.B., Mitchell, K.T., Simmes, D., \& Jones, K.L. (2017). The Public Stigma of Birth Mothers of Children with Fetal Alcohol Spectrum Disorders. Alcoholism: Clinical and Experimental Research, 41(6), 1166-1173. http://doi.org/10.1111/acer.13381

Croxford, J \& Viljoen, D.L. (1999). Alcohol consumption by pregnant women in the Western Cape. South African Medical Journal, 89(9): 962-965

Eggertson L (2013). Stigma a major barrier to treatment for pregnant women with addictions. Canadian Medical Association Journal, 185(18), 1562-1562. http://doi.org/10.1503/cmaj.109-4653

Ernhart, C.B., Sokol, R.J., Martier, S., Moron, P, Nadler, D., Ager, J.W., \& Wolf, A. (1987). Alcohol teratogenicity in the human: A detailed assessment of specificity, critical period, and threshold. American Journal of Obstetrics and Gynecology, 156(1), 33-39. http://doi.org/10.1016/0002-9378(87)90199-2

Gossage, J.P., Snell, C.L., Parry, C.D.H., Marais, A-S., Barnard, P., De Vries, M., Blankenship, J., Seedat, S., Hasken, J.M., May, P.A. (2014). Alcohol use, working conditions, job benefits, and the legacy of the "Dop" system among farm workers in the Western Cape Province, South Africa: hope despite high levels of risky drinking. International Journal of Environmental Research and Public Health, 11(7), 7406-7424. http:// doi.org/10.3390ijerph110707406

Green, C., Cook, J.L., Racine, E., \& Bell, E. (2014). Stigma, Discrimination and Fetal Alcohol Spectrum Disorder. Canada FASD Research Network. Retrieved from https://canfasd.ca/wp-content/uploads/sites/35/2016/ 05/Stigma-and-FASD-Final.pdf

Hay A.M., Jacobson, S.W., Molteno, C.D., Viljoen, D., \& Jacobson, J.L. (2004). Alcohol exposure and infant mother attachment in a South Africa Community. Alcohol Clinical and Experimental Research 28(5), 45A 
Henderson, J., Gray, R., \& Brocklehurst, P. (2007). Systematic review of effects of low-moderate prenatal alcohol exposure on pregnancy outcome. British Journal of Obstetrics and Gynaecology: An International Journal of Obstetrics \& Gynaecology, 114(3), 243-252. http://doi.org/10.1111/j.1471-0528.2006.01163.x

Hoyme, H.E., May, P.A., Kalberg, W.O., Kodituwakku, P., Gossage, J.P., Trujillo, P.M., Buckley, D.G., Miller, J.H., Aragon, A.S. Khaole, N., Viljoen, D.L., Jones, K.L., Robinson, L.K. (2005) A Practical Clinical Approach to Diagnosis of Fetal Alcohol Spectrum Disorders: Clarification of the 1996 Institute of Medicine Criteria. Paediatrics 115(1): 39-47. DOI: 10.5142/peds.2004-0259

International Alliance for Responsible Drinking. (2017). Global prevalence of FAS and alcohol use during pregnancy. IARD RESEARCH INSIGHTS, pp. 1-5

Jacobs, L \& Jacobs, J. (2013). Narratives on Alcohol Dependence in the Family in Post-Apartheid South Africa. Journal of Addict Research \& Therapy, 4(3),152. http://doi.org/10.4172/2155-6105.1000152

Jacobson, J.L., Jacobson, S.W., Sokol, R.J., \& Ager, J.W. (1998). Relation of maternal age and pattern of pregnancy drinking to functionally significant cognitive deficit in infancy. Alcoholism: Clinical and Experimental Research, 22(2), 345-35. http://doi.org/10.1111/j.1530-0277.1998.tb03659.x

Kelly, J.F., \& Ward, C.L. (2017). Women who drank while pregnant: The importance of social context in the lives of South African pregnant women. Drugs: Education, Prevention and Policy, (April), 1-8. http://doi.org/10.1080/09687637.2017.1316703

Khaole, N.C.O., Ramchandani, V.A., Viljoen, D.L., \& Li, T-K. (2004). A pilot study of alcohol exposure and pharmakinetics in women with or without children with fetal alcohol syndrome, Alcohol and Alcoholism (Oxford, Oxfordshire), 39(6), 503-508. http://doi.org/10.1093/alcalc/agh089

Le Roux, C. (2013) Pregnant women's perceptions and knowledge regarding alcohol use during pregnancy (Master's Dissertation). University of Witwatersrand, Johannesburg.

Link, B.G., \& Phelan, J.C. (2006). Stigma and its public health implications. Lancet, 367(9509), 528-529. http://doi.org/10.1016/S0140-6736(06)68184-1

Louw, J.G., Tomlinson, M., \& Olivier, L. (2017). Unrealistic optimism with regard to drinking during pregnancy among women of childbearing age in a South African community. South African Journal of Psychology 111. http://doi.org/10.1177/0081246317717105

Masemola, M.L., van der Merwe, L., Lombard, Z., Viljoen, D., \& Ramsay, M. (2015). Reduced DNA methylation at the PEG3 DMR and KVDMR1 loci in children exposed to alcohol in utero: a South African Fetal Alcohol Syndrome cohort study. Frontiers in Genetics, 6, 85. http://doi.org/10.3389/fgene.2015.00085

May, P.A., Blankenship, J., Marais, A-S., Gossage, J.P., Kalberg, W.O., Barnard, R., De Vries, M., Robinson, L.K., Adnams, C.M., Buckley, D., Manning, M., Jones, K.L, Charles Parry, C., Hoyme, H.E., \& Seedat, S. (2013). Approaching the Prevalence of the Full Spectrum of Fetal Alcohol Spectrum Disorders in a South African Population-Based Study. Alcoholism: Clinical and Experimental Research, 37(5), 813-830. http://doi.org/10.1111/acer.12033

May, P.A., Brooke, L., Gossage, J.P., Croxford, J., Adnams, C., Jones, K.L., Robinson, L.K., \& Viljoen, D. (2000). Epidemiology of fetalalchol syndrome in a South African community in the Western Cape Province. American Journal of Public Health, 90(12), 1905-1912. http://doi.org/10.2015/ajph.90.12.1905

May, P.A., De Vries, M., Marais, A-S., Kalberg, W.O., Adnams, C.M., Hasken, J.M., Tabachnick, B., Robinson, L.K., Manning, M.A., Jones, K.L., Hoyme, D., Seedat, S., Parry, C.D.H., Hoyme, H.E. (2015). The continuum of fetal alcohol spectrum disorders in four rural communities in South Africa: Prevalence and Characteristics. Drug and Alcohol Dependence 159, 207-218. http://dx.doi.org.doi:10.1016/j.drugalcdep.2015.12.023

May, P.A., \& Gossage, J.P. (2011). Maternal risk factors for Fetal Alcohol Spectrum Disorders: Not as simple as it might seem. Alcohol Research and Health 34(1),15-26

May, P.A., Gossage, J.P., Brooke, L.E., Snell, C.L., Marais, A-S., Hendricks, L.S., Croxford, J.A., Viljoen, D.L. (2005) Maternal risk factors in the Western Cape of South Africa: A population based study. American Journal of Public Health 95(7): 1190-1199

May, P.A., Hamrick, K.J., Corbin, K.D., Hasken, J.M., Marais, A-S, Blankenship, J., Hoyme, J., Kari, J. \& Gossage, J.P. (2016). Maternal nutritional status as a contributing factor for the risk of fetal alcohol spectrum disorders. Reproductive Toxicology, 59, 101-108. http://doi.org/10.1016/j.amepre.2016.02.009 
McBride, N., \& Johnson, S. (2016). Father's Role in Alcohol-Exposed Pregnancies: Systematic Review of Human Studies. American Journal of Preventive Medicine, 51(2),240-248. http://doi.org/10.1016/j.amepre. 2016.02.009

Morojele, N.K., London, L., Olorunju, S.A., Matjila, M.J., Davids, A.S., \& Rendall-Mkosi, K.M. (2009). Predictors of risk of alcohol-exposed pregnancies among women in an urban and rural area of South Africa. Social Science \& Medicine, 70(4), 1-9. http://doi.org/10.1016/j.socscimed.2009.10.040

National Institute of Alcohol Abuse and Alcoholism. NIAAA council approves definition of binge drinking [PDF1.62MB]. NIAAA Newsletter 2004; No. 3, p. 3

O'Keeffe, L.M., Greene, R.A., \& Kearney, P.M. (2014). The effect of moderate gestational alcohol consumption during pregnancy on speech and language outcomes in children: A systematic review. Systematic Reviews, 3(1), 1.http://doi.org/10.1186/2046-4053-3-1

Olivier, L. (2017) [Fetal Alcohol Spectrum Disorder prevalence data for Bethelsdorp study]. Unpublished raw data

Olivier, L., Urban, M., Chersich, M., Temmerman, M., \& Viljoen, D. (2013). Burden of fetal alcohol syndrome in a rural West Coast area of South Africa. South African Medical Journal 103(6):402-405. http://doi.org/10.7196/samj.6249

Olivier, L. (2017a) [ Fetal Alcohol Spectrum Disorder prevalence data for Bethelsdorp study.] Unpublished raw data

Popova, S., Lange, S., Probst, C., Gmel, G. \& Rehm, J. (2017). Estimation of national, regional, and global prevalence of alcohol use during pregnancy and fetal alcohol syndrome: a systematic review and metaanalysis. The Lancet Global Health, 5(3), e290-e299. DOI: http://dx.doi.org/10.1016/S2214109x(17)30021-9

Ramsay, M., Masemola, M.L., Pitamber, P., Patel, S., Lombard, Z., \& Viljoen, D. (2010). Alcohol induced epigenetic effects on imprinted genes in human sperm DNA: Implications for fetal alcohol spectrum disorders. Alcohol Clinical and Experimental Research, 34(8), 49A

Sokol, R.J., Delaney-Black, V., \& Nordstrom, B. (2003). Alcohol Spectrum Disorder Journal of American Medical Association, 290(22), 2996-2999. http://doi.org/10.1001/jama.290.22.2996

Te Water Naude, J., London, L., Pitt, B., \& Mahomed, C. (1998). The 'dop' system around Stellenbosch results of a farm survey. South African Medical Journal = Suid-Afrikaanse Tydskrif vir Geneeskunde, 88(9), 1102-1105. Retrieved from http://www.ncbi.nlm.nih.gov/pubmed/9798497

Urban, M.F., Olivier, L., Louw, J.G., Lombard, C., Viljoen, D.L., Scorgie, F., \& Chersich, M.F. (2016) Changes in drinking patterns during and after pregnancy among mothers of children with fetal alcohol syndrome: A study in three districts of South Africa. Drug and Alcohol Dependence, 168, 13-21. http://doi.org/10.1016/j.drugalcdep.2016.08.629

Urban, M.F., Olivier, L., Viljoen, D.L., Lombard, C., Louw, J.G., Drotsky, L-M., Temmerman, M., \& Chersich, M.F. (2015). Prevalence of Fetal Alcohol Syndrome in a South African City with a Predominantly Black African Population. Alcoholism: Clinical and Experimental Research, 39(6), 1-11. http://doi.org/10.1111/acer.12726

Viljoen, D., Croxford, J., Gossage, J.P., Kodituwakku, P.W., \& May, P.A. (2002) Characteristics of mothers of children with fetal alcohol syndrome in the Western Cape Province of South Africa: a case control study. Journal of Studies on Alcohol, 63(1), 6- 17. Retrieved from http://www.ncbi.nlm.nih.gov/pubmed/ 11925060

Watt, M.H., Eaton, L.A., Dennis, A.C., Choi, K.W., Kalichman, S.C., Skinner, D., \& Sikkeman, K.J. (2016). Alcohol use during pregnancy in a South African community: Reconciling knowledge, norms, and personal experience. Maternal and Child Health Journal 20(1), 48-55. http://doi.org/10.1007/s10995-015-1800-4

Wood, K., \& Jewkes, R. (2006). Blood Blockages and Scolding Nurses: Barriers to Adolescent Contraceptive Use in South Africa. Reproductive Health Matters 14(27), 109-118. http://doi.org/10.1016/S09688080(06)27231-8 

Chapter

The Individual with a Fetal Alcohol Spectrum Disorder 



\section{Introduction}

The children with Fetal Alcohol Spectrum Disorders (FASD) are in many ways the products of the family and society that they find themselves in. FASD prevention is therefore integrally linked to the management of the detrimental conditions that children face pre- and postnatally. Once children are born with FASD, their caregiving environment, family function, influences and support from society, largely determine if they are going to be able to achieve their potential. It thus defines the long-term outcome of their lives. Faced with many health and psycho-social challenges these children start life at a considerable disadvantage. It is therefore of vital importance to strive for early identification, correct diagnosis and to start with appropriate, needs-based interventions as early as possible. That being said, identifying alcohol exposed children and diagnosing FASD in an attempt to assist affected individuals and their families is not an easy task, especially in a developing country like South Africa

\section{Physical characteristics}

During the past 44 years $(1973$ - 2017) the diagnostic journey has taken us from a focus on the physical phenotype and identification of Central Nervous Systems problems to the current emphasis on the importance of the neuro-cognitive deficits. According to Riley and colleagues (2011) a diagnostic goal is to recognize FASD as a 'disorder of the brain rather than one of physical characteristics' (Riley, et al., 2011).

The 'typical FAS phenotype' might facilitate a diagnosis, but there is concern that the children with a less severe phenotype on the FASD continuum, might go undetected through life as their physical signs are subtler (Hoyme, et al., 2005). This poses a serious problem as the 'lesser forms' of the disorder occurs worldwide much more commonly than FAS. Various researchers have raised concern about this in South Africa (May et al., 2015, Olivier et al., 2016, Urban et al., 2016, Viljoen et al., 2001). At present, the IOM's diagnostic citeria (Hoyme et al., 2016) are used in South Africa with the dysmorphological assessments as supportive evidence in making a FAS(D) diagnosis.

In the areas where FASD prevalence studies have been conducted to date there is a high level of awareness regarding the prevalence of the condition. Children with possible FASD are mostly detected by family members or service providers. This is done based on their low birth weights (the so-called 'small for date babies'), continued growth retardation (often referred to as 'failure to thrive'), developmental delays, facial features and/or maternal history of alcohol use. In areas where health professionals have been trained or where referrals to regional or provincial hospitals (with Paediatric and/or Human Genetic units) are possible, these children are referred for FASD assessments. In low resourced areas these referrals are often not possible. This sometimes leads to a 'layman's diagnosis', for example when a learner experiences learning difficul- 
ties and expresses behavioural problems at school, FASD is often considered, especially if the family history is known or maternal alcohol use is suspected. If the child is not referred for a proper assessment and diagnosis, there is a danger of an incorrect diagnosis and labelling. Stigmatization of the child, his siblings and family might follow.

Due to the teratogenic effects of alcohol on the developing cells, congenital structural organ damage is possible. Children with FASD can therefore present with Alcohol Related Birth Defects (ARND) such as defects to the heart, eyes, palate, skeletal structure and other organ systems. In South Africa many of these birth defects go undetected or, if diagnosed via the public health or private health sectors, are not investigated or seldom linked to possible-FASD.

The diagnosis of older children ( $\leq 10$ years of age), adolescents and adults with possible FASD pose a diagnostic challenge as the craniofacial anomalies might diminish over time. Physical deficits such as the thin upper lip, poorly developed philtrum, microcephaly and short stature persist. Underweight in males, not necessarily females, also remains an important characteristic (Spohr, Willms, \& Steinhausen, 2007).

The Research Group is currently busy with a study involving a cohort of 40 young adults who were diagnosed with FASD when they were $7-9$ years of age $(2002-2003)$, their controls (who also participated in the 2002 - 2003 study) and their parents/guardians. Dysmorpology assessments and interviews to assess their health and psycho-social well-being are core aspects of the study (Olivier, 2017).

\section{Neurocognitive characteristics}

Numerous neuro pathways, at all stages from neurogenesis to myelination, can be affected (Riley, et al., 2011). The same processes that determines the facial anomalies of FAS, also cause abnormal brain development and/or structural damage (Lebel, Rasmussen, Wyper, Walker, Andrew, Yager \& Beaulieu, 2008). Animal studies, autopsy and brain imaging studies indicate reduction and anomalies in the overall size and shape of the brain, specifically in the cerebellum, basal ganglia and the corpus callosum. This leads to a wide range of neuropsychogical shortfalls, such as visuospatial functioning, attention, verbal and nonverbal learning, motor control and executive functioning. Behavioural problems affecting the child's daily functioning are common since the child might find it difficult to perform complex tasks such as planning, problem-solving, emotional control, abstraction and arithmetic. Language deficits also frequently occur (Hoyme et al., 2005; Mattson et al., 1999; Riley et al., 2005). These disorders often overshadow the dysmorphology in a child with Alcohol Related Neurodevelopmental Disorders or ARND (Hoyme et al., 2016), another condition in the FASD continuum, that often goes undetected.

Kodituwakku (2006) raises the concern that although children with FASD present with deficits in intellectual functioning, it is still uncertain if there is a unique FASD cog- 
nitive-behavioural functioning or 'behavioural phenotype'. Slow information processing and concentration problems, in particular inattentiveness, are key challenges, coupled with those already mentioned. This indicates a generalized deficit in complex information processing and might form the basis of the central cognitive-behavioral characteristics of children who were prenatally exposed to alcohol. It provides some explanation why these children display substantial shortfalls in their daily functioning and adaptive behaviours, which typically leads to problematic socialization during adolescence (Kodituwakku, 2006).

Accessing 121 children diagnosed with FAS and pFAS in a South African cohort it was found that the higher order abilities of all of the children, as measured with the Griffiths Mental Developmental Scales - Extended Revised were compromised. Significant difference between the controls and the children with FAS and pFAS were evident at 1 year of age, but it became more profound as the children got older. At the age of 5 years the affected children displayed significant lower functioning in eye-hand performance and practical reasoning. Of further concern was that the children's GQ further decreased at 5 years of age. The study furthermore indicated that there was a more positive outcome for the children whose mothers identified their pregnancies earlier and who stopped drinking at that stage (Davies, Crockcroft, Olinger, Chersich, Urban, Chetty Makan, .... \& Viljoen, D., 2017).

One of the challenges experienced by people with FASD is emotional control and expression. Rasmussen (2005), warns against the oversimplification of emotion-related functioning deficits as it is not merely due to a low IQ. There is a need for more in-depth research and the development of appropriate measurement tools. This will enable researchers to study the relationship between emotion-related functioning and the working memory, and ultimately executive functioning. Since this should provide some clarity on the unfolding of these deficits since childhood, it will hopefully enhance earlier diagnosis and improved treatment.

Figure 6, below, provides a summary of some of the neurodevelopmental challenges faced by individuals with FASD as described by Koren, Nulman, Chudley and Loocke (2003): 


\section{Common Cognitive and Behavioural Problems in Children with FASD}

- Attention deficit hyperactivity disorder (ADHD)

- Inability to foresee consequences

- Inability to learn from previous experience

- Inappropriate or immature behaviour

- Lack of organization

- Learning difficulties

- Poor abstract thinking

- Poor adaptability

- Poor impulse control

- Poor judgement

- $\quad$ Speech, language and other communication problems

Figure 6: Common cognitive and behavioural problems in children with FASD (Koren, et al., 2003)

\section{Comorbidity}

Due to potential prenatal injuries in a multitude of organs and the resulting implications, there is a high prevalence of comorbid conditions in individuals with FASD. It is important to recognise these potentially disabling conditions as early as possible in order to start with interventions in an effort to curb the development of secondary disabilities. In a systematic review and meta-analysis undertaken by Popova and colleagues (2016), 428 comorbid conditions, spanning across 18 of the 22 chapters of the ICD-10, were identified. These conditions included chromosomal and congenital abnormalities, mental and behavioural disorders. The conditions with the highest pooled prevalence (ranging from $50 \%$ to $90 \%$ ) were peripheral nervous system and special senses malfunctioning, conduct disorder, receptive and expressive language disorders and chronic serious otitis media (Popova et al., 2016).

More attention should be given to conditions linked to FASD which might add to the challenges faced by affected individuals. In an explorative South African study, the possible prevalence of incontinence among 100 children, $7-10$ years of age, diagnosed with FASD (FAS, pFAS and ARND) were investigated. All of these children were diagnosed by the Research Group during a FASD prevalence study (Olivier, 2017). Roozen and colleagues (2017), reported an overall incontinence rate of $20 \%(n=20)$. Nocturnal Enuresis (NE) affected 16,2\% $(n=16)$ of the children (FAS $n=13$, pFASD $n=1$ ). Daytime Urinary Incontinence (DUI) was reported in one child (1\%) with FAS. Fecal Incontinence 
(FI) was present in $4(4 \%)$ of the children diagnosed with FAS. There was no indication of lower urinary tract symptoms (LUTS) in any of the children. Although the overall incontinence rate for the participants in this small study was lower than the rates for other children with special needs (e.g. $40 \%$ for Autism Spectrum) it was higher $(9,7 \%)$ than in typically developing children in the same age (Roozen, Olivier, Nemczyk, von Gontard, Peters, Kok, .... \& Curfs, 2016).

A study, involving a cohort of 61 pre-school children ( 3 - 5 years of age) with an unknown FASD status, in an urban area with a high FASD prevalence rate (130/1000) revealed some interesting findings and raised questions for further research. Assessing the participants' blood serum levels for Vitamin A and E, it was found that the children had mild to moderate Vitamin A deficiencies. The deficiency rate of 9,4\% in this cohort was markedly lower than the national South African deficiency rate of 43,6\% (Shisana, Labadarios, Rehle, Simbayi, Zuma, Dhansay, ... \& SANHANES-1 Team, 2014). A totally unexpected finding was the high prevalence of Vitamin $\mathrm{E}$ deficiency in the children. With a cut-off point of $12 \mu \mathrm{mol} / \mathrm{L}, 69 \%$ of the children had lower rates. Unfortunately, there are no published data on Vitamin E levels in pre-school children in South Africa, so no comparisons could be made (Benade, Olivier \& Bukasa, 2017). As both Vitamin A and E are important nutrients for optimal cognitive development and functioning, the implications on early childhood development in an impoverished area, with poor nutritional outcomes and a high level of FASD are potentially profound. As the children in the study showed marked improved performance after receiving fortified biscuits, the potential is there to enhance the nutritional status of children and thereby optimizing their cognitive development. This might also be beneficial to malnourished children with FASD in high-risk areas with a poor nutritional status in South Africa.

Research such as the above-mentioned and the Popova comorbidity report (Popova, et al., 2016), should stimulate researchers to explore other conditions that might be related to FASD in an attempt to further clarify and understand the range and extent of the disorders. The growth stunting of children with FASD has been documented since the first FASD reports in South Africa, but has mainly been contributed to factors related to pre- and postnatal alcohol exposure and the nutritional status of the biological mother (Armony-Sivan, Jacobson, Jacobson, Molteno, Carter, Marais, \& Viljoen, 2004; May et al., 2000; Viljoen et al., 2002). Growth retardation is an important aspect in the diagnostic criteria for children with FASD. However, publications such as the recent findings by Amos-Kroohs and colleagues (2016) on the abnormal eating patterns of children with FASD and the possible effect on growth retardation and nutritional deficiencies, might prompt us to explore 'characteristics of FASD' in more depth. 


\section{Life-long implications}

Due to these handicaps and intellectual disabilities, the child with FASD often find formal, mainstream schooling challenging and interpersonal relationships and ordinary day-to-day negotiations confusing. School-drop out is a reality. This is of concern in South Africa, maybe exacerbated by the Department of Education's Inclusive Basic Education (South African Schools Act 79 of 1996), which does not cater for the special needs of learners facing the multitude of FASD-related challenges (Murungi et al., 2015). School disruption leaves individuals with limited occupational options and dependency on families, or social grants (if this can be negotiated).

In a longitudinal study undertaken by Streissguth and colleagues (2004), it was found that of 415 clients (median age 14 years, range $6-51$ years) with FAS or FAE, $61 \%$ of them disrupted school, $60 \%$ reported 'trouble with the law', 50\% had been confined (detention, jail, prison or in substance abuse treatment institutions). Furthermore, $49 \%$ displayed 'inappropriate sexual behaviours on repeated occasions'. Encouraging, Streissguth (2004) reports that if FASD is diagnosed at an early age and the affected individual is raised in a 'good stable environment', the odds to experience these negative life-consequences or 'secondary disabilities', decrease 2- to 4-fold.

Streissguth and O'Malley (2000), recommend holistic treatment as this will best manage and prevent the secondary disabilities and associated mental disorders.

Of interest, in the Streissguth study, $80 \%$ of the participants were not raised by their biological mothers, which implicates that the family and life circumstances of the individuals might have been improved by placements with guardians, foster or adoptive parents (Streissguth, Bookstein, Barr, Sampson, O'Malley \& Young, 2004).

Most of South African children, diagnosed with FASD, remain in the care of their biological families. The majority of these families are female headed households as fathers are often absent or working elsewhere. In the case of a deceased or absent mother (e.g. due to work circumstances or poor care), the care is taken over by a family member such as a grandmother or aunt (Olivier, 2017). By implication, this means that children continue to face the same determinants in their immediate environment and society which led to their birth defects. These determinants might also hinder his postnatal development and future, unless there is a drastic change for the better. However, even the slightest chance to improve the child's conditions provides a window of hope and opportunity, especially in the prevention of secondary disabilities.

\section{Conclusion}

Information regarding the physical characteristics and neurocognitive deficits, together with the maternal factors, as discussed in Chapter 5, make it possible to make confirmed FASD diagnosis. Recent research indicates that there are numerous comorbid 
factors which should be taken into consideration in dealing with individuals who were prenatally exposed to alcohol. Service providers should be able to evaluate and manage the individual given the total gestalt of the condition, not merely by doing the basic dysmorphological assessment and neurodevelopmental testing.

Although there are still many unanswered questions regarding FASD and the needs of the affected individuals and their families, the wealth of information already at our disposal is sufficient to facilitate improved service delivery and care. It certainly provided the Research Group with valuable information to develop awareness and prevention programmes of which some are discussed in Chapter 8.

\section{Author's Publications Relevant to the Chapter 6}

* Benade, A.J.S., Olivier, L. \& Bukasa, L. (2017). Effects of consumption of biscuits baked with Red Palm Oil (RPO) shortening on the vitamin A, $\alpha$ - and $\beta$-Carotene and vitamin $E$ status of pre-school children attending an informal crèche in Bethelsdorp, Eastern Cape. Part 1. Baseline Study. Nutritional and Health Status. South African Nutritional Journal, 2017 (submitted for publication)

* Benade, A.J.S., Olivier, L. \& Bukasa, L. (2017). Effects of consumption of biscuits baked with Red Palm Oil (RPO) shortening on the vitamin A, $\alpha$ - and $\beta$-Carotene status of preschool children attending an informal crèche in Bethelsdorp, Eastern Cape. Part 2. Intervention Study. Nutritional and Health Status. South African Nutritional Journal, 2017 (submitted for publication)

* Benade, A.J.S., Olivier, L. \& Bukasa, L. (2017). Effects of biscuits baked with Red Palm Oil (RPO) shortening on the vitamin E and inflammatory status of pre-school children attending an informal crèche in Bethelsdorp, Eastern Cape. Part 3. Intervention study. Nutritional and Health Status. South African Nutritional Journal, 2017 (submitted for publication)

* Olivier, L., Curfs, L.M.G., \& Viljoen, D.L. (2016). Fetal alcohol spectrum disorders: Prevalence rates in South Africa. South African Medical Journal 106(6) Supplement 1: S103S106

* Roozen, S., Olivier, L., Nemczyk, J., von Gontard, A., Peters, G.Y., Kok, G., Viljoen, D., Curfs, L. (2017) Nocturnal incontinence in children with fetal alcohol spectrum disorders (FASD) in a South African cohort. Journal of Pediatric Urology. http:/doi: 10.1016/j.jpurol.2017.02.009

Davies, L. A., Cockcroft, K., Olinger, L., Chersich, M., Urban, M., Chetty Makkan, C. M., Turnbull, O.H., Olivier, L. \& Viljoen, D. (2017). Alcohol exposure during pregnancy altered childhood developmental trajectories in a rural South African community. Acta Paediatrica 


\section{References}

Amos-Kroohs, R., Fink, B.A., Smith, C.J., Chin, L., Van Calcar, S.C., Wozniak, J.R., \& Smith, S.M. (2016). Abnormal Eating Behaviors Are Common in Children with Fetal Alcohol Spectrum Disorder. Journal of Pediatrics 169:194-200.e1. https://doi-org.ez.sun.ac.za/10.1016/j.jpeds.2015.10.049

Armony-Sivan, R., Jacobson, J.L., Jacobson, S.W., Molteno, C.D., Carter, R.C., Marais A-S., \& Viljoen, D.L. (2004). Does iron deficiency anaemia mediate the relation of fetal alcohol exposure to postnatal growth? Alcohol Clinical and Experimental Research 28(5), 44A

Benade, A.J.S., Olivier, L. \& Bukasa, L. (2017). Effects of consumption of biscuits baked with Red Palm Oil (RPO) shortening on the vitamin $A, \alpha$ - and $\beta$-Carotene status of pre-school children attending an informal crèche in Bethelsdorp, Eastern Cape. Part 2. Intervention Study. Nutritional and Health Status. South African Nutritional Journal, 2017 (submitted for publication)

Benade, A.J.S., Olivier, L. \& Bukasa, L. (2017). Effects of consumption of biscuits baked with Red Palm Oil (RPO) shortening on the vitamin $A, \alpha$ - and $\beta$-Carotene status of pre-school children attending an informal crèche in Bethelsdorp, Eastern Cape. Part 2. Intervention Study. Nutritional and Health Status. South African Nutritional Journal, 2017 (submitted for publication)

Benade, A.J.S., Olivier, L. \& Bukasa, L. (2017). Effects of biscuits baked with Red Palm Oil (RPO) shortening on the vitamin $E$ and inflammatory status of pre-school children attending an informal crèche in Bethelsdorp, Eastern Cape. Part 3. Intervention study. Nutritional and Health Status. South African Nutritional Journal, 2017 (submitted for publication)

Davies, L. A., Cockcroft, K., Olinger, L., Chersich, M., Urban, M., Chetty Makkan, C. M., Turnbull, O.H., Olivier, L. \& Viljoen, D. (2017). Alcohol exposure during pregnancy altered childhood developmental trajectories in a rural South African community. Acta Paediatrica

Hoyme, H.E., Kalberg, W.O., Elliott, A.J., Blankenship, J., Buckley, D., Marais, A.-S., Robinson, L.K., \& May, P.A. (2016). Updated Clinical Guidelines for Diagnosing Fetal Alcohol Spectrum Disorders. Pediatrics, 138(2). http://doi.org/10.1542/peds.2015-4256

Hoyme, H.E., May, P.A., Kalberg, W.O., Kodituwakku, P., Gossage, J.P., Trujillo, P.M., Buckley, D.G., Miller, J.H., Aragon, A.S. Khaole, N., Viljoen, D.L., Jones, K.L., \& Robinson, L.K. (2005). A Practical Clinical Approach to Diagnosis of Fetal Alcohol Spectrum Disorders: Clarification of the 1996 Institute of Medicine Criteria. Paediatrics 115(1), 39-47. http://doi.org/10.5142/peds.2004-0259

Kodituwakku, P.W. (2006) Defining the behavioral phenotype in children with fetal alcohol spectrum disorders: A review. Neuroscience and Biobehavioral Reviews. 31(2), 192-201 http://doi.org/10.1016/ j.neubiorev.2006.06.020

Koren, G., Nulman, I., Chudley, A.E., \& Loocke, C. (2003). Fetal alcohol spectrum disorder. Canadian Medical Association Journal, 169(11), 1181-1185

Lebel, C., Rasmussen, C., Wyper, K., Walker, L., Andrew, G., Yager, J., \& Beaulieu, C. (2008). Brain Diffusion Abnormalities in Children with Fetal Alcohol Spectrum Disorder. Alcoholism: Clinical and Experimental Research, 32(10), 1732-1740. http://doi.org/10.1111/j.1530-0277.2008.00750.x

May, P.A., De Vries, M., Marais, A-S., Kalberg, W.O., Adnams, C.M., Hasken, J.M., Tabachnick, B., Robinson, L.K., Manning, M.A., Jones, K.L., Hoyme, D., Seedat, S., Parry, C.D.H., \& Hoyme, H.E. (2015). The continuum of fetal alcohol spectrum disorders in four rural communities in South Africa: Prevalence and Characteristics. Drug and Alcohol Dependence 159, 207-218. http://dx.doi.org.doi:10.1016/j.drugalcdep. 2015.12.023

May P, Gossage J, Brooke L, Croxford J, Viljoen D. (2000) The maternal risk factors from a second wave of data from mothers of children with fetal alcohol syndrome in the Western Cape, South Africa. Alcoholism: Clinical and Experimental Research, 24(5) 41A

Mattson, S.N., Goodman, A.M., Caine, C., Delis, D.C., \& Riley, E.P. (1999) Executive Functioning in Children with Heavy Prenatal Alcohol Exposure. Alcoholism Clinical and Experimental Research. 23(11), 18081815. Retrieved from http://www.ncbi.nlm.nih.gov/pubmed/10591598 
Murungi, L.N. (Editor) (2015) Inclusive Basic Education in South Africa: Issues in its Conceptualisation and Implementation http://dx.doi.org/10.4314/pelj.v18i1.07

Olivier, L., Curfs, L.M.G., \& Viljoen, D.L. (2016). Fetal alcohol spectrum disorders: Prevalence rates in South Africa. South African Medical Journal 106(6) Supplement 1: S103-S106

Olivier, L. (2017) Fetal Alcohol Spectrum Disorder prevalence data for Bethelsdorp study]. Unpublished raw data

Olivier, L. (2017) [Fetal Alcohol Spectrum Disorders: From diagnoses as a child to adulthood - 15 years later]. Unpublished raw data

Popova, S., Lange, S., Shield, K., Mihic, A., Chudley, A.E., Mukherjee, R.A.S., Bekmuradov, D., \& Rehm, J. (2016) Comorbidity of fetal alcohol spectrum disorder: a systematic review and meta-analysis. The Lancet 6736(15), 1-10. http://dx.doi.org/10.1016/S0140-6736(15)01345-8

Rasmussen, C. (2005) Executive Functioning and Working Memory in Fetal Alcohol Spectrum Disorder. Alcoholism: Clinical and Experimental Research. 29(8), 1359-1367. http://doi.org/10.1097/01.alc.000017 5040.91007.d0

Riley, E. P., Infante, M. A., \& Warren, K. R. (2011). Fetal Alcohol Spectrum Disorders: An Overview. Neuropsychology Review, 21(2), 73-80. http://doi.org/10.1007/s11065-011-9166-x

Riley, E.P., Court, A., Diego, S., Infante, M.A., \& Warren, K.R. (2011). Fetal Alcohol Spectrum Disorders: An Overview. Neuropsychology Revieww, 21(2), 73-80. http://doi.org/10.1007/s11065-011-0166-xFetal

Riley, E.P., \& McGee, C.L. (2016) Fetal Alcohol Spectrum Disorders: An Overview with Emphasis on Changes in Brain and Behavior. Experimental Biology and Medicine. 230(6), 357-365. http://doi.org/10.1177/ 15353702-0323006-03

Roozen, S., Olivier, L., Nemczyk, J., von Gontard, A., Peters, G.Y., Kok, G., Viljoen, D., Curfs, L. (2017) Nocturnal incontinence in children with fetal alcohol spectrum disorders (FASD) in a South African cohort. Journal of Pediatric Urology. http:/doi: 10.1016/j.jpurol.2017.02.009

Shisana, O., Labadarios, D., Rehle, T., Simbayi, L., Zuma, K., Dhansay, A., Reddy, P., Parker, W., Hoosain, E., Naidoo, P., Hongoro, C., Mchiza, Z., Steyn, N.P., Dwane, N., Makoae, M., Maluleke, T., Ramlagan, S., Zungu, N., Evans, M.G., Jacobs, L., Faber, M. \& SANHANES-1 Team, (2014) The South African National Health and Nutrition Examination Survey, 2012: SANHANES-1: the health and nutritional status of the nation. 2014 edition. Cape Town: HSRC Press www.hsrc.ac.za/.../Research_Areas_PHHSI/sanhanes-health-andnutrition

Sokol, R.J., Delaney-Black, V., Nordstrom, B. (2003) Fetal Alcohol Spectrum Disorder JAMA. 290(22):29962999. DOI:10.1001/jama.290.22.2996. http://jama.ama-assn.org/cgi/content/full/290/22/2996

Spohr, H-L., Willms, J., \& Steinhausen, H-C. (2007). Fetal Alcohol Spectrum Disorders in Young Adulthood. Journal of Pediatrics, 150(2), 175-179.e1. http://doi.org/S0022-3476(06)01124-3[pii] \r10.1016/ j.jpeds.2006.11.044

Streissguth, A.P., Bookstein, F.L., Barr, H.M., Sampson, P.D., O'Malley, K., \& Young, J.K., (2004) Risk Factors for Adverse Life Outcomes in Fetal Alcohol Syndrome and Fetal Alcohol Effects. Journal of Developmental and Behavioral Pediatrics. 25(4), 228-238

Streissguth, A.P., \& O'Malley, K. (2000) Neuropsychiatric implications and long-term consequences of fetal alcohol spectrum disorders. Seminars in Clinical Neuropsychiatry. 5(3):177-190. DOI: 10.1053/scnp.2000.6729

Urban, M.F., Olivier, L., Louw, J.G., Lombard, C., Viljoen, D.L., Scorgie, F., \& Chersich, M.F. (2016) Changes in drinking patterns during and after pregnancy among mothers of children with fetal alcohol syndrome: A study in three districts of South Africa. Drug and Alcohol Dependence, 168, 13-21. http://doi.org/10.1016/j.drugalcdep.2016.08.629

Viljoen, D. \& Craig, P. (2001). Epidemiological studies for fetal alcohol syndrome in four Gauteng communities. Report prepared for National Department of Health, Directorate Mental Health and Substance Abuse, Pretoria, South Africa

Viljoen, D., Croxford, J., Gossage, J.P., \& May, P.A. (2002) Characteristics of Mothers of Children with Fetal Alcohol Syndrome in the Western Cape Province of South Africa, A Case-Control Study. Journal of Studies on Alcohol, 63(1), 6-17 

Chapter

Fetal Alcohol Spectrum Disorders Intervention Opportunities in South Africa 



\section{Introduction}

The high Fetal Alcohol Spectrum Disorders (FASD) prevalence rates in South Africa have been well documented in peer reviewed literature and widely shared in the country. It is often quoted as the highest reported in the world and a public health concern. Understandably this gave rise to the expectation, amongst some, that there should be designated national government policies and programmes (or a so-called vertical programme) to address this preventable public health condition. Unfortunately, like other congenital and birth defects FASD is facing multiple public health competitors and challenges in the race to acclaim attention and some of the scarce resources in the country (Christianson \& Modell 2004; Christianson, Howson \& Modell, 2006; Coovadia, Jewkes, Barron, Sanders \& McTyre, 2009; Downie, et al., 2015; Gray \& Vawda, 2016; Department of Health, 2012)

\section{Public health concern}

Although at least 11 prevalence studies have been undertaken in the country, all of these studies have been in the Gauteng, Free State, Western, Eastern and Northern Cape Provinces (Olivier, et al., 2016). The unavailability of rates in the remaining provinces create the impression that FASD is not prevalent there. In order to lobby for more support from central government, a national FASD rate is needed. This can only be achieved by a national surveillance (which is at present not feasible due to resource limitations) or FASD prevalence studies in the remaining five provinces. A new FASD prevalence study (the $12^{\text {th }}$ ) is currently in process in the Free State province (2017 2020), this will soon provide rates for 5 of the 9 provinces in South Africa, moving closer to a national overview of the disorder.

Malherbe, and colleagues, in the South Africa Health Review (2016) explain the dangers pertaining to underreporting on the prevalence of a condition. The model used (Figure 7), refers to 'Congenital Disorders' (or Birth Defects) (Malherbe, Aldous, Woods \& Christianson, 2016). Since the National Guidelines for the Care and Prevention of the Most Common Genetic Disorders, Birth Defects and Disabilities (Department of Health, 2004) refers to FASD as a Congenital Disorder/Birth Defect the diagram below is also relevant to FASD: 


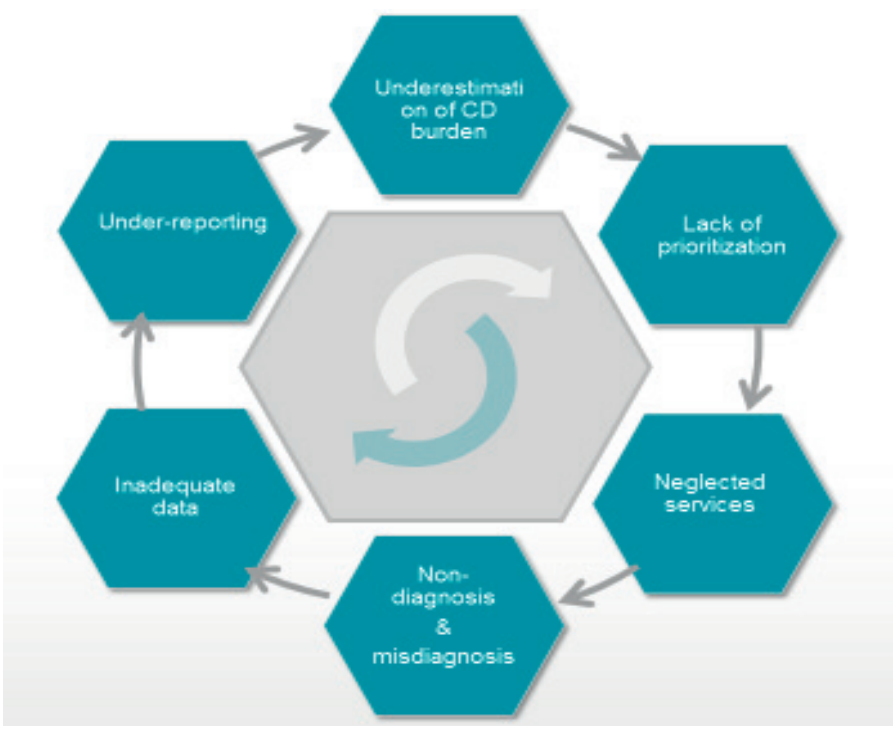

Figure 7: The cycle caused by the underestimation of congenital disorders, such as FASD (Malherbe, et al., 2016)

The model clearly illustrates how underreporting leads to underestimation of the extent of the problem. In an under-resource, developing country like South Africa, conditions with the highest prevalence are perceived as a public health threat and are therefore prioritized. If a condition or problem is not prioritized it does not rank high enough on the 'needs ladder' to warrant the development and provision of services. This often leads to a type of 'Cinderella phenomenon' where a condition or problem is either ignored or placed very low on the priority list. The inferior ranking order might result in, for example, limited or no training provided to service providers, which might cause under-diagnoses or misdiagnosis (due to a lack of knowledge, skills, tools, time, etc.). If a condition is not diagnosed and prioritized, there is limited chance of it being recorded and reported, therefore available data about the phenomenon is restricted. In its worst form the community might also believe that it is not a problem. Patients/clients affected by the condition or problem therefore will find it difficult to access services and skilled service providers. They might thus either refrain from seeking help or become unhappy about the situation. In a best case scenario, the unhappy clients will put pressure on the system to provide services (e.g. patient lobby groups of which the HIV/AIDS groups in South Africa are excellent examples).

\section{Existing structures}

Looking at 'government' to provide services necessitates an exploration of the existing systems and opportunities within government structures. At present the departments 
involved in possible FASD service rendering are mainly the Departments of Social Development, Health, Education, Agriculture, Trade, Industry and Economic Affairs.



Figure 8: FASD stakeholders

In order to best utilize potential opportunities, the author proposes that 'the net should be cast wider' so as to include other NGOs (relevant to FASD), people with FASD and their families, tertiary institutions (which includes researchers), churches and religious groups, the Liquor Industry and the media (Figure 8). It is essential to focus on different aspects such as viticulture; wine and beer manufacturing; legislation; research; service provision; psyhco-social, economic and religious support; health care; education; awareness and information dissemination. All of the above-mentioned are essential role-players in the comprehensive management and prevention of FASD.

\section{Available opportunities}

As it is the author's belief that there are many available opportunities holding huge potential for interventions Table 2 below provides an overview of the links to the main structures and indicates possible 'missed opportunities'. 


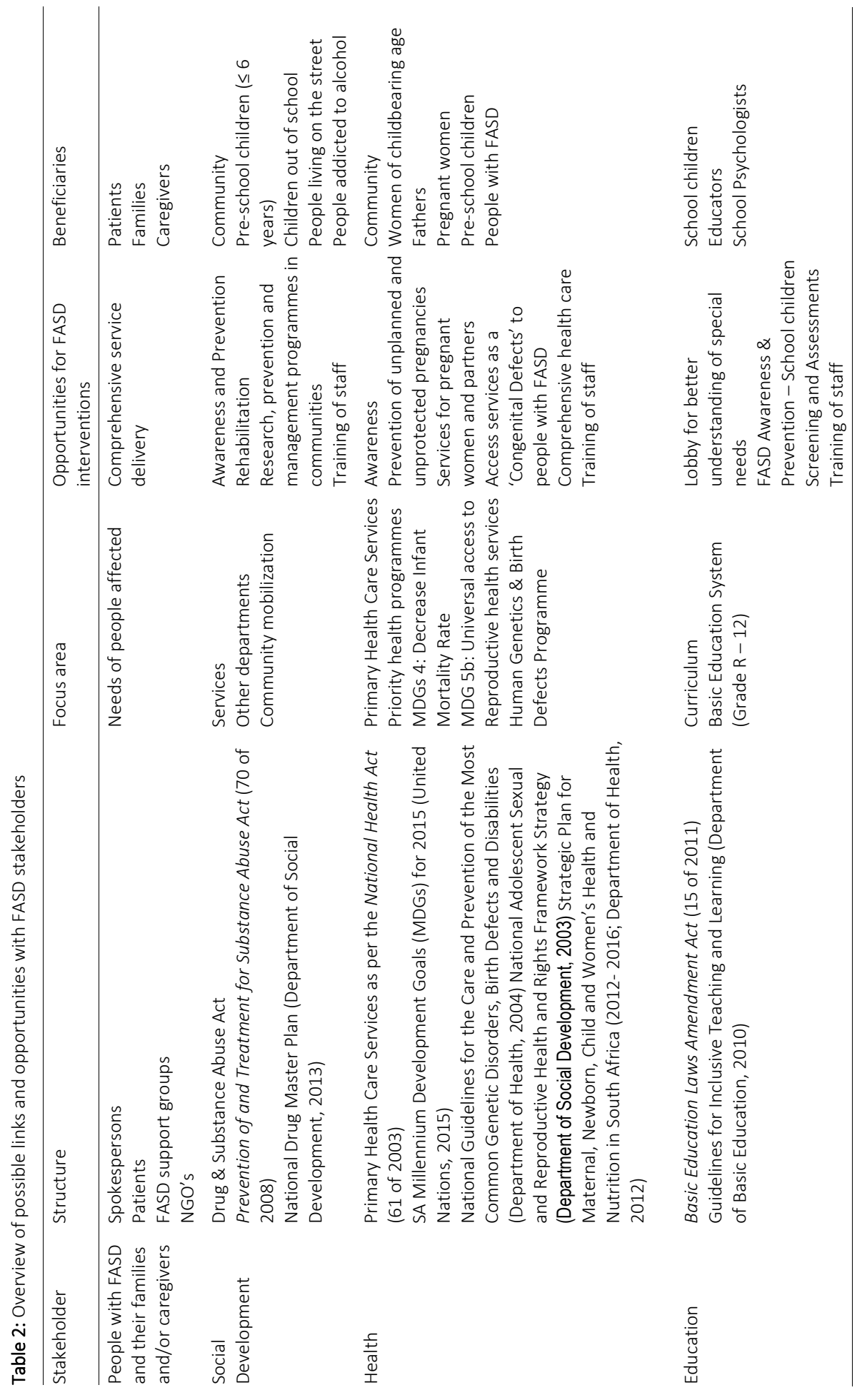


Fetal Alcohol Spectrum Disorders Intervention Opportunities in South Africa

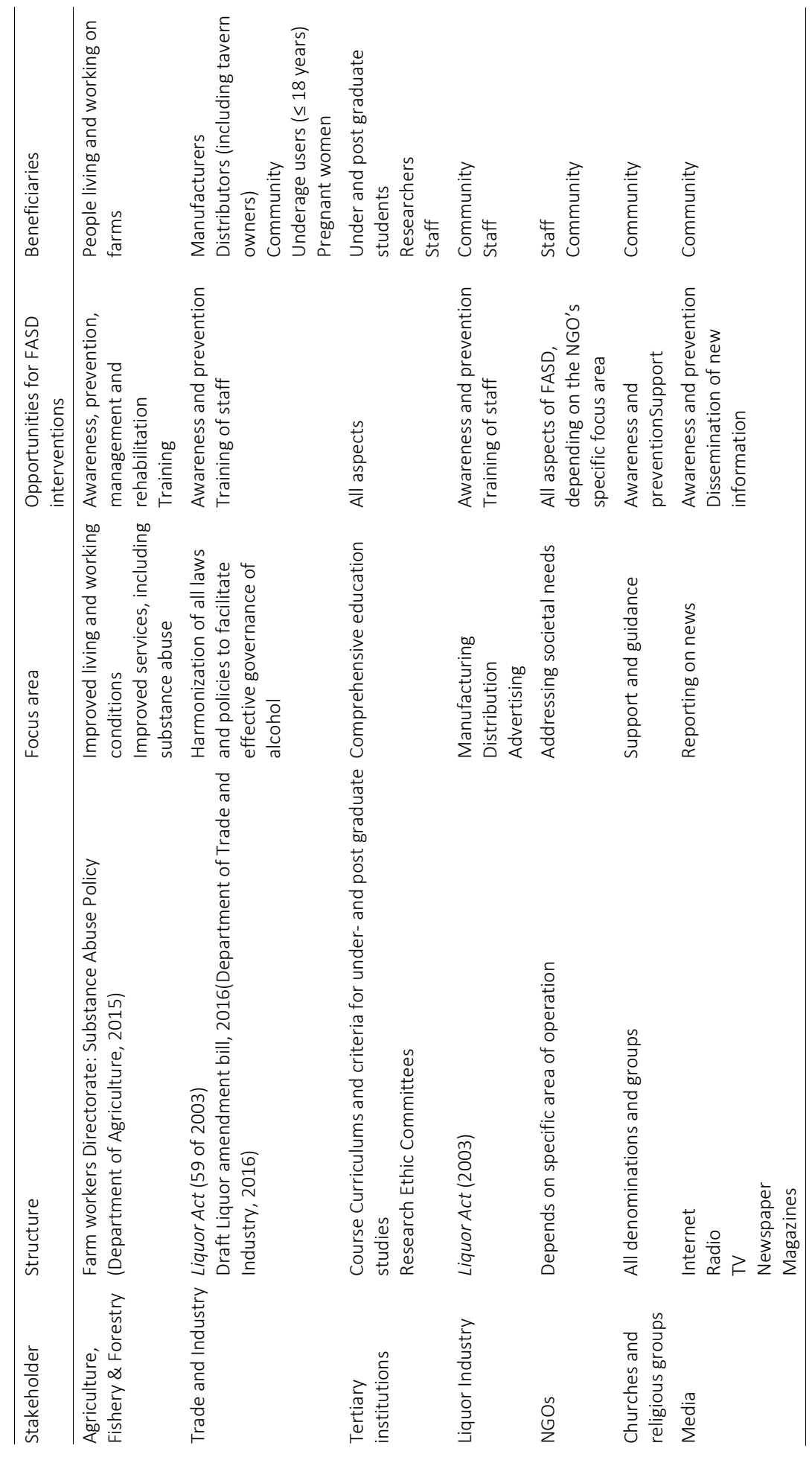




\section{FASD coordinating structure}

FASD awareness and advocacy for service delivery have to be negotiated against the afore-mentioned backdrop. In theory it lays the foundation for an interdepartmental service delivery model. Unfortunately, the task is bedevilled by all the different roleplayers, agendas, and again, competing interests. It also calls for the so-called 'champion person to drive a champion system', which makes it very fragile as the system then relies on the driver and his/her availability. It does however pose the opportunity for the establishment of an inter-sectoral structure, involving stakeholders of all the relevant institutions which will lead to more comprehensive and improved service delivery.

In South Africa a structure like this was established in April 2001 by the author of this dissertation, who was then the provincial manager of the Maternal, Child and Women's Health Directorate in the Western Cape Province. This interdepartmental FASD Reference Group coordinated FASD services in the different government departments (Health, Education and Social Development) and NGOs, developed a FASD training manual, implemented training, established a service and research data base and identified gaps in the management of FASD in the province (2001-2006).

Since the author left the Department of Health (2006) and handed over the chairmanship, the FASD Reference Group lost the representatives from other two government departments, except the Department of Health. The current membership comprises members of three NGOs, one representative of the Department of Health, a local authority representative and one or two private researchers. The main focus of the new group, now called the FASD Task Team, revolves around FASD awareness, prevention and training, largely through the 'International FASD Day - 9 September' activities, pamphlets and posters (FASD Task Team, n.d.). It, therefore, mainly functions as an awareness and support group, relying heavily on the good will and limited resources of its members, with some support from the Department of Health.

\section{SA-FASD Network}

In South Africa there is a need for a national coordinating structure or network, similar to the CanFASD Network (CanFASD, n.d.). The South African structure should be coordinated by a strong and respected leader in the field, collaborating closely with the Departments of Health (Directorate: Maternal, Newborn, Child and Women's Health and Nutrition), the Department of Social Development (Directorates: Substance Abuse and Persons with Disabilities), the Department of Education, as well as the Departments of Agriculture, Community Safety, Trade Industry and Economic Affairs. The support and partnership with the relevant stakeholders, NGOs and researchers in this field is essential. Like the CanFASD Network, it should focus on the provision of support to South Africa's leadership in terms of the management of FASD in the country. 
A clear mandate for this structure (possibly called the SA-FASD Network) has to be developed and should start with a focus on the establishment of the following:

- $\quad$ Database of existing resources, services and interventions;

- Collaboration of research;

- Dissemination of information (e.g. research findings);

- Identification of gaps and opportunities;

- $\quad$ Advocacy for improved prevention strategies and support services;

- Lobby for changes in under-graduate education of relevant professional groups to include substance abuse and management education;

- $\quad$ Promote relevant policy formulation and legislation;

- Training of professionals.

The provision of services, promotion of a specific NGO/government department's policies/programmes and the management of stakeholders should not be part of this mandate. The structure should rather focus on the establishment of a collaborative and supportive network.

\section{A framework of priority actions}

To move the country forward and to prioritize service delivery in terms of FASD, involving all stakeholders, the following should be considered:

- Increased political will and financial commitment for better service delivery;

- $\quad$ Establishment of a national data base and monitoring of FASD prevalence;

- $\quad$ Capacity building in all sectors, including the training of health professionals;

- $\quad$ Establishment of a research agenda pertaining to specific FASD questions applicable to the country;

- Increased community education and awareness; this should also include information regarding the available services and how to use them;

- Lay advocacy and patient support groups should be strengthened and encouraged to partner with government to lobby for better service delivery.

\section{Conclusion}

Considering the information to our disposal, the existing knowledge and skills and the vast number of missed opportunities, South Africa might not be so under-resourced as some believe. Reviewing the current structures, laws and guidelines in the government departments and other organizations, it is evident that there are a vast number of ave- 
nues that can be explored and utilised to address the complex problem of FASD. To do so one needs to have an in-depth knowledge and understand of the existing opportunities, the service delivery models and how to optimally use it. Priority public health conditions, such as HIV/AIDS and TB, are tapping a considerable amount of the country's resources and the focus on the management of these conditions often leave little time, energy and funding to address any other health and psycho-social challenges (Van Rensburg, 2016). Keeping in mind that FASD is the symptom of a complex myriad of challenges faced by those affected, it becomes clear that even a focussed programme to address FASD is not necessarily the solution. Available resources such as the Department of Social Developments National Substance Abuse Programme, the Department of Health's comprehensive Primary Health Care Services and the Department of Agriculture's programme for people living and/or working on farms provide excellent opportunities for prevention, early identification and management. Children with special needs (including children who are severely affected by FASD) have access to schools for children with special needs (where these schools are available). NGO's, churches and other support groups can provide focussed interventions to fill the gap. What is of the utmost importance though is to acknowledge that the available services are not enough and do not adequately cater for the needs of people affected with FASD. Here the crucial advocacy role of NGO's and other stakeholders are to be acknowledged. With the necessary leadership and combined goodwill, improved FASD management in South Africa is indeed possible.

\section{Author's Publications Relevant to the Chapter 7}

* Olivier, L., Curfs, L. M. G., \& Viljoen, D. L. (2016). Fetal alcohol spectrum disorders: Prevalence rates in South Africa. South African Medical Journal, 106(6 Suppl. 1), S103S106. http://doi.org/10.7196/SAMJ.2016.v106i6.11009 


\section{References}

Basic Education Laws Amendment Act, no. 15 of 2011

CanFASD. (n.d.) History Document. Retrieved August 16, 2017, from https://canfasd.ca/about/hisotrydocument/

Christianson, A., \& Modell, B. (2004) Medical Genetics in Developing Countries. Annual Review: Genomics Human Genetics (5), 219-265

Christianson, A., Howson, C.P., \& Modell, B. (2006) March of Dimes Global Report on Birth Defects, the Hidden Toll of Dying and Disabled Children. White Plains, NY: March of Dimes Birth Defects Foundation. (Internet) (cited 15 January 2016). htpp://www.marchofdimes.org/materials/glodal-report-on-birth-defectsthe-hidden-toll-of-dying-and-disabled-children-full-report.pdf

Coovadia, H., Jewkes, R., Barron, P., Sanders, D., \& McTyre, D. (2009). The health and health system of South Africa: historical roots of current public health challenges. The Lancet 374(9692), 817-834

Department of Agriculture. (2015). Strategic plan for the fiscal years 2015/2016 to 2020/2021. [Adobe PDF version]. Retrieved from http://www.elsenburg.com/sites/default/files/publications/2015-04-29/strategicplan-draft3\%28h\%29-2015-2021.pdf

Department of Basic Education. (2010). Guidelines for Full-service/Inclusive schools 2010. Pretoria, South Africa: [Adobe PDF version]. Retrieved from http://www.thutong.doe.gov.za/ResourceDownload. aspx?id=44323

Department of Health. (2004). Human genetics policy guidelines for management and prevention of genetic disorder, birth defects and disabilities. [Adobe PDF version]. Retrieved from http://www.gov.za/documents/ human-genetics-policy-guidelines-management-and-prevention-genetic-disorder-birth-defects

Department of Health. (2012). Strategic Plan for Maternal, Newborn, Child and Women's Health (MNCWH) and Nutrition in South Africa: 2012- 2016. Retrieved from http://www.health.gov.za/index.php/2014-0317-09-09-38/strategic-documents/category/95-2012s

Department of Social Development. (2003). National adolescent sexual and reproductive health and rights framework strategy. [Adobe PDF version]. Retrieved from http://www.dsd.gov.za/index2.php?option= com_docman\&task=doc_view\&gid=578\&ltemid=3

Department of Social Development. (2013). National drug master plan 2013 - 2017. [Adobe PDF version]. Retrieved from http://www.dsd.gov.za/cda/

Department of Trade and Industry. (2016). Draft Liquor amendment bill, 2016. Government Gazette, (No. 40319). Retrieved from http://www.gov.za/sites/www.gov.za/files/40319_gon1206.pdf

FASD Task Team. (n.d.). The Task Team. Retrieved August 16, 2017, from http://www.fasdsa.org./team.htmlh

Gray A \& Vawda Y. (2016). Health Policy and Legislation. In: Padarath A, King J, Mackie E, Casciola J, editors. South African Health Review 2016. Durban: Health Systems Trust. http://www.hst.org.za/publications/ south-african-health-review-2016

Liquor Act, no. 59 of 2003

Malherbe, H. L., Aldous, C., Woods, D., \& Christianson, A. (2016). The contribution of congenital disorders to child mortality in South Africa. In A. Padarath, J. King, E. Mackie, \& J. Casciola (Eds.), South African Health Review 2016. Durban: Health Systems Trust.

National Health Act, no. 61 of 2003

Olivier, L., Curfs, L. M. G., \& Viljoen, D. L. (2016). Fetal alcohol spectrum disorders: Prevalence rates in South Africa. South African Medical Journal, $106(6$ Suppl. 1), S103-S106. http://doi.org/10.7196/SAMJ. 2016.v106i6.11009

Prevention of and Treatment for Substance Abuse Act, no. 70 of 2008

United Nations. (2015). The Millennium Development Goals Report. United Nations. [Adobe PDF version]. Retrieved from http://www.un.org/millenniumgoals/2015_MDG_Report/pdf/MDG 2015 rev (July 1).pdf

Van Rensburg, H.C.J. (2016). South Africa's protracted struggle for equal distribution and equitable access still not there. Human Resource Health 2014:12-26. http://www.human-resources-health.com/content/ $12 / 1 / 26$ 

Chapter

\section{Discussion: \\ Lessons Learnt from the Past 20 Years}





\section{Introduction}

The author of this thesis is also the chief executive officer of FARR (the Research Group). This chapter will focus on the interventions that were specifically designed to research and combat FASD in South Africa ("About us, "n.d.)

\section{The birth of FARR and FASD awareness in South Africa: 1997- 2001}

FARR was founded in 1997 by Prof Denis L Viljoen. In his capacity as the Associated Professor of Human Genetics at the University of Cape Town (UCT), Viljoen was responsible for the UCT Human Genetics Outreach Programme to rural areas in the Western Cape, Northern Cape and Eastern Cape Provinces, in collaboration with the Department of Health. This programme was established in the early 1980's. During these outreach visits and clinics, Viljoen became increasingly concerned about the number of young children presenting with growth retardation (height, length and head circumference) and developmental delays. Some of the children displayed similar physical and facial dysmorphology. The common denominator was a maternal history of prenatal alcohol exposure.

In 1995 at a National Institute of Health (NIH) and National Institute for Alcoholism and Alcohol Abuse (NIAAA) FASD Meeting in Washington, DC, concern was raised about a suspected FASD prevalence of $10-30$ per 1000 in the USA. Attending the meeting, Viljoen expressed his fear that the FASD rate in high-risk South African communities might be as high as 100 per 1000 of the population. He stated the need for empirical research in this regard.

His statement led to a site visit in 1996 by a NIH and NIAAA delegation and the first three NIH funded FASD prevalence studies in Wellington, Western Cape Province (1997 - 2001). To facilitate this process and the research, FARR was founded in 1997 in collaboration with UCT. The Association for Responsible Alcohol Use (ARA) provided seed funding for the initial administration. The NGO was registered with the National Department of Social Development in compliance with the required legislation and regulations.

The main focus of the Research Group, at this time, was centred on the three FASD prevalence studies in Wellington. The two principal investigators for the studies were Prof Denis L Viljoen and Prof Phillip A May (then from the University of New Mexico, Albuquerque, USA). South African based staff were appointed and worked in collaboration with the visiting research colleagues and subject specialists from the USA. The last FASD prevalence study in this series was completed in the early 2000's.

The results of the studies were published in a number of peer reviewed journals and widely reported in the media, thereby raising the awareness regarding FASD, and specifically in the study area (as mentioned in Chapter 4). 


\section{Beyond the Millennium: 2001-2006}

Although it was initially foreseen that the Research Group will only exist until the end of the above-mentioned three FASD prevalence studies in the Wellington area, the awareness regarding FASD in South Africa was growing. As such, the need for more research became imperative.

In 2001 Viljoen was consulted by the Department of Health regarding a possible FASD problem in an isolated rural town in the Northern Cape Province, $780 \mathrm{~km}$ from Cape Town. This town, De Aar, was situated in the middle of South Africa, in a semidesert, sheep-farming area. The 'dop system' has never been practiced in this area. A prevalence study soon revealed a FASD rate of 119,4 per 1000 of the population. The research findings were soon published in the lay media by journalists under sensational headings such as "Alcohol ravages De Aar's children" and terms such as 'the highest reported in the world' were used (Mail \& Guardian, 23 September 2007). This clearly indicated a need for universal awareness regarding FASD and raised the concern regarding possible stigmatization of clients and communities.

Studies in a second town in the Northern Cape (Upington) and in Gauteng province soon followed. In an attempt to address the maternal and community risk factors perpetuating the high prevalence rates, the Research Group commenced community awareness programmes (e.g. talks at Primary Health and Antenatal Care clinics) and lectures to educators and health care workers in the Northern Cape study areas. Within 3 years after the implementation of these interventions, a decrease of approximately $30 \%$ was reported in both the De Aar and Upington sites (Olivier, Urban, Chersich, \& Viljoen, 2010). This spurred the Research Group on to explore new and culturally friendly interventions to address the FASD-problem in high-risk areas.

\section{A growth spurt: 2006-2017}

Since 2006 the Research Group has grown beyond expectations and, through the leadership of the author and her research teams, have developed innovative interventions that are well-accepted by community members and professionals alike. Where previously, the focus was on FASD prevalence studies, it was now expanded to include the four focus areas as depicted in Figure 9 below: 




Figure 9: The Research Group's main focus areas

These focus areas are included in all Research Group's Comprehensive FASD Projects that are implemented on all the project sites.

As stated before, the Research Group has completed 11 community prevalence studies in 4 provinces to date (see Table 1 and Figure 12) and undertaken extensive awareness and prevention work in the same provinces (Olivier, et al., 2016). A new study site in the Free State province has just been added. No studies have been done as yet in the Limpopo, Mpumalanga, KwaZulu Natal and North West provinces.

\section{Comprehensive FASD projects}

\section{Initiation of a project}

The Research Group enters a community by invitation only. The invitations might be extended by government departments (e.g. Premiers of provinces, Department of Social Development, Department of Trade and Industry), local authorities (e.g. Municipal Managers and Mayors) and/or Community Leaders. As described in Chapter 4, an invitation is followed by a lengthy process whereby the expectations of the invitation, proposed project, the research and the implications on the community are discussed. Consultative and information meetings with the various stakeholders in the community may be lengthy and take up to 2 years before permission and support is provided. During 
this time funding is secured and Research Ethical approval is obtained from the research ethics committees and the relevant government structures (See Chapter 4).

By engaging with the community and the various stakeholders involved the Research Group uses an interactive approach to develop the project. In this process the stakeholders are represented on a Project Planning Committee (the community might decide to name it differently). In the Research Group's experience this process is vital in order to secure continued community support and engagement. Communities often wish to give the project a name that describes the intervention or depicts a vision. Examples of these are "My healthy child project" (Renosterberg Municipal Area, Northern Cape Province) and the "PAth Project", short for the "Prince Albert towards health Project" (Prince Albert, Western Cape Province). By naming a project, the community takes ownership of the project. In the case of the PAth Project the community developed a project logo (Figure 10):



Figure 10: PAth project logo

The Project Committee is furthermore instrumental in the process whereby challenges pertaining to FASD, as well as possible ways to address these, are identified.

In setting up the project, principles of the Intervention Mapping planning approach, as described by Bartholomew, Parcel, Kok, Gottlieb \& Fernandez, 2016, are utilized (Table 3). Due to the complexity of the Comprehensive FASD research, awareness, prevention and training project, a framework has to developed for each component of the project. Below is an example of the framework used for the prevention part of the project, specifically in this case the Healthy Mother Healthy Baby (HMHB) Programme. 
Table 3: Intervention Mapping Model used to develop the HMHB Programme as part of the Comprehensive FASD research, awareness, prevention and training project

\begin{tabular}{|c|c|c|}
\hline & Steps & Examples of Tasks \\
\hline $\begin{array}{l}\text { On-going } \\
\text { evaluation } \\
\text { and } \\
\text { adaptation as } \\
\text { indicated }\end{array}$ & $\begin{array}{l}1 \text { Logic Model of } \\
\text { the Problem }\end{array}$ & $\begin{array}{l}\text { Establish Planning Committee including stakeholders in project area such as } \\
\text { other service providers, community members and project staff (e.g. } \\
\text { Community Workers) } \\
\text { Describe the layout of the project, timeframe, location, services that will be } \\
\text { rendered additional to the project (e.g. referrals of health or psycho-social } \\
\text { problems identifies), informed consent procedure, confidentiality, } \\
\text { protection of the rights of all participants (especially the children), grievance } \\
\text { procedure, disclose the funder, determine the participants and goals. }\end{array}$ \\
\hline
\end{tabular}

2 Program State the outcomes of the project, e.g. for the Healthy Mother Healthy Baby Outcomes \& $\quad$ (HMHB) Programme (see below) a decrease in prenatal maternal drinking as Objectives to reduce the number of alcohol exposed pregnancies, increase in Logic Model of awareness regarding dangers of alcohol and substance use, participation of Change fathers/partners, etc.

3 Program Create a program theme and components, such as the HMHBC Programme Design with recruitment of pregnant women $<20$ weeks' gestation from the $\mathrm{PHC}$ clinic or in the community, informed consent procedure, individual and group sessions, brief intervention techniques, home visits, clinical assessments, recordkeeping, referral procedures when appropriate. Design brief intervention individual and group sessions, as well as home visits according to the selected methods and related theories, e.g. Group 1 and 2: Elaboration method, supported by theories such as information, processing, elaboration and likelihood and interventions such as group discussions regarding alternative drinks (e.g. cold drinks rather than alcoholic drinks), individual sessions can focus on management of situations that clients find difficult, e.g. pressure to drink at parties. Group 3 and 4: Goal-setting method, supported by the goal-setting theory and self-regulation. Individual sessions can focus on setting of goals pertaining to the specific challenges that each client is facing. Group sessions can be used to share information and possible ways that other clients use to address similar challenges. With the support of the Buddy (which is part of the programme), a client can review her goals, achievements and also receive positive reinforcement and praise for even the smallest of successes.

4 Program Finalize the programme and protocols to be in line with the policy of the Production Department of Health and the needs of the community. Develop clear guidelines as to ensure that the aforementioned meets with the research protocol of the Research Group.

Design the programme material to be acceptable and appropriate for the specific target group (e.g. "My Special Booklet"), monitor and evaluate the programme (e.g. regular audits of the records and client files by the Project Manager, Clinical Assessment of babies at 9 months of age by a Paediatrician/FASD Clinician)

5 ImplementationIdentify the participants, e.g. participants of courses, such as the Health Plan Professionals, Educators, Social Workers and Pregnant Women in the highrisk areas (as identified by the FASD Prevalence Study) Develop the implementation interventions, such as the brief interviewing sessions, scripts for group work, material for group sessions, procedure for home visits and post labour contact. 
6 Evaluation Plan Develop indicators (such as the number of sessions per risk group - see below) and measurements for evaluation by means of recording in the attendance register, client files, My Special Booklet, etc.

Develop an evaluation plan and tools, linked to the above-mentioned as to ensure that problems are detected as early as possible as to rectify and/or re-assessment of the IM model in use. E.g. AUDIT screening on enrolment and AUDIT screening just before delivery to assess impact of $\mathrm{HMHB}$ interventions and evaluate possible changes in behaviour.

The above-mentioned process is never complete and cannot necessarily be used as a generic model for every project or even the different interventions in the same project. As each community has its own needs, a new model needs to be developed for every aspect and new project. Due to constant changes in communities, unexpected variables and challenges, models require regular revision. By doing so the Research Group keeps track of the communities' unique challenges and needs and thereby also facilitates ongoing monitoring and evaluation of the project.

\section{Project implementation}

With the implementation of the 3-year Comprehensive FASD Projects, the Research Group takes the three phased approach as illustrated in Figure 11 below.

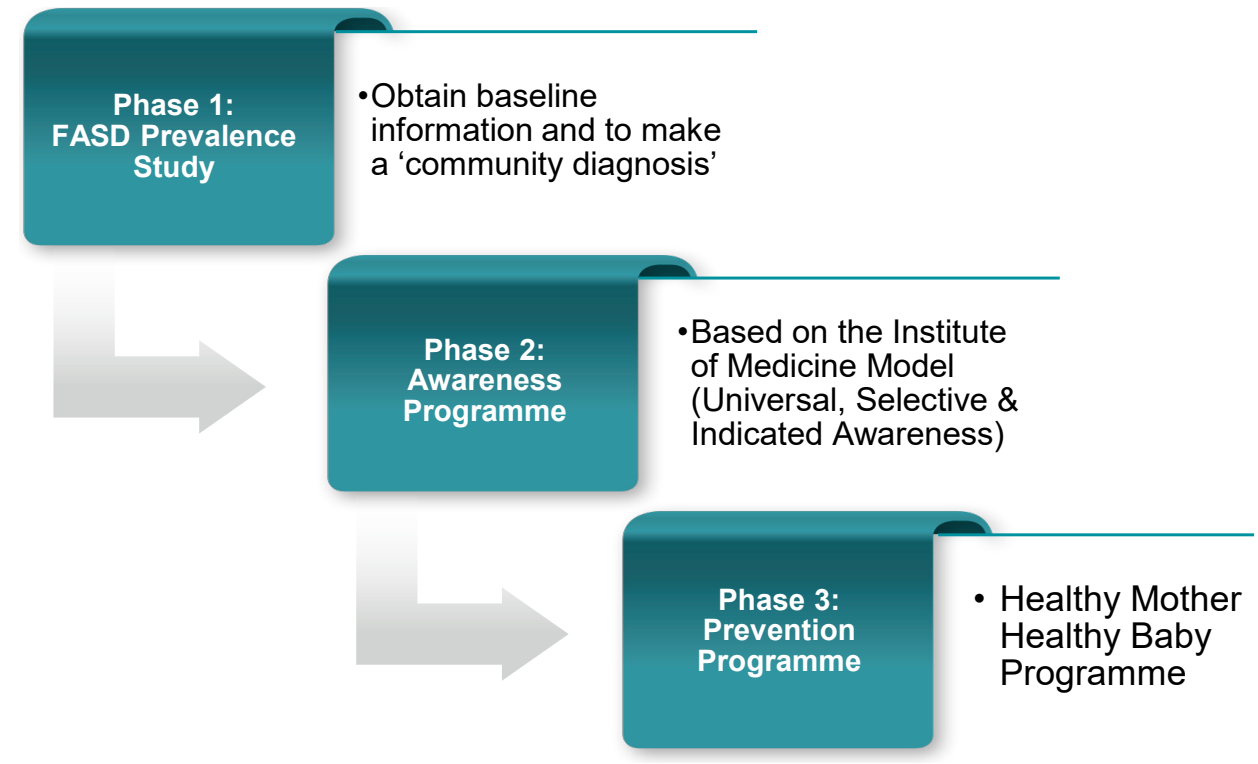

Figure 11: The 3-phased approach of the Comprehensive FASD Projects

Phase 1 continues until the $3^{\text {rd }}$ project year, whilst Phases 2 and 3 commence towards the end of the first project year and continue until the end. 
This approach was used on all the Research Group's research sites to date. The focus is therefore not only on FASD research. Great care is taken to develop the capacity of local service providers and to empower community members to make informed decisions related to FASD prevention.

\section{Phase 1: FASD prevalence study (refer to Figure 3)}

It is important to note that during the FASD prevalence study, specifically whilst doing the anthropometric screenings and medical examinations, the Research Group detects a wide variety of health and psycho-social conditions. As the studies are often conducted in remote areas, access to adequate care and services remain challenging. Due to the vast distances that community members have to travel to the available services, accessibility and affordability often deter clients from using these. The service rendered to the community at large by means of the Research Group's interventions is therefore highly valued by those in need, but it places a huge resource constraint on all the projects. (Refer to Chapter 4 for a more detailed description of this phase.)

The map in Figure 12 provides a snapshot of the prevalence studies done by the Research Group to date (2017) and the rates.

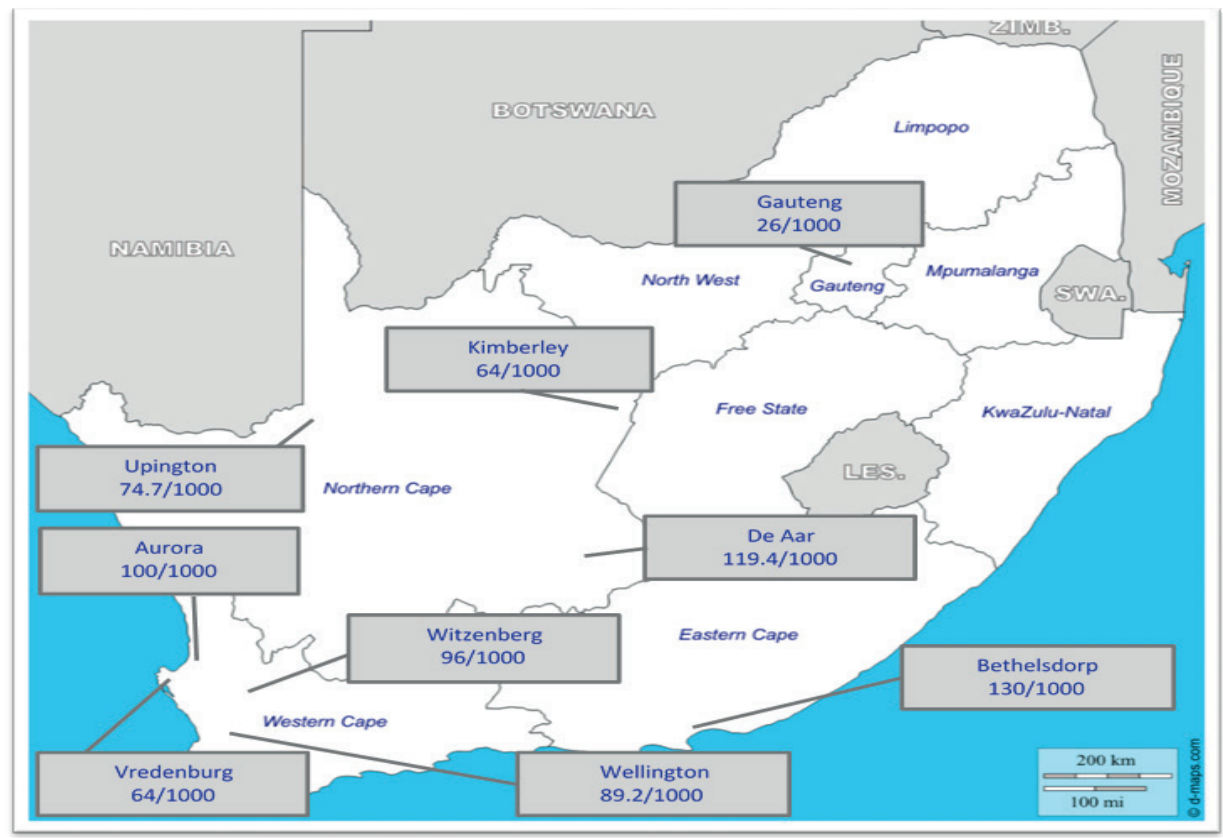

Figure 12: The Research Group's prevalence study sites and rates 
Phase 2: Awareness Programme (refer to Figure 9 and Figure 11)

\section{Universal awareness programmes}

In presenting these programmes, the Research Group strives to involve as many community members as possible to create universal awareness of FASD and the prevention thereof amongst policy makers, service providers, community leaders, employers, church and religious groups, etc. This is done by means of community events such as the International FASD Day (9 September) events which might take the form of imbizos (community meetings/gatherings), and workshops or awareness walks involving 'everybody'. Media reporters are involved which often leads to reports in newspapers and talks on radio or television. A recent example is an Afrikaans 13-episode radio drama " $n$ Tweede kans" (A second chance), which is currently (2017) being broadcasted on national and a regional radio station. The Research Group provided the factual information and final editing (De Bruin, 2017).

\section{Selective awareness programmes}

Selective awareness programmes includes specific interventions with high-risk groups as identified during the prevalence study and the community consultative process. These programmes aim to share information with specific groups in order to enable them to make better informed decisions and to encourage empathy and support to pregnant women.

- The LoveChild industrial theatre and workshop

In many South African communities story-telling and drama are popular ways of entertainment and means to convey messages. Tapping into this, the Research Group partnered with a drama NGO, takeAWAY theatre, in writing a script for an industrial theatre production, LoveChild/Liefdeskind.

Industrial theatre is an interactive, flexible play aiming to engage the audience emotionally and intellectually. Real life scenarios are acted out and the audience is encouraged to participate by assisting the actors in making decisions or commenting on their actions. By depicting real-life issues, the audience is confronted with their own daily challenges, but with the use of humor it is served with a twist. The learning opportunities provided leave the audience motivated and better empowered to reflect on their own decisions. (www.takeawaytheatre.com/favorites/industrial-theatre).

The play and workshop are offered to community members (older than 12 years of age) in areas with a high FASD prevalence rate (Figure 13). Venues such as school halls, community and church halls are used, but the play has even been performed in the open field. 


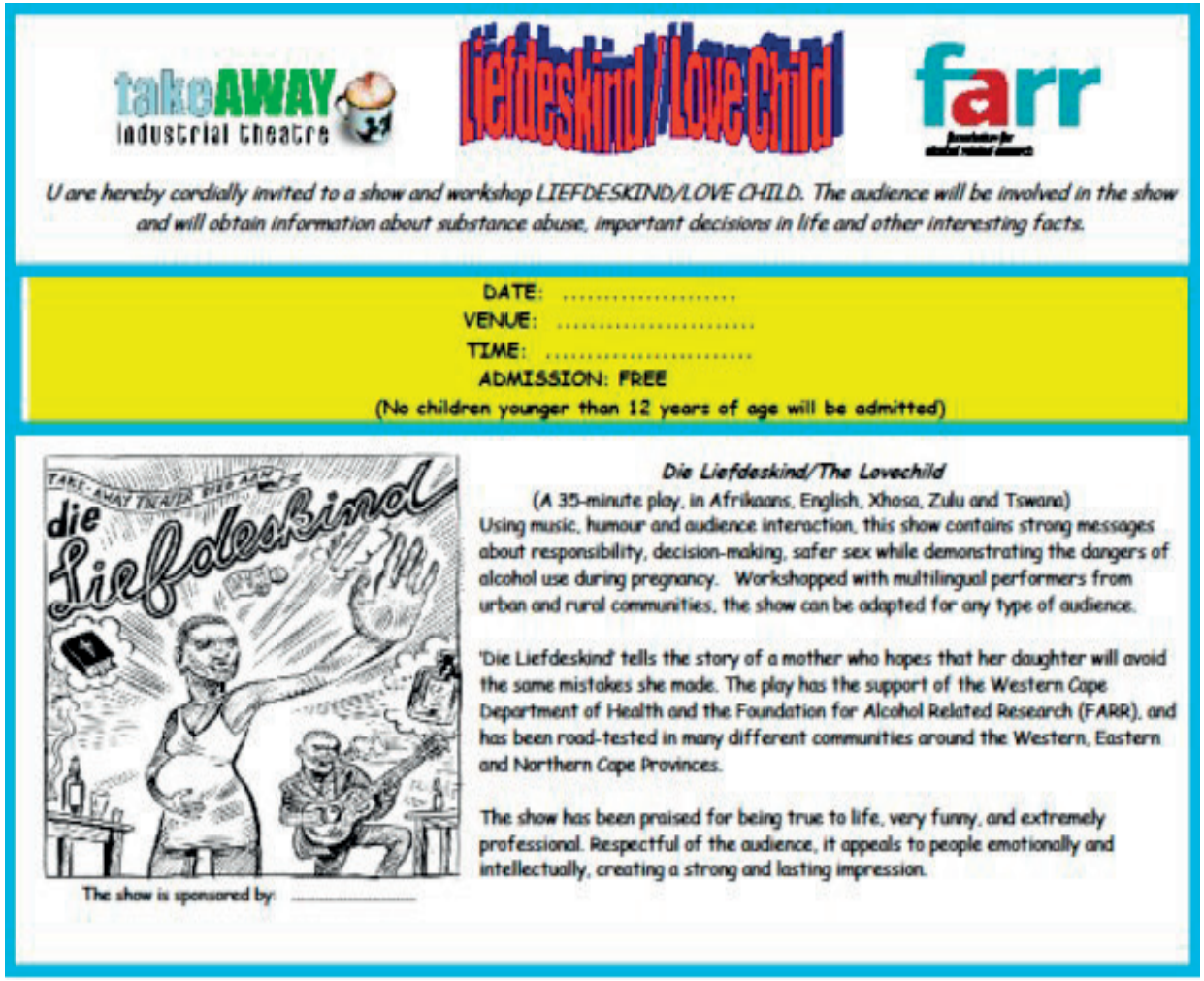

Figure 13: Flyer for the LoveChild industrial theatre show and workshop

In 2016 the play was reviewed. By using the Intervention Mapping criteria, the script was revised and the production was relaunched in August 2016. The Research Group will start with the monitoring and evaluation process towards the beginning of 2018.



Figure 14: One of the LoveChild actors in action 
- Training and workshops for professionals

In an attempt to share knowledge and skills and to encourage service providers to include FASD and substance abuse awareness, prevention and management in their service delivery programmes, the Research Group offers training workshops to educators (teachers), health professionals, social workers and community workers in the project areas. The Research Group's Training Academy is registered with the Health and Welfare Seta (HWSeta). Some of the courses (e.g. for social workers and psychologists) are also registered via the specific accreditation and professional registration bodies. To offer these accredited courses the course material and presenters have to be approved by these professional bodies. Course participants receive Continued Professional Development accreditation (CPD-points), required for their annual registrations by attending the courses and completing the course assignments. A typical course assignment is the development of an intervention strategy that a social worker can implement in her area of work.

\section{Indicated awareness programmes}

- FAStrap course

Families who are abusing alcohol and women who have children with confirmed FASD are at the highest risk of having children with FASD. As not to stigmatize these families, all the parents in a community with a high FASD prevalence rate are encouraged to attend the FAStrap course. This interactive, 4-day life skills course comprises 10 modules. These models were identified in consultation with communities, government departments and are also based on the Research Group's research findings (e.g. determinants for FASD).

The name of the course derived from the Afrikaans word 'trap' which refers to taking steps towards a greater goal (e.g. like climbing a flight of stairs to the top floor) or to trample on something (in this case FAS) as to destroy it. By implication it means that by taking this course the participants are taking small steps towards personal growth and thereby taking action to prevent FAS in their own families and communities.

This basic 10-module course contains interactive learning exercises, demonstrations and games. It is suitable for community members with 7 or less years formal schooling, but has been offered with great success to illiterate participants as well. 


\section{FAStrap Course modules}

- I am Number One (Self-esteem)

- Good parent - bad parent (Parenting skills)

- No means no (Discipline)

- My precious child (Basic childcare)

- Just one more, or not at all (Alcohol and drugs)

- Where to go to (Childcare services and support)

- What do we eat tonight (Nutrition)

- My child is sick (Childhood diseases and minor ailments)

- Soap it in (Hygiene)

- Stay safe around here (Safety in and around the house and community)

Figure 15: FAStrap Course Modules

\section{Phase 3: Prevention Programme (refer to Figure 9 and Figure 11)}

- Healthy Mother Healthy Baby (HMHB) Programme

The HMHB Programme was developed within the Research Group after an initial pilot study with colleagues from the South African Medical Research Council (Marais, Jordaan, Viljoen, Olivier, de Waal \& Poole, 2010). The overall aim of the HMHB Programme is to provide high risk pregnant women with the necessary support and guidance to ensure that they have healthier and safer pregnancies. The ultimate goal is the birth of healthier babies, who do not have FASD.

Pregnant women in high-risk areas are identified by the Research Group's community workers (appointed from the project areas), family and community members. All the pregnant women in the project area are eligible to enrol in the programme before 20 weeks' gestation. These women do not necessarily all use and/or abuse alcohol. Pregnant women are also enrolled via the anternatal (ANC) clinics at the Primary Health Care (PHC) facilities as the Research Group has agreements in this regard with the respective Departments of Health and the local PHC clinics (refer to Chapter 4).

On enrolment the pregnant woman receives information about the HMHB Programme from the community worker $(\mathrm{CW})$. If she agrees to join the programme, she completes an informed consent form (she has the option to leave at any stage during the programme). With the assistance of the CW, she completes an Alcohol Use Disorders Identification Test (AUDIT) (Babor, Higgins-Biddle, Saunders, \& Monteiro, 2001; De 
Meneses-Gaya, Zuardi, Loureiro, \& Crippa, 2009). (Addendum 4) Based on the findings of the AUDIT she is allocated to one of four Risk Groups:

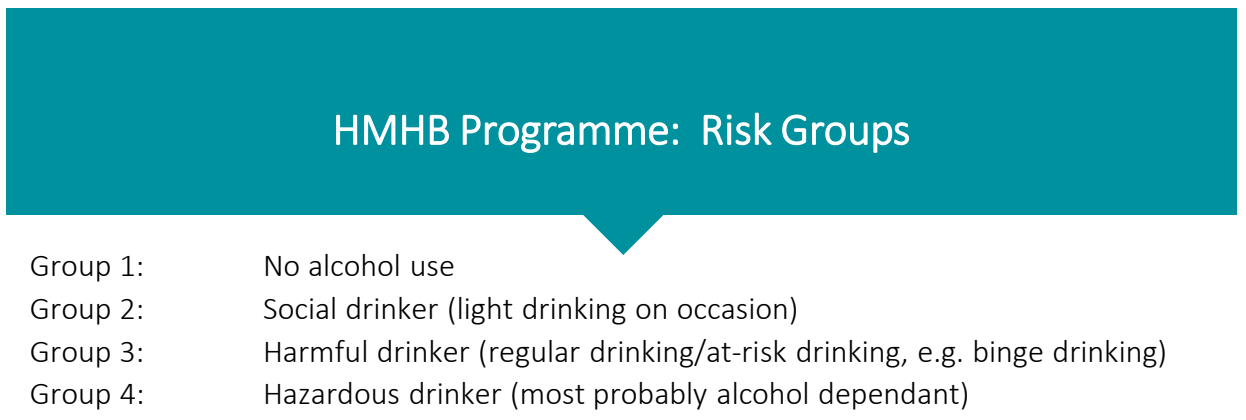

Figure 16: Healthy Mother Healthy Baby Programme: Risk Groups (Babor, et.al., 2001)

The specific risk group to which a pregnant woman is allocated is never disclosed to her or mentioned during the programme, but guides the CWs on the specific intervention that she is advised to receive. Each HMHB Client is allocated to a specific CW who will remain her support person until her baby is 9 months old (and sometimes even after this).

By not disclosing the group allocation and including pregnant women who are not drinking in the programme, the Research Group ensures that this programme is perceived as providing support to all the pregnant women in the project area. The programme is therefore non-stigmatizing, facilitates optimal health of all the participants and is not seen as a 'FASD prevention programme' which merely focusses on 'women who drink during pregnancy'.

CWs use brief interviewing techniques, video material, participant workbooks ('My Special Booklet'), group work and individual sessions to share information regarding pregnancy health (e.g. nutrition, exercise), coping mechanisms, substance abuse, child care, etc. with the participants (Addendum 5). The pregnant women in the highest risk group (Group 4) are also encouraged to enrol a 'buddy'. This can be a friend, family member or member of the church who is trained to support the woman during her pregnancy, especially during times that she finds it difficult to abstain from alcohol. The buddy can also accompany her to parties or places where she feels vulnerable and supports her in achieving her goals.

At the last session, before delivery, the participants complete another AUDIT screening. This information is used to assess the impact of the project. (This data is currently being collected for evaluation.)

As soon as possible after the delivery of her baby, the CW visits the new mother at home to determine if she is coping. During this visit the general health of the mother and baby is assessed. Any problems or concerns are reported to the Resesarch Group's Project Manager and the PHC nurse at the PHC Clinic. 
A further assessment takes place when the baby is examined by one of the Research Group's dysmorphologists at 9 months of age. If any health and/or psycho-social problems are detected the mother and/or baby receives a referral to the appropriate services. If the baby presents with any developmental delays and/or FASD, the child receives a Neurocognitive Assessment. A therapeutic programme is developed for the baby. The mother receives the necessary support to implement it. Currently a prenatal stimulation and early childhood development (ECD) programme is being developed and piloted on one of the Research Group's project sites. Women participating in the HMHB Programme receive training and are invited to enrol their children in the ECD programme. They also receive training on ECD and how to prepare their children for school. (This intervention forms part of a Masters study.)

\begin{tabular}{|c|c|c|c|c|c|c|c|c|c|c|}
\hline \multirow[b]{2}{*}{ 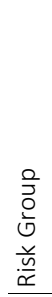 } & \multirow[b]{2}{*}{ 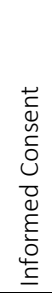 } & \multirow[b]{2}{*}{$\stackrel{\circ}{\mathrm{Q}}$} & \multicolumn{4}{|c|}{ Brief Intervention Sessions } & \multirow[b]{2}{*}{ 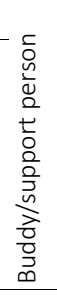 } & \multirow[b]{2}{*}{ 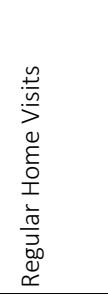 } & \multirow[b]{2}{*}{ 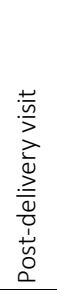 } & \multirow[b]{2}{*}{ 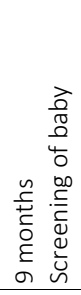 } \\
\hline & & & 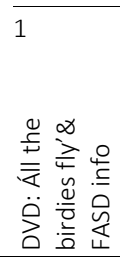 & 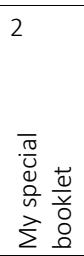 & 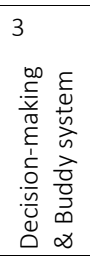 & 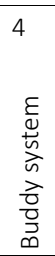 & & & & \\
\hline 1 & $x$ & $x$ & $x$ & $x$ & & & & & $x$ & $x$ \\
\hline 2 & $X$ & $\mathrm{x}$ & $x$ & $\mathrm{x}$ & & & & $\begin{array}{l}1 \text { home } \\
\text { visit }\end{array}$ & $\mathrm{x}$ & $\mathrm{x}$ \\
\hline 3 & $x$ & $x$ & $x$ & $x$ & $x$ & $x$ & $x$ & $x$ & $x$ & $x$ \\
\hline 4 & $x$ & $x$ & $x$ & $x$ & $x$ & $x$ & $x$ & $\mathrm{x}$ & $x$ & $x$ \\
\hline
\end{tabular}

Figure 17: Summary of brief interviewing sessions in HMHB Programme

At present the impact of this programme has amazing results with very few babies born with FASD (Figure 18). It is currently being evaluated and will be presented as a journal article soon.

- FASD Support Groups

Mothers/guardians/caregivers of people (children and adults) with FASD receive information and support in a variety of support groups. Members can choose the type of support group according to their needs and available resources. The different versions include groups meeting face-to-face once a month; an on-line group receiving information and support via e-mails; a group who receives information by means of mobile phone (texted messages) and a group who receives information and support via slow mail (letters). 


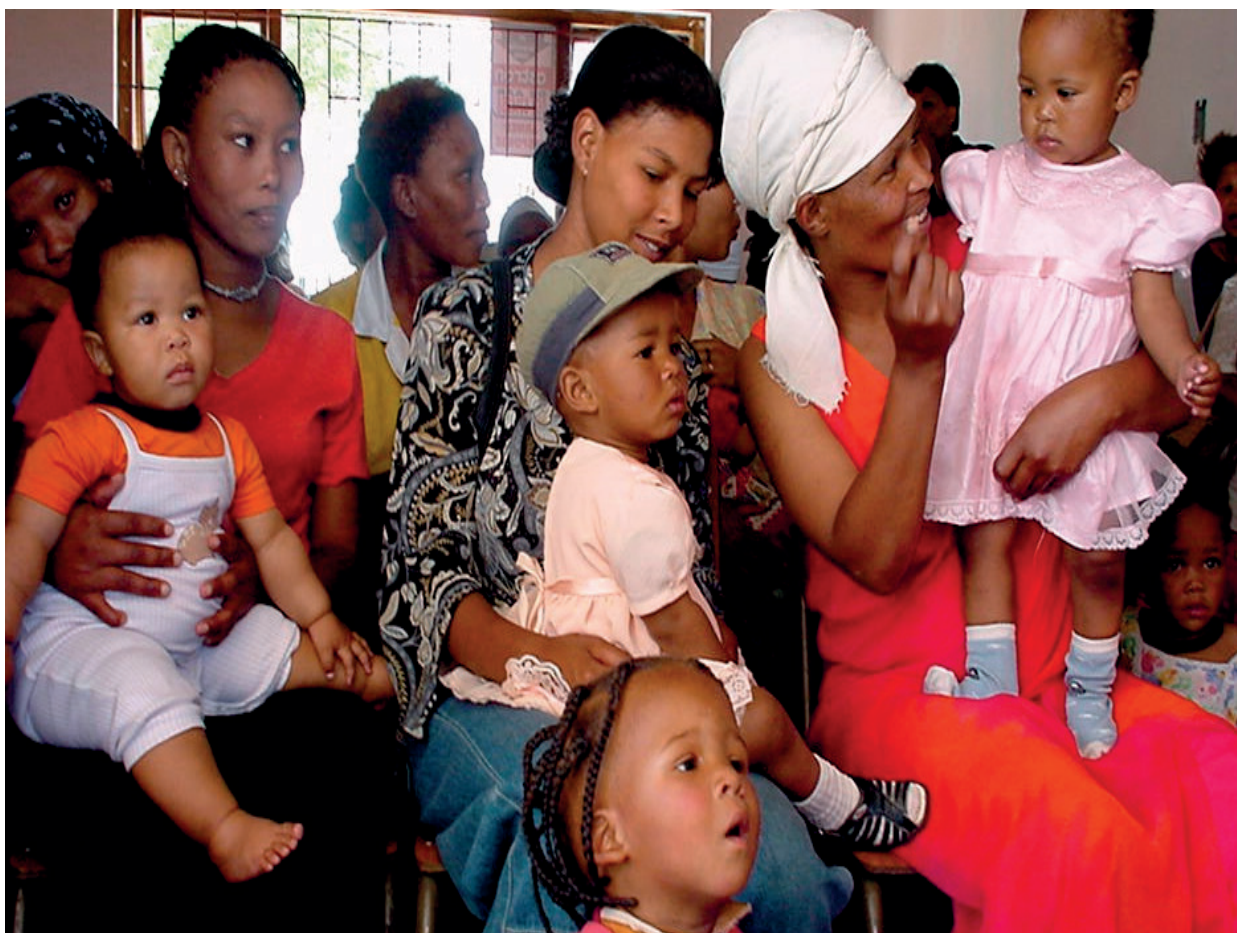

Figure 18: A group of high-risk clients who completed the HMHB Programme with their healthy infants

- 'Do you have 3 Minutes?' Programme

Due to the success of the HMHB Programme, the Department of Social Development (Western Cape Province) has requested the Research Group to develop a short, practical and impactful awareness intervention that government officials in the Departments of Health, Social Development and Education can implement as part of their normal duties. The Department of Social Development provided funding for the development and a 2-year pilot project (2016 - 2018).

Since PHC nurses indicated during training and other contact sessions that, due to work pressure, they can only spend 3 minutes per patient, the programme that is currently being developed was named the 'Do you have 3 Minutes?' Programme.

It entails the following:

Service providers receive basic training on FASD awareness, prevention and management. During the training participants get a 'Do you have 3 Minutes?' card applicable to their specific professional group. The cards contain 3 key statements/messages that participants have to discuss with their clients. The discussion should not take longer than 3 minutes. For example, the cards for health professionals focus on the pregnant women and information regarding a healthy, alcohol-free pregnancy (see Addendum 6). Cards for social workers focus on the prevention of FASD and where to seek help for substance abuse. The educators' cards contain information regarding the sup- 
port of learners with FASD in the classroom (see Addendum 7). Cards are also being issued to reporters (media cards) as to provide them with guidelines in an effort to limit sensational and possibly harmful publications.

A similar process is followed with community members who also receive 'Do you have 3 Minutes?' cards. Their cards contain information how to safeguard themselves against having children with FASD and provides information that they can share with peers and family (See Addendum 8).

By using the cards trainees receive the correct information and can use this in discussions with others. The ultimate goal is to raise awareness regarding FASD, to stimulate discussion and information sharing in the community. The programme is scheduled to run until the end of 2018 and will be evaluated.

\section{- Sensible Drinking Workshop}

Corporates and employers in the study areas expressed a need for employees to receive training in terms of alcohol harm and abuse, and the effect thereof in the workplace. To steer away from a blame and shame approach a 'Sensible drinking' workshop was developed. All employees, irrespective of their alcohol consumption practices, are encouraged to attend the training.

The training includes self-assessment exercises and largely focusses on attitudes towards substance abuse (including alcohol), information about different substances of abuse and the effect on the body (including FASD), the impact of addition, how to seek help and a list of available rehabilitation resources. Participants are also given information to share with their friends, family and other colleagues.

Corporates and employers have the option to enrol in a longer programme whereby employees with substance abuse problems receive additional support as part of the company's human resources programme and in accordance with the South African Labour Law. (As this falls outside of the ambit of this dissertation it will not be discussed in detail).

\section{Conclusion}

As many researchers and community workers will testify, the best teacher in community development and action research is the community itself. Being committed to the development of evidence based models to address the needs in a community compels the researcher or community developer to be guided by dynamics, needs and processes within the specific area. To do so requires a high level of patience and the ability to constantly adapt to the fluidity of the situation. To negotiate and implement high quality research projects and exercise monitoring and evaluation in situations like this calls for great creativity and insight. But in the true Ubuntu spirit of 'I am what I am because 
of who we all are', successful community research and the development of sustainable interventions for communities in South Africa cannot be done in any other way.

Guided by the above-mentioned, the Research Group has used research findings, recommendations and approaches such as Intervention Mapping, industrial theatre and brief interviewing to develop original interventions to share information with community members, facilitate decision-making, guide and support them in the journey to selfefficacy and behaviour change.

\section{Author's Publications Relevant to the Chapter 8}

* Urban, M.F., Olivier, L., Louw, J.G., Lombard, C., Viljoen, D.L., Scorgie, F., \& Chersich, M.F. (2016) Changes in drinking patterns during and after pregnancy among mothers of children with fetal alcohol syndrome: A study in three districts of South Africa. Drug and Alcohol Dependence, 168, 13-21. http://doi.org/10.1016/j.drugalcdep.2016.08.629

Chersich, M.F., Urban, M.F., Olivier, L., Davies, L-A., Chetty, C., \& Viljoen, D. (2012). Universal Prevention is Associated with Lower Prevalence of Fetal Alcohol Spectrum Disorder in Northern Cape, South Africa: A Multi-centre Before-After Study. Alcohol and Alcoholism, 47(1):66-74. http://doi.org/10.1093/alcalc/agr145

Marais, S., Jordaan, E., Olivier, L., \& Viljoen, D. (2012). Fetal Alcohol Spectrum Disorders. In A. Van Niekerk, S. Suffla, \& M. Seedat (Eds.), Crime, Violence and Injury in South Africa, $21^{\text {st }}$ Century Solutions for Child Safety (pp.214-228). [Adobe PDF version]. Retrieved from http://www.mrc.ac.za/crime/Chapter15.pdf

Marais, S., Jordaan, E., Viljoen, D., Olivier, L., de Waal, J. \& Poole, C. (2010) The effect of brief interventions on the drinking behaviour of pregnant women in a high-risk rural South African community: a cluster randomised trial. Early Child Development and Care. http://dx.doi.org/10.1080/03004430903450392 


\section{References}

Babor, T. F., Higgins-Biddle, J. C., Saunders, J. B., \& Monteiro, M. G. (2001). The Alcohol use disorders identification tests - guidelines for use in primary care (2nd ed.). Retrieved from http://whqlibdoc.who.int/hq/ 2001/who_msd_msb_01.6a.pdf

Batholomew, E.L.K., Markham, C., Ruiter, R.A.C., Fernandez, M., Kok, G. (2016) Planning health promotion programs; an intervention mapping approach. New York: Wiley: 2016

Chersich, M.F., Urban, M.F., Olivier, L., Davies, L-A., Chetty, C., \& Viljoen, D. (2012). Universal Prevention is Associated with Lower Prevalence of Fetal Alcohol Spectrum Disorder in Northern Cape, South Africa: A Multi-centre Before-After Study. Alcohol and Alcoholism, 47(1):66-74. http://doi.org/10.1093/alcalc/ agr145

De Meneses-Gaya, C., Zuardi, A. W., Loureiro, S. R., \& Crippa, J. A. S. (2009). Alcohol Use Disorders Identification Test (AUDIT): An updated systematic review of psychometric properties. Psychology \& Neuroscience, 2(1), 83-97. http://doi.org/10.3922/j.psns.2009.1.12

Marais, S., Jordaan, E., Olivier, L., \& Viljoen, D. (2012). Fetal Alcohol Spectrum Disorders. In A. Van Niekerk, S. Suffla, \& M. Seedat (Eds.), Crime, Violence and Injury in South Africa, $21^{\text {st }}$ Century Solutions for Child Safety (pp.214-228). [Adobe PDF version]. Retrieved from http://www.mrc.ac.za/crime/Chapter15.pdf

Marais, S., Jordaan, E., Viljoen, D., Olivier, L., de Waal, J. \& Poole, C. (2010) The effect of brief interventions on the drinking behaviour of pregnant women in a high-risk rural South African community: a cluster randomised trial. Early Child Development and Care. http://dx.doi.org/10.1080/03004430903450392

Olivier, L., Urban, M., Chersich, M., Viljoen, D. (2010) Holistic interventions are effective in reducing the prevalence of FASD in the Northern Cape Province in South Africa: A multi-centre, before-after Study. Alcohol Clinical and Experimental Research, 34(6)211A

Urban, M.F., Olivier, L., Louw, J.G., Lombard, C., Viljoen, D.L., Scorgie, F., \& Chersich, M.F. (2016) Changes in drinking patterns during and after pregnancy among mothers of children with fetal alcohol syndrome: A study in three districts of South Africa. Drug and Alcohol Dependence, 168, 13-21. http://doi.org/10.1016/j.drugalcdep.2016.08.629 

Chapter

Publications 


\section{Publications}

1* Olivier, L., Curfs, L.M.G. \& Viljoen, D.L. (2016). Fetal alcohol spectrum disorders: Prevalence rates in South Africa. South African Medical Journal 106(6) Supplement 1: S103-S106. http://doi.org/10.7196/samj.2016.v106i6.11009

2* Olivier, L., Urban, M.F., Chersich, M.F., Temmerman, M., \& Viljoen, D.L. (2013). Burden of fetal alcohol syndrome in a rural West Coast area of South Africa. South African Medical Journal 103(6): 402-405. http://doi.org/10.7196/samj.6249

3* Urban, M.F., Olivier, L., Viljoen, D.L., Lombard, C., Louw, J.G., Drotsky, L-M., Temmerman, M., \& Chersich, M.F. (2015). Prevalence of fetal alcohol syndrome in a South African city with a predominantly Black African population. Alcohol Clinical and Experimental Research 39(6), 1016-1026. http://doi.org/10.1111/acer.12726

4* Urban, M.F., Olivier, L., Louw, J.G., Lombard, C., Viljoen, D.L., Scorgie, F., \& Chersich, M.F. (2016) Changes in drinking patterns during and after pregnancy among mothers of children with fetal alcohol syndrome: A study in three districts of South Africa. Drug and Alcohol Dependence, 168, 13-21. http://doi.org/10.1016/j.drugalcdep. 2016.08.629

5* Roozen, S, Olivier, L., Nemczyk, J., von Gontard, A., Peters, G.Y., Kok, G., Viljoen, D., Curfs, L. (2017) Nocturnal incontinence in children with fetal alcohol spectrum disorders (FASD) in a South African cohort. Journal of Pediatric Urology, 13(5), 496.e1-496.e7. http:/doi: 10.1016/j.jpurol.2017.02.009

6* Benade, A.J.S., Olivier, L. \& Bukasa, L. (2017). Effects of consumption of biscuits baked with Red Palm Oil (RPO) shortening on the vitamin A, $\alpha$ - and $\beta$-Carotene and vitamin $E$ status of pre-school children attending an informal crèche in Bethelsdorp, Eastern Cape. Part 1: Baseline study. Nutritional and Health Status. South African Nutritional Journal, 2017 (submitted for publication)

7* Benade, A.J.S., Olivier, L. \& Bukasa, L. (2017). Effects of consumption of biscuits baked with Red Palm Oil (RPO) shortening on the vitamin A, $\alpha$-and $\beta$-Carotene status of pre-school children attending an informal crèche in Bethelsdorp, Eastern Cape. Part 2. Intervention Study. Nutritional and Health Status. South African Nutritional Journal, 2017 (submitted for publication)

8* Benade, A.J.S., Olivier, L. \& Bukasa, L. (2017). Effects of biscuits baked with Red Palm Oil (RPO) shortening on the vitamin E and Inflammatory status of pre-school children attending an informal crèche in Bethelsdorp, Eastern Cape. Part 3. Intervention study. Nutritional and Health Status. South African Nutritional Journal, 2017 (submitted for publication) 
9 Chersich, M.F., Urban, M.F., Olivier, L., Davies, L-A., Chetty, C., \& Viljoen, D. (2012). Universal Prevention is Associated with Lower Prevalence of Fetal Alcohol Spectrum Disorder in Northern Cape, South Africa: A Multi-centre Before-After Study. Alcohol and Alcoholism, 47(1):66-74. http://doi.org/ 10.1093/alcalc/agr145

10 Davies, L. A., Cockcroft, K., Olinger, L., Chersich, M., Urban, M., Chetty Makkan, C. M., Turnbull, O.H., Olivier, L. \& Viljoen, D. (2017). Alcohol exposure during pregnancy altered childhood developmental trajectories in a rural South African community. Acta Paediatrica, 106(11), 1802-1810. hhtp://doi.org/10.1111/apa.13978

11 Louw, J.G., Tomlinson, M., \& Olivier, L. (2017). Unrealistic optimism with regard to drinking during pregnancy among women of childbearing age in a South African community. South African Journal of Psychology, 1-11. http://doi.org/10.1177/ 0081246317717105

12 Marais, S., Jordaan, E., Olivier, L. \& Viljoen, D. (2012). Fetal Alcohol Spectrum Disorders. In A Van Niekerk, S. Suffla. \& M. Seedat (Eds.), Crime, Violence and Injury in South Africa, $21^{\text {st }}$ Century Solutions for Child Safety (pp.214-228). \{Adobe PDF version\}. Retrieved from http://www.mrc.ac.za/ crime/Chapter15.pdf

13 Marais, S., Jordaan, E., Viljoen, D., Olivier, L., de Waal, J. \& Poole, C. (2010) The effect of brief interventions on the drinking behaviour of pregnant women in a high-risk rural South African community: a cluster randomised trial. Early Child Development and Care, 181(4), 463-474. http://dx.doi.org/10.1080/03004430903450392

Note:

Publications indicated with an asteriks $\left({ }^{*}\right)$ are part of this thesis. 



\section{Article}

\section{Fetal alcohol spectrum disorders: Prevalence rates in South Africa}

Published as:

Olivier, L., Curfs, L.M.G. \& Viljoen, D.L. (2016). Fetal alcohol spectrum disorders: Prevalence rates in South Africa. South African Medical Journal 106(6) Supplement 1: S103s106. 


\section{Article 1}

\section{Abstract}

Background. Fetal alcohol spectrum disorder (FASD) is an under-diagnosed condition in South Africa (SA). Fetal alcohol syndrome and FASD community prevalence studies were undertaken in 17 towns in three of the nine provinces in SA.

Objective. The objective for all the studies was to determine the FASD prevalence rates by assessing the grade 1 learners in all the studies, using international FASD diagnostic criteria.

Methods. The same methodology was used for all the studies in Gauteng, Western and Northern Cape provinces. Consenting Grade One Learners received anthropometric screening, clinical examinations and neurodevelopmental assessments. Structured interviews were used to assess maternal alcohol consumption during pregnancy.

Results. Reported prevalence rates ranged from 29 to 290/1000 live births.

Conclusion. FASD rates from studies conducted in SA are among the highest worldwide. FASD affects all communities in SA and is therefore a major public health concern in SA. Multidisciplinary and intersectoral interventions are urgently required to raise awareness about the dangers of prenatal alcohol exposure and the devastating effect of FASD on the lives of children, families and communities. 


\section{Background}

Alcohol consumption in South Africa (SA) has a long and complex social, cultural and political history. First nation South Africans consumed home-brewed alcoholic drinks as part of social and ritual events and used it as a mode of trade for cattle and merchandise. During the colonial times from 1652 to 1948, settlers introduced the 'dop' system whereby farm workers were partially paid with alcohol for their labour. ${ }^{[1,2]}$ During the 'apartheid' era alcohol was used paternalistically to economically and socially control mine and farm workers. In an attempt to curb social deterioration, black South Africans were prohibited to use alcohol. Paradoxically, local authorities installed beerhalls (taverns) in black townships to enhance local economic development, but at the same time, exercising control over the inhabitants of these townships. ${ }^{[3]}$ This ambivalence led to resistance, with local residents opening their own illegal liquor outlets ('shebeens') and brewing their own beer. ${ }^{[4]}$ Since 2004, home-brewed beer has been increasingly replaced by industrial beverages. ${ }^{[5]}$

According to the World Health Organization Global Status Report on Alcohol and Health ${ }^{[6]}, 43.7 \%$ of SA males and $73.7 \%$ females above 15 years of age abstained from alcohol in 2013. In countries with a high abstention rate it is highly likely that the per capita consumption rate will be understated. This, as well as under-reporting, provides some reasons why there is often a discrepancy in the reported absolute alcohol (AA) per capita consumption rate in SA. The report states the average SA consumption rate as 11 litres AA per person ${ }^{[6]}$ while Peltzer and Ramiagan $^{[5]}$ note a rate of between 10.3 and 12.4 litres, compared with a global average of 62 litres. $^{[7]}$ This gives SA one of the highest alcohol consumption rates per drinker in the world. ${ }^{[5]}$ Peltzer and Ramiagan ${ }^{[5]}$ furthermore link the high burden of alcohol use to hazardous and harmful drinking resulting in social ills such as alcohol-related deaths in transport and due to homicide, risky sexual behaviour among persons living with HIV/AIDS, and a fetal alcohol syndrome (FAS) rate of 10 - 74 per 1000 Grade One Learners.

\section{FAS as a burden of disease attributed to alcohol use in South Africa}

Among the burdens of alcohol consumption is fetal alcohol spectrum disorder (FASD). FASD is an under-diagnosed umbrella term for a range of disorders caused by the teratogenic effects of alcohol on the developing fetus (Table 1). FAS, the most severe form of these disorders, was first described by Lemoine and colleagues in France in 1968, with Jones et al. ${ }^{[8]}$ coining the term in $1973 .{ }^{[8]}$ Replicating reports of the condition soon followed from Canada, European countries and SA. 


\section{FAS and FASD prevalence studies in South Africa}

In SA, the condition remained under-reported until the end of the last century. The first FAS and partial FAS (pFAS) prevalence study was undertaken by May and Viljoen ${ }^{[10-12]}$ in the Western Cape Province in 1997, reporting rates of 46 per 1000 grade 1 learners in 1997, increasing to 74 per 1000 in 1999 and 89.2 per 1000 in 2001. In these studies, the focus was on FAS and PFAS involving all the consenting grade 1 learners in the study area.

Since 1997, various prevalence studies in SA have revealed FAS rates as high as 26 per 1000 in Gauteng ${ }^{[13]} ; 64,74.7$ and 119.4 per 1000 in Upington, Kimberley and De Aar, Northern Cape respectively, ${ }^{[14,15]}$; 6.7, 9.6 and 100 per 1000 in the Saldanha Bay Municipality, the Witzenberg sub-district and Aurora on the West Coast, respectively ${ }^{[16]}$ and 290 per 1000 in the Winelands area. ${ }^{[1] 7}$ The SA studies involve all the cultural groups living in these rural, peri-urban and urban communities (Fig 1).

Two more evaluations are currently underway in a rural area in the Northern Cape and an urban area in the Eastern Cape.

When compared to similar studies undertaken in other countries, such as the reported FASD rates of 10 - 15 per 1000 in the USA, ${ }^{[18]} 10$ per 1000 in Canada; ${ }^{[19]} 35$ per 1000 in Italy; ${ }^{[20]} 18$ per 1000 in France; ${ }^{[21]} 20$ per 1000 in Poland ${ }^{[22]}$ and 12 per 1000 in Croatia $^{[23]}$ the extent of the SA FASD challenge is self-evident.

In a 2015 study in a rural community in Australia, a FAS rate of 120 per 1000 was reported, ${ }^{[24]}$ this being the first study outside of SA to report figures close to the SA rates. In 2006, the National Institute on Alcohol Abuse and Alcoholism already raised concern for this 'large and rapidly increasing public health problem'. ${ }^{[25]}$

\section{Methods}

In all the SA community prevalence studies mentioned above, the prevalence of FAS and FASD were determined by active case ascertainment, using a tiered screening and diagnostic approach that was validated and used in SA before. ${ }^{[10,11]}$ The studies were conducted on invitation only. These invitations were received from government departments, local municipalities and/or community leaders. Approval was obtained from the Health Research Ethics Committees of either the University of the Witwatersrand (until 2005) or Stellenbosch University (since 2005) and the relevant Provincial Departments of Education in SA. All the studies involved grade 1 learners (school entry level, 6 years or older) attending all the schools in the research area, or from randomly selected schools (Witzenberg sub-district). Parents/guardians of these children were invited to enrol their children in the study by signing an informed consent form. They could withdraw their children at any time during the study. Demographic data pertaining to names, addresses and dates of birth were obtained from the schools. 
Table 1. Key concepts and terms as described by Stratton (et al) from the Institute of Medicine in 1996

Prenatal alcohol exposure refers to the fetus being exposed to any amount of alcohol consumed by the biological mother during her pregnancy.

Fetal alcohol spectrum disorders (FASD) is an umbrella term used for a group of permanent, life-long and irreversible conditions caused by the teratogenic effects of alcohol on the fetus. The Institute of Medicine acknowledges the following four categories:

- Fetal alcohol syndrome (FAS) is the most severe form of FASD with at least 2 characteristic facial features, growth retardation (height and weight), head circumference $<10$ th centile, and central nervous system damage with neurodevelopmental delays. A history of regular and/or heavy maternal prenatal alcohol exposure may be present or unknown.

- Partial fetal alcohol syndrome (pFAS) is characterised by some of the discriminating facial features, as well as growth retardation and neurodevelopmental delays. A confirmed history of prenatal alcohol use might be present or not.

- Alcohol-related neurodevelopmental deficits (ARBD) refer to structural and/or functional central nervous system damage with neurodevelopmental delays with a confirmed history of prenatal alcohol exposure.

- Alcohol-related birth defects (ARBD) are characterised by congenital skeletal, cardiac, eye, kidney or other organ imperfections with a confirmed history of prenatal maternal alcohol use.

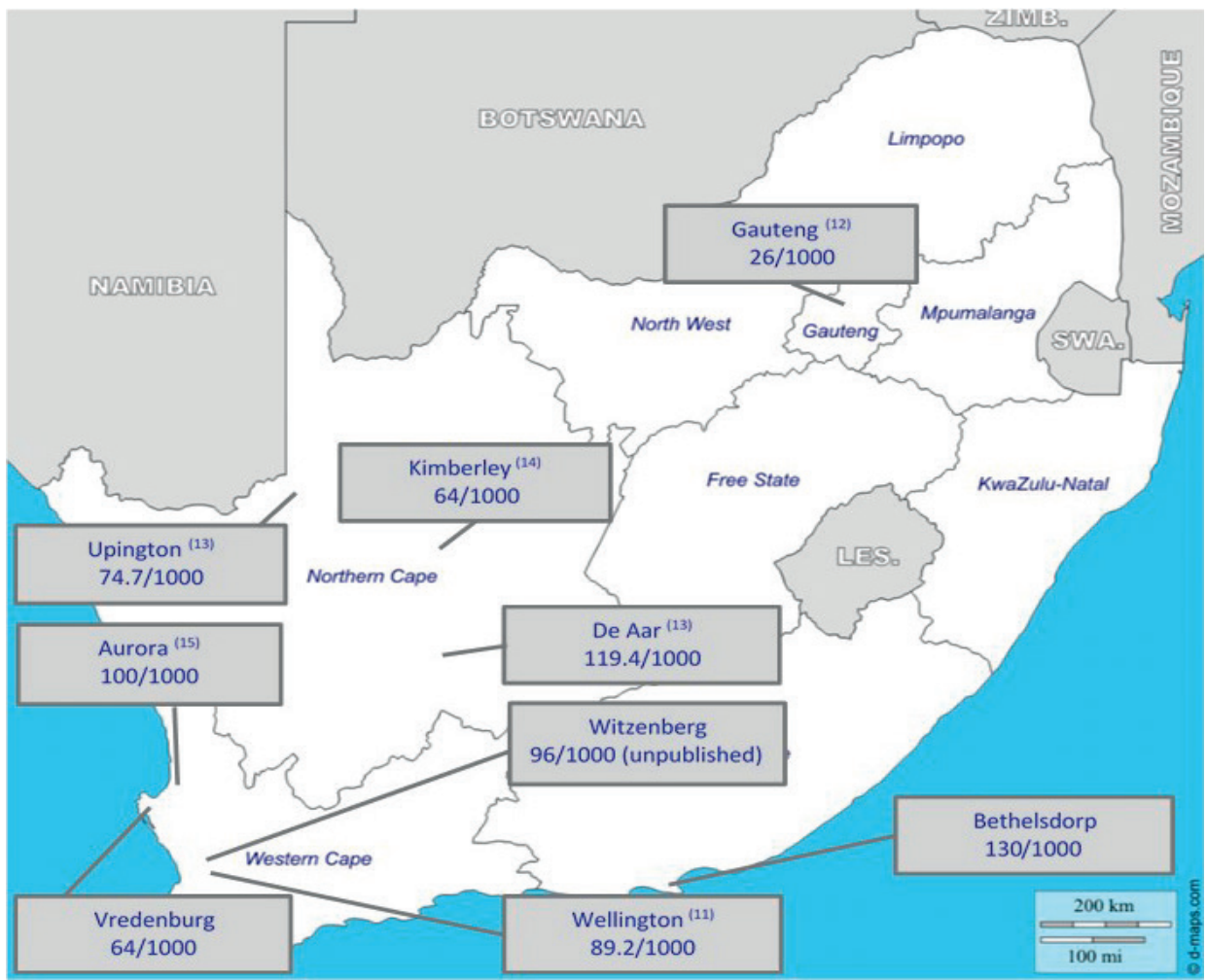

Figure 1. FAS prevalence study sites and rates per 1000 live births. 


\section{Screening and clinical assessments}

A research team visited the schools on pre-arranged dates; parents/guardians were encouraged to attend these sessions. Members of the research team were blinded to the findings of other team members throughout the studies. Anthropometric assessments of head circumference (OFC) growth and height, as well as general physical examinations, were undertaken by Primary Healthcare nursing professionals with the support of community workers. As many of the studies were conducted in underresourced areas, the physical examinations were important and detected a number of health and psychosocial problems unrelated to FASD. All of these were managed by the research team or through referrals if the relevant resources were available. The Centers for Disease Control and Prevention clinical growth charts were used to determine individual learners' centiles. $^{[26]}$ If a learner's measurements were $\leq 10$ th centile on OFC and/or height and weight, he/she was referred for a dysmorphology exam by an experienced medical doctor (also qualified as a human geneticist and paediatrician). The Hoyme checklist ${ }^{[27]}$ was adapted to develop a standardised assessment tool yielding a dysmorphology score with a maximum of 50. The dysmorphology features included the primary facial features of FAS such as short palpebral fissures, narrow upper vermillion border, smooth philtrum of the upper lip. ${ }^{[15]}$ School educators could also refer consented grade 1 learners with learning, health or psychosocial problems.

Learners with a dysmorphology score of $11 / 50$ or higher were referred for neurodevelopmental assessments and maternal interviews. All the grade 1 learners, irrespective of whether they participated in the study or not, received refreshments (fruit juice and a muffin).

\section{Maternal interviews}

Community workers were trained to use standardised questionnaires to interview biological mothers or guardians. The questionnaire was developed and refined by May and Viljoen $^{[28-30]}$ and further adapted in an unpublished Masters study. ${ }^{[31]}$ Information was gathered to determine maternal risk factors before, during and after the gestation of the index child, pertaining to the mother's nutritional and health status, alcohol and nicotine usage, socioeconomic status, educational level, and the child's birth weight and health status immediately after birth. During the interview, both the interviewer (community worker) and the mother/guardian were unaware of the FASD-status of the child. Interviewees received a food voucher (ZAR85) to be used at a local food store as an incentive. 


\section{Neurodevelopmental Assessments}

Neurodevelopmental assessments were done by trained psychologists and an occupational therapist, using the Griffiths Mental Developmental Scales-Extended Revised (GMDS-ER). ${ }^{[32]}$ Six developmental domains, namely locomotor (gross motor skills), eyehand (fine motor coordination), personal-social (adaptive functioning), hearing-speech (verbal ability), performance (pattern construction and speed of performance) and practical reasoning (numerical, time and spatial concepts) were assessed. ${ }^{[15]}$ For each domain, raw scores were converted to $z$-scores and ultimately a GQ. (general quotient as an aggregated scored based on all 6 sub domains on which the learner is tested). Two or more standard deviations below the mean of the GMDS-ER were indicative of a significant delay. ${ }^{[33]}$

\section{Case conference}

Final diagnoses were made in a case conference, using the Hoyme criteria ${ }^{[27]}$ for the diagnostic categories FAS, pFAS, ARBD, ARND and 'not FASD'.

To verify a diagnosis of FAS, at least two of the three discriminating facial features, plus growth retardation and neurodevelopmental delay with or without prenatal alcohol exposure, were required. pFAS was diagnosed when two of the three FAS facial features were present, as well as growth retardation and neurodevelopmental delay, plus a maternal history of alcohol consumption during pregnancy. To confirm a diagnosis of ARND, confirmed maternal alcohol use and neurodevelopmental delays, unrelated to any other reason, were required. A diagnosis of ARBD was made when a birth defect such as a heart murmur was present, as well as a history of prenatal alcohol exposure. $^{[15,16,27]}$

Due to limitations related to the study and the instruments used, the primary focus was on the identification of FAS. The researchers therefore acknowledge that most cases of ARND, and ARBD, and even some cases of pFAS, were missed. Therefore, the FASD rates in the research sites could in fact be higher than reported.

\section{Discussion}

The published FASD prevalence rates in SA unfortunately indicate that our country has the highest reported rates of this permanently crippling but totally preventable condition. In some of the researched areas, the prevalence of FASD is higher than the HIV/AIDS or tuberculosis rates, but it is yet to be acknowledged as a public health priority by the National Department of Health. Governmental prevention and awareness programmes are limited to a few high-risk areas in the Northern Cape (Kimberley, De Aar and Upington) and the Western Cape (Witzenberg and West Coast). The greatest 
awareness initiative at present in $\mathrm{SA}$ is, as controversial as it might be, driven by the wine and beer beverage industry. This is despite the constant threat of the National Minister of Health to ban alcohol advertising in SA. With the exception of the Vredenburg/Saldanha Municipal area in the Western Cape, the industry is currently funding all the FASD training in SA provided to government employees in the Northern, Eastern and Western Cape Provinces.

The unfortunately delay in the acknowledgement of this devastating, but highly preventable disorder and the reluctance to take action is costing the current and future communities in SA dearly. The cost to families, communities and the country at large has a lifelong crippling effect on the psychosocial, vocational and overall wellbeing of the nation. A concerted effort involving the relevant government departments, civil society, private industry and the SA community at large is needed to break the cycle of misfortune perpetuating the ever-increasing FASD epidemic in SA.

\section{Acknowledgements}

Without the cooperation of the parents/guardians and participating children these studies would not have been possible. The support of the various school principal and educators on all the study sites was admirable. Special acknowledgement goes to the dedicated staff of the Foundation for Alcohol Related Research. The health care facilities and social services are thanked for the management of referrals. The generous support and sponsorships of the funders and philanthropists who funded the research and prevention programmes is acknowledged. The Departments of Social Development in the Northern Cape and Western Cape Provinces are thanked funding the research in Kimberley and the Saldanha Bay District. The Provincial Departments of Education and Health (Western and Northern Cape Provinces), as well as the Research Ethics Committees of the Witwatersrand and Stellenbosch Universities, are thanked for granting ethical approval for the studies.

\section{Conflict of interest.}

The Foundation for Alcohol Related Research received funding for awareness and training programmes from the Industry Association for Responsible Alcohol Use, the South African Breweries and Distell Foundation. 


\section{References}

1. London L, Sanders D, te Water Naude J. Farm workers in South Africa - the challenge of eradicating alcohol abuse and the legacy of the 'dop' system. S Afr Med J 1998;88(9):1092-1095.

2. London L. Alcohol consumption amongst South African farm workers: A challenge for post-apartheid health sector transformation. Drug Alcohol Depend 2000;59(2):199-206. http://dx.doi.org/10.1016/ s0376-8716(99)00120-9

3. Parry CDH. South Africa: Alcohol today. Addiction 2005;100(4):426-429. http://dx.doi.org/10.1111/ j.1360-0443.2005.01015.x

4. Schneider M, Norman R, Parry C, Bradshaw D, Pluddemann A, South African Comparative Risk Assessment Collaborating Group. Estimating the burden of disease attributable to alcohol use in South Africa in 2000. S Afr Med J 2007;97(8Pt2):664-672.

5. Peltzer K, Ramlagan S. Alcohol use trends in South Africa. J Soc Sci 2009;18(1):1-12.

6. World Health Organization. Global Status Report on Alcohol and Health 2014. Geneva: WHO, 2014;1392.

7. Rehm J, Mathers C, Popova S, Thavorncharoensap M, Teerawattananon Y, Patra J. Global burden of disease and injury and economic cost attributable to alcohol use and alcohol-use disorders. Lancet 2009;373(9682):2223-2233. http://dx.doi.org/10.1016/s0140-6736(09)60746-7

8. Jones KL, Smith DW, Ulleland CN, Streissguth P. Pattern of malformation in offspring of chronic alcoholic mothers. Lancet 1973;1(7815):1267-1271. http://dx.doi.org/10.1016/s0140-6736(73)91291-9

9. May PA, Brooke L, Gossage JP, Croxford J, Adnams C, Jones KL, et al. Epidemiology of fetal alcohol syndrome in a South African community in the Western Cape Province. Am J Public Health 2000;90(12):1905-1912. http://dx.doi.org/10.2105/ajph.90.12.1905

10. Viljoen DL, Gossage JP, Brooke L, Adnams CM, Jones KL, Robinson LK, et al. Fetal alcohol syndrome epidemiology in a South African community: A second study of a very high prevalence area. J Stud Alcohol 2005;66(5):593-604. http://dx.doi.org/10.15288/jsa.2005.66.593

12. May PA, Gossage JP, Marais A-S, et al. The epidemiology of fetal alcohol syndrome and partial FAS in a South African community. Drug Alcohol Depend 2007;88(2-3):259-271. DOI:10.1016/j.drugalcdep. 2006.11.007

13. Viljoen DL, Craig P, Hymbaugh K, Boyle C, Blount S. Fetal alcohol syndrome - South Africa, 2001. Morb Mortal Wkly Rep 2003;52(28):660-662.

14. Urban M, Chersich MF, Fourie L-A, Chetty C, Olivier L, Viljoen D. Fetal alcohol syndrome among Grade 1 school children in Northern Cape Province: Prevalence and risk factors. S Afr Med J 2008;98(11):877-882.

15. Urban MF, Olivier L, Viljoen D, Lombard C, Louw JG, Drotsky L-M, et al. Prevalence of fetal alcohol syndrome in a South African city with a predominantly Black African population. Alcohol Clin Exp Res 2015;39(6):1016-1026. http://dx.doi.org/10.1111/acer.12726

16. Olivier L, Urban M, Chersich M, Temmerman M, Viljoen D. Burden of fetal alcohol syndrome in a rural West Coast area of South Africa. S Afr Med J 2013;103(6):402-405. http://dx.doi.org/10.7196/samj.6249

17. May PA, Blankenship J, Marais A-S, Gossage JP, Kalberg WO, Barnard R, et al. Approaching the Prevalence of the Full Spectrum of Fetal Alcohol Spectrum Disorders in a South African Population-Based Study. Alcohol Clin Exp Res 2013;37(5):818-830. http://dx.doi.org/10.1111/acer.12033

18. Riley EP, Infante MA, Warren KR. Fetal alcohol spectrum disorders: An overview. Neuropsychol Rev 2011;21(2):73-80. http://dx.doi.org/10.1007/s11065-011-9166-x

19. Stade B, Ali A, Bennett D, Campbell D, Johnston M, Lens $C$, et al. The burden of prenatal exposure to alcohol: revised measurement of cost. Can J Clin Pharmacol 2009;16(1):e91-e102.

20. May PA, Fiorentino D, Coriale G, Kalberg WO, Eugene Hoyme H, Aragón AS, et al. Prevalence of children with severe fetal alcohol spectrum disorders in communities near Rome, Italy: New estimated rates are higher than previous estimates. Int J Environ Res Public Health 2011;8(6):2331-2351. http://dx.doi.org/10.3390/ijerph8062331 
21. Chazeron I, Llorca P-M, Ughetto S, Vendittelli F, Boussiron D, Sapin V, et al. Is pregnancy the time to change alcohol consumption habits in France? Alcohol Clin Exp Res 2008;32(5):868-873. http://dx.doi.org/10.1111/j.1530-0277.2008.00646.x

22. Okulicz-kozaryn K, Borkowska M, Brzozka K. FASD prevalence among schoolchildren in Poland. J Appl Res Intellect 2015. http://dx.doi.org/10.1111/jar.12219

23. Petković G, Barišić I. Prevalence of fetal alcohol syndrome and maternal characteristics in a sample of schoolchildren from a rural province of Croatia. Int J Environ Res Public Health 2013;10(4):1547-1561. http://dx.doi.org/10.3390/ijerph10041547

24. Fitzpatrick JP, Elliott EJ, Latimer J, et al. The Lililwan Project: Study protocol for a population-based active case ascertainment study of the prevalence of fetal alcohol spectrum disorders (FASD) in remote Australian Aboriginal communities. BMJ Open 2012;2(3):e000968-e000968. http://dx.doi.org/10.1136/ bmjopen-2012-000968

25. Calhoun F, Attilia ML, Spagnolo PA, Rotondo C, Mancinelli R, Ceccanti M. National Institute on Alcohol Abuse and Alcoholism and the study of fetal alcohol spectrum disorders. The International Consortium. Ann Ist Super Sanita 2006;42(1):4-7.

26. Centers for Disease Control and Prevention, National Center for Health Statistics. Growth Charts. Atlanta, Georgia: Centers for Disease Control, 2010 http://www.cdc.gov/growthcharts/(accessed 20 November 2015).

27. Hoyme HE, May PA, Kalberg WO, Kodituwakku P, Gossage JP, Trujillo PM, et al. A practical clinical approach to diagnosis of fetal alcohol spectrum disorders: Clarification of the 1996 institute of medicine criteria. Pediatr 2005;115(1):39-47

28. May PA, Gossage JP, Brooke LE, et al. Maternal risk factors for fetal alcohol syndrome in the Western Cape Province of South Africa: A population-based study. Am J Public Health 2005;95(7):1190-1199. http://dx.doi.org/10.2105/ajph.2003.037093

29. May PA, Gossage JP, Marais A-S, et al. Maternal risk factors for fetal alcohol syndrome and partial fetal alcohol syndrome in South Africa: A third study. Alcohol Clin Exp Res 2008;32(5):738-753. http://dx.doi.org/10.1111/j.1530-0277.2008.00634.x

30. Viljoen D, Croxford J, Gossage JP, Kodituwakku PW, May PA. Characteristics of mothers of children with fetal alcohol syndrome in the Western Cape Provence of South Africa: A case control study. J Stud Alcohol 2002;63:6-17.

31. Breytenbach B. A revision of a maternal interview questionnaire used in fetal alcohol spectrum disorder prevention programmes in South Africa (Doctoral Dissertation, University of Stellenbosch) 2014.

32. Griffiths R. The ability of young children: A comprehensive system of mental measurement for the first eight years of life. Oxford: The Test Agency, 1970.

33. Luiz D, Faragher B, Barnard A, et al. Griffiths Mental Developmental Scales-Extended Revised - Two to Eight Year. Anal Man 2006. 


\section{Article}

\section{Burden of fetal alcohol syndrome in the rural West Coast of South Africa}

Published as:

Olivier, L.* , Urban, M.F.*, Chersich, M.F., Temmerman, M., \& Viljoen, D.L. (2013). Burden of fetal alcohol syndrome in a rural West Coast area of South Africa. South African Medical Journal 103(6): 402-405.

*equal contribution 


\section{Abstract}

Background. Fetal alcohol syndrome (FAS) is common in parts of South Africa and rural residence is a frequently cited risk factor. We conducted a FAS school prevalence survey of an isolated rural community in the Western coast district of Western Cape province, obtaining the first directly measured rate of FAS and partial-FAS in a local rural setting.

Methods. The study area (Aurora village), a community of about 2500 people in a grainproducing area, has a single primary school. All learners were eligible for study inclusion. Initial anthropometry screening was followed by a diagnostic stage entailing examination by a dysmorphologist for features of FAS, neurodevelopmental assessment, and an interview assessing maternal alcohol consumption.

Results. Of 160 learners screened, 78 (49\%) were screen-positive, of whom 63 (81\%) were clinically assessed for FAS. The overall FAS/partial FAS rate among the screened learners was $17.5 \%$ (95\% confidence interval=12.0\%-24.2\%), with 16 children having (10.0\%) FAS and 12 (7.5\%) partial FAS. High rates of stunting, under-weight and microcephaly were noted in all learners, especially those with FAS or partial FAS. Five (18\%) mothers of affected children were deceased by the time of assessment.

Conclusion. We describe very high rates of FAS/partial-FAS in an isolated rural part of the Western Cape not located in a viticulture region. Our study suggests that prevalence of FAS may be very high in isolated communities, or in particular hot-spots. It adds to the growing evidence that is a significant, and underestimated, health problem in South Africa. Expanded screening and surveillance programmes, and preventive inventions, are urgently needed. 
Fetal alcohol ayndrome (FAS) and the less severe fetal consequences of maternal drinking, collectively described as fetal alcohol spectrum disorders (FASD), are endemic in impoverished communities of the Western and Northern Cape Province ${ }^{[1-4]}$. Over the past decade, levels of FASD ranging between 40.5 and 119.4 per 1000 have been documented in several parts of these provinces ${ }^{[1,4]}$. A recent study examined the prevalence of FASD (which is a broader and less well defined group) in an area of the Western Cape, and estimated the prevalence at between 135.1 and 207.5 per $1000^{[5]}$.

Heavy alcohol intake during pregnancy, usually in a binge-drinking pattern, occurs in over $20 \%$ of women in the Western Cape ${ }^{[6]}$. Drinking in pregnancy remains a problem despite considerable media attention, some efforts by the national government to limit alcohol harm ${ }^{[7]}$, and isolated initiatives to increase universal and other prevention activities in these provinces ${ }^{[8]}$. Heavy drinking has been socially entrenched and 'normalised' through a centuries-old history including, but not restricted to, the dop system. For many women, the underlying social-determinants of heavy alcohol consumption remain largely unchanged. These include poor socio-economic conditions, single parent families, low levels of maternal education, concomitant use of tobacco and other substances, low religiosity and lack of alternative recreational opportunities ${ }^{[6,9]}$.

Most surveys have been conducted in small towns, and have consistently shown that FASD is more common where mothers were resident in a rural area at the time of pregnancy ${ }^{[1-3]}$. To date, no studies have directly documented FASD rates in entirely rural or remote parts of the country. In 2008, community leaders of a rural area in the West Coast district of the Western Cape invited our research team to assess levels of FASD, as well as substance use in pregnancy. The study thus aimed to document the prevalence and risk factors for FASD in this isolated rural community, and to provide information to assist the community to advocate for increased resources to counter substance use and related problems in the area.

\section{Methods}

The study site is a rural village, Aurora, of approximately 2500 inhabitants. The population works mostly as seasonal labourers in surrounding farming areas. These are involved in potato and grain production, as occurs in many other parts of the West Coast district. There is one school in the area (Grade 0-7), at which the parents/guardians of all learners were invited to enrol in the study. Workshops were held with about 220 people to generate awareness of the study, with involvement of community and local government leaders, including social workers, police officers, health workers, community leaders and educators from the school. The school principal and educators also attended a course on how to manage children with FASD in the classroom. 


\section{FAS diagnosis process}

Prevalence of FAS and partial FAS was determined by active case ascertainment using a validated two-tier screening method ${ }^{1}$. This entails an initial screening stage, followed by a comprehensive diagnostic stage (clinical evaluation, neurocognitive assessment and maternal interview). In the first stage, school pupils were screened by a professional nurse, who measured height, weight and head circumference $(\mathrm{HC})$, using standard methods. Children $\leq 10$ th percentile of the National Center for Health Statistics charts for height and weight, or $\leq 10$ th centile for $\mathrm{HC}$, were considered screen-positive and invited to the second stage.

The diagnostic stage entailed assessment by an experienced dysmorphologist (DV) for clinical features of FAS ${ }^{[10]}$. The clinical diagnosis of FAS/partial FAS was substantiated by a battery of neurodevelopmental tests. Positive evidence of neurological abnormality required an $\mathrm{HC} \leq 10$ th centile, the presence of 'hard' signs on neurological examination, or significant abnormalities on neurocognitive assessment (below average in more than 4 of 10 tests) using the Griffiths Mental Development Scale ${ }^{[11]}$.

Trained interviewers completed a semi-structured questionnaire with the mother (or guardian) of screen-positive children. Interviews were in the home language of participants and focused on drinking habits during the index pregnancy, which was elicited using a timeline follow-back method ${ }^{[12]}$.

The final diagnosis, based on criteria published by Hoyme et al (2005), ${ }^{[10]}$ was made by bringing together all data from the clinical evaluation, the neurodevelopmental profile and maternal history. Final diagnostic categories were FAS and partial FAS. The clinical diagnosis of FAS, but not partial FAS, is considered distinctive even in the absence of a history of maternal alcohol use.

\section{Study ethics and data management}

Permission was obtained from the Department of Education (Provincial and District) to evaluate learners and informed consent was given by the parents or legal guardians of each child. If consent was given but the child was not present for clinical or neurodevelopmental assessment, two further attempts were made to assess the child. Similarly, three attempts were made to secure maternal interviews.

A trained counsellor communicated the FASD diagnosis to the parents or guardians, as well as its implications and a proposed intervention tailored to each child. Children identified as having FAS/partial FAS were referred to local government services, including speech and hearing therapists, occupational therapists, physiotherapists and social workers. With parental permission, school personnel were informed of each child's FASD status in order to facilitate educational support and further remedial assessment. Children with other medical conditions were linked with local and regional medical services, as required. 
Intercooled Stata 12.1 (Stata Corporation, College Station, USA) was used for statistical analysis. For analysis of categorical variables, the chi-square test was used, while for continuous variables we used an unpaired Student's $t$-test or Mann-Whitney U-test for normally and non-normally distributed data, respectively.

Table 1. Characteristics of Grade 0-7 learners with fetal alcohol syndrome

\begin{tabular}{|c|c|c|c|c|}
\hline Variable & $\begin{array}{l}\text { All Grade 0-7 learners } \\
(\mathrm{n}=160)\end{array}$ & $\begin{array}{l}\text { Children without } \\
\text { FAS/PFAS }(n=132)\end{array}$ & $\begin{array}{l}\text { Children with } \\
\text { FAS/PFAS }(n=28)\end{array}$ & $P$ \\
\hline \multicolumn{5}{|l|}{ Sex n/N (\%) } \\
\hline Female & $80 / 160(50.0)$ & $67 / 132(50.8)$ & $13 / 28(46.4)$ & \\
\hline Male & $80 / 160(50.0)$ & $65 / 132(49.2)$ & $15 / 28(53.6)$ & 0.68 \\
\hline \multicolumn{5}{|l|}{ Age (years) n/N (\%) } \\
\hline 4.8-8 & $59 / 160(37.8)$ & $47 / 132(35.6)$ & $12 / 28(42.9)$ & \\
\hline $9-11$ & $53 / 160(33.6)$ & $45 / 132(34.1)$ & $8 / 28(28.6)$ & \\
\hline $12-16$ & $48 / 160(28.6)$ & $40 / 132(30.3)$ & $8 / 28(28.6)$ & 0.75 \\
\hline \multicolumn{5}{|l|}{ School grade n/N (\%) } \\
\hline $0-1$ & $52 / 160(32.5)$ & $40 / 132(30.3)$ & $12 / 28(42.9)$ & \\
\hline $2-4$ & $53 / 160(33.1)$ & 44/132 (33.3) & $9 / 28(32.1)$ & \\
\hline $5-7$ & $55 / 160(34.4)$ & $48 / 132(36.4)$ & $7 / 28(25.0)$ & 0.37 \\
\hline $\begin{array}{l}\text { Weight for age } \\
\text { median z-score (IQR) }\end{array}$ & $-1.2(-2.1$ to -0.5$)$ & $-1.0(-1.7$ to -0.4$)$ & $-2.4(-2.9$ to -1.9$)$ & $<0.001$ \\
\hline $\begin{array}{l}\text { Height for age } \\
\text { median z-score (IQR) }\end{array}$ & $-1.2(-1.9$ to -0.7$)$ & $-1.0(-1.8$ to -0.5$)$ & $-2.1(-2.5$ to -1.5$)$ & $<0.001$ \\
\hline $\begin{array}{l}\text { BMI for age } \\
\text { median } z \text {-score (IQR) }\end{array}$ & $-0.7(-1.4$ to -0.1$)$ & $-0.6(-1.3$ to 0.1$)$ & $-1.4(-2.1$ to -0.7$)$ & 0.001 \\
\hline \multicolumn{5}{|l|}{ Head circumference } \\
\hline 3rd-10th centile $\mathrm{n} / \mathrm{N}(\%)$ & $20 / 160(12.6)$ & 13/131 (9.9) & $7 / 28(25.0)$ & \\
\hline$\leq 3 r d$ centile $n / N(\%)$ & $30 / 160(18.9)$ & $13 / 131(14.0)$ & $17 / 28(60.7)$ & $<0.001$ \\
\hline
\end{tabular}

$\mathrm{IQR}=$ inter-quartile range; $\mathrm{BMI}=$ body mass index, $\mathrm{FAS}=$ fetal alcohol syndrome, PFAS = partial fetal alcohol syndrome

\section{Results}

Consent for participation in the study was sought for all 171 learners in the school, and 160 consenting learners were available for anthropometric screening. Of 160 screened learners, 78 (49\%) were screen positive on anthropometry, with 60 (38\%) falling below the $10^{\text {th }}$ centile for both height and weight. Status regarding FAS/partial FAS diagnosis was determined for 63 children (81\% of screen-positives) (Table 1). Fifteen learners could not be clinically assessed because they were absent from school on all follow-up visits made to assess them.

The screened group, who were all of mixed ancestry, were aged 4.8 to 16.4 years. About 9\% (14/160) of learners were older than 14 years. Exactly half the pupils were male, though females predominated in grades 0 and $1(62 \%, 32 / 52 ; p=0.04)$. 
In the group of the 160 learners screened, based on full assessment, 16 FAS and 6 PFAS cases $(13.8 \% ; 95 \% \mathrm{Cl}=8.8 \%-20.0 \%)$ were ascertained based on full clinical assessment. Mean dysmorphology score for the 16 confirmed FAS children was 17.1 (SD) \pm 2.2 and 9.1 (SD) \pm 4.5 for children with PFAS. A further 6 were suspected of having partial FAS based on facial features of FAS, $\mathrm{HC}<10^{\text {th }}$ centile, and positive history of maternal alcohol use, but did not have a neurodevelopmental assessment.

Table 2. Characteristics of Grade 0-7 learners with fetal alcohol syndrome

\begin{tabular}{|c|c|c|c|c|}
\hline Variable & $\begin{array}{l}\text { All Grade } 0-7 \text { learners } \\
(n=160)\end{array}$ & $\begin{array}{l}\text { Children without } \\
\text { FAS/PFAS }(n=132)\end{array}$ & $\begin{array}{l}\text { Children with } \\
\text { FAS/PFAS }(n=28)\end{array}$ & $P$ \\
\hline \multicolumn{5}{|l|}{ Sex n/N (\%) } \\
\hline Female & $80 / 160(50.0)$ & $67 / 132(50.8)$ & $13 / 28(46.4)$ & \\
\hline Male & $80 / 160(50.0)$ & $65 / 132(49.2)$ & $15 / 28(53.6)$ & 0.68 \\
\hline \multicolumn{5}{|l|}{ Age (years) n/N (\%) } \\
\hline $4.8-8$ & $59 / 160(37.8)$ & 47/132 (35.6) & $12 / 28(42.9)$ & \\
\hline $9-11$ & $53 / 160(33.6)$ & $45 / 132(34.1)$ & $8 / 28(28.6)$ & \\
\hline $12-16$ & $48 / 160(28.6)$ & $40 / 132(30.3)$ & $8 / 28(28.6)$ & 0.75 \\
\hline \multicolumn{5}{|l|}{ School grade n/N (\%) } \\
\hline $0-1$ & $52 / 160(32.5)$ & 40/132 (30.3) & $12 / 28(42.9)$ & \\
\hline $2-4$ & $53 / 160(33.1)$ & 44/132 (33.3) & $9 / 28(32.1)$ & \\
\hline $5-7$ & $55 / 160(34.4)$ & $48 / 132(36.4)$ & $7 / 28(25.0)$ & 0.37 \\
\hline $\begin{array}{l}\text { Weight for age } \\
\text { median z-score (IQR) }\end{array}$ & $-1.2(-2.1$ to -0.5$)$ & $-1.0(-1.7$ to -0.4$)$ & $-2.4(-2.9$ to -1.9$)$ & $<0.001$ \\
\hline $\begin{array}{l}\text { Height for age } \\
\text { median } z \text {-score (IQR) }\end{array}$ & $-1.2(-1.9$ to -0.7$)$ & $-1.0(-1.8$ to -0.5$)$ & $-2.1(-2.5$ to -1.5$)$ & $<0.001$ \\
\hline $\begin{array}{l}\text { BMI for age } \\
\text { median z-score (IQR) }\end{array}$ & $-0.7(-1.4$ to -0.1$)$ & $-0.6(-1.3$ to 0.1$)$ & $-1.4(-2.1$ to -0.7$)$ & 0.001 \\
\hline \multicolumn{5}{|l|}{ Head circumference } \\
\hline 3rd-10th centile n/N (\%) & $20 / 160(12.6)$ & 13/131 (9.9) & $7 / 28(25.0)$ & \\
\hline$\leq 3 r d$ centile $\mathrm{n} / \mathrm{N}(\%)$ & $30 / 160$ (18.9) & 13/131 (14.0) & $17 / 28(60.7)$ & $<0.001$ \\
\hline
\end{tabular}

$\mathrm{IQR}=$ inter-quartile range; $\mathrm{BMI}=$ body mass index, $\mathrm{FAS}=$ fetal alcohol syndrome, PFAS = partial fetal alcohol syndrome

Despite the lack of a neurodevelopmental assessment, they had sufficient features to meet the Hoyme criteria for partial FAS or FAS ${ }^{[9]}$. They were assigned as partial FAS cases, and included as such for further analysis, bringing the total to 28 affected children (17.5\%; 95\% Cl 12.0\%-24.2\%).

No associations were detected between having FAS/ partial FAS and gender or grade. Children with FAS were a median 8.5 years old, while other children were a median 10.0 years $(p=0.09$ ). The median body mass index of children without FAS/ partial FAS was $15.8 \mathrm{~kg} / \mathrm{m}^{2}$ (IQR 14.6-17.5), compared to a median $14.7 \mathrm{~kg} / \mathrm{m}^{2}$ in children with FAS/partial FAS (IQR 13.7-15.6; $p=0.001$ ). The whole cohort of children, and especially those with FAS/partial FAS, showed very high levels of stunting and under-weight for age (Table 1). 
Five (18\%) of the mothers of the 28 cases of FAS/partial FAS had died, and in 2 instances the father was also known to have died. The study team referred 20 children to the school psychologist.

\section{Discussion}

Researchers have previously noted that levels of FAS/partial FAS in parts of the Western and Northern Cape provinces are several-fold higher than elsewhere in the world ${ }^{3}$. Our data represent the first directly measured FAS/partial FAS prevalence data from an entirely rural community in South Africa, and demonstrate levels that are high even compared with similar local studies.

Table 2 shows FAS rates across published school prevalence studies in South Africa. Although direct comparisons between studies can be misleading, these school surveys all used similar methodologies, except that ours is the only study to include learners who are beyond first grade (there was, however, no significant difference in the prevalence of FAS across school grades).

Though the FAS rate of $10 \%$ in Aurora is very high, the true scale of overall FASD is certainly considerably higher. A further $7.5 \%$ were assessed as having FAS/partial FAS, although this assessment was complicated by some participants not completing all study procedures. This stemmed mostly from truancy from school (teachers suspected a high FASD rate amongst truant children). In addition to study-specific issues, it is likely that FASD prevalence studies inherently underestimate its prevalence because of the difficulties in diagnosing cases without typical facial features, and as children get old$\mathrm{er}^{12}$. In this regard, the high rate of non-syndromic microcephaly found in 'unaffected' children may relate, in part, to sub-clinical cases of FASD.

Table 3: FAS prevalence rates from studies among school children in diverse South African communities

\begin{tabular}{llll}
\hline Site (reference) & Site description & $\begin{array}{l}\text { Viticulture area } \\
(\mathrm{Y} / \mathrm{N})\end{array}$ & $\begin{array}{l}\text { FAS cases*/Sample size** } \\
\text { (Cases per 1000) }\end{array}$ \\
\hline Gauteng (13) & Metropole & N & $16 / 830(19.3)$ \\
Wellington, Western Cape (1) & Town & Y & $46 / 992(46.5)$ \\
Wellington, Western Cape (2) & Town & Y & $64 / 863(74.2)$ \\
Wellington, Western Cape (3) & Town & Y & $55 / 818(67.2)$ \\
Upington, Northern Cape (4) & Town & Y & $69 / 1299(53.1)$ \\
De Aar, Northern Cape (4) & Isolated town & N & $54 / 536(100.7)$ \\
Aurora, Western Cape (current study) & Isolated village & N & $16 / 160(100.0)$ \\
\hline
\end{tabular}

*Excludes PFAS cases, ** To maximise comparability, data are restricted to fully assessed FAS cases divided by the number actually screened

The high prevalence of FAS/PFAS found in the isolated village of Aurora is consistent with (i) the rural-urban gradient in FAS prevalence shown in Table 2, (ii) studies that 
show a higher FAS/partial FAS rate in children born in rural than urban areas ${ }^{[1-4]}$; and (iii) evidence that binge drinking is more prevalent in rural (20\%) than urban informal (16\%) and urban formal (15\%) areas ${ }^{[15]}$. FASD also, appears more prevalent in very isolated communities - the communities with the highest published prevalence of FAS/PFAS (Aurora and De Aar), are very geographically isolated. Conversely, high rates do not appear to relate to the presence of viticulture in an area.

Despite mounting evidence from school surveys and other sources that FASD is a significant public health problem, it remains under-recognised. For example, the Western Cape Burden of Disease study considered FASD only inasmuch as it is a cause of low birth weight, rather than as a significant cause of morbidity, mortality and disability in its own right ${ }^{[16]}$. In part because it is under-recognised, there is a dearth of local measures aimed at preventing FASD, despite international acceptance of the utility of a range of interventions to reduce alcohol-related harm, ranging from policy and community level approaches, to setting-specific approaches such as 'brief interventions' in prenatal care ${ }^{[17]}$. As a local example of a successful intervention, we have reported a $30 \%$ reduction in FAS/PFAS rates associated with a community-level intervention comprising intensive 'universal prevention' measures ${ }^{[8]}$.

Interventions within the health sector that should be implemented, upgraded or urgently investigated include: strengthened family planning services; improved antenatal education regarding the risks of drinking; identification of risky drinking in pregnancy and implementation of brief interventions to reduce it; strategies aimed at early identification of FASD to allow early intervention in the child and prevention of recurrence in future children; and national-level surveillance of risky drinking and FASD rates to improve data on the problem of FASD.

Table 2 indicates that, although there is a high level of FAS in many parts of South Africa, the prevalence is heterogeneous. There is a need for a systematic approach to determining overall FASD levels in the country that is both wide is scope, but also provides local actionable detail in higher-risk areas. We recommend repeated surveillance of a systematic sample of schools and/or antenatal clinics across the country, which would allow for provincial and national baseline rates to be established and monitored over time, and would inform more intensive and cost-effective targeting of communities at highest risk.

We found nearly one in five of mothers to children with FAS/partial FAS were deceased. This phenomenon has not been studied in detail to date, although it is noteworthy that the three Wellington studies ${ }^{[1-3]}$ reported significant maternal mortality for FAS/PFAS children. Collectively they report 13 (7\%) maternal deaths among 185 mothers of children with FASD by the time the index cases were assessed at about 7 years of age. Causes of death, where known, appeared to be associated with alcohol-use, including: accidents such as house fires; homicide and other violent death; pulmonary tuberculosis and liver disorders. These data are consistent with evidence that binge-drinking, in addition to being associated with FASD, is also strongly associated with unintentional 
injury, interpersonal violence, unsafe sex and other negative health consequences for adults ${ }^{[19,20]}$. A case of FASD should therefore be considered a marker for adverse maternal health consequences.

This study aims to benefit the local population, NGOs, community-based organisations, as well as government departments, specifically: Health, Education, Social Services and Agriculture. The study heightened the community's awareness of substance abuse problems and FASD in particular. Although this district has not featured on the government's priority list for high-risk substance abuse areas and/or other health needs to date, the community specifically requested that the study findings be publicised and used to rectify this omission. Findings will also inform development of a comprehensive NGO-led intervention to address these local problems.

\section{Acknowledgements}

We acknowledge the dedication and invaluable contributions from the children and their parents, community members and leaders in Aurora, the school principal and educators, the Women's Agricultural Society and the Women's Forum. Special acknowledgment goes to FARR staff, Elizabeth Pegram, Yumna Martin, Debbie Lombard, Lian Drotsky, Karina Coetzer, Safia Abrahams and Lebo Khusu, who were responsible for the screening and neurodevelopmental assessments, maternal interviews, administration, data capturing, as well as training conducted during this project. The Department of Education is thanked for the permission granted and willingness to entrust the study to FARR. The project was funded by the Department of Education and TopSpar. Pam Tilley initiated the invitation to FARR to assess the problem in Aurora. If not for her, this study would not have happened.

\section{Conflict of interest statement}

The Foundation for Alcohol-Related Research receives some funding from the Industry Association for Responsible Alcohol Use (ARA) and donations from the Whiskey Live Festival. 


\section{References}

1. May PA, Brooke LE, Gossage JP, et al. Epidemiology of fetal alcohol syndrome in a South African community in the Western Cape Province. Am J Public Health 2000; 90(12): 1905-12. [http://dx.doi.org/10.2105\%2FAJPH.90.12.1905] [PMID 11111264]

2. Viljoen DL, Gossage JP, Brooke L, et al. Fetal alcohol syndrome epidemiology in a South African community: a second study of a very high prevalence area. J Stud Alcohol 2005; 66(5): 593-604. [PMID 16331845]

3. May PA, Gossage JP, Marais AS, et al. The epidemiology of fetal alcohol syndrome and partial FAS in a South African community. Drug Alcohol Depend 2007; 88(2-3): 259-71. [http://dx.doi.org/10.1016\% 2Fj.drugalcdep.2006.11.007][PMID 17127017]

4. Urban M, Chersich MF, Fourie LA, et al. Fetal alcohol syndrome among grade 1 schoolchildren in Northern Cape Province: prevalence and risk factors. S Afr Med J 2008; 98(11): 877-82. [PMID 19177895]

5. Croxford J, Viljoen D. Alcohol consumption by pregnant women in the Western Cape. S Afr Med J 1999; 89(9): 962-5. [PMID 10554632]

6. South African Revenue Services. Excise duties and levies 2012. http://www.sars.gov.za/home.asp? pid=483 (accesed 1 May 2012).

7. Chersich MF, Urban M, Olivier L, et al. Universal prevention is associated with lower prevalence of fetal alcohol spectrum disorders in Northern Cape, South Africa: a multicentre before-after study. Alcohol Alcohol 2012; 47(1): 67-74. [http://dx.doi.org/10.1093\%2Falcalc\%2Fagr145][PMID 22037537]

8. Viljoen D, Croxford J, Gossage JP, et al. Characteristics of mothers of children with fetal alcohol syndrome in the Western Cape Province of South Africa: a case control study. J Stud Alcohol 2002; 63(1): 6-17. [PMID16331845]

9. Hoyme HE, May PA, Kalberg WO, et al. A practical clinical approach to diagnosis of fetal alcohol spectrum disorders: clarification of the 1996 Institute of Medicine Criteria. Pediatrics 2005; 115: 39-47. [http://dx.doi.org/10.1542\%2Fpeds.2005-0702] [PMID 15629980]

10. Griffiths R. The Ability of Young Children: A Comprehensive System of Mental Measurement for the First Eight Years of Life. England: The Test Agency Ltd., 1970.

11. Sobell LC, Agrawal S, Annis H, et al. Cross-cultural evaluation of two drinking assessment instruments: alcohol timeline followback and inventory of drinking situations. Subst Use Misuse 2001; 36(3): 313-31. [http://dx.doi.org/10.1081\%2FJA-100102628][PMID11325169]

12. Alberta Partnership on Fetal Alcohol Syndrome. Diagnosis of fetal alcohol syndrome. Can Child Adol Psych Rev 2003; 12(3): 81-86.

13. Viljoen D, Craig P, Hymbaugh K, et al. Fetal alcohol syndrome - South Africa 2001. MMWR 2003; 52(28): 660-662.

14. Harker N, Kader R, Myers B, et al. Substance abuse trends in the Western Cape, a review of studies conducted since 2000. hhtp://www.sahealthinfo.org/admodule/substance.pdf (accessed 22 April 2012).

15. Sanders D, Reynolds L, Eley B, et al. Western Cape Burden of Disease Reduction Project Volume 7: Decreasing the Burden of Childhood Disease, 2007. http://www.westerncape.gov.za/eng/pubs/reports_research/W/157844 (accessed 20 May 2012)

16. Monteiro M. The road to a World Health Organisation global strategy for reducing the harmful use of alcohol. Alc Res Health 2011, 34(2): 257-260.

17. Chang G. Screening and brief intervention in prenatal settings. Alcohol Res Health 2005; 55: 80-84. [PMID 19006995]

18. Naimi TS, Brewer RD, Mokdad A, et al. Binge drinking among US adults. JAMA 2003; 289(1): 70-5. [http://dx.doi.org/10.1001\%2Fjama.289.1.70][PMID 20682942]

19. Razvodovsky YE. Contribution of alcohol in accident related mortality in Belarus: a time series approach. J Inj Violence Res 2012, 4(2): 58-64. [PMID 21502784] 


\section{Article}

\section{Prevalence of Fetal Alcohol Syndrome in a South African City with a Predominantly Black African population}

Published as:

Urban, M.F.*, Olivier, L.*, Viljoen, D.L., Lombard, C., Louw, J.G., Drotsky, L-M., Temmerman, M., \& Chersich, M.F. (2015). Prevalence of fetal alcohol syndrome in a South African city with a predominantly Black African population. Alcohol Clinical and Experimental Research 39(6), 1016-1026.

*equal contribution 


\section{Abstract}

Background: Fetal alcohol spectrum disorder (FASD) and fetal alcohol syndrome (FAS) are common in some South African populations, notably those of mixed ancestry descent in rural areas and small towns. Little is known about FAS/FASD prevalence in the majority of South Africans: city-dwellers of Black African ethnicity. The current study describes prevalence of FAS in a South African city, comparing two suburbs with predominantly mixed ancestry (Roodepan) and Black African (Galeshewe) populations that house over $60 \%$ of the city population.

Methods: We conducted a tiered, active case-ascertainment study for prevalence of FAS, and also detected some less clinically specific FASD cases. All first grade learners in the two suburbs were eligible for anthropometric screening, and screen-positive learners were assessed for dysmorphic features of FAS. Those with suggestive clinical features received neurocognitive assessment, and maternal or collateral interview. Final diagnosis was made following a case conference.

Results: Complete ascertainment of FAS status was made in 1503 (94.7\%) of 1587 eligible learners (435 in Roodepan and 1152 in Galeshewe). Overall, FAS was diagnosed in $83(5.5 \%, 95 \% \mathrm{Cl}=4.4-6.8 \%)$ learners and FASD in $96(6.4 \%, 95 \% \mathrm{Cl}=5.2 \%-7.7 \%)$. Levels of FAS were high in both areas: $26(6.3 \%, 95 \% \mathrm{Cl}=4.3 \%-9.1 \%)$ learners from Roodepan, compared to $57(5.2 \%, 95 \% \mathrm{Cl}=4.0 \%-6.7 \%)$ from Galeshewe $(\mathrm{p}=0.39)$. No cases were previously diagnosed. The mortality rate for mothers of FASD children from Galeshewe was 19 of 65 (29\%), compared to 3 of 31 (9.7\%; p=0.03) for Roodepan. Interviewed mothers in Galeshewe were older and had higher BMI.

Conclusion: Prevalence of FAS is high in both Galeshewe and Roodepan, and the lack of prior diagnoses indicates that awareness remains low. The maternal mortality rate was especially high in Galeshewe. The unexpectedly high burden of FAS in an urban area with predominantly Black African population mandates extension of surveillance and intervention measures in Southern Africa.

Key words: Fetal Alcohol Syndrome; South Africa; Prevalence; Ethnicity; Alcohol 
Fetal alcohol syndrome (FAS) and fetal alcohol spectrum disorder (FASD) more broadly, result from the adverse effects of alcohol on the developing fetus, and constitute an important cause of developmental disability worldwide (Jonnsen et al, 2014). The primary risk factor for FASD is alcohol consumption by pregnant women, especially in a regular and heavy episodic drinking pattern, but multiple environmental cofactors are important and it is more common in women of low socio-economic status (Abel and Hannigan, 1995; May and Gossage, 2011; May et al, 2013a). Genetic factors may also predispose to FASD (Khaole et al, 2004; Warren and Li, 2005).

Rates of FASD vary between ethnic groups - for example, in the USA there is an increased risk among Native Americans and Blacks, compared to Whites and Hispanics (Chartier et al, 2013). Ethnicity however is a complex concept that encompasses ancestry, national group, birthplace and language - each of which could have distinct relationships to alcohol-related harm (Cheung, 1993). This makes it difficult to determine whether ethnic variation in FAS prevalence relates to drinking behaviour and associated cultural or historical factors, or to environmental and even genetic cofactors. Nonetheless, ethnicity is a commonly used demographic indicator and it is therefore important to explore the extent to which it serves as a risk factor for FAS in a particular environment.

FAS and FASD occur with very high prevalence in some South African populations (May et al 2000, Viljoen et al 2003, Viljoen et al 2005, May et al 2007, Urban et al 2008, May et al 2013b, Olivier et al 2013), but nationwide data are not available. To date, FAS prevalence studies in South Africa have almost exclusively targeted populations with two demographic characteristics believed to confer increased risk: (1) residents of rural areas or small towns; and (2) areas with populations comprising predominantly the mixed ancestry minority group, designated officially as 'Coloured'. However, the South Africa population is $79 \%$ Black African and only $9 \%$ Coloured, and currently over $60 \%$ of the population is urbanized due to rapid urbanization in the last 3 decades (Statistics South Africa, Census 2011). See the footnote for a fuller description of the 'Coloured' and "Black African' population groups in South Africa.

Alcohol abuse is common among adults in South and Southern Africa (World Health Organization, 2014), and risky drinking is among the commonest modifiable risk factors for ill-health in the region (Lim et al, 2012). Two national surveys found that $15-19 \%$ of Black African women reported ever drinking alcohol, a rate approximately half that of Coloured women (Parry et al, 2005; Department of Health and Medical Research Council, 2007). Among Black African women, alcohol consumption was higher if they were urbanized, and risky weekend drinking was a common drinking pattern. Morojele et al (2009) also found significant rates of risky drinking among urban Black African women.

The evidence regarding FAS prevalence in city-dwelling and Black African populations of South Africa is limited to a single study in metropolitan Gauteng (Viljoen et al, 2003). This study found $1.9 \%$ prevalence of FAS among 830 first grade learners, with $1.7 \%$ prevalence in the subset of 414 learners from two predominantly black African 
suburbs. The small sample size did not allow for extrapolation to the whole metropole, with over 8 million Black African inhabitants.

The current study, conducted at the request of the Northern Cape provincial government, aimed to describe the prevalence of FAS in an urban centre where risky drinking is believed to be common. Two suburbs were selected for the study, with predominantly Coloured and Black African populations respectively.

\section{Materials and methods}

\section{Study Population}

The study was conducted at primary schools in the Galeshewe and Roodepan suburbs of Kimberley, the capital city of the sparsely populated Northern Cape province of South Africa. Kimberley has 236,000 inhabitants, and is among the oldest towns in the interior of the country. It developed during the diamond rush of the 1870s and diamond mining has been the backbone of its economy, which has stagnated in recent decades due to downscaling of mining operations.

Galeshewe developed during the diamond rush and is among the oldest 'townships' in South Africa, dating to the 1880's (the term township refers to a high density suburb set aside for Black South Africans, often in the Apartheid era). It has a population of 118,000 people (Sol Plaatjie Municipality, unpublished data) with an ethnic composition of $92 \%$ black African, $7 \%$ Coloured and $<1 \%$ other; by first spoken language the composition is: $71 \%$ indigenous African languages, 25\% Afrikaans and 3\% English (Statistics South Africa, Census 2011). Most housing is formal and it is relatively well-serviced. There is little economic activity in Galeshewe itself, and a high level of unemployment and concomitant social problems including risky drinking and domestic violence (Department of Provincial and Local Government, unpublished data).

Roodepan was established as an area for Coloured people under the Apartheid Group Areas Act in 1975 (unpublished data, B Nagel, Africana Museum, Kimberley). Although of much more recent origin than Galeshewe, Roodepan is characterised by similar socio-economic conditions. The population of 27,500 people (Sol Plaatjie Municipality, unpublished data), is predominantly of Coloured ethnicity (83\%), with $12 \%$ Black African and $5 \%$ other. Afrikaans is the first spoken language for $84 \%, 5 \%$ speak indigenous African languages, 9\% English, and 2\% other (Statistics South Africa, Census 2011).

\section{Study Participants and Recruitment}

The study took place from March 2012-November 2013 in all 11 primary schools in Galeshewe and all 3 primary schools in Roodepan. All first grade children were eligible for inclusion. 


\section{Study Process}

The prevalence of FAS was determined by active case ascertainment, using a tiered screening and diagnostic method that was previously validated and used in South Africa (May et al, 2000; Viljoen et al 2005). The process includes an initial screening stage (anthropometric measurement), followed by a comprehensive diagnostic stage (clinical evaluation, neurocognitive assessment and maternal interview) for screen-positive individuals.

\section{Anthropometric Screening}

Study nurses obtained anthropometric measurements. Using standard methods, height, weight and head circumference $(\mathrm{HC})$ were measured. Children who were $\leq 10$ th percentile of the CDC clinical growth charts for height and weight (Centers for Disease Control, 2000), or alternatively $\leq 10$ th centile for HC (using charts of Nellhaus, 1968), were offered clinical assessment.

\section{Clinical Evaluation}

Screen-positive children were assessed by an experienced dysmorphologist for dysmorphic features of FAS and neurological signs. To standardise assessment of dysmorphic features, a checklist was used that yielded a 'dysmorphology score' with a maximum of 50, which was adapted from that of Hoyme et al (2005). These features included the primary facial features of FAS, namely smooth philtrum of the upper lip, narrow upper vermilion border, and short palpebral fissures ( $\leq 10$ th centile for age using the chart of Thomas et al, 1987). Positive evidence of neurological abnormality required an $\mathrm{HC}<3^{\text {rd }}$ centile or the presence of 'hard' signs on neurological examination.

Children with at least two of three primary facial features of FAS, or neurological abnormality, went on to a full neurocognitive assessment, and an interview was conducted with a parent or guardian.

\section{Neurocognitive Assessment}

Neurocognitive assessments were conducted by a psychologist and occupational therapist experienced in developmental assessment. The Griffiths Mental Developmental Scales - Extended Revised (GMDS-ER) were used to assess neurodevelopment (Griffiths, 1970; Preston, 2006). The GMDS-ER assesses six developmental domains from infancy to middle childhood and the general quotient (GQ) is a composite of the six subscale scores, namely: locomotor (gross motor skills), personal-social (adaptive functioning), hearing-speech (verbal ability), eye-hand (fine-motor co-ordination), performance (pattern construction and speed of performance) and practical reasoning (numerical, time 
and spatial concepts). Raw scores were converted into z-scores for each subscale as well as for the GQ. The z-scores are considered significantly delayed if they are 2 or more standard deviations below the mean of the GMDS-ER norms (Luiz et al, 2006). For the study, neurodevelopment was considered delayed if the z-score for either the GQ or for at least two subscales was significantly delayed.

\section{Maternal Interview}

Three community workers, trained as interviewers, completed a structured questionnaire with mothers of children. Interviews obtained data on demographics, socioeconomic status, alcohol consumption and other risk factors for having a child with FAS/PFAS. History of alcohol consumption was elicited using a validated timeline followback method (Sobell et al, 2001). A shorter 'collateral' interview was used with a close family member, or other informant, if the mother was untraceable. This focused on reasons for the mother's unavailability, and whether she used alcohol during the index pregnancy.

\section{Final Diagnosis}

A final diagnosis was made following a case conference. The final diagnostic categories were 'FAS', 'partial FAS', 'alcohol-related neurodevelopmental deficit' (ARND), 'alcoholrelated birth defects' (ARBD) or 'not FASD'. The modified Institute of Medicine criteria (Hoyme et al, 2005) were used to define diagnostic categories. A diagnosis of FAS required at least two of the three primary facial features, together with growth retardation and either neurological or neurocognitive abnormalities, with or without a history of alcohol use. A diagnosis of partial FAS required at least two of the three FAS facial features and one of growth retardation, neurological or neurocognitive abnormality. In addition, we required a history of alcohol use in pregnancy for this diagnosis to be made. The clinical diagnosis of ARND required a history of alcohol use in pregnancy, and otherwise unexplained neurological, cognitive or behavioural abnormalities. It is important to note that the aim of this tiered study methodology is primarily to detect cases of FAS, and it is expected to miss some cases of partial FAS and most cases of ARND.

\section{Ethics and Health Care}

The Premier of the Northern Cape Province requested the study and the provincial Department of Social Development funded it. Approval was obtained from the Departments of Education, Health and Social Development. Informed consent was obtained from a parent or guardian for all participating children. Consent forms were sent from schools to parents. A home visit was conducted if parents did not respond to a second 
reminder, to ensure that learners whose parents were illiterate were not excluded from the study. IRB approval was granted by the Health Research Ethics Committee of the University of Stellenbosch (Approval number N13/01/008).

Permission was obtained from the Department of Health of the Northern Cape Province for children with developmental deficits, health and social problems to be referred to local professionals and other services, including speech and hearing therapists, occupational therapists and physiotherapists, school psychologists and health care facilities.

With parental permission, school personnel were informed of each child's diagnosis to facilitate educational support, remedial assessment and follow-up by the Department of Education.

\section{Statistical Analysis}

Intercooled Stata 13 (2013) was used for statistical analysis. For analysis of continuous variables, we used an unpaired Student's $t$-test or Mann-Whitney U-test for normally and non-normally distributed data, respectively. The Mantel-Haenszel chi square or Fisher's exact tests were used for analysis of categorical data. These tests were used to identify differences between the characteristics of children and of mothers of FASD children in Roodepan and in Galeshewe.

\section{Results}

\section{Participant Flow and Retention}

Complete ascertainment of FAS status, requiring up to 3 visits, was made on $94.7 \%$ of children (1,503 of 1,587; Fig. 1). Lack of diagnosis was mostly due to consent not been given (77 of 1,$587 ; 4.9 \%$ ), with only a further 7 children not completing the study procedures. A total of 113 received full assessment comprising anthropometric measurement, dysmorphology examination, neurodevelopmental assessment and maternal interview. Stratified by school, ascertainment for FAS status was over $90 \%$ for 12 schools and over $85 \%$ for the remaining 2 schools (Table 1 ).

\section{Characteristics of Learners}

The mean age of children at the beginning of the school year was 2.4 months higher in Galeshewe than Roodepan $(P<0.001)$ (Table3). There was a slight excess of males in the whole study population, even higher among the learners with FASD (59 of 93, 61\% male). Dysmorphology data pertaining to all children who received dysmorphology assessment, and dysmorphology and neurocognitive data for those with FASD, are also summarized in Table 3. Of learners with FASD, over $90 \%$ had a z-score of 2 or more 
standard deviations below the GMDS-ER norms for the GQ, and for the language and practical reasoning domains.

\section{Prevalence of FAS and FASD}

A FASD diagnosis was made in 96 children (6.4\%) including 83 (5.5\%) with FAS, 6 (0.4\%) with partial FAS, and 7 (0.5\%) with ARND, and none with ARBD (Figure 1). No differences were detected between the FAS or FASD prevalence in Roodepan and Galeshewe. Twenty learners with FASD were repeating first grade: 5 in Roodepan (16\% of FASD cases in Roodepan) and 18 (28\%) in Galeshewe ( $p=30$, Fisher's exact test) (Table 2). We did not have information on whether any non-FASD children were repeating first grade, and estimated the rate of FAS and FASD in new school entrants using the total number of students as denominator.

In learners with FASD, the dysmorphology scores ranged from 10 to 28 of 50 (median $=16)$, and the GMDS assessments were: that 88 (94\%) were severely delayed for $G Q$, with $6(16 \%)$ being less severely delayed.

\section{Characteristics of Mothers of FASD Children}

Interview data were obtained from mothers of learners with FASD ( $n=94)$, or mothers and collateral informants $(n=94)$ (Table 4$)$. In most cases, the collateral informant was a family member, although two interviews were with a social worker. The reasons for requiring a collateral informant were: 22 (23\%) mothers were deceased, 9 (10\%) had abandoned the child, 6 (6\%) learners had been removed by social services, and 7 (7\%) for other reasons, such as the mother working or studying elsewhere.

Women in Galeshewe were much more likely to use an indigenous African language at home, and to report their ethnicity as Black African. Most women were currently unemployed (Table 4) and, of 49 respondents, 22 (43\%) gave their occupation as longterm unemployed, 16 (31\%) as domestic workers, 9 (18\%) blue-collar workers, 2 (4\%) office workers and $2(4 \%)$ other, with no difference between suburbs $(p=0.21)$. 


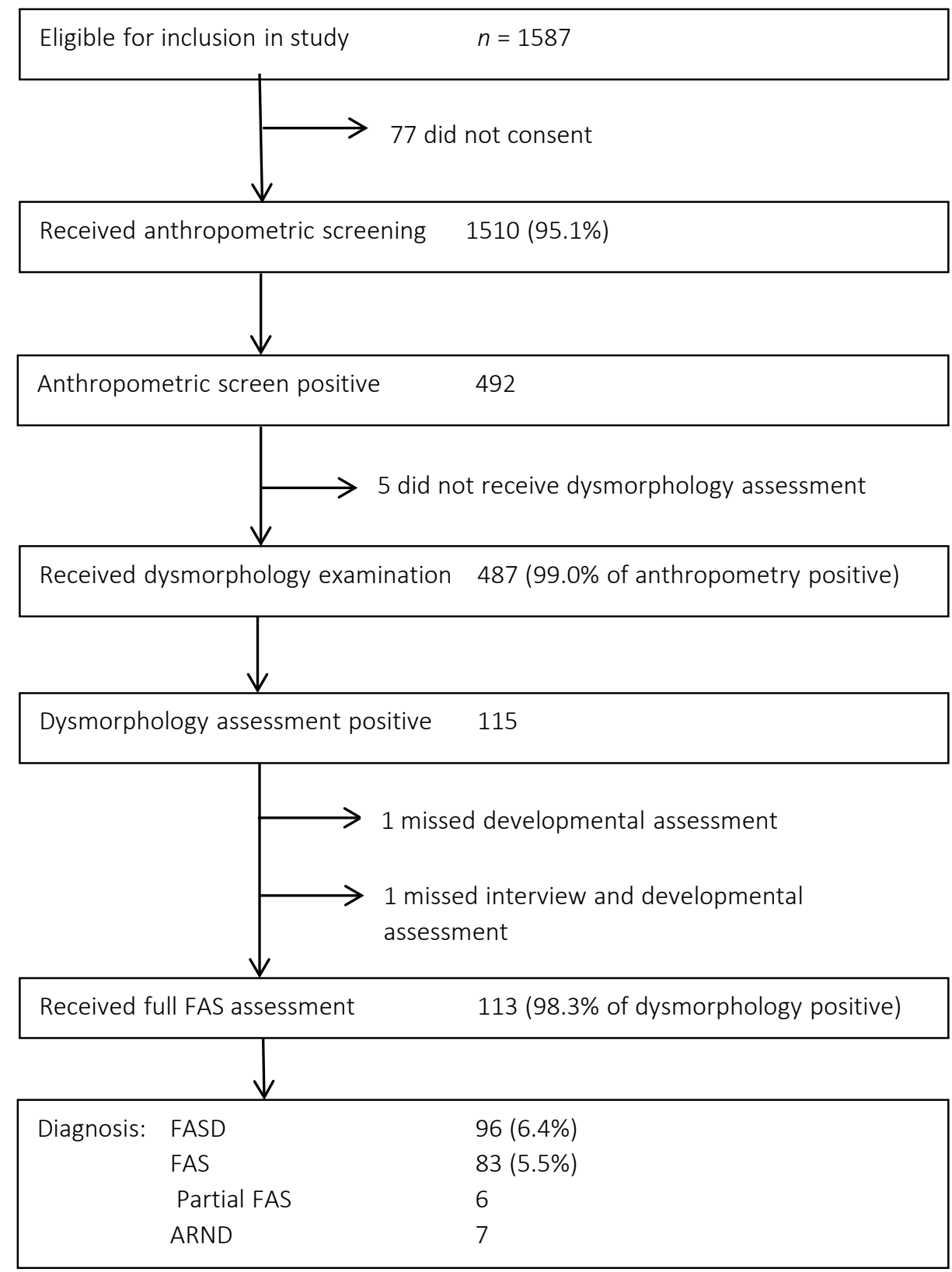

Figure 1. Participant flow chart 
Table 1. Prevalence of Fetal Alcohol Syndrome and Fetal Alcohol Spectrum Disorder Per School

\begin{tabular}{|c|c|c|c|c|c|c|c|}
\hline $\begin{array}{l}\text { School } \\
\text { (R=Roodepan } \\
\text { G=Galeshewe) }\end{array}$ & $\begin{array}{l}\text { N Grade } 1 \\
\text { pupils }\end{array}$ & $\begin{array}{l}N \text { classes } \\
\text { (mean class } \\
\text { size) }\end{array}$ & $\begin{array}{l}\text { N Screened } \\
s(\%)\end{array}$ & $\begin{array}{l}N \text { with study } \\
\text { endpoint }\end{array}$ & $\begin{array}{l}\text { Age } \\
\text { Mean (SD) }\end{array}$ & $\begin{array}{l}\text { FAS } \\
\text { prevalence } \\
\text { (as \% of } \\
\text { screened) }\end{array}$ & \\
\hline R1 & 191 & & $185(97 \%)$ & 185 (97\%) & $6.21(0.55)$ & $9(4.9 \%)$ & $13(7.0 \%)$ \\
\hline $\mathrm{R} 2$ & 103 & $3(34)$ & $89(86 \%)$ & $88(85 \%)$ & $6.17(0.60)$ & $7(8.0 \%)$ & $8(9.1 \%)$ \\
\hline R3 & 141 & $4(35)$ & 137 (97\%) & 137 (97\%) & $6.18(0.58)$ & $10(7.3 \%)$ & $10(7.3 \%)$ \\
\hline $\begin{array}{l}\text { Roodepan } \\
\text { subtotal }\end{array}$ & 435 & $12(36.3)$ & $411(94.5 \%)$ & $410(94.3 \%)$ & & $\begin{array}{l}26(6.3 \%) \\
95 \% \mathrm{Cl}=4.2- \\
9.2\end{array}$ & $\begin{array}{l}31(7.6 \%) \\
95 \% \mathrm{Cl}=5.2- \\
10.6\end{array}$ \\
\hline G1 & 194 & $6(32)$ & 181 (93\%) & 180 (93\%) & $6.32(0.65)$ & $8(4.4 \%)$ & $12(6.6 \%)$ \\
\hline $\mathrm{G} 2$ & 96 & $3(32)$ & 95 (99\%) & 95 (99\%) & $6.05(0.50)$ & $0(0 \%)$ & $0(0 \%)$ \\
\hline G3 & 129 & $3(43)$ & $125(97 \%)$ & $125(97 \%)$ & $6.27(0.53)$ & $2(1.6 \%)$ & $2(1.6 \%)$ \\
\hline G4 & 53 & $2(27)$ & $53(100 \%)$ & 53 (100\%) & $6.20(0.65)$ & $3(5.7 \%)$ & $4(7.5 \%)$ \\
\hline G5 & 81 & $3(27)$ & 73 (90\%) & $69(85 \%)$ & $6.60(0.75)$ & $3(4.1 \%)$ & $3(4.1 \%)$ \\
\hline G6 & 35 & $1(35)$ & $33(94 \%)$ & 33 (94\%) & $6.40(0.65)$ & $1(3.0 \%)$ & $2(6.1 \%)$ \\
\hline G7 & 98 & $3(33)$ & 93 (95\%) & $92(94 \%)$ & $6.58(0.57)$ & $11(11.8 \%)$ & $13(14.0 \%)$ \\
\hline G8 & 103 & $4(26)$ & 95 (92\%) & 95 (92\%) & $6.61(0.64)$ & $7(7.4 \%)$ & $7(7.4 \%)$ \\
\hline G9 & 178 & $5(36)$ & $174(98 \%)$ & 174 (98\%) & $6.65(0.45)$ & $9(5.2 \%)$ & $9(5.2 \%)$ \\
\hline G10 & 132 & $4(33)$ & $129(98 \%)$ & 129 (98\%) & $6.24(0.65)$ & $12(9.3 \%)$ & $12(9.3 \%)$ \\
\hline G11 & 53 & $2(27)$ & 48 (91\%) & $48(91 \%)$ & $6.16(0.45)$ & $1(2.1 \%)$ & $1(2.1 \%)$ \\
\hline $\begin{array}{l}\text { Galeshewe } \\
\text { subtotal }\end{array}$ & 1152 & $36(32.0)$ & 1099 (95.4\%) & ) 1093 (94.9\%) & & $\begin{array}{l}57(5.2 \%) \\
95 \% \mathrm{Cl}=4.0- \\
6.7\end{array}$ & $\begin{array}{l}65(5.9 \%) \\
95 \% \mathrm{Cl}=4.6- \\
7.5\end{array}$ \\
\hline Total & 1587 & $48(33.1)$ & 1510 (95.1\%) & ) 1503 (94.7\%) & & $\begin{array}{l}83(5.5 \%) \\
95 \% \mathrm{Cl}=4.4- \\
6.8\end{array}$ & $\begin{array}{l}96(6.4 \%) \\
95 \% \mathrm{Cl}=5.2- \\
7.7\end{array}$ \\
\hline
\end{tabular}


Table 2. Characteristics of Learners Screened for Fetal Alcohol Syndrome in 2 suburbs of Kimberley

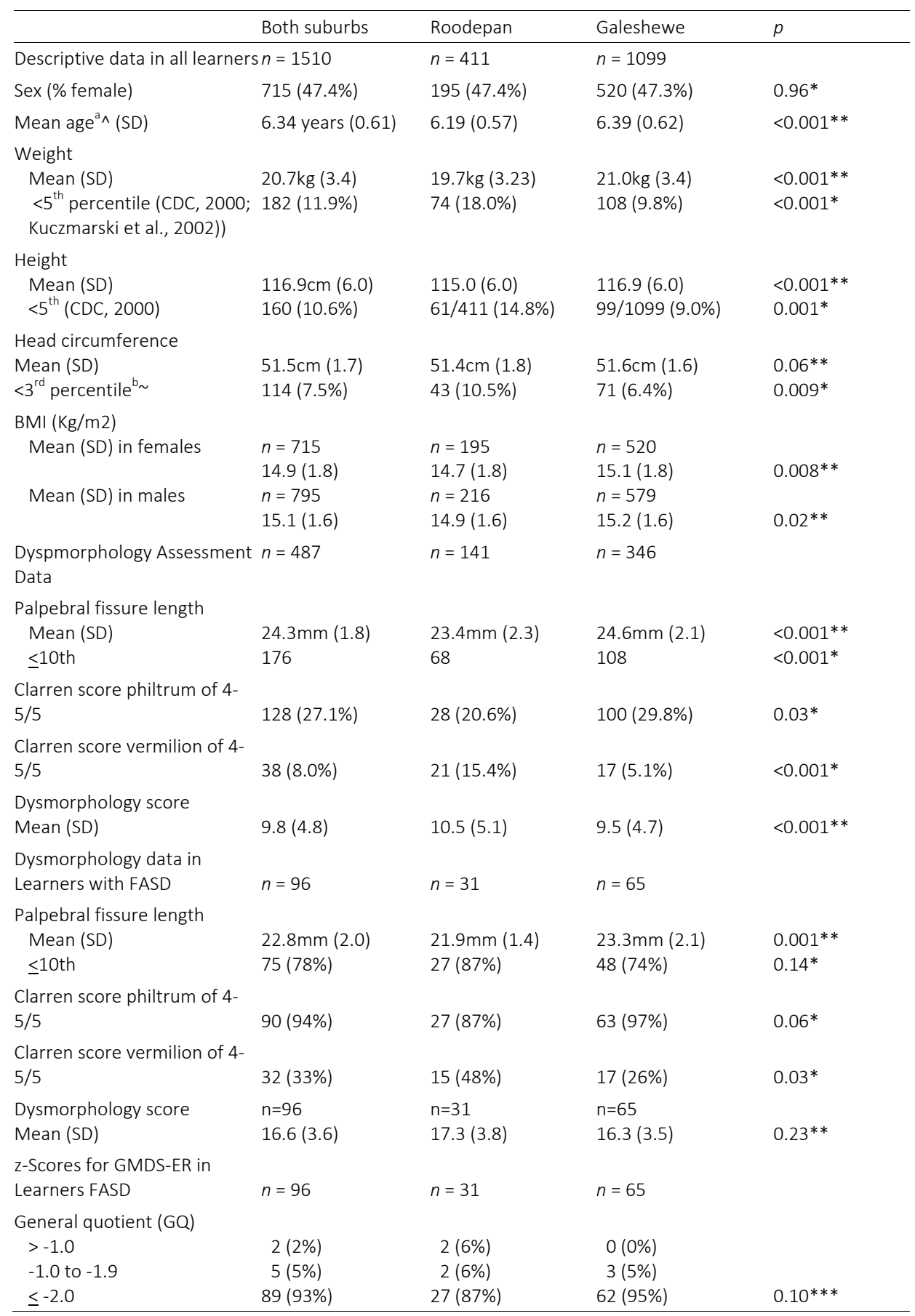




\begin{tabular}{|c|c|c|c|c|}
\hline & Both suburbs & Roodepan & Galeshewe & $p$ \\
\hline \multicolumn{5}{|l|}{ Locomotor } \\
\hline$>-1.0$ & $64(67 \%)$ & $23(74 \%)$ & $41(63 \%)$ & \\
\hline-1.0 to -1.9 & $28(29 \%)$ & $6(19 \%)$ & 22 (34\%) & \\
\hline$\leq-2.0$ & $4(3 \%)$ & $2(6 \%)$ & $2(3 \%)$ & $0.27 * * *$ \\
\hline \multicolumn{5}{|l|}{ Personal-social } \\
\hline$>-1.0$ & $23(24 \%)$ & $10(32 \%)$ & $13(20 \%)$ & \\
\hline-1.0 to -1.9 & 39 (41\%) & $14(45 \%)$ & 25 (38\%) & \\
\hline$\leq-2.0$ & $34(35 \%)$ & $7(23 \%)$ & $27(42 \%)$ & $0.14 * * *$ \\
\hline \multicolumn{5}{|l|}{ Language } \\
\hline$>-1.0$ & $1(1 \%)$ & $0(0 \%)$ & $1(2 \%)$ & \\
\hline-1.0 to -1.9 & $2(2 \%)$ & $1(3 \%)$ & $1(2 \%)$ & \\
\hline$\leq-2.0$ & 93 (97\%) & 30 (97\%) & 63 (97\%) & $0.69 * * *$ \\
\hline \multicolumn{5}{|l|}{ Eye-hand } \\
\hline$>-1.0$ & $5(5 \%)$ & $4(13 \%)$ & $1(2 \%)$ & \\
\hline-1.0 to -1.9 & $23(24 \%)$ & $7(23 \%)$ & $16(25 \%)$ & \\
\hline$\leq-2.0$ & $68(71 \%)$ & $20(65 \%)$ & $48(74 \%)$ & $0.08 * * *$ \\
\hline \multicolumn{5}{|l|}{ Performance } \\
\hline$>-1.0$ & $42(43 \%)$ & $14(45 \%)$ & $28(43 \%)$ & \\
\hline-1.0 to -1.9 & $26(27 \%)$ & $7(23 \%)$ & $19(29 \%)$ & \\
\hline$\leq-2.0$ & $28(29 \%)$ & $10(32 \%)$ & $18(28 \%)$ & $0.82 * * *$ \\
\hline \multicolumn{5}{|c|}{ Practical reasoning } \\
\hline$>-1.0$ & $0(0 \%)$ & $0(0 \%)$ & $0(0 \%)$ & \\
\hline$-1,0$ to -1.9 & $5(5 \%)$ & $4(13 \%)$ & $1(2 \%)$ & \\
\hline$\leq-2.0$ & 91 (95\%) & $27(87 \%)$ & 64 (98\%) & $0.04 * * *$ \\
\hline
\end{tabular}

SD standard deviation.

*Chi-square test; **unpaired Student's $t$-test; ***Fischer's exact test.

${ }^{a}$ Age at start of school year.

bee reference Nellhaus (1968).

Table 3. Prevalence of fetal alcohol syndrome in two suburbs of Kimberley

\begin{tabular}{|c|c|c|c|c|}
\hline & $\begin{array}{l}\text { Both suburbs } \\
(n=1503)\end{array}$ & $\begin{array}{l}\text { Roodepan } \\
(n=410)\end{array}$ & $\begin{array}{l}\text { Galeshewe } \\
(n=1093)\end{array}$ & $p$ \\
\hline FASD prevalence & $\begin{array}{l}96(6.4 \%) \\
95 \% \mathrm{Cl}=5.2 \%-7.7 \%\end{array}$ & $\begin{array}{l}31(7.6 \%) \\
95 \% \mathrm{Cl}=5.2 \%-10.5 \%\end{array}$ & $\begin{array}{l}65(5.9 \%) \\
95 \% \mathrm{Cl}=4.6 \%-7.5 \%\end{array}$ & $0.25^{*}$ \\
\hline FAS prevalence & $\begin{array}{l}83(5.5 \%) \\
95 \% \mathrm{Cl}=4.4 \%-6.8 \%)\end{array}$ & $\begin{array}{l}26(6.3 \%) \\
95 \% \mathrm{Cl}=4.2 \%-9.2 \%)\end{array}$ & $\begin{array}{l}57(5.2 \%) \\
95 \% \mathrm{Cl}=4.0 \%-6.7 \%)\end{array}$ & $0.39 *$ \\
\hline $\begin{array}{l}\text { "Minimum" FASD } \\
\text { prevalence }\end{array}$ & $\begin{array}{l}73(4.9 \%) \\
95 \% \mathrm{Cl}=3.8 \%-6.1 \%)\end{array}$ & $\begin{array}{l}26(6.3 \%) \\
95 \% \mathrm{Cl}=4.2 \%-9.2 \%)\end{array}$ & $\begin{array}{l}47(4.3 \%) \\
95 \% \mathrm{Cl}=3.2 \%-5.7 \%)\end{array}$ & $0.10 *$ \\
\hline $\begin{array}{l}\text { "Minimum" FAS } \\
\text { prevalence }^{\mathrm{a}}\end{array}$ & $\begin{array}{l}65(4.3 \%) \\
95 \% \mathrm{Cl}=3.4 \%-5.5 \%)\end{array}$ & $\begin{array}{l}23(5.6 \%) \\
95 \% \mathrm{Cl}=3.6 \%-8.3 \%)\end{array}$ & $\begin{array}{l}44(4.0 \%) 95 \% \mathrm{Cl}=2.90 \%- \\
5.4 \%)\end{array}$ & $0.18^{*}$ \\
\hline
\end{tabular}

*Chi-square test.

${ }^{a}$ Excludes FASD-?FAS-affected participants who were repeating grade 1.

\section{Maternal Alcohol and Substance Use}

A history of drinking in pregnancy was given by $80(87 \%)$ of 92 informants in total, and by 45 (90\%) of 50 mothers. Information regarding current drinking could only be ob- 
tained from mothers: of 48 maternal respondents, 44 (92\%) had consumed alcohol in the preceding 12 months (current drinkers). Of current drinkers, 29 (66\%) indicated that they drank more now than in the index pregnancy, and 36 (82\%) that they had been drunk at least once in the past year or couldn't remember how often they had been drunk. The women were primarily weekend drinkers, with only one woman reporting daily drinking. The number of standard drinks they reported personally consuming per drinking session were: 3-4 drinks in ten women (23\%), 5-9 drinks in fourteen (32\%), over 10 drinks in ten (23\%), and ten women were uncertain (23\%). One (2\%) said she received alcohol as part of her salary.

In both Roodepan and Galeshewe, the commonest drink was commercial lager beer [27/50 (54\%)], followed by cider [10/50 (20\%)]. In Galeshewe, 6 (17\%) of 35 mothers drank traditional (sorghum) beer and three (9\%) drank spirits, whereas in Roodepan, five (33\%) of 15 drank wine. Women in Galeshewe were less likely to be smokers, and no other substance abuse was reported.

\section{Risk of FASD Recurrence}

Mothers reported that 32 (64\%) of 52 index pregnancies were unplanned. Of 48 maternal respondents, 25 (52\%) were at risk of a further child with FASD, as they currently used alcohol and were either pregnant ( 3 women; $6 \%$ ), or sexually active and not using contraception (22 women; 46\%). A related point is that none of the interviewees were aware of the index child having FAS/FASD prior to the diagnosis being made in the study.

\section{Discussion}

\section{Characteristics of the Study Population of Learners}

This study focused on 2 low-income suburbs that comprise $62 \%$ of the population of one of the secondary cities, and a provincial capital, of South Africa. Consistent with the low-income setting, the rate of growth stunting (height $<5^{\text {th }}$ percentile) was high in both suburbs. There was a higher prevalence of low height, weight and head circumferencefor-age, and lower mean BMI in schools with predominantly Coloured scholars. This may relate in part to FASD, but may also indicate other environmental, nutritional, epigenetic and genetic differences between the communities.

The mean dysmorphology score was significantly higher for learners receiving assessments in Roodepan than Galeshewe, but not when only comparing children with FASD between the two sites. It is unclear whether this relates to prenatal alcohol exposure, or for other reasons, such as possible ethnic variation. 
There was no significant difference in GQ between learners with FASD in the two suburbs. A significant difference was detected for the practical reasoning domain, though this may relate to the more frequent use of interpreters in Galeshewe. The vast majority of learners were significantly delayed for language and practical reasoning, compared to a minority with significant delay for the locomotor, personal-social and performance domains. This is consistent with evidence from a prior study on South African children with FAS that the predominant effect is on higher order cognitive function (Adnams et al, 2001).

\section{Prevalence of FAS/FASD}

The study found a very high prevalence of FAS/FASD (prevalence above $4 \%$ in all but 3 of 14 schools), in both communities. Since the study included all learners at all 14 primary schools in the study area, and FAS status was determined for almost $95 \%$ of learners, the study demonstrates clearly that FAS/FASD is a significant public health problem in both communities. We noted that a number of learners with FASD were repeating grade 1 , thus possibly overestimating the FASD rates per age-cohort entering school. We corrected for this by calculating rates of FASD excluding learners with FASD who were repeating first grade - the reduced estimate for both FASD and FAS prevalence remains above $4 \%$, and not significantly different between the two communities.

\section{FASD in a City Setting, and in Predominantly Black African Suburbs}

Since the study area includes almost two thirds of the population of Kimberley, the study provides evidence of a high rate of FAS/FASD within this city as a whole. The findings in Galeshewe are the first conclusive evidence that FAS/FASD is a sizeable public health problem in a predominantly Black African community in South Africa.

The only prior study to assess rates of FAS in a South African city (Viljoen et al, 2003) found 16 cases of FAS $(1.9 \%, 95 \% \mathrm{Cl}=1.2 \%$ to $3.1 \%)$ among 830 learners in four selected low income areas in metropolitan Gauteng, which includes the city of Johannesburg. That study found 7 cases of FAS $(1.7 \%, 95 \% \mathrm{Cl}=0.8 \%$ to $3.5 \%)$ among 414 school entry children from two areas with a predominantly Black African population. Although giving preliminary evidence of a possible FAS problem in the metropole, the sample was not large or representative enough to draw firm conclusions. This is particularly true of the sub-sample from two Black African areas.

One other study has reported rates of FAS among children of women who selfidentified as Black African (Urban et al, 2008), but in the context of two small towns with predominantly Coloured populations. In that environment a substantial proportion of Black Africans had FAS (5.3\% of 282), compared to 7.2\% of 1501 Coloured children. 


\section{Generalizability of Findings}

The extent to which our findings can be extrapolated to other predominantly Black African communities in South Africa is uncertain. The South African Demographic and Health Survey found heterogeneous levels of alcohol consumption, with greater consumption by urban than rural Black African women, and variation by province (Parry et al, 2005). Areas with known high rates of female alcohol consumption are expected to be high risk, though the existing data gives little geographic detail.

The generalizability of our findings in Galeshewe depend on the reasons for high FASD rate. If broad socio-economic factors such as unemployment and poverty are important, then Galeshewe has many features in common with other townships in South Africa. However, there may be more specific historical factors at play: the record indicates a long history of problem drinking in Kimberley, with 'drinking, fighting, beer making and gambling' already frequent in the early twentieth century (unpublished data, Lunderstedt, 2000). In addition, there is evidence to suggest a history of female drinking, e.g. municipal beer halls were established in the 1940's, with separate drinking areas for women (unpublished data, Allen et al, 2004).

The long history of Galeshewe as an urban settlement may have allowed for attrition of socio-cultural prohibitions on female drinking, similar to descriptions of 'acculturation' in other populations (Caetano, 1987; Caetano et al, 2009). Kimberley's mining history may also be contributory, in keeping with evidence that residents of cities with a mining history have higher rates of alcohol and substance use compared to those in other South African cities (Sharp et al, 2014). In addition, more recent economic difficulties due to downscaling of mining activity may be important, since there is good evidence that binge drinking increases during economic downturns - amongst both unemployed and employed individuals (Dee, 2001).

\section{Variation in FAS rate between schools}

The rates of FAS/FASD varied widely between schools, especially in Galeshewe. There was no obvious reason for this, and schools with high rates of FASD were often located nearby schools with low rates. Further investigation is warranted. The heterogeneity of FASD rates has implications for surveillance - if schools are sampled, a sufficient number should be included to ensure representativeness.

\section{Prior Diagnosis of FAS in the Study Population}

It is clear that FASD remains very under-diagnosed in this community: none of the cases had been previously diagnosed, even those with pathognomonic clinical features of FAS or who repeated first grade. For this reason, few received a grant to assist with care of a disabled child, although most received the child support grant, which is a small sum 
available for all children from families with limited financial means. This is consistent with the idea that FASD is an 'unseen disability' (Paley, 2009) as a result of limited awareness by the community and professionals, as well as the frequently subtle clinical features (May et al, 2009), and specific measures are required to increase awareness.

\section{Maternal Demographic Characteristics}

Many of the previously described social determinants of FASD were prevalent in this study. A high proportion of women were unemployed and a significant minority lived in informal housing. Mothers from Galeshewe were older, and had a higher BMI than those from Roodepan, despite lower household income. The reasons are unclear, but the difference in BMI may reflect the low average BMI of South African Coloured mothers of a FASD child, as previously been described by comparison with Plains Indian women from the USA (May et al, 2004).

\section{Maternal Alcohol Consumption Patterns and Risk of FASD Recurrence}

The high rate of FASD suggests that traditional patterns of alcohol use have broken down to a significant degree within this Black African community. In keeping with this, sorghum beer (the type of alcohol originally brewed by black African communities in the pre-colonial era) was only used by a minority of those studied, whereas commercial lager beer was widely used.

Most surviving mothers continued with risky drinking behaviours and at least half were at risk of another alcohol exposed pregnancy, in which case the risk of FASD recurrence would exceed 50\% (Paintner et al, 2012).

Maternal alcohol consumption was denied in 11 (12\%) of cases. In four of the eleven cases $(36 \%)$ the interviewer had other evidence to indicate that the history was unreliable. It was unclear whether the remaining six cases (7\%) represented women who concealed their history of alcohol use, collateral informants who were unaware, or whether there was some misclassification as FASD. Although the numbers in this group were small, there were no differences evident in maternal characteristics compared to other study participants. It has been suggested that stigmatisation of female drinking results in under-reporting of alcohol use among Black African women (Mphi, 1994; Siegfried et al, 2001), but we found no difference between Black African and Coloured women.

\section{Maternal Mortality Rate}

Almost a quarter of mothers to children with FASD had died by the time the child reached first grade. This is higher than the rates of $7-18 \%$ described in previous FASD prevalence surveys in South African communities (May et al, 2000; Viljoen et al, 2005; 
May et al, 2007; Olivier et al, 2013). The maternal death rate of 29\% in Galeshewe was particularly high, and above that in Roodepan.

The difference in maternal mortality rates is likely to relate to maternal HIV infection which, together with co-infections such as tuberculosis, is the commonest cause of death in adults in the Northern Cape province (Statistics South Africa, 2014). There is a high prevalence of HIV among women attending antenatal clinics in the district $[18.7 \%$ in 2011] (Health Systems Trust, 2014), and prevalence in adults is twice as high in Galeshewe as in Roodepan (Northern Cape Province Department of Health, unpublished data). In addition, alcohol consumption, and especially heavy episodic drinking, is a risk factor for contracting HIV (Baliunas et al, 2010) and for poor HIV treatment outcomes (Azar et al, 2010). Violence and injury is also a relatively frequent cause of death in the province, and also potentially alcohol-related, but there is no evidence that this or another cause would account for the difference in mortality rates between the two communities.

\section{Strengths and Limitations}

Strengths: The study was conducted by a team experienced in FAS surveillance, investigating a large and representative study cohort, and a high proportion of participants reached their study endpoint.

Limitations: For logistical reasons, a tiered screening and diagnostic process was used, with neurodevelopmental assessments only being conducted on children who screened positive on both anthropometric and dysmorphic features. This method is expected to detect virtually all cases of FAS, but will underestimate the prevalence of partial FAS and especially ARND.

The methodology used did not allow for calculation of FAS rates per ethnic or language group, as these data were not collected for the whole study population. In addition, while each area had a predominant ethnic group, there was some overlap in the self-identified ethnicity of participants in the two communities. Nevertheless, the study does show that FAS is present at significant levels in an area with a predominantly Black African population, and in individuals whose mothers self-identified as Black African, and spoke an African language at home.

\section{CONCLUSIONS AND RECOMMENDATIONS}

We found a high rate of FAS in a South African city with a predominantly Black African population. This challenges the notion that that FAS/FASD is largely a condition of the minority Coloured population of South Africa, and demonstrates that FAS is more wide- 
spread than previously thought. It remains unclear to what extent the findings are generalizable to other apparently similar environments.

There is a need to further delineate the high-risk groups for FAS, and to better define target groups for surveillance and prevention measures. We recommend, in line with Jonnsen et al (2014), that surveillance be extended to further urban areas in South and Southern Africa. Specific characteristics of this community which may be relevant are that it is a long-established city, with a predominantly mining heritage, and current economic difficulties.

The fact that no cases of FAS had been previously diagnosed suggests a lack of awareness by health professionals in this area, and perhaps the community more broadly. Interventions have been shown to reduce both alcohol consumption (Chang, 2004-2005) and rates of FASD (Chersich et al, 2012), and practical implementation of primary, secondary and tertiary prevention measures is urgently required.

The reasons for the very high mortality rate of mothers in Galeshewe require further investigation, but may relate to co-occurrence with HIV/AIDS.

\section{Appendix}

The South African Census uses the terms "Black African to denote the majority population of South Africa, and "Coloured" to designate the largest minority population group (although the term 'Coloured' remains contested in South Africa, it does not have a necessarily derogatory meaning). The history and ancestral background of these two groups differ significantly.

The term "Coloured" refers to a highly admixed population that developed during successive periods of colonization by the Dutch and British (between 1652 and 1910). This population derives from a variety of ancestral sources, and is best recorded in the Western Cape province of South African, where the historical record and genomic evidence (de Wit et al, 2010) concur that the major ancestries are Khoisan (the indigenous population of the area into which the Cape colony encroached), European, Black African (predominantly slaves from East Africa) and Asian (slaves or political exiles from South Asia and the Dutch East Indies). This population remained subject to discriminatory colonial laws throughout the colonial period. Over time, this largely Afrikaans-speaking population became identified as "Coloured", and the term was subsequently used as a designation in the apartheid era (1948-1990) when, although discriminated against, Coloureds held an intermediate status between White and Black South Africans.

From the early days of the Cape colony, the development of viticulture ensured that alcohol was readily available. A daily measure of alcohol (or "tot") was given to slaves on the wine farms. After slavery was abolished in 1834, this evolved into the "tot system" that entailed the provision of alcohol as part-payment or incentive for farm work. The tot system was widely used on farms in the expanding Cape colony and continued 
in modified form until 1990. It is considered important in the entrenchment and spread of risky drinking practices in the Coloured population (Viall et al, 2011).

In contrast, Black Africans originate primarily from several bantu-language indigenous tribes that inhabited parts of modern South Africa that were mostly outside the early Cape colony. They suffered land dispossession from the 1830s and especially in the early $20^{\text {th }}$ century, and were subjected to the worst effects of subsequent apartheid, but did not receive large scale exposure to effects of earlier colonial rule such as slavery and the tot system. Urbanization of Black Africans increased from the late $19^{\text {th }}$ century, was severely curtailed in the apartheid era, and has increased rapidly since.

Black South Africans retain significant elements of their pre-colonial cultures, such as the use of an indigenous African language. An alcohol-related example is the cultural prohibition on female drinking (Mphi, 1994; Siegfried et al, 2001), the reduction of which may partially explain why the prevalence of risky drinking by urbanized Black African women is higher than those from more traditional rural areas.

\section{Acknowledgements}

We would like to thank the Department of Social Development, Northern Cape Province for the invitation and funding of the study. Particular thanks to the Departments of Education and Health, specifically the school principals, teachers, psychologists and primary health care staff. The FARR staff in Kimberley (Nono Senwedi, Alina Ngcofo and Beaurane Pienaar) and the rest of the FARR team went far beyond the call of duty. Special thanks to the parents, guardians, children and community members in Galeshewe and Roodepan for their cooperation and participation in the study. 


\section{References}

Abel EL, Hannigan JH (1995) Maternal risk factors in fetal alcohol syndrome: provocative and permissive factors. Neurotoxicol Teratol 17(4): 445-462.

Adnams CM, Kodituwakku PW, Hay A, Nolteno CD, Viljoen D, May PA (2001) Patterns of cognitive-motor development in children with fetal alcohol syndrome from a community in South Africa. Alcohol Clin Exp Res 25(4):557-562.

Azar MM, Springer SA, Meyer JP, Altice FL (2010) A systematic review of the impact of alcohol use disorders on HIV treatment outcomes, adherence to antiretroviral therapy and health care utilization. Drug Alcohol Depend 112(3): 178-193.

Baliunas D, Rehm J, Irving H, Shuper P (2010) Alcohol consumption and risk of incident human immunodeficiency virus infection: A meta-analysis. Int J Public Health 55(3): 159-166.

Caetano R (1987) Acculturation, drinking and social settings among U.S. Hispanics. Drug Alcohol Depend 19(3):215-226.

Caetano R, Ramisetty-Mikler S, Rodriguez LA (2009) The Hispanic Americans Baseline Alcohol Survey (HABLAS): The association between birthplace, acculturation and alcohol abuse and dependence across Hispanic national groups. Drug Alcohol Depend 99(1-3): 215-221.

Centers for Disease Control, 2000. CDC clinical growth charts. Available at: http://www.cdc.gov/growthcharts/. Accessed September 27, 2014.

Chang G (2004-2005) Screening and brief intervention in prenatal care settings. Alcohol Res Health 28(2): 8084.

Chartier KG, Vaeth PA, Caetano R (2013) Focus on: ethnicity and the social and health harms from drinking. Alcohol Res 35(2): 229-237.

Chersich MF, Urban M, Olivier L, Davies LA, Chetty C, Viljoen D (2012) Universal prevention is associated with lower prevalence of fetal alcohol spectrum disorders in Northern Cape, South Africa: a multicentre before-after study. Alcohol Alcohol 47(1): 67-74.

Cheung YW (1993) Approaches to ethnicity: clearing roadblocks in the study of ethnicity and substance use. Int J Addict 28(12): 1209-1226.

Dee TS (2001) Alcohol abuse and economic conditions: evidence from repeated cross-sections of individuallevel data. Health Econ 10(3): 257-270.

Department of Health and Medical Research Council (2007) South Africa Demographic and Health Survey, 2003. Pretoria: Department of Health. Available from: http://www.mrc.ac.za/bod/sadhs.htm. Accessed September 12, 2014

De Wit E, Delport W, Rugumika CE, Meintjies A, Moller M, Van Helden PD, Seoighe C, Hoal EG (2010) Genomewide analysis of the structure of the South African Coloured Population in the Western Cape. Hum Genet 128(2): 145-153.

Griffiths, Ruth (1970) The abilities of young children: a comprehensive system of mental measurement for the first eight years of life (Association for Research in Infant and Child Development). Reprinted by The Test Agency Ltd, Amersham, UK, 1984.

Health Systems Trust. 2012 National Antenatal Sentinel HIV \& Herpes Simplex type-2 prevalence survey. Pretoria: Department of Health (2014). Available at: http://www.hst.org.za/publications/2012-nationalantenatal-sentinel-hiv-herpes-simplex-type-2-prevalence-survey. Accessed September 14, 2014

Hoyme HE, May Pay, Kalberg WO, Kodituwakku P, Gossage JP, Trujillo PM, Buckley DG, Miller JH, Aragon AS, Khaole N, Viljoen DL, Jones KL, Robinson LK (2005) A Practical Clinical Approach to Diagnosis of Fetal Alcohol Spectrum Disorders: Clarification of the 1996 Institute of Medicine Criteria. Pediatrics 115(1): 39-47.

Jonsson E, Salmon A, Warren KR (2014) The International Charter on the Prevention of Fetal Alcohol Spectrum Disorder. Lancet Glob Health 2(3): e135-137.

Khaole NCO, Ramchandani VA, Viljoen DL, Li T (2004) A pilot study of alcohol exposure and pharmacokinetics in women with or without children with fetal alcohol syndrome. Alcohol Alcohol 39(6): 503-508. 
Kuczmarski RJ, Ogden CL, Guo SS, Grummer-strawn LM, Flegal KM, Mei Z, Wei R, Curtin LR, Roche AF, Johnson CL. (2002) 2000 CDC Gowth Charts for the United States: methods and development. National Center for Health Statistics. Vital Health. Stat 11(246):1-190.

Lim SS, Vos T, Flaxman AD, Danaei G, Shibuya K, Adair-Rohani H, AlMazroa MA, Amann M, Anderson HR, Andrews KG, Aryee M, Atkinson C, Bacchus LJ, Bahalim AD, Balakrishnan K, Balmes J, Barker-Collo S, Baxter A, Bell ML, Blore JD (2012) A comparative risk assessment of burden of disease and injury attributable to 67 risk factors and risk factor clusters in 21 regions, 1990-2010: a systematic analysis for the Global Burden of Disease Study 2010. Lancet 380(9859): 2224-2260.

Luiz DM, Barnard A, Knoesen N, Kotras N, Horrocks S, McAlinden P, Challis D, O'Connel RO (2006) Griffiths Mental Developmental Scales -Extended Revised: Two to Eight Years. Administration Manual, Oxford MS: Hogrefe.

May PA, Blankenship J, Marais A, Gossage JP, Kalberg WO, Barnard R, de Vries M, Robinson LK, Adnams CM, Buckley D, Manning M, Jones KL, Parry C, Hoyme HE, Seedat S (2013b) Approaching the prevalence of the full spectrum of fetal alcohol spectrum disorders in a South African population-based study. Alcohol Clin Exp Res 37(5): 818-830.

May PA, Tabachnick BG, Gossage JP, Kalberg WO, Marais A, Robinson LK, Manning MA, Blankenship J, Buckley D, Hoyme HE, Adnams CM (2013a) Maternal factors predicting cognitive and behavioural characteristics of children with fetal alcohol spectrum disorders. J Dev Behav Pediatr 34(5): 314-325

May PA Brooke LE, Gossage JP, Croxford J, Adnams C, Jones KL, Robinson L, Viljoen D (2000) Epidemiology of fetal alcohol syndrome in a South African community in the Western Cape Province. Am J Public Health 90(12): 1905-1912.

May PA, Gossage JP (2011) Maternal risk factors for fetal alcohol spectrum disorders: not as simple as it might seem. Alcohol Res Health 34(1): 15-26.

May PA, Gossage JP, Kalberg WO, Robinson LK, Buckley D, Manning M, Hoyme HE (2009) Prevalence and epidemiological charateristics of FASD from various research methods with an emphasis on recent inschool studies. Dev Disabil Res Rev 15(3): 176-192.

May PA, Gossage JP, Marais AS, Colleen MA, Hoyme HE, Jones KL, Robinson LK, Khaole NCO, Snell C, Kalberg WO, Hendricks L, Brooke L, Stellavato C, Viljoen DL (2007) The epidemiology of fetal alcohol syndrome and partial FAS in a South African community. Drug Alcohol Depend 88(2-3): 259-271.

May PA, Gossage JP, White-Country M, Goodhart K, Decoteau S, Truijillo PM, Kalberg WO, Viljoen DL, Hoyme $\mathrm{HE}$ (2004) Alcohol consumption and other maternal risk factors for fetal alcohol syndrome among three distinct samples of women, before, during and after pregnancy: the risk is relative. Am J Med Genet C Semin Med Genet 127C:10-20.

Morojele NK, London L, Olorunju SA, Matjila MJ, Davids AS, Rendall-Mkosi KM (2010) Predictors of risk of alcohol-exposed pregnancies among women in an urban and a rural area of South Africa. Soc Sci Med 70(4): 534-542.

Mphi M (1994) Female alcoholism problems in Lesotho. Addiction 89(8): 945-949.

Nellhaus G (1968) Head circumference from birth to eighteen years. Practical composite international and interracial graphs. Pediatrics 41(1): 106-114.

Olivier L, Urban M, Chersich MF, Temmerman M, Viljoen D (2013) Burden of fetal alcohol syndrome in a rural West Coast area of South Africa. S Afr Med J 103(6):402-405.

Paintner A, Williams AD, Burd L (2012) Fetal alcohol spectrum disorders - implications for child neurology, Part 2: Diagnosis and Management. J Child Neurol 27(3):355-362.

Paley B (2009) Introduction: Fetal alcohol spectrum disorder - Shedding light on an unseen disability. Dev Dis Res Rev 15(3): 167-169.

Parry CD, Plüddemann A, Steyn K, Bradshaw D, Norman R, Laubscher R (2005) Alcohol use in South Africa: findings from the first Demographic and Health Survey (1998). J Stud Alcohol 66(1): 91-97.

Preston P (2006) Testing Children - A practitioner's guide to the Assessment of Mental Development in Infants and Young Children. Oxford MS: Hogrefe. 


\section{Article 3}

Sharp C, Dellis A, Hofmeyer A, Kincaid H, Ross D (2014) First evidence of comorbidity of problem gambling and other psychiatric problems in a representative urban sample of South Africa. J Gambl Stud Jun 14 [epub ahead of print].

Siegfried N, Parry CDH, Morojele NK, Wason D (2001) Profile of drinking behaviour and comparison of selfreport with the CAGE questionnaire and carbohydrate deficient transferrin in a rural Lesotho community. Alcohol Alcohol 36(3): 243-248.

Sobell LC, Agrawal S, Annis H, Ayala-Velasquez H, Echeverria L, Leo GI, Rybakowski JK, Sandahl C, Saunders B, Thomas S, Zioikowski M (2001) Cross-cultural evaluation of two drinking assessment instruments: alcohol timeline follow-back and inventory of drinking situations. Subst Use Misuse 36(11): 313-331.

Stata [computer program] release 13. College Station, Texas: Stata Corporation; 2013.

Statistics South Africa. Census 2011 in brief. https://www.statssa.gov.za/Census2011/Products/Census_2011_ Census_in_brief.pdf. Pretoria: Statistics South Africa, 2012. Accessed July 25, 2014.

Statistics South Africa. Mortality and causes of death in South Africa, 2011: findings from death notification. http://beta2.statssa.gov.za/publications/P03093/P030932011.pdf. Pretoria: Statistics South Africa. Accessed February 2, 2015.

Thomas IT, Gaitantzis YA, Frias JL (1987) Palpebral fissure length from 29 weeks gestation to 14 years. J Pediatr 111(2): 267-268.

Urban M, Chersich MF, Fourie LA, Chetty C, Olivier L, Viljoen D (2008) Fetal alcohol syndrome among grade 1 schoolchildren in Northern Cape Province: prevalence and risk factors. S Afr Med J 98(11): 877-882.

Viall J, James W, Gerwel J (2011) Grape: from slavery to BEE, pp132-151. Tafelberg publishers, Cape Town. ISBN: 978-0-624-04938-8.

Viljoen D, Craig P, Hymbaugh K, Boyle C, Blount S (2003) Fetal alcohol syndrome - South Africa 2001. Morb Mortal Wkly Rep 52: 660-662.

Viljoen DL, Gossage JP, Brooke L, Adnams CM, Jones KL, Robinson LK, Hoyme HE, Snell C, Khaole NCO, Kodituwakku P, Asante KO, Findlay R, Quinton B, Marais AS, Kalberg WO, May PA (2005) Fetal alcohol syndrome epidemiology in a South African community: a second study of a very high prevalence area. J Stud Alcohol 66(5):593-604.

Warren KR, Li TK (2005) Genetic polymorphisms: impact on the risk of fetal alcohol spectrum disorders. Birth Defects Research (Part A) 73(4):195-203.

World Health Organization. Global status report on alcohol and health - 2014 edition. http://www.who.int/ substance_abuse/publications/global_alcohol_report/en/retrieved on 18 September 2014 


\section{Article}

Changes in drinking patterns during and after pregnancy among mothers of children with fetal alcohol syndrome: A study in three districts of South Africa

Published as:

Urban, M.F.*, Olivier, L.* , Louw, J.G., Lombard, C., Viljoen, D.L., Scorgie, F., \& Chersich, M.F. (2016) Changes in drinking patterns during and after pregnancy among mothers of children with fetal alcohol syndrome: A study in three districts of South Africa. Drug and Alcohol Dependence, 168, 13-21.

*equal contribution 


\section{Abstract}

Background: Mixed ancestry populations in South Africa have amongst the highest rates of fetal alcohol syndrome (FAS) worldwide. Defining the drinking patterns of women with a FAS child guides FAS preventive interventions.

Methods: Data were drawn from FAS prevalence surveys conducted in three districts: Witzenberg (Cape Winelands), Frances Baard (inland mining town) and Saldanha Bay (coastal towns). 156 mothers and 50 proxy informants of school-entry children diagnosed with FAS and partial-FAS were interviewed, and compared with 55 controls recruited in Saldanha Bay.

Results: Study participants were of low socio-economic status (SES), and a majority of children were either in foster care $(12 \%)$ or had been cared for by relatives for long periods (44\%). Of cases, 123/160 (77\%) reported current drinking, similar between sites. During pregnancy, only 35\% (49/139) of cases had stopped drinking, varying between sites (from $21 \%-54 \%$ in chronological order of surveys; $p<0.001$ ), while $6 \%$ (7/109) increased drinking. Though many women who stopped in pregnancy resumed postpartum, cessation in pregnancy was strongly associated with discontinuation in the long run $(\mathrm{OR}=3.3 ; 95 \% \mathrm{Cl}=1.2-8.9 ; \mathrm{p}=0.005)$. At interview, $36 \%$ of cases $(54 / 151)$ and $18 \%$ of controls (9/51) were at risk of an alcohol-exposed pregnancy $(p=0.02)$. Median maternal mass of cases was $22 \mathrm{~kg}$ lower than controls, with $20 \%$ being underweight and $14 \%$ microcephalic.

Conclusions: Increasing rates of drinking cessation during pregnancy over time suggest rising awareness of FAS. Cessation is associated with recidivism after pregnancy but also with reduced long-term drinking. Interventions should target alcohol abstinence in pregnancy, but extend into the puerperium.

\section{Key words:}

Fetal alcohol syndrome

Maternal risk factors

South Africa

Drinking patterns 


\section{Introduction}

Alcohol use in pregnancy is associated with a risk of fetal alcohol syndrome (FAS), partial FAS (PFAS, and jointly abbreviated as P/FAS), and other diagnoses within the cluster of fetal alcohol spectrum disorders (FASD). Regular binge-drinking is the major risk factor, but risk is modified by many other factors (Abel and Hannigan, 1995). May and Gossage (2011) cluster these factors into three categories. Exposures include binge-drinking, smoking and drug use, and poor nutrition. Host factors include more advanced age, high gravidity and parity, short stature and low body mass index (BMI), depression and genetics. Environmental factors include low socioeconomic status (SES), social isolation, family and cultural factors, and limited awareness of FASD.

Some regions of South Africa have high rates of P/FAS, with published figures ranging from 2.7\% (Viljoen et al., 2003) to $11.9 \%$ (Urban et al., 2008). The prevalence of P/FAS is well documented in the Cape Winelands district of the Western Cape Province (May et al., 2000, 2007; Viljoen et al., 2005; May et al., 2013a), but information is limited in other settings (Viljoen et al., 2003; Urban et al., 2008, 2015).

About $14 \%$ of South African women binge-drink, with rates varying by ethnic group, urban and rural areas and province, with high rates in the Western Cape and Northern Cape). Levels of binge drinking in women of mixed racial ancestry, designated South African 'Coloured' (SAC) by the census, are as high as in their male counterparts, and considerably higher than women in other ethnic groups (Department of Health and Medical Research Council, 2007).

For this reason, most participants in previous South African prevalence surveys have come from the SAC population group, a highly admixed population whose roots - indigenous Khoisan, European, Black African, and South and South-East Asian - reflect the unique history of the Cape Colony and South Africa.

Comprising only 9\% of the South African population (Statistics South Africa, 2012), the SAC group experienced a long history of oppression under colonial and then Apartheid rule. In the colonial era, a regular allowance of wine was given to slaves on the wine farms, and after emancipation in the 1830s, this evolved into the 'Dop' system, whereby weekly wages were supplemented with cheap alcohol. This remained prevalent on farms in the Western Cape Province until as late as the 1990s (London, 1999). The 'Dop' system is popularly credited with entrenching risky drinking practices, at least on wine farms in the Western Cape Province.

A detailed understanding of the at-risk populations and their drinking patterns is important for developing appropriate FAS prevention strategies. To date, interventions to reduce alcohol harm in South Africa have focused largely on broad policy measures e.g. increased taxation and awareness-raising. These have had mixed results, with binge drinking even increasing over time, and particularly so among females (Ramsoomar and Morojele, 2012). Additional measures such as 'screening, brief intervention and referral to treatment' have been proven effective in reproductive age women both internation- 
ally (Floyd et al., 2009) and in South Africa (Rendall-Mkosi et al., 2013). Such selective interventions require more detailed insight into target populations, and to date have not been implemented beyond a handful of sites. With this in mind, we compared mothers of children with P/FAS (cases) and control mothers, to identify factors relevant to designing preventive interventions in the SAC population.

\section{Methods}

\subsection{Survey sites and study population}

Since the 1990s, about 10 FAS prevalence surveys have been performed - at the request of government departments - by the Foundation for Alcohol Related Research (FARR; http://www.farrsa.org.za), a not-for-profit organization that brings together a range of health professionals.

Surveys were included in this study if they used a similar approach to FAS diagnosis (described by Hoyme et al., 2005), and enrolled a representative group of school-entry children. Three surveys met these criteria. These surveys entailed successive screening and diagnostic phases to detect cases of P/FAS. The diagnostic procedures are described in detail elsewhere (Urban et al., 2015). Maternal interviews were conducted if clinical features indicated a high risk of FAS.

The first survey, in 2008, was carried out in Witzenberg (WB) sub-district of the Cape Winelands district, Western Cape Province. 18 primary schools were included, which were in the town of Ceres (population 30,000), in several smaller towns, or on farms. Prevalence of combined P/FAS was $8.7 \%$ (88 cases in 1010 enrolled children) and of FAS was $5.0 \%$ (51/1010; unpublished data). WB is a viticulture and fruit farming region where the 'Dop' system was widespread until the early 1990's (London, 2003).

The second survey was conducted in 2012, in Frances Baard (FB) district municipality, Northern Cape Province. It found a 5.7\% (89 of 1587 enrolled) prevalence of P/FAS, and $5.2 \%(83 / 1587)$ of FAS (Urban et al., 2015). FB is a long-established, now economically depressed, mining town (population 236,000). It is located in a semi-arid region, approximately $1000 \mathrm{~km}$ inland from the other sites.

The third survey was held in 2013 in the largely urban Saldanha Bay (SB) sub-district of the West Coast district, Western Cape Province. Here the prevalence of P/FAS was 6.4\% (99 cases in 1540 enrolled children) and FAS 4.7\% (73/1540; unpublished data). This site is approximately $180 \mathrm{~km}$ north-west of WB. It includes the town of Vredenburg (population 38,000), the harbour town of SB (population 28,000), and surrounding coastal villages. Economic activity relates predominantly to shipping and fishing.

Interviews with mothers (or proxies) of children with P/FAS were included in this analysis if the mother was of SAC ethnicity, as indicated by the mother herself or a proxy informant. Interviews at one site with mothers (or proxies) of a randomly selected 
group of children without P/FAS were included as controls using the same ethnicity criteria. People of SAC ancestry comprise a majority of the population in the SB and WB sites, but a minority in the inland FB site.

\subsection{Interviews}

Professional study staff or community workers were trained to carry out interviews, which were conducted with the mother of the index case, or with a proxy informant (usually close family member) if the mother was unavailable after two tracing attempts. Information was less complete from proxies than mothers, causing variation in the denominator between study variables.

Interviewers used a semi-structured questionnaire to elicit information on the mother's history of alcohol and substance use, drinking context, self-perception of her drinking, demographics, SES and reproductive health. Anthropometric measurements of the mother were also performed.

The questionnaire was adapted from a previous validated tool (Viljoen et al., 2002). While the questions and general flow of the questionnaire were mostly identical across sites, the length was reduced from 114 items in the earliest survey, to 101 items thereafter. This was achieved by decreasing the number of free-text probes, or the number of questions addressing a specific topic. In some instances, additional questions were added. Where the data permitted, questions were recoded to create a variable common to all sites.

History of alcohol consumption in pregnancy was elicited by asking for recent drinking practices, then drinking practices prior to the index pregnancy, and any changes during and shortly after the pregnancy. Similar questionnaires for retrospective report of alcohol use have been validated in several populations (Sobell et al., 2001). Reported alcohol use was expressed as the number of standard drinks consumed, with a standard drink being defined as one containing 14g of absolute alcohol (National Institute on Alcoholism and Alcohol Abuse, 2005). Reported use of four or more standard drinks on a day was designated as an episode of binge drinking. Women who were pregnant or not using contraception were described as at risk for alcohol-exposed pregnancy (AEP) if they were drinking, or at high risk for AEP if binge drinking in the last three months as suggested by Balachova et al. (2015).

Women's anthropometric measurements were obtained using standard methods and compared to charts for height, weight and body mass index (BMI) of the Centers for Disease Control (2005), and for head circumference of Nellhaus (1968). Underweight was defined as a BMI of $<18.5 \mathrm{~kg} / \mathrm{m}^{2}$ and obesity as a BMI of $\geq 30 \mathrm{~kg} / \mathrm{m}^{2}$.

Internal control questions were included to test validity of responses, and responses were generally consistent. Interviewers qualitatively assessed each interview for reliability of information received. 


\subsection{Statistical Analysis}

Intercooled Stata 13 (StataCorp, Texas) was used to merge and recode questionnaire databases, and conduct statistical analysis. Univariate analysis compared controls to all cases, the main focus of the paper (Tables 1 and 2). Cases in the three sites were also compared, described as 'inter-site variation', and these findings are mentioned where they illustrate key points relevant to a future intervention. Categorical data were analysed using the Pearson chi square, or Fisher exact tests. Ordinal and continuous data were analysed with the Student's t, Kruskal-Wallis, or one-way Anova tests, as applicable.

\subsection{Ethics}

IRB approval was granted by the Health Research Ethics Committee of the University of Stellenbosch (N13/01/008). The study was approved by the Department of Social Development at provincial level. Consent was individually obtained from the mother or guardian of each child. Confidentiality was maintained by appropriate training of staff, storing records in a locked room, and ensuring that electronic records were password protected.

\section{Results}

\subsection{Participants (Fig. 1)}

Of 346 women with a P/FAS child, 261 (75\%) were included in analysis: 206 (79\%) cases, and 55 (21\%) controls. Two thirds of case women had a child with FAS $(141,68 \%)$, and a third with PFAS (65, 32\%). 156 (76\%) case interviews were with mothers and 50 (24\%) with proxy informants. Mean time elapsed between index pregnancy and interview was $7.6(S D=0.72)$ years for controls and $8.0(2.3)$ years for cases $(p=0.27)$.

\subsection{Alcohol and other substance use (Table 1)}

\subsubsection{Drinking history}

A history of ever drinking was several fold higher in cases than controls $(O R=8.1$; $95 \% \mathrm{Cl}=2.1-37.5 ; \mathrm{p}<0.001)$. A higher proportion of all cases than controls initiated drinking before 16 years of age ( $15 \%$ versus $2 \% ; p=0.03$ ). Eight (5\%) of 175 cases had received 'Dop' in the past, of whom 7 were from WB $(p=0.02)$. 


\subsubsection{Drinking in pregnancy}

Of 206 case interviews, 36 (17\%) did not provide information about drinking in pregnancy - mostly because proxy informants lacked knowledge of the mother's drinking status (33 cases). Twenty women denied drinking in pregnancy, of whom 10 were considered reliable informants ( $5 \%$ of P/FAS cases).

Fig. 2 compares the proportion of women who were drinking at several time intervals, from shortly before pregnancy until the time of interview. Among cases, cessation of drinking in pregnancy varied by site from $21 \%$ (13 of 62) in WB, and $26 \%$ (5 of 19) in $\mathrm{FB}$, to $54 \%$ (32 of 59) in SB ( $p<0.001$ ). Most resumed drinking within 12 months but, despite this, case women who had stopped drinking in pregnancy were 3.3 fold more likely to currently abstain from drinking than those who drank throughout pregnancy (OR=3.3; 95\% $\mathrm{Cl}=1.2-8.9 ; \mathrm{p}=0.005)$.

Fig. 3 gives additional detail about changes in actual amounts drank during pregnancy, compared to pre-pregnancy levels for each site. This was based on information from 121 cases or control drinkers who gave information that was sufficiently detailed and considered reliable by the interviewers. 8 (7\%) women, including one control, started or increased drinking in pregnancy - more often in WB than elsewhere $(p=0.04)$. Among 109 cases, 62 (57\%) either stopped or reduced drinking in pregnancy.

\subsubsection{Current drinking}

Three quarters of cases reported drinking in the past year, much higher than controls $(\mathrm{OR}=5.3 ; 95 \% \mathrm{Cl}=2.6-10.0 ; \mathrm{p}<0.001)$. Most cases were current binge drinkers, with intersite variation in prevalence of least one episode per month (WB 38/50 [76\%], FB 16/20 [80\%], SB 28/51 [55\%]; $p=0.04)$. Virtually all were primarily weekend drinkers, with 67 (50\%), 112 (83\%) and 39 (29\%) of 135 cases drinking on Fridays, Saturdays and Sundays respectively.

\subsubsection{Drinking companions and location}

Most cases and controls drank with friends or family, and at someone's home, with few drinking alone or in public spaces. Frequency of drinking with partners was similar across cases at the different sites, but WB cases more often had a heavy-drinking partner in pregnancy than other sites (37/50 [74\%], $p<0.001)$.

\subsubsection{Mother's perception of her drinking}

A majority of drinkers at all sites had previously tried to reduce drinking. Self-perception of having a drinking problem, however, was low and varied between sites (WB 15/55 [27\%], FB 3/20 [15\%], SB 2/70 [4\%); $p<0.001)$. These figures closely paralleled their perception of need for treatment. 


\subsubsection{Other substance use}

Smoking was much more common among cases than controls, and especially among WB cases (WB 51/51 [100\%]; p<0.001). Other drugs were reported by a small minority.

\subsection{Demographic, socio-economic, reproductive health and anthropometric} characteristics (Table 2)

\subsubsection{Demographics and socio-economics}

As with the SAC population more generally, more than 95\% of women were Afrikaans speaking. There were some inter-site differences between cases, most strikingly between WB and the two urban sites (FB and SB).

Fewer cases than controls were married, with the majority cohabiting in WB $(33 / 63$ [52\%]), but being single parents at the two urban sites (51/92 [55\%]). In WB, educational level was lower, with almost half not having completed primary education (29/62 [47\%]), but there were also lower rates of unemployment (12/66 [18\%]) and of informal housing in this site $(4 / 68$ [6\%]). The inland FB site had particularly high rates of unemployment (18/22 [82\%]) and of informal housing (8/22 [36\%]). Income was low among both cases and controls, although lower in cases (note that the comparison is affected by the time gap between studies).

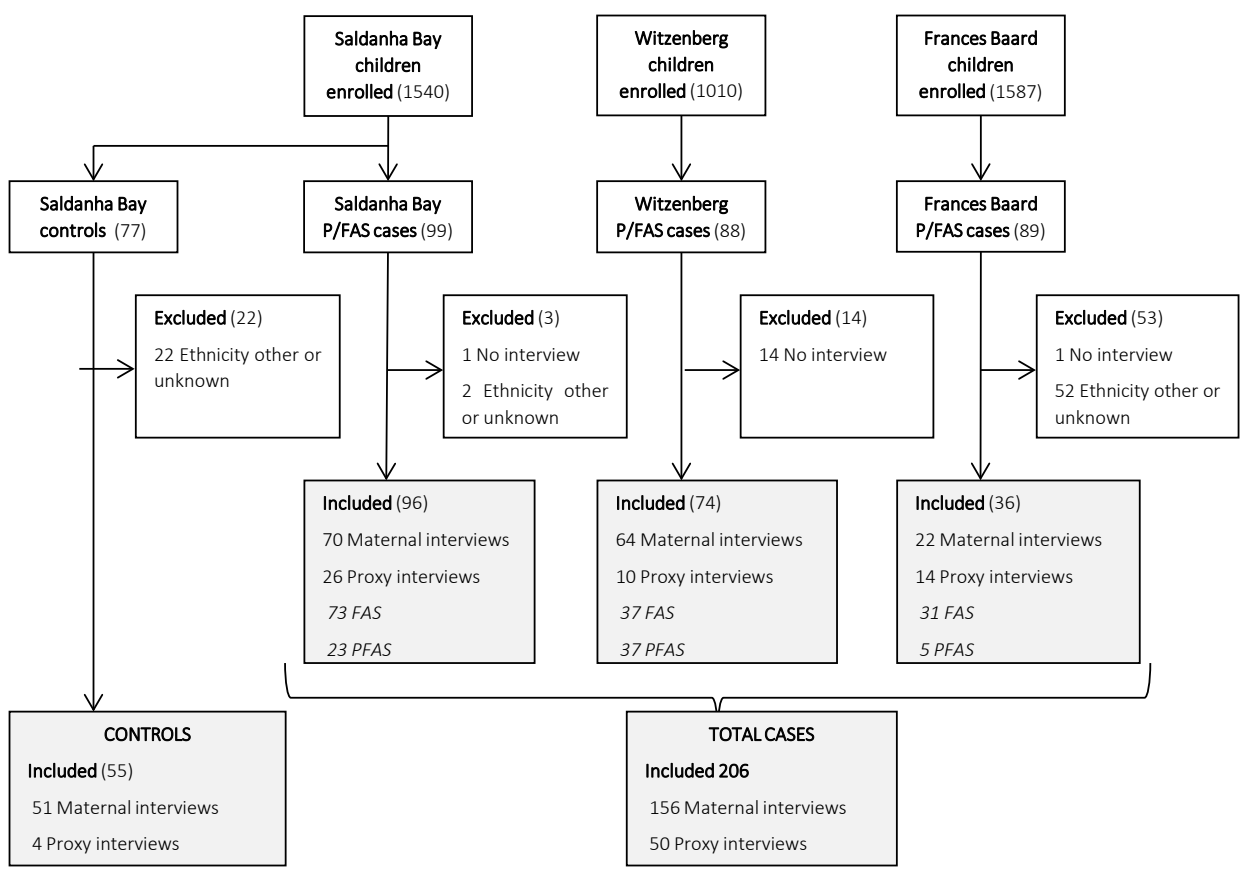

Figure 1. Flowchart of participant selection 


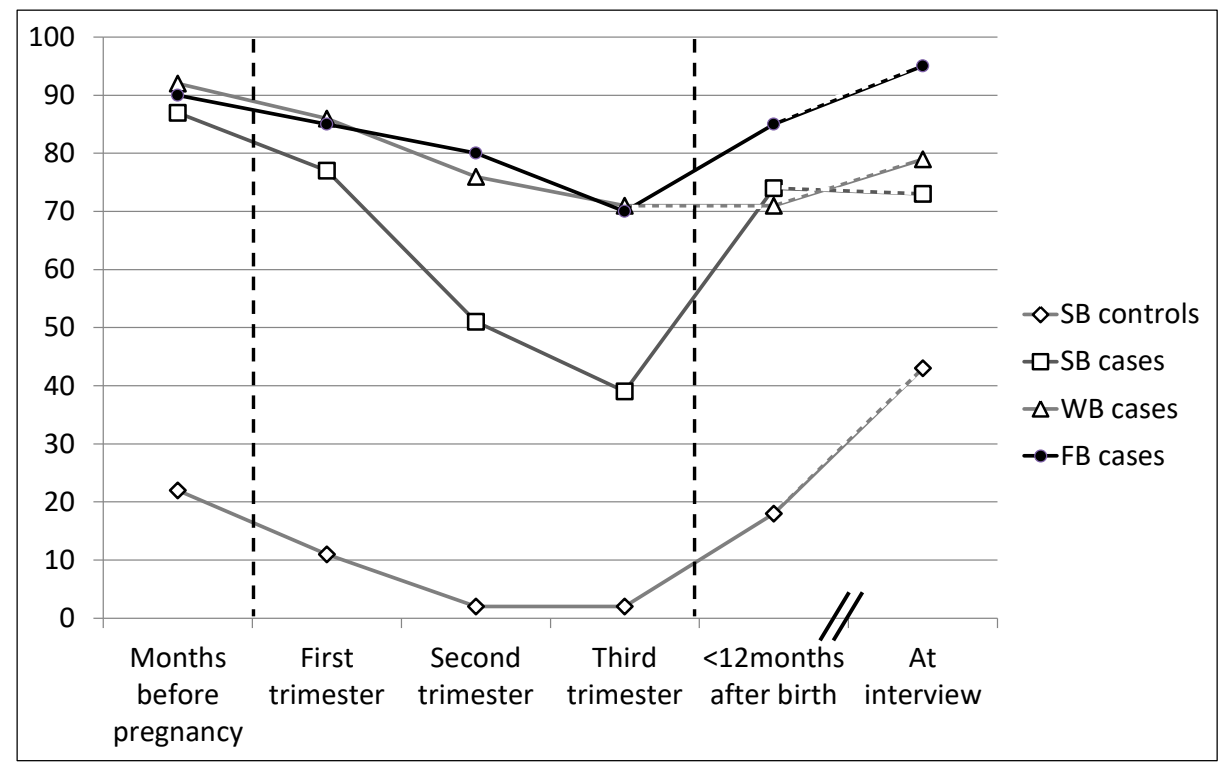

Figure 2. Percentage of women drinking per site, before, during and after pregnancy

Table 1 Alcohol and substance use among control women, and all cases at three sites in South Africa

\begin{tabular}{|c|c|c|c|}
\hline Variable & SB controls ( $N$ & $\begin{array}{l}\text { Total cases } \\
(\mathrm{N}=206)\end{array}$ & $P$ \\
\hline \multicolumn{4}{|l|}{ DRINKING ONSET AND 'DOP' } \\
\hline Ever drank alcohol n/N (\%) & $42 / 51(82 \%)$ & $152 / 156(97 \%)$ & $<0.001$ \\
\hline Mean age initiated drinking (SD) $N$ & $19.4(3.4) 42$ & $18.7(3.4) 139$ & 0.22 \\
\hline Mean age started drinking regular ly(SD) N & $22.7(4.6) 39$ & $21.8(4.7) 130$ & 0.26 \\
\hline Ever received 'Dop' n/N (\%) & $0 / 55(0 \%)$ & $8 / 175(5 \%)$ & 0.20 \\
\hline \multicolumn{4}{|l|}{ DRINKING IN PREGNANCY } \\
\hline Any alcohol in pregnancy $\mathrm{n} / \mathrm{N}(\%)$ & $12 / 51(24 \%)$ & $150 / 170(88 \%)$ & $<0.001$ \\
\hline Stopped drinking in pregnancy & $11 / 12(92 \%)$ & $49 / 139(35 \%)$ & $<0.001$ \\
\hline \multicolumn{4}{|l|}{ Changes in drinking in pregnancy* } \\
\hline Still drinking at end of $1^{\text {st }}$ trimester $\mathrm{n} / \mathrm{N}(\%)$ & $5 / 12(42 \%)$ & $101 / 109(93 \%)$ & $<0.001$ \\
\hline Still drinking at end of $2^{\text {nd }}$ trimester $\mathrm{n} / \mathrm{N}(\%)$ & $1 / 12(8 \%)$ & $84 / 109(77 \%)$ & $<0.001$ \\
\hline Still drinking at end of $3^{\text {rd }}$ trimester $\mathrm{n} / \mathrm{N}(\%)$ & $1 / 12(8)$ & $73 / 109(67 \%)$ & $<0.001$ \\
\hline Reduced drinking by $3^{\text {rd }}$ trimester $\mathrm{n} / \mathrm{N}(\%)$ & $1 / 12(8 \%)$ & $26 / 109(24 \%)$ & 0.30 \\
\hline Unchanged drinking by $3^{\text {rd }}$ trimester $\mathrm{n} / \mathrm{N}(\%)$ & $0 / 12(0 \%)$ & $41 / 109(38 \%)$ & 0.008 \\
\hline Increased at any time in pregnancy n/N (\%) & $1 / 12(8 \%)$ & $7 / 109(6 \%)$ & 0.58 \\
\hline \multicolumn{4}{|l|}{ CURRENT ALCOHOL USE } \\
\hline Alcohol use in past year $\mathrm{n} / \mathrm{N}(\%)$ & $22 / 51(43 \%)$ & $123 / 160(77 \%)$ & $<0.001$ \\
\hline Drinks on $\geq 1$ weekend/month $n / N(\%)^{* *}$ & $7 / 22(32 \%)$ & $82 / 121(68 \%)$ & 0.001 \\
\hline$\geq 4$ drinks per occasion $\mathrm{n} / \mathrm{N}(\%)^{* *}$ & $15 / 20(75 \%)$ & $82 / 117(70 \%)$ & 0.66 \\
\hline Median alcohol units/weekend (IQR) $\mathrm{N}^{* *}$ & $6(3-6) 20$ & $8.3(5-13.5) 120$ & 0.05 \\
\hline
\end{tabular}




\begin{tabular}{|c|c|c|c|}
\hline Variable & SB controls $(\mathrm{N}=$ & $\begin{array}{l}\text { Total cases } \\
(\mathrm{N}=206)\end{array}$ & $P$ \\
\hline \multicolumn{4}{|l|}{ RISK OF AEP: n/N (\%) } \\
\hline At risk & $9 / 51(18 \%)$ & $54 / 151(36 \%)$ & 0.02 \\
\hline At high risk & $4 / 51(8 \%)$ & $41 / 151(27 \%)$ & $<0.001$ \\
\hline \multicolumn{4}{|l|}{ ALCOHOL TYPE } \\
\hline Beer & $11 / 22(50 \%)$ & $88 / 135(65 \%)$ & 0.17 \\
\hline Cider or alcopop & $8 / 22(36 \%)$ & $13 / 135$ (10\%) & 0.001 \\
\hline Wine & $5 / 22(23 \%)$ & $30 / 135(22 \%)$ & 0.96 \\
\hline Spirits & $3 / 22(14 \%)$ & $13 / 135(10 \%)$ & 0.56 \\
\hline Homebrew & $0 / 22(0 \%)$ & 0/135 (0\%) & - \\
\hline \multicolumn{4}{|l|}{ DRINKING COMPANIONS: n/N (\%) } \\
\hline Drinks alone & $1 / 20(5 \%)$ & $12 / 105(11 \%)$ & 0.69 \\
\hline Partner^ & $6 / 36(17 \%)$ & $26 / 83(31 \%)$ & 0.47 \\
\hline Family & $7 / 20(35 \%)$ & $32 / 105(30 \%)$ & 0.69 \\
\hline Friends & $12 / 20(60 \%)$ & $57 / 105(54 \%)$ & 0.64 \\
\hline Partner drank heavily in index pregnancy^ & $8 / 31(26 \%)$ & $50 / 90(56 \%)$ & 0.004 \\
\hline \multicolumn{4}{|l|}{ DRINKING LOCATION: n/N (\%) } \\
\hline At a home & $18 / 18(100 \%)$ & 101/104 (97\%) & 1.0 \\
\hline In tavern & $0 / 20(0 \%)$ & $3 / 104(3 \%)$ & 1.0 \\
\hline Outdoors & $1 / 18(6 \%)$ & $5 / 106(5 \%)$ & 1.0 \\
\hline \multicolumn{4}{|l|}{$\begin{array}{l}\text { MOTHER'S PERCEPTION OF HER DRINKING: } n / N \\
(\%)\end{array}$} \\
\hline Drinking ever a problem & $1 / 51(2 \%)$ & $20 / 145(14 \%)$ & 0.02 \\
\hline Drinking currently a problem & $0 / 51(0 \%)$ & $9 / 141(6 \%)$ & 0.12 \\
\hline Has tried to stop or reduce drinking & $28 / 37(76 \%)$ & $111 / 136(82 \%)$ & 0.42 \\
\hline Ever treated for drinking problem & $0 / 51(0 \%)$ & $1 / 136(1 \%)$ & 1.0 \\
\hline Wants alcohol treatment & $0 / 51(0 \%)$ & $18 / 132(14 \%)$ & 0.004 \\
\hline \multicolumn{4}{|l|}{ OTHER SUBSTANCE USE: n/N (\%) } \\
\hline Smoked in pregnancy & $23 / 51(45 \%)$ & $118 / 141(84 \%)$ & $<0.001$ \\
\hline Ever used drugs other than alcohol & $1 / 50(2 \%)$ & $8 / 140(6 \%)$ & 0.44 \\
\hline
\end{tabular}

*Excludes possible unreliable histories; **Of drinkers; ^If married or cohabiting

SD standard deviation; IQR Interquartile range

\subsubsection{Other social}

In keeping with the predominantly social pattern of drinking, case women were unlikely to be socially isolated, though they were less likely than controls to have a best friend. A majority of case children had either spent an extended period in the care of other relatives or were in foster care. Foster care was much more common in cases than controls $(\mathrm{OR}=7.5,95 \% \mathrm{Cl}=1.3-42 ; \mathrm{p}=0.02)$, and was often due to maternal death. 


\subsubsection{Reproductive health}

Most index pregnancies were unplanned. Pregnancy confirmation and first antenatal visit occurred after the first trimester in $40 \%$ and $48 \%$ of women respectively. At interview, 9 (4\%) of 201 women were pregnant, of whom 5 were drinking. Current use of contraception was similar among drinkers (72/130 [55\%]) and non-drinkers (35/62 [56\%], $p=0.89$ ). Risk of AEP, and high risk of AEP (see Table 1), were over twice and three times higher in cases than controls respectively.

\subsubsection{Anthropometry}

Control women were of relatively short stature, but average BMI was in the obese range. Cases were of much lower mass and BMI than controls. Cases in FB had a particularly low median mass (47kg [IQR 41-60]) and a high prevalence of underweight BMI (9/21 [43\%]). Fourteen percent of case women had a head circumference below the $3^{\text {rd }}$ centile (20/142).

Table 2 Demographic, socio-economic, reproductive and anthropometric characteristics of control women, and women with an affected child, at three sites in South Africa

\begin{tabular}{|c|c|c|c|}
\hline Variables & $\begin{array}{l}\text { SB controls } \\
(\mathrm{N}=55)\end{array}$ & $\begin{array}{l}\text { Total cases } \\
(\mathrm{N}=206)\end{array}$ & $P$ \\
\hline \multicolumn{4}{|l|}{ DEMOGRAPHICS } \\
\hline Median age at birth of index child (IQR) N & $29.3(22.5-34.4) 53$ & $29.0(23.0-33.0) 181$ & 0.73 \\
\hline \multicolumn{4}{|l|}{ Years of education completed: n/N (\%) } \\
\hline $0-6$ years & $8 / 54(14 \%)$ & $53 / 179(30 \%)$ & 0.006 \\
\hline $7-11$ years & $33 / 54(61 \%)$ & $109 / 179(61 \%)$ & \\
\hline$\geq 12$ years & $13 / 54(24.1 \%)$ & $17 / 179(10 \%)$ & \\
\hline Member of religious group $\mathrm{n} / \mathrm{N}(\%)$ & $54 / 54(100 \%)$ & $165 / 180(92 \%)$ & 0.03 \\
\hline \multicolumn{4}{|l|}{ Marital status in index pregnancy: n/N (\%) } \\
\hline Married & $18 / 51(35 \%)$ & $24 / 155(15 \%)$ & \\
\hline Single & 19/51 (37\%) & $66 / 155(43 \%)$ & \\
\hline Cohabiting & $14 / 51(27 \%)$ & $63 / 155(41 \%)$ & \\
\hline Other & $0 / 51(0 \%)$ & $2 / 155(1 \%)$ & 0.02 \\
\hline \multicolumn{4}{|l|}{ SOCIOECONOMIC STATUS } \\
\hline \multicolumn{4}{|l|}{ Employment: n/N (\%) } \\
\hline Fulltime & 19/54 (35\%) & $50 / 165(30 \%)$ & \\
\hline Part time & $8 / 54(15 \%)$ & $24 / 165(15 \%)$ & \\
\hline Seasonal & $7 / 54(13 \%)$ & $18 / 165(11 \%)$ & \\
\hline Unemployed, seeking work & $20 / 54(37 \%)$ & $68 / 165(41 \%)$ & \\
\hline Unemployed, not seeking work & $0 / 54(0 \%)$ & $5 / 165(3 \%)$ & 0.78 \\
\hline $\begin{array}{l}\text { Median monthly household income in ZAR* } \\
\text { (IQR) N }\end{array}$ & $3300(1950-7100) 51$ & $\begin{array}{l}2390(1180-4200) \\
125\end{array}$ & 0.004 \\
\hline \multicolumn{4}{|l|}{ Housing type: n/N (\%) } \\
\hline House & $45 / 51(88 \%)$ & $135 / 159(85 \%)$ & \\
\hline Informal structure & $6 / 51(12 \%)$ & 24/159 (15\%) & 0.55 \\
\hline
\end{tabular}




\begin{tabular}{|c|c|c|c|}
\hline \multicolumn{4}{|l|}{ OTHER SOCIAL } \\
\hline \multicolumn{4}{|l|}{ Friendships } \\
\hline Has a best friend & $41 / 51(80 \%)$ & $90 / 153(59 \%)$ & 0.005 \\
\hline Has no friends at all & $0 / 51(0 \%)$ & $7 / 153(5 \%)$ & 0.12 \\
\hline \multicolumn{4}{|l|}{ Household size: } \\
\hline Median adults in home (IQR) N & $2(1-3) 155$ & $2(1-3) 46$ & 0.87 \\
\hline Median children in home (IQR) N & $2(2-3) 150$ & $3(2-4) 49$ & 0.71 \\
\hline Median years living in home (IQR) & $15(7-15) 51$ & $15(5-25) 151$ & 0.93 \\
\hline \multicolumn{4}{|l|}{ Childcare: $\mathrm{n} / \mathrm{N}(\%)$} \\
\hline Child in formal foster care & $1 / 55(2 \%)$ & $25 / 206(12 \%)$ & 0.01 \\
\hline $\begin{array}{l}\text { Child cared for by relatives for extended peri- } \\
\text { ods }\end{array}$ & $13 / 54(24 \%)$ & $80 / 181(44 \%)$ & 0.02 \\
\hline Mother deceased n/N (\%) & $1 / 55(2 \%)$ & $15 / 206(7 \%)$ & 0.21 \\
\hline \multicolumn{4}{|l|}{ REPRODUCTIVE HEALTH } \\
\hline Mean times pregnant (SD) $\mathrm{N}$ & $3.7(1.7) 51$ & $3.5(1.6) 158$ & 0.33 \\
\hline Mean live births (SD) $\mathrm{N}$ & $3.4(1.8) 51$ & $2.9(1.6) 150$ & 0.08 \\
\hline Index pregnancy unplanned n/N (\%) & $33 / 51(65 \%)$ & $118 / 156(76 \%)$ & 0.13 \\
\hline $\begin{array}{l}\text { Median gestation at pregnancy confirmation } \\
\text { [months] (IQR) N }\end{array}$ & $3(1-4) 50$ & $3(3-5) 146$ & 0.07 \\
\hline $\begin{array}{l}\text { Median gestation at 1st antenatal visit } \\
\text { [months] (IQR) N }\end{array}$ & $4(2-5) 50$ & $3(3-5) 146$ & 0.56 \\
\hline Current use of contraception n/N (\%) & 29/49 (59\%) & $78 / 146(53 \%)$ & 0.48 \\
\hline \multicolumn{4}{|l|}{ ANTHROPOMETRY } \\
\hline Median height (IQR) $[\mathrm{cm}] \mathrm{N}$ & $157.5(152-162) 48$ & $155(150-158) 148$ & 0.03 \\
\hline Height $<3^{\text {rd }}$ centile $n / N(\%)$ & $10 / 48(21 \%)$ & $40 / 147(27 \%)$ & 0.38 \\
\hline Median mass (IQR) $[\mathrm{kg}] \mathrm{N}$ & $76(58-83) 51$ & $54(45-70) 148$ & $<0.001$ \\
\hline Mass $<3^{\text {rd }}$ centile $n / N(\%)$ & $3 / 51(6 \%)$ & $34 / 148(23 \%)$ & 0.006 \\
\hline Median BMI (IQR) $\left[\mathrm{kg} / \mathrm{m}^{2}\right] \mathrm{N}$ & $30.0(23.7-32.7) 48$ & $23.0(19.6-28.8) 147$ & $<0.001$ \\
\hline $\mathrm{BMI}<18.5 \mathrm{~kg} / \mathrm{m}^{2}$ & $4 / 48(8 \%)$ & $29 / 146(20 \%)$ & 0.08 \\
\hline Median head circumference (IQR) $[\mathrm{cm}] \mathrm{N}$ & $55(53.8-57) 46$ & $54(53-55.5) 142$ & 0.002 \\
\hline Head circumference $<3^{\text {rd }}$ centile $n / N(\%)$ & $3 / 46(7 \%)$ & $20 / 142(14 \%)$ & 0.17 \\
\hline
\end{tabular}

SD standard deviation; IQR Interquartile range; ZAR = South African Rands

\section{Discussion}

This study compares mothers of over 200 children with P/FAS with control women, and extends knowledge of P/FAS prevalence, maternal drinking practices and other risk factors for P/FAS in a highly vulnerable population. Controls displayed similar drinking rates (ever, current and binge episodes) to those in a recent population-based study among rural women of the same district (SB) (Morojele et al., 2010), suggesting that their drinking rates are representative of the area's general population. The prevalence of P/FAS was above $5 \%$ in all three sites, although highest at the WB site, which was 
expected, as it is a more rural site and situated in the Cape Winelands - both factors considered major risks for FAS.

Two aspects of women's drinking that are especially pertinent to P/FAS risk are frequency of binge drinking and whether the woman stops drinking in pregnancy. Our study sheds light on cessation versus continuation of drinking during pregnancy, as well as changes in the volume drank during pregnancy. Over $90 \%$ of control women reported cessation in pregnancy, compared to only a third to a half of P/FAS women. Rates of cessation of drinking among control women are comparable to reductions of binge drinking found among pregnant women in other populations outside South Africa (Fortin et al., 2015; Balachova et al., 2011). Stopping or reducing drinking is clearly important, but the presence of P/FAS in case children whose mothers had stopped, demonstrates that it is often 'too little, too late', in part because of delayed recognition of pregnancy.



Figure 3. Women's drinking patterns in each pregnancy trimester, compared to pre-pregnancy, by site

Sites with higher rates of cessation showed greater increases in drinking after pregnancy, with prevalence of drinking returning to high levels in cases and increasing among controls. This replicates a trend reported internationally (Substance Abuse and Mental Health Services Administration, 2009). More encouraging was the fact that cessation in pregnancy was associated with less likelihood of drinking at the time of interview, and may therefore predict reduced drinking in the longer term. Pregnancy may thus be a key opportunity to secure long-term cessation of drinking. This warrants investigation. Despite this, ongoing binge drinking, together with limited use of contraception meant that, when interviewed, 1 in 4 cases and 1 in 12 controls were vulnerable to high-risk AEP.

It is likely that inter-site variations in cessation relate in part to levels of awareness of the risks of drinking in pregnancy. Increasing efforts are being made to educate the public about such risks, especially in urban areas of the Western Cape Province. The fact that the surveys show increasing rates of cessation in the chronological order of the 
surveys is also consistent with growing awareness over time. A similar temporal trend was also noted in a separate series of FAS prevalence surveys in the Cape Winelands (May et al., 2000, 2007; Viljoen et al, 2005; May et al, 2013a). An alternative interpretation is that women more frequently report a reduction in drinking during pregnancy due to growing stigma. We think this is less likely, since our findings are compatible with a previous South African study showing that an awareness-raising intervention can lower rates of P/FAS in infants (Chersich et al., 2012).

In terms of shifts in the volume of alcohol consumed during pregnancy, a small minority of women, especially at WB, increased drinking in pregnancy. Our participants' free text comments support the contention of Watt et al. (2014) that stress and unwanted pregnancy contribute to this: of eight women increasing drinking, five reported being 'very' or 'extremely' stressed during pregnancy. All were farm labourers, which we think is important, because pregnant female farm workers are a particularly vulnerable and disempowered group (Kehler, 2001). Also, although strict enforcement is believed to have eliminated 'Dop' (Gossage et al., 2014), the fact that 'Dop' was previously received by some in the WB site suggests that ongoing vigilance is required.

Smoking prevalence was lower in the later studies, perhaps indicating that public health measures such as increased pricing are having an effect. Infrequent use of other drugs probably relates to alcohol use not being historically linked to drugs in these regions, though this is changing in metropolitan areas (Myers et al., 2014).

The predominantly social pattern of drinking - together with partners, family or friends - is well described in South African settings (London, 1999; Watt et al., 2014). We concur with Watt et al. (2014) that women in this population probably drink to retain social connections, though the quality of these connections is unclear - drinkers were less likely to have a 'best friend'. Few women drank in taverns or other public venues, suggesting that venue-based interventions may have limited impact.

Despite ongoing binge drinking, relatively few perceived this as a problem, reducing the likelihood of change or of entering harm reduction services. There was inter-site variation in levels of concern about drinking, with hardly any SB women perceiving it to be a problem. Women at this site were also more likely to stop drinking in pregnancy, and to restart afterwards. We hypothesize that this pattern is consistent with women being more aware of FAS as a problem, but less concerned about other personal risks of drinking.

Case children were much more likely than controls to have been placed in foster care, or to have spent prolonged periods with relatives. While relatives often play a role in childcare in South Africa, formal placement in foster care was a strong marker for FAS at all sites. This is well described elsewhere (Lange et al., 2013), but has not been evident in previous South African studies, and may reflect improving social services.

The background of low income, unemployment and poor education was common to most case women. The rural WB site showed particularly low educational levels, but higher rates of employment (though often seasonal or part time), which is consistent 
with the fact that most women at this site were farm labourers (London, 2003). The inland FB site showed relatively higher levels of education and household income, but this income was eroded by larger household size and several markers of deprivation were evidence: more frequent unemployment, informal housing, and high prevalence of $\mathrm{BMI}$ in the underweight range.

Control subjects had a mean BMI in the obese range - a finding that is consistent with the rapidly increasing prevalence of obesity in South Africa, particularly among poor, urban females (Kruger et al., 2005). The high prevalence of underweight among cases, especially at the FB site, heightens their vulnerability. It is an independent risk factor for poor pregnancy outcomes (Rahman et al., 2015) and for lower developmental function in children (May et al., 2013b). In addition, body weight affects alcohol metabolism (Khaole et al, 2004) among other morbidities. For these reasons, nutritional interventions may be important for future P/FAS prevention initiatives. This could include state support during pregnancy as provided in a multitude of countries (Murray et al., 2012), enabling women to improve the quantity and quality of their food intake during pregnancy.

\subsection{Limitations}

Interviewers questioned the reliability of a minority of interviews. However, the proportion of case women who denied using alcohol in pregnancy was somewhat higher than in previous South African studies (May et al., 2005). It is possible that a small proportion of cases were misclassified as P/FAS, or that responses may indicate social desirability bias or recall bias. Recall may be affected by binge drinking, and by the 7-8year interval between the index pregnancy and the interview, though there is evidence to support the validity of retrospective methods to detect alcohol use (Hannigan et al., 2010).

A control group was only available for one site, but nevertheless provided an important point of comparison. Also, because most available interview data pertained to women in the mixed ancestry SAC group, and because ethnicity is a determinant of drink-related harm (Chartier et al., 2013), we decided to restrict our focus to this group. Although P/FAS is present in other South African populations (Urban et al., 2015) it is likely that our findings are not generalizable to these groups, because of variation in drinking practices (O'Connor et al., 2014) and other factors affecting alcohol-related harm.

\subsection{Conclusions and implications for intervention}

This study extends knowledge of maternal drinking practices and risk factors for P/FAS in a high risk South African population: the prevalence of P/FAS was in excess of $5 \%$ at all 3 study sites. 


\section{Article 4}

Between the time of pregnancy and the interview 7-8 years later, the prevalence of maternal drinking remained high in cases and increased in controls, usually in a weekend binge-drinking pattern. During pregnancy, most controls and some cases stopped drinking, although this did not necessarily prevent P/FAS, perhaps in part due to delayed recognition of pregnancy. Although cessation in pregnancy was often followed by recidivism in the year thereafter, it was associated with lower prevalence of drinking in the longer term.

Given that a significant proportion of high-risk drinkers contemplate stopping or reducing drinking in pregnancy, we recommend that selective interventions target antenatal care, and that early initiation of antenatal care be strongly promoted. However, interventions should continue into the puerperium, encompass a focus on contraception and take into account that most women do not consider their drinking a problem. These features could be incorporated into broader health promotion interventions targeting pregnancy and early childhood, such as the community health worker program being developed in South Africa (Tomlinson et al., 2016).

\section{Conflict of interest}

No conflict declared.

\section{Role of funding source}

Nothing declared.

\section{Acknowledgements}

We thank the district and provincial Departments of Social Development in the Northern and Western Cape Provinces for funding the surveys, the Departments of Education for the ethical approval and support, and the Departments of Health for case management of referrals. Special thanks to the parents and learners who participated, and to the FARR field workers and support staff who worked on the surveys. 


\section{References}

Abel, E.L., Hannigan, J.H., 1995. Maternal risk factors in fetal alcohol syndrome: provocative and permissive influences. Neurotoxicol. Teratol. 17, 445-462, http://dx.doi:10.1016/0892-0362(95)98055-6.

Balachova, T., Bonner, B., Chaffin, M., Bard, D., Isurina, G., Tsvetkova, L., Volkova, E., 2011. Women's alcohol consumption and risk for alcohol-exposed pregnancies in Russia. Addiction 107, 109-117.

Balachova, T., Sobell, L.C., Agrawal, S., Isurina, G., Tsvetkova, L., Volkova, E., Bohora, S., 2015. Using a single binge drinking question to identify Russian women at risk for an alcohol-exposed pregnancy. Addict. Behav. 46, 53-57, http://dx.doi:10.1016/j.addbeh.2015.03.003.

Chartier, K., Vaeth, A.C., Caetano, R., 2013. Focus on: ethnicity and the social and health harms from drinking. Alcohol Res. 35, 229-237.

Centers for Disease Control, 2005. CDC clinical growth charts. Available at: http://www.cdc.gov/growthcharts/. Accessed January 30, 2016.

Chersich, M.F., Urban, M., Olivier, L., Davies, L., Chetty, C., Viljoen, D., 2012. Universal prevention is associated with lower prevalence of fetal alcohol spectrum disorders in Northern Cape, South Africa: a multicentre before-after study. Alcohol Alcohol. 47, 67-74, http://dx.doi:10.1093/alcalc/agr145.

Department of Health and Medical Research Council, 2007. South Africa Demographic and Health Survey 2003. Dep. Heal. Pretoria. Available at: http://www.mrc.ac.za/bod/sadhs.htm. Accessed December 5, 2015.

Floyd, R.L., Weber, M.K., Denny, C., O'Connor, M.J., 2009. Prevention of fetal alcohol spectrum disorders. Devel. Disabil. Res. Rev. 15, 193-199, http://dx.doi: 10.1002/ddrr.75.

Fortin, M., Muckle, G., Anassour-Laouan-Sidi, E., Jacobson, S.W., Jacobson, J.L., Bélanger, R.E., 2015. Trajectories of alcohol use and binge drinking among pregnant Inuit women. Alcohol Alcohol. 51, 339-346, http://dx.doi:10.1093/alcalc/agv112.

Gossage, J.P., Snell, C., Parry, C.D.H., Marais, A.S., Barnard, R., de Vries, M., Blankenship, J., Seedat, S., Hasken, J.M., May, P.A., 2014. Alcohol use, working conditions, job benefits and the legacy of the "Dop" system among farm workers in the Western Cape Province, South Africa: hope despite high levels of risky drinking. Int. J. Env. Res. Public Heal. 11, 7406-7424, http://dx.doi: 10.3390/ijerph110707406.

Hannigan, J.H., Chiodo, L.M., Sokol, R.J., Janisse, J., Ager, J., Greenwald, M.K., Delaney-Black, V., 2010. A 14 year retrospective maternal report of alcohol consumption in pregnancy predicts pregnancy and teen outcomes. Alcohol 44, 583-594, http://dx.doi: 10.1016/j.alcohol.2009.03.003.

Hoyme, H.E., May, P.A., Kalberg, W.O., Kodituwakku, P., Gossage, J.P., Trujillo, P.M., Buckley, D.G., Miller, J.H., Aragon, A.S., Khaole, N., Viljoen, D.L., Jones, K.L., Robinson, L.K, 2005. A practical clinical approach to diagnosis of fetal alcohol spectrum disorders: clarification of the 1996 Institute of Medicine criteria. Pediatrics 115, 39-47, http://dx.doi:10.1542/peds.2004-0259.

Kehler, J., 2001. Women and poverty: the South African experience. J. Int. Women's Stud. 3, 41-53.

Khaole, N.C.O., Ramchandani, V.A., Viljoen, D.L., Li, T. A pilot study of alcohol exposure and pharmacokinetics in women with or without children with fetal alcohol syndrome. Alcohol Alcohol. 39: 503-508, http://dx.doi.org/10.1093/alcalc/agh089.

Kruger, H.S., Puoane, T., Senekal, M., van der Merwe, M., 2005. Obesity in South Africa: challenges for government and health professionals. Public Health Nutr. 8, 491-500, http://dx.doi: 10.1079/PHN2005785.

Lange, S., Shield, K., Rehm, J., Popova, S., 2013. Prevalence of fetal alcohol spectrum disorders in child care settings: a meta-analysis. Pediatrics 132, 980-995, http://dx.doi:10.1542/peds.2013-0066.

London, L., 1999. The "dop" system, alcohol abuse and social control amongst farm workers in South Africa: a public health challenge. Soc. Sci. Med. 48, 1407-1414, http://dx.doi:10.1016/S0277-9536(98)00445-6.

London, L., 2003. Health of farm workers in South Africa. Int. J. Occup. Environ. Health 9, 59-68.

May, P.A., Blankenship, J., Marais, A., Gossage, J.P., Kalberg, W.O., Barnard, R., De Vries, M., Robinson, L.K., Adnams, C.M., Buckley, D., Manning, M., Jones, K.L., Parry, C., Hoyme, H.E., Seedat, S., 2013a. Approaching the prevalence of the full spectrum of fetal alcohol spectrum disorders in a South African populationbased study. Alcohol. Clin. Exp. Res. 37, 818-830, http://dx.doi:10.1111/acer.12033. 
May, P.A., Brooke, L., Gossage, J.P., Croxford, J., Adnams, C., Jones, K.L., Robinson, L., Viljoen, D., 2000. Epidemiology of fetal alcohol syndrome in a South African community in the Western Cape Province. Am. J. Public Health 90, 1905-1912, http://dx.doi:10.2105/ajph.90.12.1905.

May, P.A., Gossage, J.P., 2011. Maternal risk factors for fetal alcohol spectrum disorders. Alcohol Res. Heal. 34, 15-26.

May, P.A., Gossage, J.P., Brooke, L.E., Snell, C.L., Marais, A.S., Hendricks, L.S., Croxford, J.A., Viljoen, D.L., 2005. Maternal risk factors for fetal alcohol syndrome in the Western Cape Province of South Africa: a population-based study. Am. J. Public Health 95, 1190-1199, http://dx.doi: 10.2105/AJPH.2003.037093.

May, P.A., Gossage, J.P, Marais, A., Adnams, C.M., Hoyme, H.E., Jones, K.L., Robinson, L.K., Khaole, N.C.O., Snell, C., Kalberg, W.O., Hendricks, L., Brooke, L., Stellavato, C., Viljoen, D.L., 2007. The epidemiology of fetal alcohol syndrome and partial FAS in a South African community. Drug Alcohol Depend. 88, 259-71, http://dx.doi:10.1016/j.drugalcdep.2006.11.007.

May, P.A., Tabachnick, B.G., Gossage, J.P., Kalberg, W.O., Marais, A., Robinson, L.K., Manning, M.A., Blankenship, J., Buckley, D., Hoyme, H.E., Adnams, C.M., 2013b. Maternal factors predicting cognitive and behavioral characteristics of children with fetal alcohol spectrum disorders. J. Dev. Behav. Pediatr. 34, 314325, http://dx.doi:10.1097/DBP.0b013e3182905587.

Morojele, N.K., London, L., Olorunju, S.A., Matjila, M.J., Davids, A.S., Rendall-Mkosi, K.M., 2010. Predictors of risk of alcohol-exposed pregnancies among women in an urban and a rural area of South Africa. Soc. Sci. Med. 70, 534-542, http://dx.doi:10.1016/j.socscimed.2009.10.040.

Murray, S.F., Hunter, B.M., Bisht, R., Ensor, T., Bick, D., 2012. Demand-side financing measures to increase maternal health service utilisation and improve health outcomes: a systematic review of evidence from low- and middle-income countries. JBI Library of Systematic Reviews JBL000592 10(58), 4165-4567.

Myers, B., Kline, T.L., Doherty, I.A., Carney, T., Wechsberg, W.M., 2014. Perceived need for substance use treatment among young women from disadvantaged communities in Cape Town, South Africa. BMC Psychiatry 14:100, http://dx.doi:10.1186/1471-244X-14-100.

National Institute on Alcoholism and Alcohol Abuse, 2005. Helping patients who drink too much: a clinician's guide, updated 2005 edition. http://pubs.niaaa.nih.gov/publications/Practitioner/CliniciansGuide2005/guide.pdf. Accessed 21 August 2016.

Nellhaus, G., 1968. Head circumference from birth to eighteen years. Practical composite international and interracial graphs. Pediatrics 41, 106-114.

O'Connor, M.J., Rotheram-Borus, M.J., Tomlinson, M., Bill, C., LeRoux, I.M., Stewart, J., 2014. Screening for Fetal Alcohol Spectrum Disorders by nonmedical community workers. Journal of Population Therapeutics and Clinical Pharmacology, 21 (3): 442-452.

Rahman, M.M., Abe, S.K., Kanda, M., Narita, S., Rahman, M.S, Bilano, V., Ota, E., Gilmour, S., Shibuya, K., 2015. Maternal body mass index and risk of birth and maternal health outcomes in low- and middle-income countries: a systematic review and meta-analysis. Obes. Rev. 16, 758-770, http://dx.doi: 10.1111/obr.12293.

Ramsoomar, L., Morojele, N., 2012. Trends in alcohol prevalence, age of initiation and association with alcohol-related harm among South African youth: Implications for policy. S. Afr. Med. J. 102, 609-612.

Rendall-Mkosi, K., Morojele, N., London, L., Moodley, S., Singh, C., Girdler-Brown, B., 2013. A randomized controlled trial of motivational interviewing to prevent risk for an alcohol-exposed pregnancy in the Western Cape, South Africa. Addiction 108, 725-732, http://dx.doi: 10.1111/add.12081.

Sobell, L.C., Agrawal, S., Annis, H., Ayala-Velasquez, H., Echeverria, L., Leo, G.I., Rybakowski, J.K., Sandahl, C., Saunders, B., Thomas, S., Zioikowski, M., 2001. Cross-cultural evaluation of two drinking assessment instruments: alcohol timeline follow-back and inventory of drinking situations. Subst. Use Misuse 36, 313331, http://dx.doi: 10.1081/JA-100102628.

Statistics South Africa., 2012. Census 2011 in brief. Stat. South Africa, Pretoria.

Substance Abuse and Mental Health Services Administration, Office of Applied studies., 2009. The NSDUH report: Substance use among women during pregnancy and following childbirth. Rockville, MD.

Tomlinson, M., Rotheram-Borus, M.J., Le Roux, I.M., Youssef, M., Nelson, S., Scheffler, A., Weiss, R., O'Connor, M.J., Worthman, C.M., 2016. Thirty-six-month outcomes of a generalist paraprofessional perinatal home 
visiting intervention in South Africa on maternal health and child health and development, Prevention Science, DOI 10.1007/s11121-016-0676-X

Urban, M., Chersich, M.F., Fourie, L., Chetty, C., Olivier, L., Viljoen, D., 2008. Fetal alcohol syndrome among grade 1 schoolchildren in Northern Cape Province: prevalence and risk factors. S. Afr. Med. J. 98, 877882.

Urban, M.F., Olivier, L., Viljoen, D., Lombard, C., Louw, J.G., Drotsky, L., Temmerman, M., Chersich, M.F., 2015. Prevalence of fetal alcohol syndrome in a South African city with a predominantly black African population. Alcohol. Clin. Exp. Res. 39, 1016-1026, http://dx.doi: 10.1111/acer.12726.

Viljoen, D., Craig, P., Hymbaugh, K., Boyle, C., Blount, S., 2003. Fetal alcohol syndrome - South Africa 2001. Morb. Mortal. Wkly. Rep. 52, 660-662.

Viljoen, D., Croxford, J., Gossage, J.P., Kodituwakku, P.W., May, P.A., 2002. Characteristics of mothers of children with fetal alcohol syndrome in the Western Cape Province of South Africa: a case control study. J. Stud. Alcohol 63, 6-17.

Viljoen, D., Gossage, J.P., Brooke, L., Adnams, C.M., Jones, K.L., Robinson, L.K., Hoyme, H.E., Snell, C., Khaole, N.C.O., Kodituwakku, P., Asante, K.O., Findlay, R., Quinton, B., Marais, A.S., Kalberg, W.O., May, P.A., 2005. Fetal alcohol syndrome epidemiology in a South African community: a second study of a very high prevalence area. J. Stud. Alcohol 66, 593-604.

Watt, M.H., Eaton, L.A., Choi, K.W., Velloza, J., Kalichman, S.C., Skinner, D., Sikkema, K.J., 2014. "It's better for me to drink, at least the stress is going away": Perspectives on alcohol use during pregnancy among South African women attending drinking establishments. Soc. Sci. Med. 116, 119-125, http://dx.doi:10.1016/j.socscimed.2014.06.048. 



\section{Article}

\section{Nocturnal incontinence in children with fetal alcohol spectrum disorders (FASD) in a South African cohort}

Published as:

Roozen, S.*, Olivier, L.*, Nemczyk, J., von Gontard, A., Peters, G.Y., Kok, G., Viljoen, D., Curfs, L. (2017) Nocturnal incontinence in children with fetal alcohol spectrum disorders (FASD) in a South African cohort. Journal of Pediatric Urology, 13(5), 496.e1-496.e7.

*equal contribution 


\section{Absract}

Introduction Fetal alcohol spectrum disorders (FASD) are one of the leading preventable causes of intellectual disabilities (ID). Not much is known about the topic of pediatric incontinence related to FASD, for example nocturnal enuresis (NE), daytime urinary incontinence (DUI), and fecal incontinence (FI). So far, in-continence problems have been examined among children with other specific syndromes.

Objective The aim of the present study is to investigate the possible presence of incontinence among children with FASD in a South African cohort.

Study design The South African version of the combined questionnaire including the "Parental Questionnaire: Enuresis/Urinary Incontinence" and "Encopresis Questionnaire - Screening Version"; and lower urinary tract symptoms (LUTS) were assessed by the "International-Consultation-on-Incontinence-Questionnaire - Pediatric Lower Urinary Tract Symptom" (ICIQ-CLUTS) among 99 interviewees (e.g. mothers, grandparents) of children with FASD. Moreover, scores on the "Griffiths Mental Development Scales Extended Revised" (GMDS-ER) were obtained of all included children for further statistical analysis.

Results The overall incontinence rate was 20\% $(n=20)$, in children diagnosed within the FASD spectrum (fetal alcohol syndrome or FAS $n=17$, partial fetal alcohol syndrome or pFAS, $n=1$, alcohol related neuro-developmental disorder or ARND $n=2)$. NE affected $16 \%(n=16)$ of children with a FASD (FAS $n=13$, pFAS $n=1$, and ARND $n=2)$. DUI was reported in one child (FAS), and FI in $4 \%(n=4)$ of children (again, only FAS). No indication of lower urinary tract symptoms (LUTS) in the clinical range was re-ported (sample mean score $=5.17$ ). Based on the GMDS-ER, $88 \%$ of the children scored lower than 10th percentile.

Discussion This is a first study to examine the problems of incontinence among children diagnosed within the spectrum of FASD. The rates for children with a FASD are lower than the rates for many children with special needs, but much higher than for typically developing children. Children with a FASD are mainly affected by NE.

Conclusion The problem of incontinence among children with a FASD in South Africa needs to be assessed and considered for clinical management. Future research is necessary to examine problems of in-continence in relation to cognitive and behavioral functioning among children with a FASD, as well as identifying possible causes.

Keywords: Fetal alcohol syndrome; Fetal alcohol spectrum disorder(s); Daytime urinary incontinence; Nocturnal enuresis; Fecal incontinence 


\section{Abbreviations}

$\begin{array}{ll}\text { ARBD } & \text { alcohol-related birth defects } \\ \text { ARND } & \text { alcohol-related neurodevelopmental disorders } \\ \text { CI } & \text { confidence interval } \\ \text { CNS } & \text { central nervous system } \\ \text { DUI } & \text { daytime urinary incontinence } \\ \text { FAS } & \text { fetal alcohol syndrome } \\ \text { FASD } & \text { fetal alcohol spectrum disorders } \\ \text { FI } & \text { fecal incontinence } \\ \text { GMDS-ER } & \text { Griffiths Mental Development Scales e Extended Revised } \\ \text { GQ } & \text { general quotient } \\ \text { ICCS } & \text { International Children's Continence Society } \\ \text { ICIQ-CLUTS } & \text { International-Consultation-on-Incontinence-Questionnaire - Pediatric } \\ & \text { Lower Urinary Tract Symptom } \\ \text { ID } & \text { intellectual disabilities } \\ \text { LUTS } & \text { lower urinary tract symptoms } \\ \text { NE } & \text { nocturnal enuresis } \\ \text { PFAS } & \text { partial fetal alcohol syndrome }\end{array}$

\section{Introduction}

Fetal alcohol spectrum disorders (FASD) are the most common preventable causes of developmental disabilities. FASD is an all-compassing term for disorders caused by prenatal alcohol consumption including the diagnosis of fetal alcohol syndrome (FAS), partial fetal alcohol syndrome (pFAS), alcohol related neurodevelopmental disorder (ARND), and alcohol related birth defects (ARBD). Potential consequences of FASD are abnormalities in the central nervous system (CNS). These may include structural (e.g. small head circumference), neurological, or functional deficits (e.g. poor executive functioning, motor functioning delays, poor social skills, poor decision making, or memory deficits) [1,2]. Global prevalence estimates range from 0 to 176.77 per 1000 livebirths [3]. To date, there are no data available on incontinence in children and adolescents, although this has been described as a problem area for children diagnosed within the spectrum of FASD $[4,5]$.

According to the International Children's Continence Society (ICCS), non-organic urinary incontinence is defined by an intermittent loss of urine in a child aged 5 years or older with a frequency of at least once a month e after organic causes have been ruled out [6]. If it occurs during sleep it is called nocturnal enuresis (or just enuresis) (NE), and if it manifests during the daytime, daytime urinary incontinence (DUI). Many different subtypes can be differentiated. Fecal incontinence $(\mathrm{FI})$ is defined by the passage of stool 
in inappropriate places in a similar way, but is considered to be a condition from the age of 4 years onwards $[7,8]$. Approximately $10 \%$ of typically developing children aged 7 years have NE, 2-3\% DUI, and 1-3\% FI $[9,10]$. The rates of all types of incontinence are much higher in children with special needs [11]. In individuals with intellectual disability (ID), the rates of incontinence are inversely related to intelligence, that is the more severe the ID, the higher the likelihood of being affected by incontinence [12]. However, there are differences in rates and types of incontinence from one syndrome to another [11].

Children who suffer from incontinence may develop adverse psychological and social consequences which have an impact on quality of life [13]. Incontinence in children with special needs is not just distressing for the children themselves, but also a burden for parents and caregivers.

Because children diagnosed within the spectrum of FASD may present with a broad array of behavioral and neuro-developmental impairments, it is suggested that problems of incontinence are also present among children with a FASD. As no study results are available on incontinence among children with a FASD, the aim of the present study is to assess incontinence among a cohort of South African children diagnosed with a FASD.

\section{Materials and methods}

\section{Ethics}

The research project received approval from the Maastricht University ethics committee with reference number ECP-04-09-2012.

\section{Materials}

Incontinence was assessed by a combined questionnaire including the "Parental Questionnaire: Enuresis/Urinary Incontinence" [14] and "Encopresis Questionnaire - Screening Version" [15]. Lower urinary tract symptoms (LUTS) were assessed by the "International-Consultation-on-Incontinence-Questionnaire - Pediatric Lower Urinary Tract Symptom" (ICIQ-CLUTS) [16]. The ICIQ-CLUTS is validated in three languages (English, Italian, and German; [16]) but not yet in a South African language. The 10 questions of the ICIQ-CLUTS build a LUTS score with clinically relevant scores over 13 . According to the ICCS, NE and DUI were diagnosed in persons older than 5 years when wetting occurs at least once per month. According to DSM-5, FI was diagnosed from the age of 4 years when soiling occurs at least once per month. Overall incontinence was considered to be present if any subtype of incontinence is present. Moreover, less commonly reported problems of incontinence were described. 
To use this questionnaire in this community, it was translated to the appropriate South African language in this community, followed by a back-translation. Small culture relevant adjustments have been made in wording (e.g. "diaper" was replaced by "underwear" as no diapers are being used in this community). Moreover, scores based on the "Griffiths Mental Development Scales - Extended Revised" (GMDS-ER) were included for all subjects [17]. The GMDS-ER measures the mental development of children aged between 2 and 8 years based on six subscales including locomotor (subscale A), personal-social (subscale B), language (subscale $\mathrm{C}$ ), eye and hand coordination (subscale $D$ ), performance (subscale E), and practical reasoning (sub-scale F). Raw scores were computed for each individual subscale and were converted to a standard score (using zscores and General Quotient) representing a developmental score of the children.

\section{Study area and population}

The study was conducted in a peri-urban area in the Eastern Cape Province, South Africa and followed a FASD prevalence study [18]. This area has a total population of 182,012 inhabitants from the following cultural groups: $64.4 \%$ mixed ancestry, $34.1 \%$ black, $0.2 \%$ white, $0.6 \%$ Asian/Indian, and other $0.8 \%$. The residence in this area faces many challenges such as poverty, high level of unemployment, recurrent political unrest, and limited health services [19]. The FASD prevalence study was aimed at firstgrade children in this area. Out of 1928 consenting children (from 2455), 244 received a FAS, pFAS, ARND, or ARBD diagnosis. Resource limitations (e.g. accessibility) meant it was not possible to include all these children. Hence, a total sample of 99 parents or guardians of these 244 diagnosed first-graders was randomly selected.

\section{Methods}

Two trained community workers visited all 99 consenting parents or guardians at home to complete the parental questionnaire on incontinence and the structured interviews, thereby overcoming challenges in terms of illiteracy, motivation, and completion of the questionnaires.

\section{Statistical analysis}

Study data were collected and managed using REDCap electronic data capture hosted at the Foundation for Alcohol Related Research (FARR) [20]. The research coordinator verified the captured data by the project manager for a randomly selected sample of questionnaires. Thereafter, data from the parental questionnaires were further processed by the SPSS software package version 22.0 (IBM Corp, IBM SPSS Statistics for Windows, 2013) and R version 3.2.3 (R Development Core Team. R: A Language and Environment for Statistical Computing, 2016). LUTS scores were calculated whereby a 
score above 13 was regarded as clinically relevant. Additional data for sample characteristics (e.g. maternal educational attainment, child BMI) and z-scores based on the GMDS-ER were obtained for further analysis. Statistical analyses were then carried out using SPSS software package version 22.0 and $\mathrm{R}$ version 3.2.3 using descriptive statistics. For each outcome, primarily $95 \%$ confidence intervals (Cls) were reported, followed by sample point estimates. To keep the probability of making a Type-1 error at $5 \%$, all $p$-values were adjusted for multiple testing using the False Discovery Rate approach [21]. All statistical analyses are made publicly available (https:// osf.io/g683k/).

\section{Results}

\section{Sample characteristics}

The total sample included 99 children. Sample characteristics are described in Table 1. There was no refusal of participation. The interviewees included mothers ( $n=68)$, fathers $(n=5)$, foster parent or guardians $(n=13)$, or other family members (e.g. grandmother, aunt; $n=13$ ). Maternal data showed that the majority of mothers finished high school $(n=84)$, followed by primary school $(n=14)$, and university $(n=1)$. All mothers ( $n=99$ ) reported alcohol consumption during pregnancy (necessary condition for FASD diagnosis), to be from mixed ancestry, and $80 \%$ reported unwanted pregnancies. The mean approximate age at delivery was 27.14 years (SD 6.89).

All children were previously diagnosed within the FASD spectrum; 72 with FAS, 15 pFAS, 11 ARND, and one ARBD. Age ranged from 6 to 10 years (mean age 8.5 years). The majority of subjects were boys $(n=57)$, and of all children, $11.1 \%$ were prematurely born (<37 weeks). Birth weights ranged from $1200 \mathrm{~g}$ to $3660 \mathrm{~g}$ (mean weight $2608 \mathrm{~g}$, SD 0.536). The body mass index (BMI) ranged from 10.34 to 18.05 (mean BMI 14.27, SD 1.27) and the mean occipital frontal circumference (OFC) was $49.9 \mathrm{~cm}$ (SD 1.58). Current data showed an average weight of $17.78 \mathrm{~kg}$ (SD 2.53) and average height of 111.44 $\mathrm{cm}$ (SD 6.5).

For the population under study there are no reliable biometric reference charts (e.g. OFC, BMI). Compared with other international norms, the majority of children score below the third percentile. Very rare cases score above the 50th percentile (e.g. charts used in the United States). For example, according to the United States head circumference growth reference charts, the reference values for children aged 6 - 10 years are 49.2 - 50.7 (third percentile) for males and 48.75 to 50.10 (third percentile) for females [22]. Compared with the values in the present study, the mean average for males was 49.94 (SD 1.67) and for females 49.9 (SD 1.45).

Data on the GMDS-ER subscales showed that $87.8 \%$ ( $n=98$ ) had GQ scores below the 10th percentile and $71.7 \%(n=99)$ were severely delayed (z-scores of -2 and lower). Overall z-score averages were 0.34 (SD 5.29) for locomotor, -0.95 (SD 1.19) for person- 
al-social, -2.84 (SD 0.48) for language, -2.11 (SD 0.93) for eye-hand coordination, -0.64 (SD 1.45) for performance, and -2.63 (SD 1.1) for practical reasoning.

Furthermore, $61.6 \%$ of the children with a FASD lived with their parents and $38.4 \%$ elsewhere (e.g. grandparents, foster parents, aunt and uncle). Of the children with a FASD, $4.0 \%$ had a congenital heart defect, $2.0 \%$ seizures, and $4.0 \%$ other conditions (e.g. arthritis, asthma, deafness). Moreover, $6.1 \%$ are currently on medication (e.g. methylphenidate, albuterol). The interviewees also re-ported that $4.0 \%$ of the children had complaints such as stomach cramps, $4.0 \%$ withheld stools because of inadequate toilet facilities at school, and $5.1 \%$ had problems with passing urine or stool (e.g. painful, burning sensations).

\section{Incontinence}

Rates of incontinence are described in Table 2, and can be inspected at https://osf.io/g683k/. Based on the ICCS guidelines, overall incontinence was present in $20.2 \%(n=20)$ of children with a FASD (FAS $n=17$, pFAS $n=1$, ARND $n=2)$. No incontinence was reported for children with $\operatorname{ARBD}(n=0)$. NE was present in $16.2 \%(n=16)$ of children (FAS $n=13, \operatorname{pFAS} n=1$, and ARND $n=2$ ). DUI was reported for one child (FAS), and FI for four children (all FAS). There were two children who wet their beds less than once a month. No indication of lower urinary tract symptoms (LUTS) in the clinical range was observed as all scores were lower than 13. Also, no anomalies of the urogenital tract were reported. Questions related to specific symptoms of straining and postponement were not reported, whereas urgency was reported for one child (FAS). Moreover, frequency data showed that $12.1 \%$ of the children pass urine one to three times during the day and $87.9 \%$ of the children four to seven times a day.

Table 1. Sample characteristics

\begin{tabular}{|c|c|c|c|c|c|}
\hline Variable & Total FASD & FAS & pFAS & ARND & ARBD \\
\hline & $(n=99)$ & $(n=72)$ & $(n=15)$ & $(n=11)$ & $(n=1)$ \\
\hline \multicolumn{6}{|l|}{ Maternal characteristics } \\
\hline Mean age at delivery $(S D)^{a, b}$ & $27.14(6.89)$ & $27.99(7.23)$ & $23.99(5.84)$ & $25.89(5.01)$ & 25.61 \\
\hline \multicolumn{6}{|l|}{ Educational attainment (\%) } \\
\hline Primary school & $14(14.1)$ & $12(16.7)$ & $1(6.7)$ & $1(9.1)$ & - \\
\hline High school & $84(84.8)$ & $60(83.3)$ & $14(93.3)$ & $9(81.8)$ & $1(100.0)$ \\
\hline University & $1(1.0)$ & - & - & $1(9.1)$ & - \\
\hline \multicolumn{6}{|l|}{ Child characteristics } \\
\hline Male (\%) & $57(57.6)$ & $42(73.7)$ & $8(14.0)$ & $7(12.3)$ & $0(0.0)$ \\
\hline Mean age of testing in years (SD) & $8.49(0.71)$ & $8.53(0.77)$ & $8.40(0.51)$ & $8.42(0.59)$ & 7.84 \\
\hline \multirow[t]{2}{*}{ Mean birth weight in $g(S D)^{b}$} & 2607.92 & 2450.58 & 2903.33 & 3138.18 & 3200.00 \\
\hline & $(535.92)$ & $(474.24)$ & $(508.21)$ & $(437.65)$ & \\
\hline Premature birth $(\%)^{c}$ & $11(11.1)$ & $7(63.6)$ & $3(27.3)$ & $1(9.1)$ & - \\
\hline Mean weight for age in $\mathrm{kg}(\mathrm{SD})^{\mathrm{d}}$ & $17.78(2.53)$ & $17.56(2.46)$ & $17.17(1.86)$ & $19.48(2.64)$ & 24 \\
\hline
\end{tabular}




\begin{tabular}{|c|c|c|c|c|c|}
\hline Variable & Total FASD & FAS & pFAS & ARND & ARBD \\
\hline & $(n=99)$ & $(n=72)$ & $(n=15)$ & $(n=11)$ & $(n=1)$ \\
\hline Mean height for age in $\mathrm{cm}(\mathrm{SD})^{\mathrm{d}}$ & $111.44(6.5)$ & $111.22(6.6)$ & $110.27(6.16)$ & $113.91(6.11)$ & 118 \\
\hline Mean head circumference or & $49.9(1.58)$ & $49.75(1.45)$ & $49.93(1.42)$ & $51.6(1.66)$ & 51.1 \\
\hline \multicolumn{6}{|l|}{ OFC in $\mathrm{cm}(S D)^{d}$} \\
\hline Mean BMI for age $(S D)^{d}$ & $14.27(1.27)$ & $14.16(1.3)$ & $14.13(1.16)$ & $14.95(0.74)$ & 17.24 \\
\hline \multicolumn{6}{|l|}{ Living } \\
\hline With parents (\%) & $61(61.6)$ & $46(63.9)$ & $9(60.0)$ & $6(54.5)$ & - \\
\hline Other (\%) & $38(38.4)$ & $26(36.1)$ & $6(40.0)$ & $5(45.5)$ & $1(100.0)$ \\
\hline Family members (e.g. grandmother) & $30(30.3)$ & $18(25.0)$ & $6(40.0)$ & $5(45.5)$ & $1(100.0)$ \\
\hline Foster or guardian & $7(7.07)$ & $7(7.07)$ & - & - & - \\
\hline Neighbor & $1(1.01)$ & $1(1.01)$ & - & - & - \\
\hline $\begin{array}{l}\text { Physical disability or chronic illness } \\
\text { (\%) }\end{array}$ & $10(10.1)$ & $9(12.5)$ & $1(6.67)$ & - & - \\
\hline Congenital heart defect & $4(4.04)$ & $4(5.56)$ & - & - & - \\
\hline Seizures & $2(2.02)$ & $2(2.78)$ & - & - & - \\
\hline Anomalies of the urogenital tract & - & - & - & - & - \\
\hline Other (e.g. asthma, arthritis) & $4(4.04)$ & $3(4.17)$ & $1(6.67)$ & - & - \\
\hline \multicolumn{6}{|l|}{ Griffiths mental development scales (\%) } \\
\hline Mild delay & $6(6.1)$ & $2(0.8)$ & $3(20.0)$ & $1(9.1)$ & $1(100.0)$ \\
\hline Developmental delay & $22(22.2)$ & $12(16.7)$ & $4(26.7)$ & $5(45.5)$ & $0(0.0)$ \\
\hline Severe delay & $71(71.7)$ & $58(80.6)$ & $8(53.3)$ & $5(45.5)$ & $0(0.0)$ \\
\hline
\end{tabular}

${ }^{a}$ Maternal age at delivery is an approximate measure.

${ }^{\mathrm{b}}$ Data only available for $n=96$.

${ }^{c}$ Data only available for $n=98$.

${ }^{\mathrm{d}}$ Height, weight, OFC, and BMI were measured previously, 2 years before current study.

Table 2. Sample point estimates and $95 \% \mathrm{Cl}$ for incontinence among children with FASD.

\begin{tabular}{lllll}
\hline Incontinence & Total FASD & FAS & pFAS & ARND \\
Overall & $20.2_{n=20}(13-30)$ & $23.6_{n=17}(14.4-35.1)$ & $6.67_{n=1}(0.17-31.95)$ & $18.18_{n=2}(2.28-51.78)$ \\
incontinence $^{a}$ & & & & \\
NE & $16.2 n=13(10-25)$ & $18.1_{n=13}(9.98-28.89)$ & $18.06_{n=1}(0.17-31.95)$ & $18.18_{n=2}(2.28-51.78)$ \\
DUI & $1.0_{n=1}(0-6)$ & $1.39_{n=1}(0-7.5)$ & $0_{n}=0(0-21.8)$ & $0_{n}=0(0-28.49)$ \\
FI & $4.0_{n=4}(1-10)$ & $5.56_{n=4}(1.53-13.62)$ & $0_{n}=0(0-21.8)$ & $0_{n}=0(0-28.49)$ \\
\hline
\end{tabular}

This table represents percentages of incontinence sample point estimates including the associated confidence intervals per FASD diagnoses whereby $n$ represents number of cases.

a Overall incontinence was measured when criteria met for: NE "Every night," "2x /week or more," or " $2 x$ /month or more"; DUI, "Every day," "2x /week or more," or "1x /month or more"; or Fl, "Every day," "2x /week or more," or "1x /month or more." For more details, see https://osf.io/g683k/. 
Table 3. Association between incontinence and Griffiths Mental Development Scales.

\begin{tabular}{|c|c|c|c|c|c|c|c|}
\hline & Group & Mean & Std. error & $95 \% \mathrm{Cl}$ & & $p$ Value $^{a}$ & Effect size ${ }^{b}$ \\
\hline & & & & Lower & Upper & & \\
\hline Total GQ score & Incontinence & -2.6 & 0.2 & -3.01 & -2.18 & 0.767 & $0.3(-0.19$ to 0.8$)$ \\
\hline Subscales & No incontinence & -2.34 & 0.1 & -2.53 & -2.15 & & \\
\hline \multirow[t]{2}{*}{ A. Locomotor } & Incontinence & -0.41 & 0.24 & -0.92 & 0.1 & 0.8 & $0.25(-0.24$ to 0.74$)$ \\
\hline & No incontinence & -0.13 & 0.13 & -0.38 & 0.12 & & \\
\hline \multirow[t]{2}{*}{ B. Personal-social } & Incontinence & -1.36 & 0.24 & -1.86 & -0.85 & 0.46 & $0.42(-0.07$ to 0.91$)$ \\
\hline & No incontinence & -0.88 & 0.13 & -1.14 & -0.63 & & \\
\hline \multirow[t]{2}{*}{ C. Language } & Incontinence & -2.83 & 0.14 & -3.12 & -2.53 & 0.878 & $-0.11(-0.6$ to 0.38$)$ \\
\hline & No incontinence & -2.88 & 0.04 & -2.96 & -2.79 & & \\
\hline \multirow{2}{*}{$\begin{array}{l}\text { D. Eye-hand } \\
\text { coordination }\end{array}$} & Incontinence & -2.31 & 0.2 & -2.72 & -1.89 & 0.8 & $0.24(-0.25$ to 0.73$)$ \\
\hline & No incontinence & -2.09 & 0.1 & -2.29 & -1.89 & & \\
\hline \multirow[t]{2}{*}{ E. Performance } & Incontinence & -1.39 & 0.28 & -1.98 & -0.79 & 0.1 & $0.71(0.22$ to 1.21$)$ \\
\hline & No incontinence & -0.38 & 0.16 & -0.7 & -0.06 & & \\
\hline \multirow[t]{2}{*}{ F. Practical reasoning } & Incontinence & -2.62 & 0.27 & -3.17 & -2.06 & 0.906 & $-0.07(-0.56$ to 0.42$)$ \\
\hline & No incontinence & -2.69 & 0.95 & -2.91 & -2.48 & & \\
\hline
\end{tabular}

${ }^{a} p$-Values represent the values after correction for multiple testing using the False Discovery Rate approach.

${ }^{b}$ Effect sizes represent sample point estimate $d$ and the $95 \% \mathrm{Cl}$ for Cohen's d (note that Glass' correction for the bias in Cohen's d in small samples was applied). For more details, see https://osf.io/g683k/.

Subsequent analyses on associations between incontinence and scores on the GMDS-ER scales yielded no significance (Table 3 ). Children with and without incontinence did not significantly differ in their total GQ scores $(p=0.767)$. Further inspection of scores on the GMDS-ER subscales showed differences in means for example on performance (subscale E); respectively mean score of -1.39 for children with incontinence, and mean score of -0.38 without incontinence. These differences yielded no significance after correction for multiple testing $(p=0.1)$. See the supporting information for more details at https://osf.io/g683k/.

\section{Discussion}

This is the first study to analyze and report the prevalence of incontinence in children diagnosed within the spectrum of FASD. The current results provide evidence of overall incontinence to be present in $20 \%$ of children with a FASD in a South African cohort. NE was present in 16\%, DUI was reported for one child, and FI for four children. The most common subtype of reported incontinence was NE. As LUTS were not common, it can be assumed that many children have monosymptomatic NE. The main path mechanisms for the development of NE are polyuria, lack of arousal, and lack of inhibition of the 
micturition reflex during sleep. All of these are mediated by the CNS, which is also affected in children with a FASD, who have many behavioral and developmental challenges $[23,24]$. In addition, it is reasonable that environmental factors influenced the current findings. The study took place in a peri-urban area whereby all kind of factors can influence toilet use (e.g. availability or location of toilets). Further research aimed at possible environmental mechanisms responsible for in-continence and its variances is required.

These findings should be interpreted in the light of the limitations of the present study. Notably data on DUI were limited to subjective measures and most probably reflect underreporting of the problem. The low DUI rates could be explained by alternative toilet use (e.g. bushes) and underreporting (e.g. lack of supervision by parents or caregivers). Incontinence was only assessed by interviews and questionnaires without data derived from more objective clinical examination such as bladder diary, uroflowmetry, and ultrasound. Also, a control group of typically developing children was not included. There are no data available regarding incontinence in South African children. Because of the lack of controls in the local population one does not know what the incontinence rates are for day or night in typically developing children, therefore $16 \%$ NE at this age group may be possible. The same holds true for interpreting the low rates of DUI and FI. This indicates the relevance for future investigation in children diagnosed within the spectrum of FASD and typically developing children in this population. Also, it is well known that the prevalence of NE can vary in different ethnic populations. Moreover, the sample was restricted to age 6-10 years and the sample size can be considered as relatively small.

The study also had a number of strengths. First, standardized questionnaires were used by structured interviews during home visits. Second, international guidelines (ICCS; DSM-5) were used in defining subtypes of incontinence $[6,8]$. Third, all interviewees agreed to participate without any drop-outs or incomplete data.

The present study showed that children with a FASD, especially FAS, pFAS, and ARND, are at risk for incontinence. For typically developing children, the prevalence of NE is reported to be $9.7 \%$ (age 7 years) and 5.5\% (aged 10 years); for DUI, estimates range from $4.9 \%$ to $11.7 \%$ (age 7 years) and $0.8 \%$ e $12.5 \%$ (age 11 e12 years); for $\mathrm{Fl}, 0.6 \%$ - 6.9\% (age 5 - 7 years) and $0.7 \%$ - 1.6\% (age $10-12$ years) [10].

Compared with these rates, the rates among children with a FASD appear to be high. However, follow-up studies should include children with and without a FASD to replicate the current findings.

Previous studies also report gender differences. It is shown that NE and $\mathrm{FI}$ are more common in boys than girls, and DUI is more common in girls than boys [10]. In the present study, no gender differences were observed.

Prevalence estimates for children with special needs differ between studies. Problems of incontinence increase with the severity of the disability. For children with ADHD and oppositional defiant disorder (aged 4 - 8 years, mean age 5.7 ) overall incontinence 
was reported to be present in 9.1\%, NE 8.5\%, DUI 1.9\%, and FI 0.8\% [25]. For children with Noonan syndrome (aged $4-12$ years, mean age 8.19), the rates for NE were $27.3 \%$, DUI 36.4\%, and FI 11.1\% [26]. For children with autism spectrum disorders (aged 5 - 16 years, mean age 11.3), overall incontinence affected 40\%, NE 30\%, DUI 25\%, and FI $12.5 \%$ [27]. For children with Prader-Willi syndrome (aged $5-12$ years), NE was present in $56 \%$, DUI $1 \%$, and FI $1 \%$ of children [28]. For Rett syndrome (5 - 47 years, mean age 19.34), these rates for NE were as high as 100\%, DUI 100\%, and FI $58.8-76.0 \%$ [29]. The rates for children with FASD are lower than the rates for many children with special needs, but much higher than for typically developing children. However, NE is the predominant type of incontinence.

The study shows that children diagnosed within the spectrum of FASD have a higher risk of incontinence, especially NE. This has also clinical implications, as it is known that children with ID or neurodevelopmental disorders have much higher rates of incontinence, but do not always receive adequate assessment and treatment because of other more-pressing medical or behavioral symptoms [11]. Vice versa, ID or disorders that affect executive functions (e.g. ADHD), can impair or delay incontinence treatment [30]. As children diagnosed with a FASD may be challenged with ID and/or characteristics of ADHD treatment of incontinence can be more challenging [31]. However, incontinence can be treated effectively in children with ID, genetic syndromes, or neurodevelopmental disorders if their specific problems and needs are taken into consideration. Therefore, an individually adapted assessment and treatment is recommended [11]. Future research is necessary to examine problems of incontinence in relation to cognitive and behavioral functioning among children with a FASD, as well as identifying possible causes.

\section{Conflict of interest}

None.

\section{Funding sources}

None.

\section{Acknowledgements}

The authors would like to thank the Foundation for Alcohol Related Research (FARR) for their contribution to this study, as well as the parents, guardians, and children without whom this study would not have been possible. 


\section{References}

[1] BMA Board of Science. Alcohol and pregnancy: preventing and managing fetal alcohol spectrum disorders. London: British Medical Association; 2016. https://www.bma.org.uk/ collective-voice/policy-andresearch/public-and-population-health/alcohol/alcohol-and-pregnancy.

[2] Hoyme HE, May PA, Kalberg WO, Kodituwakku P, Gossage JP, Trujillo PM, et al. A practical clinical approach to diagnosis of fetal alcohol spectrum disorders: clarification of the 1996 institute of medicine criteria. Pediatrics 2005;115:39-47. http://dx.doi.org/10.1542/peds.2004-0259.

[3] Roozen S, Peters G-JY, Kok G, Townend D, Nijhuis J, Curfs L. Worldwide prevalence of fetal alcohol spectrum disorders: a systematic literature review including meta-analysis. Alcohol Clin Exp Res 2016;40:1832. http://dx.doi.org/10.1111/acer.12939.

[4] Frey L, Szalda-Petree A, Traci MA, Seekins T. Prevention of secondary health conditions in adults with developmental disabilities: a review of the literature. Disabil Rehabil 2001; 23:361-9. http://dx.doi.org/10.1080/096380010006674.

[5] Streissguth AP. A long-term perspective of FAS. Alcohol Health Res World 1994;18:74-81.

[6] Austin PF, Bauer SB, Bower W, Chase J, Franco I, Hoebeke P, et al. The standardization of terminology of lower urinary tract function in children and adolescents: update report from the standardization committee of the International Children's Continence Society. Neurourol Urodyn 2014;35:471-81. http: //dx.doi.org/10.1002/nau.22751.

[7] Rasquin A, Di Lorenzo C, Forbes D, Guiraldes E, Hyams JS, Staiano A, et al. Childhood functional gastrointestinal disorders: child/adolescent. Gastroenterology 2006;130:1527-37. http://dx.doi.org/10.1053/j.gastro.2005.08.063.

[8] American Psychiatric Association. Diagnostic and statistical manual of mental disorders (DSM-5). 2013. Washington DC.

[9] von Gontard A, Neveus T. Management of disorders of bladder and bowel control in childhood. London: MacKeith Press; 2006.

[10] Franco I, Austin P, Bauer S, von Gontard A, Homsy Y, editors. Pediatric incontinence e evaluation and clinical management. Chicester, UK: John Wiley \& Sons; 2015.

[11] Von Gontard A. Urinary and faecal incontinence in children with special needs. Nat Rev Urol 2013;10:667-74.

[12] Von Wendt L, Simila S, Niskanen P, Jarvelin MR. Development of bowel and bladder control in the mentally retarded. Dev Med Child Neurol 1990;32:515-8.

[13] Von Gontard A, Baeyens D, Van Hoecke E, Warzak WJ, Bachmann C. Psychological and psychiatric issues in urinary and fecal incontinence. J Urol 2011;185:1432-6. http: //dx.doi.org/10.1016/j.juro.2010.11.051.

[14] Von Gontard A. Enuresis. In: Rey JM, editor. IACAPAP textbook of child and adolescent mental health. Geneva: International Association for Child and Adolescent Psychiatry and Allied Professions; 2012.

[15] Von Gontard A. Encopresis. In: Rey JM, editor. IACAPAP textbook of child and adolescent mental health. Geneva: Inter-national Association for Child and Adolescent Psychiatry and Allied Professions; 2012.

[16] De Gennaro M, Niero M, Capitanucci ML, von Gontard A, Woodward M, Tubaro A, et al. Validity of the international consultation on incontinence questionnaire-pediatric lower urinary tract symptoms: a screening questionnaire for children. J Urol 2010;184:1662e7. http://dx.doi.org/10.1016/ j.juro.2010.03.075.

[17] Luiz DA, Barnard N, Knoesen N, Kotras S, Horrocks P, McAlinden D, et al. Griffiths Mental Development Scales: Extended Revised. Two to eight years. Administration manual. Oxford, UK: Hogrefe; 2006.

[18] Olivier L, Louw J, Lambrecht T, Scorgio F, Viljoen D, Chersich M, et al. Pregnant women in the Nelson Mandela Bay Municipality in South Africa used alcohol intentionally to harm their children: fact or fiction? 2016. Manuscript in preparation.

[19] Stats SA. Statistics South Africa 2011. http://www.statssa. gov.za [Accessed 28 June 2016]. 
[20] Harris PA, Taylor R, Thielke R, Payne J, Gonzalez N, Conde JG. Research electronic data capture (REDCap) - a metadata-driven methodology and workflow process for providing translational research informatics support. J Biomed Inf 2009; 42:377-81.

[21] Benjamini Y, Hochberg Y. Controlling the false discovery rate: a practical and powerful approach to multiple testing. J R Stat Soc 1995;57:289-300.

[22] Rollins JD, Collins JS, Holden KR. United States head circum-ference growth reference charts: birth to 21 years. J Pediatr 2010;156. http://dx.doi.org/10.1016/j.jpeds.2010.01.009. 907-913.e2.

[23] Popova S, Lange S, Shield K, Mihic A, Chudley AE, Mukherjee RAS, et al. Comorbidity of fetal alcohol spectrum disorder: a sys-tematic review and meta-analysis. Lancet (London, England) 2016;387:978-87. http://dx.doi.org/10.1016/S0140-6736(15) 01345-8.

[24] Tsang TW, Lucas BR, Carmichael Olson H, Pinto RZ, Elliott EJ. Prenatal alcohol exposure, FASD, and child behavior: a meta-analysis. Pediatrics 2016;137:e20152542. http://dx.doi.org/10. 1542/peds.2015-2542.

[25] Niemczyk J, Equit M, Braun-Bither K, Klein A-M, von Gontard A. Prevalence of incontinence, attention deficit/-hyperactivity disorder and oppositional defiant disorder in preschool children. Eur Child Adolesc Psychiatry 2015;24: 837-43. http://dx.doi.org/10.1007/s00787-014-0628-6.

[26] Niemczyk J, Equit M, Borggrefe-Moussavian S, Curfs L, Von Gontard A. Incontinence in persons with Noonan syndrome. J Pediatr Urol 2015;11. http://dx.doi.org/10.1016/j.j-purol.2015.06.002. 201.e1201.e5.

[27] Von Gontard A, Pirrung M, Niemczyk J, Equit M. Incontinence in children with autism spectrum disorder. J Pediatr Urol 2015;11. http://dx.doi.org/10.1016/j.jpurol.2015.04.015. 264.e1-7.

[28] Von Gontard A, Didden R, Sinnema M, Curfs L. Urinary in-continence in persons with Prader-Willi syndrome. BJU Int 2010;106:1758e62. http://dx.doi.org/10.1111/j.1464-410X. 2010.09457.x.

[29] Giesbers S, Didden R, Radstaake M, Korzilius H, von Gontard A, Lang R, et al. Incontinence in individuals with Rett syndrome: a comparative study. J Dev Phys Disabil 2012;24:287-300. http://dx.doi.org/10. 1007/s10882-012-9271-7.

[30] Crimmins CR, Rathbun SR, Husmann DA. Management of urinary incontinence and nocturnal enuresis in attention-deficit hyperactivity disorder. J Urol 2003;170:1347-50. http://dx.doi.org/10.1097/01.ju.00000 84669.59166.16

[31] Khoury JE, Milligan K. Comparing executive functioning in children and adolescents with fetal alcohol spectrum disorders and ADHD: a meta-analysis. J Atten Disord 2016:2016. http://dx.doi.org/10.1177/ 1087054715622016. 



\section{Article}

Effects of consumption of biscuits baked with Red Palm Oil (RPO) shortening on the vitamin $A, \alpha$ - and $\beta$-Carotene and vitamin $E$ status of pre-school children attending an informal crèche in Bethelsdorp, Eastern Cape. Part 1. Baseline Study. Nutritional and Health Status.

Submitted for publication:

Benade, A.J.S.*, Olivier, L.* Bukasa, L. (2017) Effects of consumption of biscuits baked with Red Palm Oil (RPO) shortening on the vitamin A, $\alpha$ - and $\beta$-Carotene and vitamin $E$ status of pre-school children attending an informal crèche in Bethelsdorp, Eastern Cape. Part 1. Baseline Study. Nutritional and Health Status. South African Nutritional Journal, 2017

*equal contribution 


\section{Abstract}

Objective Little information is available on the nutritional and health status of preschool children attending informal crèches. Attendance is usually voluntary and paid for by the parents.

Design Several crèches were approached by the study supervisor and invited to participate in a nutritional intervention study consisting of four phases namely a baseline survey and a six-months nutrition intervention study followed by a six-months post intervention survey. The study supervisor explained the purpose of the study to the parents during a meeting with the parents. Those parents who agreed to participate in the study, were provided with a form explaining the purpose of the study as well as the procedures to be followed during the survey. Those parents who gave consent for their children to participate in the study, were then asked to sign a consent form which would allow the child to participate in the study. Four crèches agreed to participate in the study and a total of 61 children reported for the baseline study. The study was approved by the Ethics Committee of the Faculty of Applied Sciences of the Cape Peninsula University of Technology (CPUT). The study was a collaborative project between the CPUT and the Foundation for Alcohol Related Research in South Africa (FARR). The results contained in this report, only reflects on data collected during the base-line survey.

Methodology On the day of the visit children were weighed on an electronic balance (with only light clothing on). Heights were measured with a sliding board with the child standing in the upright position. $10 \mathrm{ml}$ of blood was drawn from a forearm vein by an experienced paediatric sister. Red cells and plasma were separated by centrifugation on site. Samples were immediately stored on dry-ice to be air-freighted during the same week, to our laboratory in Cape Town. EDTA was used as an anti-coagulant. Plasma samples were analysed for Retinol, vitamin $E, \alpha$ - and $\beta$-Carotene and immune markers CRP and IL-6. Red cells were analysed for fatty acid composition.

Results The prevalence of under-nutrition in this group, based on their weight and height for age can be considered as low (-2 SD $=1.6 \%$ and $6.3 \%$ respectively). The prevalence of vitamin A deficiency (9.4\%) can be considered to be mild (According to WHO standards). The relatively low plasma $\alpha$ - and $\beta$-Carotene content indicated a low intake of fruit and vegetables in this group. The low plasma levels of $\alpha$-Tocopherol suggested a deficiency of vitamin $\mathrm{E}$ in these children.

Keywords: Nutritional Status, Immune status, Informal crèches, Eastern Cape. 


\section{Introduction}

Although the nutritional and health status of children falling in the same age group as reported in the present study, are well described in South Africa ${ }^{1}$, little is specifically known about the nutritional and health status of children attending an informal crèche in an urban setting. Although information is available on the prevalence of stunting, underweight and vitamin A status of children in South Africa, there is no information available on the immune status, vitamin E status, blood carotene levels or red blood cell omega-3 content in this age group. These parameters are known to be associated with several health and developmental issues in children of this age group.

Inflammatory markers are known to be indicative of infections and general state of health. Vitamin $\mathrm{E}$ has many functions in the body. It is the most important chainbreaking, lipid soluble antioxidant present in body tissues and is considered the first line of defence against lipid oxidation. It is important for normal function of immune cells. It is well established that supplementation with vitamin E significantly enhances both cell mediated and blood- immune functions in humans. ${ }^{2}$ Marginal deficiency of vitamin $E$ impairs immune response. ${ }^{3}$ The relationship between vitamin $E$ and immune function was amongst others, demonstrated in Canadian 3-year olds. ${ }^{4}$ The role of vitamin E status in cognitive function is well established. 5,6

Plasma Carotenoid levels are indicative of fruit and vegetable intake of consumers. ${ }^{7}$ Apart from $\alpha$ - and $\beta$-Carotene being pro-vitamin A they can also act as anti-oxidants in the body and it has been shown that $\alpha$-Carotene are inversely associated with the risk of death from all causes. ${ }^{8}$ Donaldson ${ }^{9}$ proposed a Carotenoid Health Index with an all risk mortality ranging from very high in those having a low Carotenoid level, to very low in those with a high plasma Carotenoid content. Donaldson ${ }^{10}$ indicated that $\beta$-Carotene could account for up to $30 \%$ of the total Carotenoids in blood. Using this information, an estimate of the total Carotenoids in the blood of these children could be made in which case an Index of less than $1 \mu \mathrm{Mol} / \mathrm{L}$ is found, which is below the lowest level of Health Index, where a high risk for death from all causes exist. It would therefore make sense to encourage consumers to adapt a lifestyle which will increase their blood Carotenoid levels and thus promote general health in the long term.

Harris $^{11}$, provided evidence that raising tissue levels of Omega- 3 fatty acids, will reduce the risk for cardiac events. The author therefore proposed the Omega-3 index. A recent paper by van der Wurff ${ }^{12}$, also reported a significant positive association between the Omega-3 Index and cognition in typically developing adolescents from the general population. The same authors also reported that students with a higher Omega3 Index paid more attention than students with a lower Omega-3 Index. They concluded that" Teenagers with higher blood levels of Omega-3 may have better information processing speeds compared with those with lower levels". Omega-3 fatty acids and especially EPA (Eicosapentaenoic acid) and DHA (Docosapentaenoic Acid) were found to serve as substrate for the production of anti-inflammatory compounds such as resolvins 
and protectins while inhibiting the activation of nuclear factors that induce inflammation. Richardson ${ }^{13}$ presented some evidence in a review paper that: "an adequate dietary intake of Omega-3 fatty acids in particular may be crucial for optimal mental health and functioning".

\section{Methods}

With the assistance of the Foundation for Alcohol Related Research (FARR) who was doing a survey in Bethelsdorp at that time, potential participating crèches were identified in Bethelsdorp and were invited to participate in the nutritional study planned by the Cape Peninsula University of Technology (CPUT). A meeting was held with the crèches in the area. Parents were then invited to participate in the survey. During the meeting which were well attended by the parents, procedures were explained to the parents. Eventually, four crèches accepted our invitation to participate. Sixty-one children between the ages of 3 and 4 years expressed their willingness to participate in the project.

With the assistance of FARR, a community worker, paediatric nurse, and a community health nurse were recruited. FARR also seconded one of their staff members as a project co-ordinator for the entire duration of the study.

Parents indicating their willingness to participate in the study were invited to sign a consent form, giving permission for the child to act as a research participant in the project. The study was approved by the Faculty of Applied Sciences of the CPUT Ethics Committee. Before the project started, all field staff were briefed and trained in the procedures to be followed during the project.

Results of this study served as baseline for an intervention study which lasted a year in order to determine the effects of consuming a biscuit baked with Red Palm Oil shortening on the nutrition and health status of these children. Results of this study will be communicated separately.

\section{Measurements and Analytical Procedures}

Weights were measured on an electronic scale, weighing to the nearest $100 \mathrm{~g}$. Heights were measured with a sliding board in the standing position $( \pm 1 \mathrm{~cm})$. Ages were recorded for all children who presented their signed consent form confirming their participation in the project.

Children were examined by the community health nurse who also took the weight and height of the child.

Blood was drawn $(10 \mathrm{ml})$ from a fore-arm vein by the paediatric nurse with the child in the supine position. EDTA was used as an anti-coagulant. Plasma was separated from 
the red blood cells on site and stored on dry ice to be air-freighted to Cape Town for analysis.

Blood Analysis $\alpha$ - and $\beta$-Carotene, Retinol and alpha-Tocopherol were extracted from plasma and analysed by HPLC. $\alpha$-and $\beta$-Carotene and Retinol were analysed by HPLC according to the method described by Mc Geachin and Baily ${ }^{14}$ and vitamin E determined by HPLC according to the method as described by Rizzo et al. ${ }^{15}$

Human C-Reactive Protein (CRP), and IL-6 activity were determined on plasma samples frozen on dry ice. Elisa kits purchased from Millipore (Millipore Catalogue numbers CYT 298 and EZHTNFA respectively) were used for determining CRP and IL-6 activities in plasma.

After separation of red blood cells from plasma, red cells were washed twice with an equal volume of saline and frozen on dry ice to be air-freighted to our analytical laboratories in Cape Town. Frozen red cells were thawed and 500 $\mu$ l extracted with $10 \mathrm{ml}$ chloroform/methanol (CM) 2:1. Extracts were evaporated under a stream of nitrogen and fatty acids were trans-methylated with $2 \mathrm{ml} 5 \%$ sulphuric acid in absolute methanol at $70^{\circ} \mathrm{C}$ for two hours. After two hours, $3 \mathrm{ml}$ water was added and methyl esters extracted with reagent grade hexane. Hexane extracts were evaporated to dryness and $100 \mu \mathrm{l}$ heptane was added, mixed and analysed on a Thermo, Focus GLC equipped with a flame ionization detector and a $60 \mathrm{M} \mathrm{BPX} 70$ capillary column. Oven temperature was programmed at 2 degrees $\mathrm{C}$ per minute from $160^{\circ}-220^{\circ} \mathrm{C}$.

The Omega-3 index of red cells were calculated as the sum of the percentage of Eicosapentaenoic acid (EPA) and Docosahexaenoic acid (DHA) as obtained from the GLC analytical results.

\section{Statistical analysis}

Data were statistically analysed to obtain mean values and standard deviations of all the measurements. Prevalence (where applicable) were calculated for parameters where cut-off values for normal/elevated levels were available. Pearson correlations were calculated on log transformed data.

\section{Results}

Table 1 summarise the anthropometric data of the children. As can be seen from the calculated Height and Weight for age, and using cut-off levels as recommended by $\mathrm{WHO}^{16}$ the prevalence of stunting and underweight in this group of children can be considered to be low. 
Table 1: Anthropometric data

\begin{tabular}{lll}
\hline & $4.15 \pm 0.84$ years & - \\
Age & $n=61$ & - \\
Weight & $16.3 \mathrm{Kg} \pm 3 \mathrm{Kg}$ & \\
& $\mathrm{n}=61$ & - \\
Height & $101.11 \pm 7.6 \mathrm{~cm}$ & \\
& $n=61$ & $6.39 \%$ \\
HAZ & - & $1.6 \%$ \\
-2 SD & & \\
WAZ & - & \\
$-2 S D$ & & \\
\hline
\end{tabular}

Table: 2 Blood Measurements

\begin{tabular}{|c|c|c|}
\hline Parameter & Plasma level & Prevalence using reference cut-off points \\
\hline Retinol & $\begin{array}{l}0.93 \pm 0.18 \mu \mathrm{mol} / \mathrm{L} \\
\mathrm{n}=51\end{array}$ & $\begin{array}{l}\text { Less than } 0.7 \mu \mathrm{mol} / \mathrm{L}=10 \% \\
\left(\mathrm{WHO}^{17}\right)\end{array}$ \\
\hline$\alpha$-Carotene & $\begin{array}{l}0.060 \pm 0.040 \mu \mathrm{mol} / \mathrm{L} \\
\mathrm{n}=51\end{array}$ & - \\
\hline$\beta$-Carotene & $\begin{array}{l}0.184 \pm 0.081 \mu \mathrm{mol} / \mathrm{L} \\
\mathrm{n}=51\end{array}$ & - \\
\hline Alpha- Tocopherol & $\begin{array}{l}11.00 \pm 4.41 \mu \mathrm{mol} / \mathrm{L} \\
\mathrm{n}=36\end{array}$ & $\begin{array}{l}\text { Less than } 12 \mu \mathrm{mo} / \mathrm{L}=69 \%-\left(\mathrm{IOM}^{18} \text { more }\right. \\
\text { than } 12 \text { but less than } 20 \mu \mathrm{mol} / \mathrm{L}=25 \% \text {; } \\
\geq 30 \mu \mathrm{mol} / \mathrm{L}=0.0 \%\end{array}$ \\
\hline CRP & $\begin{array}{l}4.18 \pm 8.50 \mathrm{mg} / \mathrm{L} \\
\mathrm{n}=51\end{array}$ & More than 3mg/L = 29\% (Test kit) \\
\hline IL-6 & $\begin{array}{l}2.96 \pm 6.11 \mathrm{pg} / \mathrm{ml} \\
\mathrm{n}=51\end{array}$ & More than $5 \mathrm{pg} / \mathrm{ml}=24 \%$ (Test kit) \\
\hline $\begin{array}{l}\text { Red Blood cell Omega-3 index } \\
\% \text { EPA + \%DHA }\end{array}$ & $6.2 \% \pm 1.2 \%$ & $\begin{array}{l}\text { Less than } 6 \%=43.7 \% \\
\text { Less than } 8 \%=97.6 \% \\
\text { Less than } 10 \%=100 \%\end{array}$ \\
\hline
\end{tabular}

Retinol: Using a $\mathrm{WHO}^{17}$, cut-off, of $0.7 \mu \mathrm{mol} / \mathrm{L}$, the prevalence of biochemical vitamin $\mathrm{A}$ deficiency of $10 \%$ is considered to be mild to moderate.

$\alpha$ - and $B$-Carotene: $\alpha$-and $\beta$-Carotene levels were found to be low namely $0.060 \pm 0.040$ and $0.184 \pm 0.081 \mu \mathrm{mol} / \mathrm{L}$ respectively.

$\alpha$-Tocopherol: Using a universal cut-off point of $12 \mu \mathrm{mol} / \mathrm{L}^{18}{ }^{18}$, indicated that $69 \%$ of children can be considered to be vitamin E deficient. Results showed that only $25 \%$ of the children had vitamin E levels falling between 12 and $20 \mu \mathrm{mol} / \mathrm{L}$ and only $6 \%$ of the children displayed values of more than $20 \mu \mathrm{mol} / \mathrm{L}$.

CRP: and IL-6: Using a cut-off value of $3 \mathrm{mg} / \mathrm{L}$ for CRP (Manufacturer's Reference Value) and $5 \mathrm{pg} / \mathrm{ml} \mathrm{IL}-6^{19}$, results indicated that $29 \%$ and $24 \%$ of the children had values exceeding $3 \mathrm{mg} / \mathrm{L}$ and $5 \mathrm{pg} / \mathrm{ml} \mathrm{CRP}$ and IL-6 respectively indicated elevated levels of inflammation in these children. 
Red Blood Cell Omega-3 Index (RBC Omega-3 Index):_Results on RBC Omega-3 index showed that the majority of children had a low index. (Less than the recommended index of $8 \%-97.6 \%)$

Table 3. Pearson correlation between some Plasma parameters

\begin{tabular}{llll}
\hline & $\beta$-Carotene & Retinol & $\alpha$-Carotene \\
\hline a-Carotene & Significant $p<0.001)$ & Non-Significant $(p=0.045)$ & Significant $(<0.001)$ \\
$\beta$-Carotene & Significant $p<0.001)$ & Significant $(p=0.012)$ & Significant $(p<0.001)$ \\
\hline
\end{tabular}

Correlation between blood Parameters (Table 3) summarize significant correlation calculated for $\alpha$ - and $\beta$-Carotene and Retinol. Significant correlations were found between $\alpha$ and $\beta$-Carotene and between $\beta$-Carotene and Retinol. No significant correlations were found between any of the other parameters.

\section{Discussion}

Results presented here formed the basis of an intervention study entitled: Effects of Biscuits Baked with Red Palm Oil on the Health and Nutritional Status of Pre-School Children. These children all attended informal crèches where parents pay for their child's attendance and subsequent care during day-time. These crèches do not get government financial support. Parents are normally working and it is fair to assume that these children come from homes with an income and a subsequent better nutritional status.

According to $\mathrm{WHO}^{16}$ standards the prevalence of under-nutrition in this group of children was low and with a prevalence of about half that of that reported in the SANHANES report. ${ }^{1}$ The SANHANES also reported a very high prevalence (43.6\%) of vitamin A deficiency in South Africa in a similar age group. The prevalence of vitamin A deficiency in our study, although lower than that reported in the SANHANES was still about $10 \%$ which can be regarded as mild/moderate. ${ }^{16}$ Children in this study were all from formal settlements in Bethelsdorp and from homes where one or both parents earned an income.

Nutritional status as judged by the different plasma and red blood cell biochemical parameters measured in this study could potentially have far reaching health and developmental consequences.

$\mathrm{Li}$ and co-workers ${ }^{8}$ using data from NHANES III of US adults 20 years and older, showed that serum $\alpha$-Carotene concentrations were inversely associated with risk of death from all causes and death from cardiovascular disease, cancer and all causes other than CVD and cancer. This inverse association was also independent of demographic characteristics, lifestyle and traditional risk factors. Donaldson ${ }^{9}$ reported on the results of a meta-analysis study in which results from sixty- two studies of plasma Carotenoids and health outcomes were analysed. Based on the data, a Carotenoid Health Index was proposed with an all risk mortality ranging from very high in those having a low $(1 \mu \mathrm{M})$ Carotenoid level, to very low in those with a plasma Carotenoid content of. 
Although the Carotenoid Health Index was not determined in the present study, some approximation could be made. According to Donaldson ${ }^{10}, \beta$-Carotene can make up to about $30 \%$ of the total Carotenoids in the blood. Using this contribution of $\beta$-Carotene to the total Carotenoid present in blood, the total mean concentration of Carotenoids in the blood of these children is estimated to be less than $1 \mu \mathrm{M}$, which is the lower end of the Carotenoid Health Index, indicating the highest risk for an all- cause mortality. Even when a lower contribution by $\beta$-Carotene is considered such as example $15 \%$, the total blood Carotene will still be low, namely about $1.23 \mu \mathrm{M}$ which will still put them in a high risk category. Whether this information can be applied to the children in the present study, is not known. However, results of the present study, do give us a futuristic indication of what could happen if the situation is not addressed at this early stage of life.

Plasma Carotenoid levels, are indicative of a habitual fruit and vegetable intake. ${ }^{7}$ The plasma levels of $\alpha$-and $\beta$-Carotene observed in these children could therefore be indicative of a low fruit and vegetable intake. Carotene values measured in these children, are in agreement with those reported for infants in Malawi ${ }^{20}$, pre-school children in rural Guatemala ${ }^{21}$, Schweigert et al., ${ }^{22}$ in Lagos but lower than values reported for Ger$\operatorname{man}^{22}$ and US children 6-7 years of age ${ }^{24}$ especially for $\beta$ - Carotene. The benefits of an adequate consumption of fruit and vegetables are well known. Carotenoids such as $\alpha-$ and $\beta$-Carotene show a high anti-oxidant capacity thus protecting DNA membranes and other cellular components against oxidative damage. Another important function of $\alpha$ and $\beta$-Carotene is their pro-vitamin A activity. It has been shown that Carotenoids can provide as much as two thirds of the Retinol requirements in some countries ${ }^{25,27}$ That $\beta$-Carotene can serve as a precursor for vitamin $A$, is also suggested by the significant association between $\beta$-Carotene and Retinol in our study.

An intervention study carried out by Watzl et al. ${ }^{27}$ showed that a four-week intervention with a high intake of Carotenoid-rich vegetables and fruit, reduces plasma Creactive protein in healthy, no-smoking men. At this point in time, only small changes in total Carotenoid levels were found. A significant increase in the plasma levels of total Carotenoids was however seen after supplementing with eight servings of fruit and vegetables for eight weeks. Fruit and vegetables are known to contain several nutrients and phytochemicals which are known to modulate immune function. It is therefore difficult to ascribe the effects of fruit and vegetable on health to any single component for example such as Carotenoids. The possibility however cannot be excluded, that the actions of all these different components are in synergism as has been reported for vitamin E and Carotenoids. ${ }^{28}$

A significant observation of the present study, is the high prevalence of vitamin $E$ deficiency in these children (69\% less than $12 \mu \mathrm{mol} / \mathrm{L}$ ). Although the importance of vitamin $E$ has always been realized, very little attention has been devoted to the prevalence of vitamin E deficiency. Recent reports indicated that vitamin E deficiency is world-wide in both children and adults. ${ }^{29}$ Circulating $\alpha$-Tocopherol concentrations $<12 \mu \mathrm{mol} / \mathrm{L}$ were defined by the $10 \mathrm{M}^{18}$ to be in the deficient /inadequate range for healthy adults. In 
general, plasma $\alpha$ - Tocopherol concentrations $<12 \mu \mathrm{mol} / \mathrm{L}$ are associated with increased infection, anaemia, stunting of growth and poor outcomes during pregnancy for both infant and mother. ${ }^{30,31}$ Péter et al., ${ }^{29}$ concluded from his review on the Global vitamin $\mathrm{E}$ status that 'from the dietary vitamin $E$ intake levels and serum concentrations of vitamin $E^{\prime}$ demonstrated that the majority of reported intake values world-wide were below the recommended value. It is therefore logical to accept that the low plasma levels of vitamin $\mathrm{E}$ recorded in the present study, was mainly due to a low dietary intake of vitamin E. It was suggested by Traber $^{29}$ that circulating $\alpha$-Tocopherol below the cut-off of $12 \mu \mathrm{mol} / \mathrm{L}$ is likely indicative of inadequacy if not frank vitamin $\mathrm{E}$ deficiency.

Vitamin $E$ has many functions in the body and is best known for its role as an antioxidant. It is the most important chain-breaking lipid-soluble antioxidant present in body tissues and is considered the first line of defence against lipid peroxidation. It is important for normal function of immune cells. It was shown that supplementation with vitamin $E$ significantly enhances both cell mediated and humoral immune functions in humans especially in elderly animals. ${ }^{2}$ It is also known that even marginal vitamin E deficiency, impairs the immune response. ${ }^{3}$ The relationship between vitamin $E$ and immune function was also demonstrated in Canadian 3-year olds. ${ }^{4}$ Those with the lowest serum vitamin $\mathrm{E}$ had the lowest lymphocyte proliferative response and serum IgM concentrations.

The implication of the low plasma vitamin E levels is far reaching, especially in the light of recent findings from a recent study, which reported that elevated levels of Tocopherol and Tocotrienol forms are associated with reduced risk of cognitive impairment in older adults. ${ }^{5}$ Koscik et al. ${ }^{31}$ concluded from a study on cognitive function of children with cystic fibrosis that minimizing the duration of vitamin E deficiency, is associated with better cognitive functioning in children with Cystic Fibrosis. As suggested by Farrel et al. ${ }^{6}$, continued extra hepatic tissue $\alpha$-Tocopherol depletion put peripheral nerves at risk. Péter et al. ${ }^{29}$ suggested that a desirable plasma vitamin E concentration of $\geq 30 \mu \mathrm{mol} / \mathrm{L}$ is required for beneficial health effects to occur.

From Table 2, it is evident that $94 \%$ of the children had plasma levels less than 20 $\mu \mathrm{mol} / \mathrm{L}$ Tocopherol and no children had plasma levels of $\alpha$-Tocophero I levels above 30 $\mu \mathrm{mol} / \mathrm{L}$. Vitamin $\mathrm{E}$ has effects on inflammatory processes due to the antioxidant functions of $\alpha$-Tocopherol. ${ }^{32} \alpha$-Tocopherol exerts anti-inflammatory effects through a number of different mechanisms for example by decreasing levels of CRP and proinflammatory cytokines and by inhibiting the activity of protein- kinase $C^{32,33}$

Our results indicated that vitamin E deficiency $(<12 \mu \mathrm{mol} / \mathrm{L}, \alpha$-Tocopherol, functional deficiency) can exist in the absence of severe malnutrition. This is in contrast to the findings in malnourished children in India. ${ }^{34}$ The prevalence of malnutrition in children participating in the present study can be regarded as very low (Table 1 ) and yet a high prevalence of vitamin E deficiency (functional deficiency) was observed (Table 2).

Whether the vitamin $E$ deficiency found in these children had an effect on the prevalence of the elevated levels of CRP $(29 \%>$ than $3 \mathrm{mg} / \mathrm{ml})$ and IL-6 $(24 \%>5 \mathrm{pg} / \mathrm{ml})$ is not known. Statistical analysis suggested that the number of observations were proba- 
bly too small to show any correlations between the different parameters. Based on evidence from the literature, we must conclude that the observed vitamin E deficiency found in these children has far reaching implications. Not only could the high prevalence of vitamin $\mathrm{E}$ deficiency have an influence on inflammation in these children, but could potentially affected their behaviour and cognitive function.

A third observation of potential relevant importance in these children, is the relatively low red blood cell n-3 fatty acid content which is indicative of a low N-3 fatty acid intake. ${ }^{35}$ An Omega-3 index range of $8 \%-11 \%$ is recommended. ${ }^{11}$ Lower levels of Omega-3 fatty acids have been associated with a variety of behavioural disorders such as attention deficit /hyperactivity disorder ADHD). ${ }^{36}$ Currently there is important scientific data confirming the beneficial and protective effects of omega-3 fatty acids and their effects against inflammation, cancer and heart disease. ${ }^{37}$ Recent research also indicated a relationship between the Omega- 3 Index and processing speeds in teenagers. ${ }^{12}$ Teenagers with higher blood levels of Omega-3 displayed better information processing speeds, compared with those with lower levels. Every $1 \%$ increase in the Omega-3 index was linked to a 1.23 digit increase on the Letter Digit Substitution Test. The Omega-3 values recorded in the present study were not as low as that recorded in the study reported by van der Wurff et al . ${ }^{12}$ Only four children had values (2.4\%), above an index of $8 \%$. The average Index of $6.2 \%$, are still below the recommended range of $8 \%-11 \%$. From Table 2 it can be seen that $97.6 \%$ of children had an Omega-3 Index $<$ than $8 \%$, which is at the lower end of the suggested Index.

\section{Summary and conclusion}

Results from this study clearly showed that although these children appeared to be nutritionally in a good state, based, on their weight and heights, certain blood biochemical parameters indicated specific deficiencies that can potentially have far reaching cognitive and future health implications. Although the application of the various indices to this age group I can be questioned, it however points to an early condition that can have serious health consequences in later life.

Plasma levels of Carotenes, vitamin $\mathrm{E}$ and a relatively low red blood cell Omega 3index, indicated a low fruit and vegetable intake as well as a low intake of fish. Low intakes of these foods are known to have negative effects on inflammation, cognitive function and general health of the consumer.

\section{Conflict of interest}

None 


\section{References}

1. South African National Health and Nutrition Examination survey (SANHANES-1) Human Sciences Research Council Media Release No. 2. August 2013.

2. Pekmezci D. Vitamin E and immunity. Vitam Horm. 2011; 86: 179- 215.

3. Beharka A., Redican S., Leka L., Meydani S.N. Vitamin E status and immune function. Methods Enzymol. 1997; 282: 247- 263.

4. Vobecky J.S., Vobecky J., Shapcott D. Nutritional influences on humoral and cell-mediated immunity in healthy infants. J Am College Nutr. 1984; 3: 265.

5. Mangialasche F., Solomon A., Kareholt I., Hooshmand B., Cechetti R., Fratiglion L. Serum levels of vitamin E forms and risk of cognitive impairment in a Finnish cohort of older adults. Exp Geront. 2013; 48: 14281435.

6. Farrel P.M., Bieri J.G., Fratantoni J.F. The occurrence and effects of human vitamin E deficiency: a study in patients with cystic fibrosis. J Clin Invest. 1977; 60: 233-241.

7. Brevik A., Andersen L.F., Karlsen A., et al. Six carotenoids in plasma used to assess recommended intake of fruits and vegetables in a controlled feeding study. Europ J Clin Nutr. 2004; 58: 1166-1173.

8. Li C., Ford E.S., Guixiang Z., Balluz L.S., Wayne H.G, Lilu S. Serum $\alpha$-Carotene concentrations and the risk of death among US adults. The Third National Health and Nutrition Examination Survey Follow-up Study. Arch Intern Med. 2011; 171:507-515.

9. Donaldson M.S. A Carotenoid Health Index Based on Plasma Carotenoids and Health Outcomes. Nutrients. 2011; 3: 1033-1022.

10. Donaldson M. Development of a rapid, simple assay of plasma total Carotenoid. BMC. Research Notes. 2012; 5: 521

11. Harris W.S. Omega-3 fatty acids and cardiovascular disease: A case for omega-3 index as a new risk factor. Pharmacol Res. 2007; 55: 217- 223.

12. Van der Wurff I.S.M., von Shacky C., Berge K., Zeegens M.P., Kirshner P.A, de Groot R.H.M. Association between Blood Omega-3 Index and Cognition in Typically Developing Dutch Adolescents. Nutrients. 2016; 8 (1): 13 doi: 10.3390/nu 8010013.

13. Richardson A.J. The importance of omega-3 fatty acids for behaviour, cognition and mood. Scand J Nutr. 2003; 47(2): 92-98.

14. McGeachin R.B., Baily C.A. Determination of carotenoid pigments, retinol, and alpha-tocophero I in feeds, tissues and blood serum by normal phase high performance liquid chromatography. Poultry Sci. 1995; 291; 407-411.

15. Rizzo C., Dionisi-Vici C., D'Ipopoliti M., et al. A simple and rapid HPLC method for simultaneous determination of plasma 7-dehidrocholesterol and vitamin E. Clin Chim Acta. 2000; 291: 97-102.

16. World Health Organization. Physical status-the use and interpretation of anthropometry. Report of WHO Expert Committee, 1995; Technical report: No 854. Geneva: WHO.

17. WHO. Indicators for assessing vitamin A deficiency and their application in monitoring and evaluation intervention programmes. Geneva. World Health Organization, 1996. http://www. who.int/nutrition/ publications/micronutrients/vitamin a deficiency/WHONUT96.10.pdf

18. Food and Nutrition Board, Institute of Medicine. Dietary Reference Intakes for vitamin C, vitamin E, selenium, and carotenoids. Washington. National Academies Press. 2000.

19. Todd J., Simpson P., Estis J., Torres V., Wub A.H. Reference range and short- and long-term biological variation of interleukin (IL)-6 IL-17A and tissue necrosis factor- alpha using high sensitivity assays. Cytokine. 2013; 64: 660-665.

20. Danchek B., Nussenblat V., Kumvenda N., et al. Status of Carotenoids, Vitamin A, and Vitamin E in the Mother-Infant Dyad and Anthropometric Status of Infants in Malawi. J Health Popul Nutr. 2005; 23(4): 343-350.

21. Romero-Abal M.E., Mendoza I., Bulux J., Solomons N.W. Blood retinol and beta-carotene levels in rural Guatamala preschool children. Europ J Epid. 1995; 11:133-139. 


\section{Article 6}

22. Schweigert F.J., Klingner J., Hurtienne A., Zinft H.J. Vitamin A, carotenoid and vitamin E plasma concentrations in children from Lagos in relation to sex and growth failure. Nutr J. 2003; 2:17.

23. Lenhartz H., Schweitzer R., Botticher D., Leichsenring M. Plasma carotenoids in German children and adolescents. Europ J Pediatr. 1997; 156: 71-73.

24. Ford E.S., Gillespie C., Ballew C., Sowell A., Mamnimo M. Serum carotenoid concentrations in US children and adolescents. Am J Clin Nutr. 2002; 76: 818-827.

25. Erdman J.W. The physiologic chemistry of carotenes in man. Clin Nutr. 1988; 7: 101 -106.

26. Erdman J.W., Biere T.L., Gugger E.T. In: Canfield LM (ed) Carotenoids in human health. M. Dekker, New York. 1993; pp 76-85.

27. Watzl B., Kulling S.E., Moseneder J., Barth S.W. A 4-wk intervention with a high intake of carotenoid-rich vegetables and fruit reduces plasma $C$ reactive protein in healthy, non-smoking men. Am J Clin Nutr. 2005; 82: 1052-1058.

28. Bõhm F., Edge R., Land E.J., Mc Garvey D.J., Truscot T.G. .B-Carotene with vitamin E and C offers synergistic cell protection against $\mathrm{NO}_{2}$. Febs Letters. 1998; 436: 387-389.

29. Péter S., Friedel A., Roos F.F., et al. A Systematic Review of Global Alpha-Tocopherol Status as Assessed by Nutritional Intake Levels and Blood Serum Concentrations. Int J Vitam Nutr Res. 2016: 1-21.

30. Traber M.G. Vitamin E Inadequacy in Humans: Causes and Consequences. Adv Nutr. 2014; 5: 503-514.

31. Koscik R.L., Farrell P.M., Kosorok M.R., et al. Cognitive Function of Children with Cystic Fibrosis: Deleterious Effect of Early Malnutrition. Pediatrics. 2004; 113(6): 1549-1558.

32. Calder P.C., Albers R., Antoine J.M., et al. Inflammatory disease processes and interactions with nutrition. Br J Nutr. 2009; 101 Suppl 1: S1-45. (PubMed)

33. Sing U., Devaraj S., Jialal L. Vitamin E, Oxidative stress, and inflammation. Annu Rev Nutr. 2005; 25: 151174

34. Kalra V., Grover J., Ahuja G.K., Rathi S., Kurana D.S. Vitamin E deficiency and associated neurological deficits in children with protein-energy malnutrition. J Trop Pediatr. 1998; 44: 291-295.

35. O’Brien D.M., Kristal A.R., Jeannet M.A., Wilkinson M.J., Bersamin A., Luick B. Red blood cell $\delta 15 N$ : a novel biomarker of dietary eicosapentaenoic acid and docosahexaenoic acid intake. Am J Clin Nutr. 2009; 89: 913- 919.

36. Antalis C.J., Stevens L.J., Campbell M., Pazdro R., Ericson K., Burgess J.R. Omega-3 fatty acid status in attention-deficit/hyperactivity disorder. Prostag Leukotr Ess. 2006; 75: 200-308.

37. Gogus U., Smith C. n-3 Omega fatty acids: a review of current knowledge. Int J Food Sci Technol. 2010; 45: 417-436. 


\section{Article}

Effects of consumption of biscuits baked with Red Palm Oil (RPO) shortening on the vitamin $A, \alpha$-and $\beta$-Carotene status of pre-school children attending an informal crèche in Bethelsdorp, Eastern Cape. Part 2. Intervention Study. Nutritional and Health Status.

Submitted for publication:

Benade, A.J.S.*, Olivier, L.* , Bukasa, L. (2017) Effects of consumption of biscuits baked with Red Palm Oil (RPO) shortening on the vitamin A, $\alpha$ - and $\beta$-Carotene status of preschool children attending an informal crèche in Bethelsdorp, Eastern Cape. Part 2. Intervention Study. Nutritional and Health Status. South African Nutritional Journal, 2017

*equal contribution 


\section{Abstract}

Objective To determine the effects of consuming biscuits baked with Red Palm Oil on the vitamin A, $\alpha$ - and $\beta$-Carotene status of pre-school children attending an informal crèche.

Design This study was a continuation of the baseline study described earlier. We compared the effects of consuming two biscuits a day for six months, baked with either a Red Palm Oil (RPO) based shortening or biscuits baked with a palm oil shortening containing no Red Palm Oil on the vitamin A, $\alpha$-Carotene and $\beta$-Carotene status in preschool children. Sixty-four Pre-School children were recruited from four informal crèches and randomly assigned to either an A group (RPO) or a B (non-RPO) group. After base-line observations on anthropometry and blood sampling ${ }^{1}$ supplementation was initiated under the supervision of a trained field worker who kept a record of attendance and biscuit consumption of each child. Two biscuits $( \pm 40 \mathrm{~g})$ contained about $8 \mathrm{~g}$ shortening. All biscuits were baked with flour fortified with Vitamin A, Iron, Zinc, Thiamin, Riboflavin, Nocotinamide, Pyrodoxine and Folic acid, according to SA Governmental regulation. Obligatory fortification of flour and maize meal was introduced in South Africa in 2002 with the result that the sale of unfortified flour in the RSA is illegal. Notwithstanding the fact that flour was fortified in South Africa, there is evidence of vitamin A deficiency in South Africa. In addition, Iron, Zinc, Selenium, Copper and Manganese as Amino Acid complexes were added to the flour used for baking the biscuits (at $50 \%$ of NRV per 2 biscuits). Two RPO biscuits provided 2,2mg total carotene. Baseline observations were repeated after three and six months of supplementation and again six months after supplementation ended. The study was approved by the Faculty of Applied Sciences Ethics Committee of the Cape Peninsula University of Technology.

Methodolgy A blood sample (last meal at least 12 hours before) was drawn from a forearm vein, while the child was in the supine position. EDTA was used as an anticoagulant. Plasma was immediately separated from red blood cells and stored on dry ice. Samples were then air-freighted to our laboratories in Bellville and stored at $-40^{\circ} \mathrm{C}$ until analysis of, $\alpha$ - and $\beta$-Carotenes and Retinol. Blood could not be analysed for Iron, Zinc and Selenium because the amount of blood drawn was inadequate for these analysis.

Results Only results of children who were present at all the sampling times were included in the statistical analysis ( 47 children). Results from the $A$ and $B$ groups during the course of the study were compared with baseline values and statistically analysed. Forty-seven participants - twenty-five in the A group and twenty-two in the B group attended all four blood collection sessions and were included in the final analysis.

During supplementation, mean plasma a-Carotene levels increased seven-fold from base-line values in the A group whilst only small non-significant changes from base-line 
levels were observed in the B group. After supplementation was stopped, group A, $\alpha$ Carotene levels declined to base-line levels. Plasma $\beta$-Carotene levels in the A group increased two-fold above baseline. After six-months supplementation, values returned to base-line levels six months after supplementation was terminated. Again only small insignificant changes from baseline were observed in the B group.

The prevalence of mean biochemical Vitamin A deficiency in the two groups was $9.8 \%$ at baseline, declined to $3.9 \%$ after six months of supplementation, to increase again to $20.5 \%$ after cessation of supplementation. No significant difference was found in the response to biscuit supplementation between the two groups. It was therefore decided to pool the results of group A and B.

Conclusion Consumption of a biscuit baked with a RPO based shortening showed significant increases in plasma $\alpha$ - and $\beta$-Carotene. Based on the increased blood levels of $\alpha$ Carotene after supplementation with the RPO biscuit, the importance of RPO in the promotion of general health should be considered.

Key words: Red Palm Oil biscuits, Blood Carotene, Vitamin A, Informal crèche children. 


\section{Introduction}

Micronutrient malnutrition in South Africa is widespread. According to UNICEF ${ }^{2}$, one out of two children in SA, in the age group 0-4 years old, had an intake of less than half the recommended level of vitamin A, vitamin C, Riboflavin, Niacin, vitamin B6, Folate, Calium, Iron and Zinc. The same report also indicated that $21.4 \%$ children in this age group were anaemic and 33\% were vitamin A deficient. This report is in agreement with that reported in SANHANES. ${ }^{3}$ Micronutrient malnutrition, also known as "hidden" hunger has serious consequences. For example, vitamin A deficiency is associated with an impaired immune response with lowered resistance against infection. ${ }^{4}$

There are several reports showing that the consumption of biscuits containing Red Palm Oil (RPO) significantly improve the vitamin A status of school children who are vitamin A deficient. ${ }^{5,6,7}$ Significant improvements in serum retinol concentrations were also reported in pre-school children supplemented with $\mathrm{RPO}^{8,9}$, or receiving RPO and carrot noodle. ${ }^{10}$

Researchers from the Institute of Nutrition and Food Science, at the University of Dhaka reported a decrease in the prevalence of acute respiratory infection from $38 \%$ to $17 \%$ in school children aged 13-17 years and who consumed biscuits baked with RPO for three months. ${ }^{11}$ To our knowledge, none of the other studies where RPO was used in school children, reported on the effect of RPO on immune function. However, other studies reported on the effect of RPO on the inflammatory and immune functions. In a study reported by Katengua-Thamahane ${ }^{12}$, the authors showed a clear antiinflammatory effect of RPO in rats treated with liposaccharide (LPS). RPO was also reported to have a positive effect on immune function. ${ }^{13}$ There is evidence that an inverse association exists between serum/plasma concentrations of $\alpha$-Carotene, $\beta$-Carotene

and Lycopene and serum/plasma C-reactive protein (CRP) concentrations. ${ }^{14,}{ }^{15}$ Although earlier studies demonstrated the ability of dietary carotenes to prevent infections, the belief was that the action of these Carotenoids may be through their prior conversion to vitamin A. It was however shown by Chew and Park ${ }^{16}$, that Carotenoids without provitamin $A$ activity, were as active and at times more active than $\beta$-Carotene in enhancing cell-mediated and humoral immune response in animals and humans.

In a study carried out by Benadé et al. ${ }^{17}$, with a RPO-based bread spread provided to primary school learners, a marked reduction in the prevalence of skin infections were seen in children consuming sandwiches containing the RPO spread.

\section{Methods}

As a result of an agreement, FARR recruited a community worker, paediatric nurse, a community nurse and seconded one of their staff members as a project co-ordinator for our proposed study. Under the guidance of the project co-ordinator, crèches were iden- 
tified as potential participants in the project. Recruitment of crèches and obtaining the necessary parental approval for the child's participation, was according to the procedures described in the baseline study. ${ }^{1}$

The RPO (A group) group received a biscuit that contained about 270 ppm Carotene and about500 ppmTocopherol/Tocotrienol (According to Certificate of Analysis as provided by the manufacturer). The $B$ biscuit was baked with palm oil shortening and contained about 500 ppm Tocopherol/Tocotrienol without carotene (according to the certificate of analysis provided by the manufacturer). The shortening for the biscuits was obtained from Carotino SDN BHD Malaysia and the biscuits baked by a bakery in Cape Town. All biscuits were baked with standard fortified flour. An additional amount of $50 \%$ of the NRV for Iron, Zinc, Copper, Manganese and Selenium as amino acid complexes was added to the flour before baking. These compounds were added to reduce the possible effects of potential deficiencies on the response of supplementation with RPO on the various parameters. Children received the biscuit five times a week except during holidays. A record of attendance and daily biscuit consumption was also kept for each child. Previous work indicated that baking had only a small effect on the carotene content of biscuits baked with RPO shortening. All biscuits used in the study had a vanilla flavour, which was the flavour of choice by the children.

The cake flour used for baking the biscuits was fortified with vitamin A, Iron, Zinc, Thiamin, Riboflavin, Nicotinamide, Pyrodoxine and Folic acid. Unfortunately, it was not possible to get unfortified flour as it is fortified in South Africa as determined by law. Obligatory fortification of flour and maize meal was introduced in South Africa in 2002 with the result that the sale of unfortified flour in the RSA is against the law and therefore illegal. Notwithstanding that flour was fortified in South Africa, there was still evidence of vitamin A deficiency in South Africa. For these reasons it was decided to go ahead with the study as planned.

Children were examined by a community health nurse at baseline, 3 months, at 6 months of supplementation and again 6 months after supplementation was stopped. Blood was drawn by a paediatric nurse at baseline, 3 and 6 months of intervention and again 6 months after intervention stopped. Plasma was separated from the red blood cells on the crèche site and stored on dry ice to be air-freighted to Cape Town during the same week that the blood was drawn.

\section{Blood Analysis}

Blood could not be analysed for Iron Manganese, Copper or Selenium because the amount of plasma obtained did not allow analysis of these elements. To be able to do these analyses as originally planned, a minimum of $10 \mathrm{ml}$ blood was required, which was seldom obtained. Some children co-operated well whilst others behaved in a very difficult way, which made it almost impossible to get blood from them. In all, the paediatric nurse was very competent and effective in obtaining blood samples. The age of the 


\section{Article 7}

children probably played a role in the amount of blood obtained. $\alpha$ - Carotene, $\beta$ Carotene and Retinol were extracted from plasma and analysed by HPLC according to the method described by McGeachin and Baily. ${ }^{18}$

\section{Statistical analysis}

All statistical analysis was performed using the NCSS statistical analysis package (NCSS 9 Statistical Software (2013) NCSS, LLC. Kaysville, Utah, USA, ncss. Com /software /ncss.). Two sets of analysis were performed, one on the full 'intention to treat' dataset and the other on data where only individuals with complete data were included. Generally, the analysis was performed on log-transformed data and then back transformed for illustration purposes to show geometric means and confidence intervals. The $95 \%$ confidence intervals were calculated throughout. To determine whether a transformation was required, descriptive analysis was performed on both untransformed and logtransformed data and the transformation decision based on the results.

For statistical reasons, only those research participants who were present on all four occasions for observations, were included in the analysis. Based on this approach, fortyseven children were present on all four occasions of which twenty-five were from group A and twenty-two were from group B. Overall, sixty-three children were present when the baseline observations were made.

\section{Results}

Due of the amount of blood obtained from the children, not enough blood was available to do any analysis for trace elements such as selenium, iron, zinc, manganese and copper.

\section{Attendance of Pre-schoolers}

The attendance of children on a daily basis was voluntary and determined by factors such as parents' availability, social programmes and holidays of the parents. Although children attended on a regular basis, they were not obliged to attend every day. Because attendance was at times erratic, as indicated on attendance lists, data on attendance was considered to be unreliable for statistical analysis. 


\section{Geometric means and 95\% Cls for Retinol}



Figure 1(a): Biochemical vitamin A status

$a=$ Not significantly different from baseline at $p=0.05^{*}$

\section{Geometric means and CLs for Retinol}

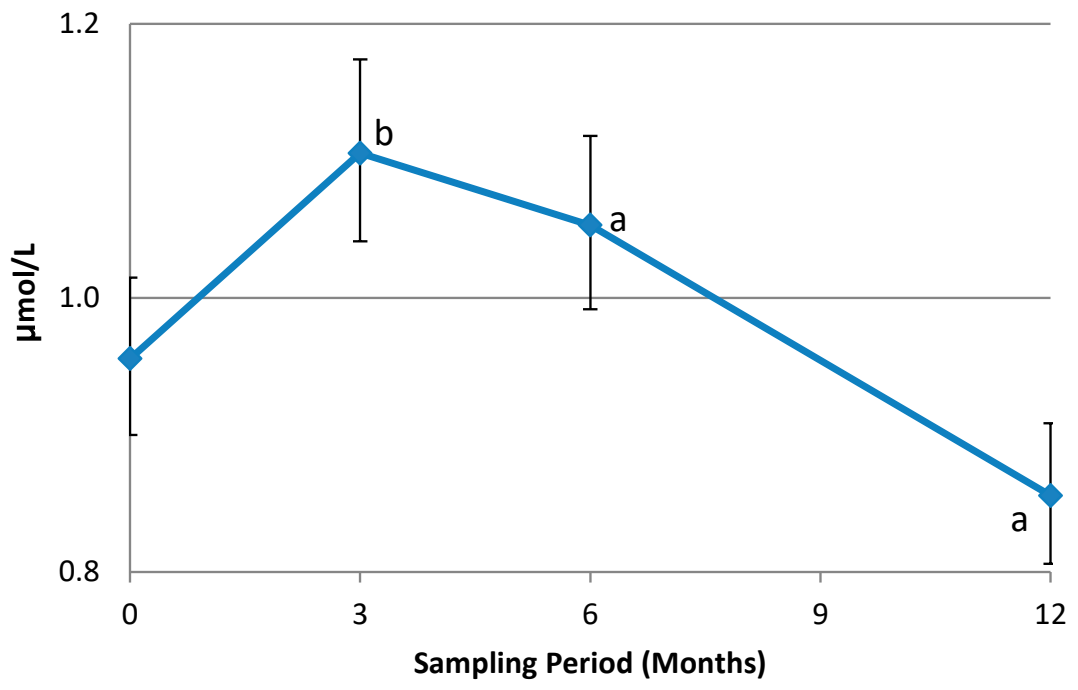

Figure 1(b): Geometric mean and CLs for Retinol

$a=$ Not significantly different from baseline at $p=0.05^{*}$

$b=$ Significantly different from baseline at $p=0.05 *$ 


\section{Article 7}

Figure 1 (a) shows the changes in the plasma Retinol levels in the $A$ and $B$ groups during supplementation. As no statistical difference was found between the two groups during intervention, data was pooled for statistical analysis as shown in Figure 1(b). Consuming two biscuits a day by both groups lead to a significant increase in plasma Retinol from baseline levels at 3-months supplementation. At 6-months of supplementation, a slight but not significant decline in plasma levels after supplementation was seen. However, the values recorded at 6-months were not significantly different from baseline levels. Six months after supplementation was stopped, plasma Retinol levels were not significantly different from baseline levels (Figure $1 \mathrm{a}$ and $1 \mathrm{~b}$ ).

As indicated in table two, vitamin A deficiency in this group of children before intervention, can be considered to be mild to moderate. ${ }^{19}$ At the end of intervention, prevalence of biochemical vitamin A deficiency declined from 9.8 - 3.9\%. When supplementation was stopped, the prevalence of vitamin A deficiency increased to $20.5 \%$ which can be considered as severe. ${ }^{19}$

Table 1. Vitamin A levels before, during and post intervention

\begin{tabular}{lr}
\hline Baseline & $9.8 \%$ \\
6 Months Intervention & $3.9 \%$ \\
Post-Intervention & $20.5 \%$ \\
\hline
\end{tabular}

Table 2. Vitamin A levels during intervention

\begin{tabular}{llr}
\hline Goup & Retinol $<0.7 \mu \mathrm{mol} / \mathrm{L}$ plasma & $\%$ \\
\hline A & Baseline & $13.8 \%$ \\
& 3 Months & $0.0 \%$ \\
& 6 Months & $6.9 \%$ \\
& 6 Months Post & $24.0 \%$ \\
B & Baseline & $4.6 \%$ \\
& 3 Months & $0.0 \%$ \\
& 6 Months & $0.0 \%$ \\
& 6 Months Post & $15.8 \%$ \\
\hline
\end{tabular}

From Table 2 it can be seen that, although the two groups were randomly assigned, group A had a higher prevalence of vitamin A deficiency than group B. The effect of intervention was however similar in the two groups, notwithstanding the fact that group A received a biscuit baked with RPO.

\section{Plasma $\alpha$-Carotene Levels}

A significant increase in plasma $\alpha$-Carotene levels from baseline was observed at three and six months in the A group whereas levels at six months after supplementation was stopped, decreased to baseline levels (Figure 2) and was not significantly different from baseline levels. 


\section{Geometric mean and 95\% CLs for $\alpha$-Carotene}

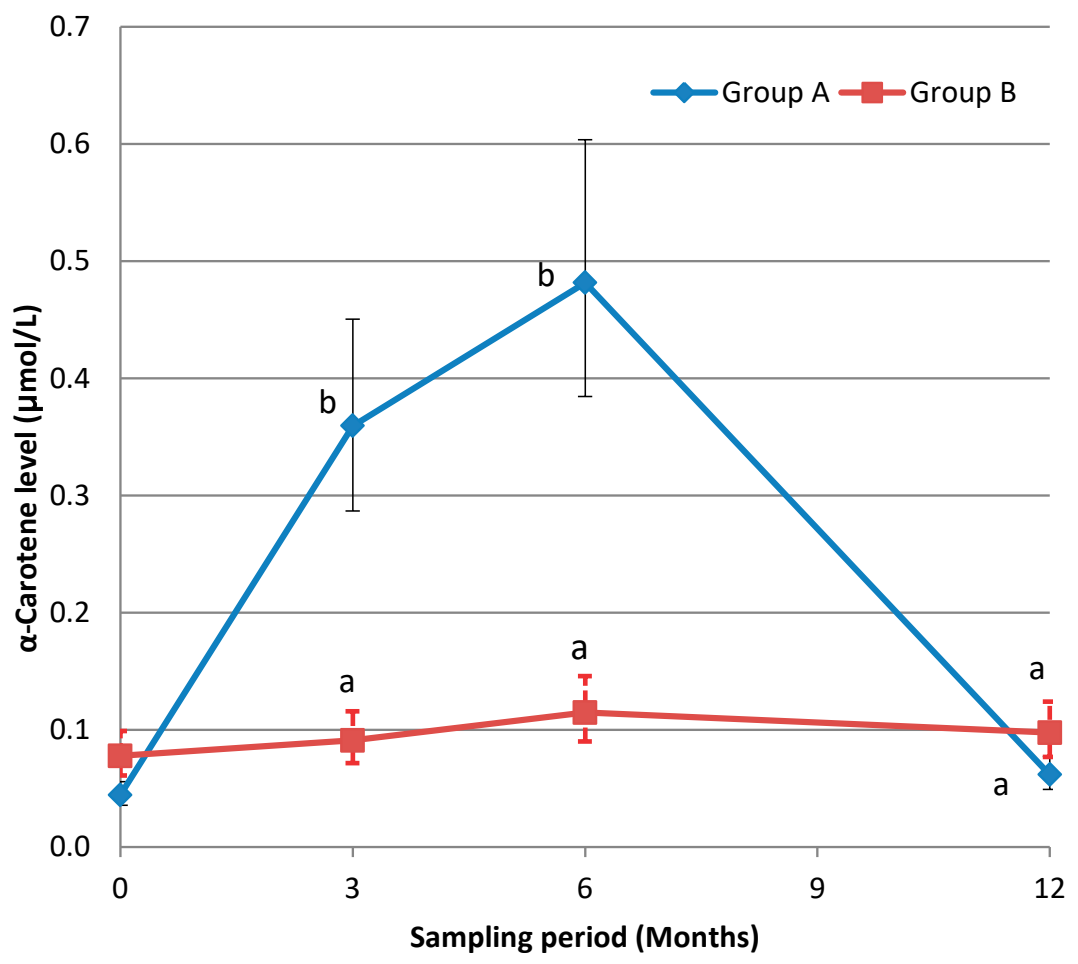

Figure 2: Changes in plasma $\alpha$-Carotene levels

$a=$ Not significantly different from baseline at $p=0.05$

$b=$ Significantly different from baseline at $p=0.05$

No significant changes from baseline, in plasma $\alpha$-Carotene levels were observed in the B group during supplementation.

\section{Plasma B-Carotene Levels}

As depicted in Figure 3, plasma $\beta$-Carotene levels increased significantly from baseline levels at three and six months after supplementation in the A group. Plasma levels declined to baseline levels six months after supplementation was stopped. No significant changes in plasma $\beta$-Carotene concentrations from baseline, were observed in the $B$ group during and after supplementation (Figure 3 ). 


\section{Geometric mean and 95\%s for ß-Carotene}

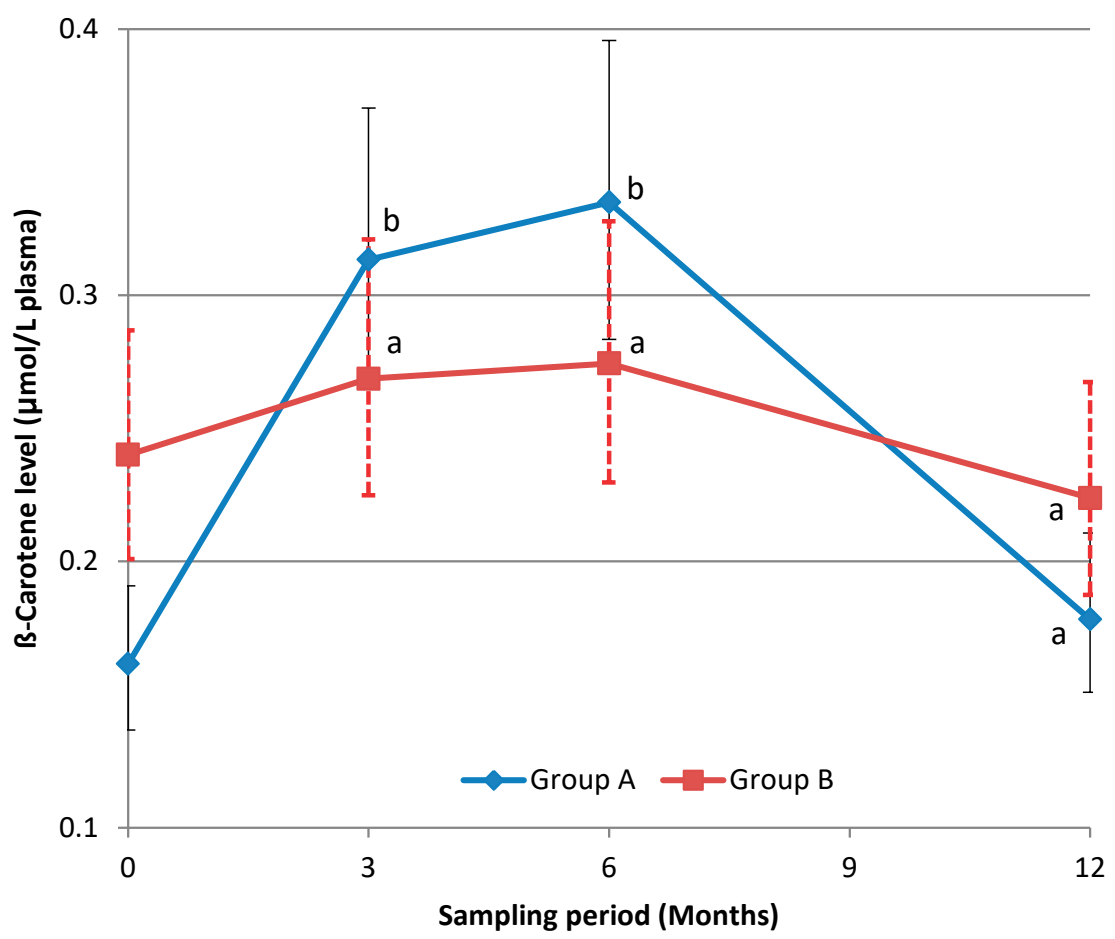

Figure 3: Plasma $\beta$-Carotene concentrations during and after supplementation

$a=$ Not significantly different from baseline at $p=0.05$

$b=$ Significantly different from baseline at $p=0.05$

\section{Discussion}

The observation of moderate biochemical vitamin A deficiency, according to $\mathrm{WHO}^{23}$ reference standards, in this group of children, notwithstanding a National Fortification Programme, warrants speculation. It could be argued that the intake of fortified foods by these children, was limited. In South Africa, staple foods such as bread and maize meal are fortified with vitamin A and other micronutrients. From information obtained from these children, maize meal porridge is seldom eaten by these children. Commercial maize meal based infant cereal is usually too expensive and parents in this low socio-economic group can hardly afford these products. Although bread flour is also fortified, bread is expensive and consumption by these children is consequently limited. Commercial fortified bread flour was used for baking the biscuits and the effect of consuming these biscuits on the vitamin A status of these children, can clearly be seen in the B group. Although the B biscuits did not contain pro-vitamin A (RPO), plasma vitamin A levels increased significantly 
during biscuit supplementation in both groups and the prevalence of vitamin A deficiency, decreased from 9.8 to $3.0 \%$ after six months of biscuit supplementation (Table 1). When biscuit supplementation stopped, the prevalence of vitamin A deficiency again increased sharply to $20.5 \%$, which can be considered as severe. ${ }^{19}$

This observation strongly supports the contention that vitamin A intake of these children was inadequate before and after supplementation.

Although previous studies proved that RPO can alleviate vitamin A deficiency in school learners ${ }^{4,5,6,11}$ and pre-schoolers ${ }^{7,9}$ results from the present study did not show any significant effect of RPO on the plasma Retinol levels. Figure 1a showed similar responses for the A and B groups with supplementation with a RPO and non-RPO biscuit. Our results suggest that when vitamin $A$ is available from food (fortification), the role of pro-vitamin A as a pre-cursor for vitamin A is less important. This is supported by the observation that plasma Retinol concentration was not affected by the presence of pro-vitamin A in the supplement. This observation further supports the contention that pro-vitamin A Carotenes are converted to vitamin A only on demand. ${ }^{20}$

Our results suggest that when adequate amounts of vitamin $A$ are present in food, pro- vitamin A carotenes play a subordinate role as a source of vitamin A. The drastic increase in vitamin A deficiency (prevalence increased from 3.9\% to $20.5 \%$ at 6 -months post intervention warrants comments. Although mean values for Retinol at 6-months post- supplementation did not differ significantly from baseline values, pooled values showed a drastic increase in the prevalence of vitamin A deficiency from $9.8 \%$ at baseline to $20.5 \%$ at 6 -months post-supplementation. These results do strongly suggest that stopping supplementation with a product fortified with vitamin A can have potential serious affects in terms of the prevalence of vitamin A deficiency. It also stresses the importance of continuation of the fortification process and even more important, a continued consumption of the fortified product once it is started.

Although no difference was seen between the $A$ and $B$ groups in terms of Retinol levels, results from the present study are vastly different from those of a previous study with biscuits baked with RPO. ${ }^{6}$ Firstly, the prevalence of vitamin A deficiency was much higher $39.1 \%$ as compared to $9.2 \%$ in the present study. Secondly, after 12 -months supplementation with a RPO biscuit, deficiency decreased from $39.1 \%$ to $12.2 \%$, whereas in our intervention mean deficiency decreased from $9.2 \%$ to $3.2 \%$ in the $A$ and $B$ groups. Also, in the first study, it was still possible to bake biscuits with unfortified flour. This was however, not possible in the present study. Results of the present study suggest that when fortified products are consumed, vitamin A deficiency will decline. As suggested earlier ${ }^{20}$, it would appear that pro-vitamin A such as $\alpha$ - and $\beta$-Carotene play subordinate roles in alleviating vitamin A deficiency when vitamin $A$ is present in the food consumed.

Consumption of a biscuit baked with RPO, lead to significant increases in plasma $\alpha$ and $\beta$-Carotene. When supplementation was stopped, blood levels of these carotenes declined to baseline levels. Mean levels of plasma $\alpha$ - and $\beta$-Carotene is in line with pub- 
lished international values. ${ }^{21,22,23}$ Plasma levels of Carotenes give some indication of fruit and vegetable intake of consumers. ${ }^{24}$ Based on the plasma Carotene levels measured in these children, fruit and vegetable intake must be considered to have been low.

It would appear that in the past, the main emphasis was on the potential role of $\alpha$ and $\beta$-Carotene as pro-vitamin $A$ and their ability to alleviate biochemical vitamin $A$ deficiency. Results from several studies carried out during the past decade, have provided more information on some of the other potential health advantages of an elevated plasma Carotene level ${ }^{25}$. Li and co-workers ${ }^{26}$ using data from NHANES III of US adults 20 years and older, showed that serum $\alpha$-Carotene concentrations were inversely associated with the risk of death from all causes and death rom cardiovascular disease, cancer and all causes other than CVD and cancer. This inverse association was also independent of demographic characteristics, lifestyle habits and traditional health risk factors. Donaldson ${ }^{27}$ reported on the results of a meta-analysis study in which results from sixty-two studies of plasma Carotenoids and health outcomes were analysed. Based on the data, a Carotenoid Health Index was proposed with an all risk mortality ranging from very high in those having a low Carotenoid index to very low, in those with a high plasma Carotenoid content. Although a Carotenoid Health Index was not determined in the present study, an approximation of the Carotenoid Health Index could be calculated. According to Donaldson ${ }^{28}, \beta$ - Carotene makes up about $30 \%$ of the total Carotenoids. It could therefore be assumed that the total Carotenoid level was about $0.6 \mu \mathrm{M}$ which is well below the lower end of the Carotenoid Health Index of $1 \mu \mathrm{M}$ which corresponds to the highest of an all mortality risk. It therefore makes a lot of sense to encourage consumers to adapt a lifestyle which will increase their blood Carotenoid levels and thus promote general health. That plasma Carotenoid levels can be improved by diet, is not only confirmed by the results of the present study, but also by the report of Brevik et al. ${ }^{24}$ Although the effect of consuming a biscuit baked with RPO on the Carotenoid Health Index can be estimated to be about 2.4 after consuming 2,2 mg of Carotenoids per day for six months, the value of Carotenoid intake as a means of increasing the Carotenoid Health Index, should not be under estimated

\section{Limitations of the study}

Several aspects of the study need to be considered.

Firstly, the question of the effects of using fortified flour for baking the biscuits must be considered. As fortification of all flour in the RSA is obligatory and non-fortified flour is subsequently not available. As mentioned earlier, the sale of unfortified flour is not permitted by law. We therefore had no choice but to use whatever was available. The reason for going ahead with the project notwithstanding the issue of using fortified flour was that some recent surveys confirmed the existence of vitamin A deficiency in children in the RSA notwithstanding the fortification of staple foods such as maize meal 
and flour. ${ }^{4}$ However, the results of this study appear to indicate that these children did not consume adequate amounts of fortified foods. This is further confirmed by the sharp increase in the prevalence of vitamin A deficiency six months after the biscuit supplementation was ended.

Secondly, not enough blood could be obtained to do micro-element analysis. Although we employed a competent paediatric nurse for blood collection, collaboration from the children was often poor, with the result that not enough blood could be collected for all the analysis indicated in the original protocol. Because of the limited amount of plasma available for analysis, we had to prioritise for which analysis the plasma will be used to obtain an acceptable number for statistical analysis.

\section{Conclusion}

Results showed that when children consumed biscuits baked with RPO shortening, plasma levels of $\alpha$ - and $\beta$-Carotene increased significantly from baseline levels during six months of supplementation. When supplementation was stopped after six months, plasma levels of $\alpha$ - and $\beta$-Carotene levels returned to baseline levels after six months without supplementation. An increase in the prevalence of vitamin A deficiency was observed at six months after the biscuit supplementation ended. No significant changes in baseline plasma levels of these Carotenes were seen during and after supplementation in the control group.

Comparable changes in plasma levels of Retinol, in the $A$ and $B$ groups during and after supplementation, appear to be un-related to the increased levels of $\alpha$ - and $\beta$ Carotene seen in the A group. At the levels of vitamin A deficiency observed in the present study, no difference was found between the Retinol response between the RPO group and the non RPO group. It must be pointed out that our previous findings on the ability of RPO to alleviate vitamin A deficiency in school children, involved children having vitamin deficiencies of $39.1 \%{ }^{6}$ This is in contrast to the present study where deficiencies of $10 \%$ were recorded. ${ }^{1}$ The efficacy of RPO in alleviating vitamin A deficiency at lower levels of deficiencies could be questioned. The role of trace elements and other micronutrients should also be considered.

\section{Acknowledgement}

We would like to thank FARR for their logistic support in the field during the execution of the study and MPOB for financially supporting the study.

\section{Conflict of interest}

None 


\section{References}

1. Benade A.J.S., Olivier L., Bukasa L. Nutritional and immune status of pre-school children attending an informal crèche in Bethelsdorp, Eastern Cape. SA J Clin Nutrional Journal (submitted for publication).

2. UNICEF, UNICEF statistical data on the status of children aged 0-4 in South Africa. 2007.

3. South African National Health and Nutrition Examination Survey (SANHANES-1), Human Sciences Research Council Media Release No. 2. 6 August 2013

4. Gibson R.S. Principles of nutritional assessment. $2^{\text {nd }}$ ed. Oxford University Press, Oxford. 2005.

5. Manorama R., Sarita M., Rukmini C. Red Palm Oil for combating vitamin A deficiency. Asia Pac J Clin Nutr. 1997; 6: 56-59.

6. Van Stuijvenberg M.E., Benade A.J.S. South African experience with the use of red palm oil to improve the vitamin A status of primary school children. Food Nutr Bull.2000:12-214.

7. Yu W., Yuexin Y., Yinhong Z., Jing Z., Tong L., Zeng W. An Intervention Study of Vitamin A Deficiency of Rural School-age Children in Gansu Province in China. MPOB International Palm Oil Congress. PIPOC 2015, Food, Health \& Nutrition, Kuala Lumpur, Malaysia.

8. Sivan Y.S., Alwin Jayakumar Y., Arumughan C., et al. Impact of vitamin A supplementation through different stages of red palm oil and retinol palmitate on preschool children. J Trop Pediats. 2002; 48: 24-28.

9. Nguyen T.L. Effects of red palm oil supplementation on vitamin A and iron status of rural under- five children in Vietnam. Proceedings of Food Technology and Nutrition Conference. International Palm Oil Congress, Kuala Lumpur, Malaysia. 2001.

10. Marliyati S.A., Sulaeman A., Damanik R.M., et al. Efficacy of Red Palm Oil and Carrot Noodle on Blood Retinol, IgG and Nutritional Status of Children Aged 7-9 Years. Pak J Nutr. 2014; 13: 134-140.

11. Shah M.D., Keramat Ali, Khaleda Adib, et al. Effects of beta-carotene on acute respiratory infection in a girls' school of Dhaka City. Chest and Heart Journal. 2003; 27: 70-76.

12. Katengua-Thamahane E., Marnewick J.L., Ajuwon O., et al. The combination of red palm oil and rooibos show anti-inflammatory effects in rats. J Inflamm. 2014; 11: 41.

13. Cooper K.A., Adelekan D.A., Esimai A.O., Northrop-Clemens C.A., Thurnham D.L. Lack of influence of red palm oil on severity of malaria infection in pre-school Nigerian children. Trans R Soc Trop Med Hyg. 2002; 96:216-223.

14. Kritchefsky D. Beta-carotene, carotenoids and the prevention of coronary heart disease. J Nutr. 2000; 129: 5-8.

15. Boosalis M.G., Snowden D.A., Tully C.L., Myron D., Gross P.H.D. Acute phase response and plasma carotenoid concentration in older women: Findings from the nun study. Nutrition. 1996; 12: 475-478.

16. Chew B.P., Park J.S. Carotenoid action on the immune response. The American Society for Nutritional Sciences. J Nutr. 2004; 134: 2575-2615.

17. Benade A.J.S., Marais C. de W, Lombard C.J. The development, nutritional composition and acceptability of a red palm oil-based micronutrient-fortified bread spread for feeding programmes. Proceedings of Food Technology and Nutrition Conference, International Palm Oil Congress, Kuala Lumpur, Malaysia, 2005.

18. McGeachin R.B., Bailey C.A. Determination of carotenoid pigments, retinol, and alpha-tocopherol in feeds, tissues and blood serum by normal phase high performance liquid chromatography. Poultry Sci. 1995; 291: 407-411.

19. WHO. Indicators for assessing vitamin A deficiency and their application in monitoring and evaluation intervention programmes. Geneva, World Health organization. 1996.

20.http://www.who.int/nutrition/publications/micronutrients/vitamin a deficiency/WHONUT96.10.pdf

21. Ribay-Mercado J.D., Solon F.S., Solon M.A., et al. Bioconversion of plant carotenoids to vitamin A in Filipine school-aged children varies inversely with vitamin A status. Am J Clin Nutr. 2002; 72: 455-465.

22. Ford E.S., Gillespie C., Ballew C., Sowell A., Mamnimo M. Serum carotenoid concentrations in US children and adolescents. Am J Clin Nutr. 2002; 76: 818-827. 
23. Schweigert F.J., Klingner J., Hurtienne A., Zunft H. Vitamin A, carotenoid and vitamin E plasma concentrations in children from Laos in relation to sex and growth failure. Nutr J. 2003; 2: 17.

24. Dancheck B., Nussenblatt V., Kumwenda N., et al. Status of Carotenoids, Vitamin A, and Vitamin E in the mother-infant Dyad and Anthropometric Status of Infants in Malawi. J Health Popul Nutr. 2005; 23: 343350.

25. Brevik A., Andersen L.F., Karlsen A., Trygg K.U. Six carotenoids in plasma used to assess recommended intake of fruits and vegetables in a controlled feeding study. Eur J Clin Nutr. 2004; 58: 1166-1173.

26. Rao A.V., Rao L.G. Carotenoids and human health. Parmacol Res. 2007; 55: 207-216.

27. Li C., Ford S., Guixiang Z., Balluz L.S., Wayne H.G., Lilu S. Serum $\alpha$-Carotene Concentrations and risk of Death Among US Adults. The Third National Health and Nutrition Examination Survey Follow-up Study. Arch Intern Med. 2011; 171: 507-515.

28. Donaldson M.S. A Carotenoid Health Index Based on Plasma Carotenoids and Health Outcomes. Nutrients. 2011; 3: 1003-1022.

29. Donaldson M. Development of a rapid, simple assay of total plasma Carotenoid. BMC. Research Notes 2012; 5: 521. 



\section{Article}

\section{Effects of biscuits baked with Red Palm Oil (RPO) shortening on the vitamin $E$ and inflammatory status of pre-school children attending an informal crèche in Bethelsdorp, Eastern Cape. Part 3. Intervention Study. Nutritional and Health Status.}

Submitted for publication:

Benade, A.J.S. ${ }^{*}$, Olivier, L.* , Bukasa, L. (2017) Effects of biscuits baked with Red Palm Oil (RPO) shortening on the vitamin $E$ and inflammatory status of pre-school children attending an informal crèche in Bethelsdorp, Eastern Cape. Part 3. Intervention Study. Nutritional and Health Status. South African Nutritional Journal, 2017

*equal contribution 


\section{Abstract}

Background Methodology We compared the effects of consuming two biscuits a day for six months, baked with either a Red Palm Oil based shortening or biscuits baked with a palm oil shortening containing no Red Palm Oil on the vitamin E and inflammatory status of pre-school children. Sixty-four pre-School children were recruited from four informal crèches and randomly assigned to either an A group (RPO) or a B (non-RPO) group. After base-line observations on anthropometry and blood sampling, supplementation was initiated under the supervision of a trained field worker who kept a record of attendance and biscuit consumption of each child. Two biscuits $( \pm 40 \mathrm{~g})$ contained about $8 \mathrm{~g}$ shortening and all biscuits were baked with flour fortified with Vitamin A, Iron, Zinc, Thiamin, Riboflavin, Nocotinamide, Pyrodoxine and Folic acid, according to SA Governmental regulation. Obligatory fortification of flour and maize meal was introduced in South Africa in 2002 with the result that the sale of unfortified flour in the RSA is illegal. Notwithstanding the fact that flour was fortified in South Africa, there is evidence of vitamin A deficiency in South Africa. In addition, Iron, Zinc, Selenium, Copper and Manganese as Amino Acid complexes were added to the flour used for baking the biscuits (at $50 \%$ of NRV per 2 biscuits). Two RPO biscuits provided approximately $4 \mathrm{mg}$ vitamin $\mathrm{E}$. Baseline observations were repeated after three and six months of supplementation and again six months after supplementation with the biscuits was ended. The study was approved by the Faculty of Applied Sciences Ethics Committee of the Cape Peninsula University of Technology.

Blood analysis A fasting blood sample (last meal at least 12 hours before) was drawn from a forearm vein, while the child was in the supine position. EDTA was used as an anti-coagulant. Plasma was immediately separated from red blood cells and stored on dry ice. Samples were then air-freighted to our laboratories in Bellville and stored on dry ice until analysis of $\alpha$ - Tocopherol by High Pressure Liquid Chromatography (HPLC) Plasma CRP and IL-6 were measured by using Elisa kits. Blood could not be analysed for Iron, Zinc and Selenium because the amount of blood drawn was inadequate to do these analyses.

Results Only results of children who were present at all the sampling times were included in the statistical analysis (47 children). Results from the A and B groups during the course of the study were compared with baseline values and statistically analysed. Forty-seven participants 25 in the A group and 22 in the B group were present at all four blood collection sessions and were included in the final analysis. Baseline values for stunting and underweight and vitamin A status were reported previously and were found to be low as reported earlier. ${ }^{1}$ A high prevalence of $\alpha$-tocopherol deficiency $(<12 \mu \mathrm{mol} / \mathrm{L})$ was observed for the group as a whole at baseline. When a cut-off value of less than $12 \mu \mathrm{mol} / \mathrm{L}$ was used a prevalence rate of $69 \%$ was seen. Using cut-off values of less than $20 \mu \mathrm{mol} / \mathrm{L}$, the prevalence was $94 \%$. After 6 -months intervention, prevalence 
levels declined to $10.0 \%$ (less than $12 \mu \mathrm{mol} / \mathrm{L}$ ) and $61 \%$ (less than $29 \mu \mathrm{mol} / \mathrm{L}$ ). Six months after biscuit supplementation was stopped, the respective prevalence levels were $0 \%$ and $61.0 \%$ respectively.

Biscuit supplementation had a tendency to reduce the levels of circulating plasma levels of CRP and IL-6. After cessation of the biscuit supplementation, plasma levels of these markers showed a clear upward trend towards baseline levels.

HPLC analysis of plasma samples with the method used, did not detect any tocotrienols in the plasma during the period of supplementation. As the plasma half-life for Tocotrienols is short and its clearance from plasma and liver is within 24 hours. Our observation of not recording any elevation in plasma levels of Tocotrienols in these fasting children about 24 hours after the last biscuit was consumed, is in line with the literature.

Conclusion Consumption of a biscuit baked with a RPO based shortening showed significant increases in plasma $\alpha$-Tocopherol. The use of palm oil shortening can play a significant role in alleviating alpha-tocopherol deficiency in populations having $\alpha$-tocopherol deficiency. 


\section{Introduction}

Researchers from the Institute of Nutrition and Food Science, at the University of Dhaka reported a decrease in the prevalence of acute respiratory infection from $38 \%$ to $17 \%$ in school children aged 13-17 years, and who consumed biscuits baked with RPO for three months. $^{2}$

To our knowledge, none of the other studies where RPO was used in school children, reported on the effect of RPO on immune function or indicators of inflammation in school- children. However, other studies reported on the effect of RPO on the inflammatory and immune functions. In a study reported by Katengua-Thamahane ${ }^{3}$, the authors showed a clear anti- inflammatory effect of RPO in rats treated with liposaccharide (LPS). RPO was also reported to have a positive effect on immune function. ${ }^{4}$

As RPO is a rich source of carotenes and vitamin E, the potential of improved immune function during consumption of products containing RPO must be considered in the light of the existing evidence regarding the ability of dietary carotenes to prevent infections. Recent results from a clinical trial with vitamin $E$ Tocotrienol ${ }^{5}$ showed the beneficial enhancing effect on the immune response of healthy human subjects following an immunogenic challenge such as vaccination. In a study on mice, it was shown that dietary supplementation with Tocotrienols enhances immune function by having a beneficial effect in improving age-related decline in T-cell function. ${ }^{6}$

In a study carried out by Benadé et al. ${ }^{7}$, with a RPO-based bread spread provided to primary school learners, a marked reduction in the prevalence of skin infections were seen in children consuming sandwiches containing the RPO spread.

\section{Methods}

As a result of an agreement, FARR recruited a community worker, paediatric nurse, a community nurse and seconded one of their staff members as a project co-ordinator for our proposed study. Under the guidance of the project co-ordinator, crèches were identified as potential participants in the project. Recruiting crèches and obtaining the necessary parental approval for the child's participation, was according to the procedures described in the baseline study. ${ }^{1}$

The RPO (A group) group received a biscuit that contained about 270 ppm Carotene and about 500 ppmTocopherol/Tocotrienol (According to certificate of analysis as provided by manufacturer). The $B$ biscuit was baked with palm oil shortening and contained about 500 ppm Tocopherol/Tocotrienol (but no Carotene, according to the certificate of analysis provided by the manufacturer). The shortening for the biscuits was obtained from Carotino SDN BHD Malaysia and the biscuits baked by a bakery in Cape Town. All biscuits contained an extra 50\% of the NRV for Iron, Zinc, Copper, Manganese and Selenium as an amino acid complex. These compounds were added to reduce the possible 
effects of potential deficiencies on the response of supplementation with RPO on the various parameters. Children received the biscuit five times a week except during holidays. Biscuits were consumed under the supervision of the field worker. A record of attendance and daily biscuit consumption was also kept for each child. Previous work indicated that baking had only a small effect on the carotene content of biscuits baked with RPO shortening. All biscuits used in the study had a vanilla flavour, which was the flavour of choice by the children.

The cake flour used for baking the biscuits was additionally fortified with vitamin A, Iron, Zinc, Thiamin, Riboflavin, Nicotinamide, Pyrodoxine and Folic acid. Unfortunately, it was not possible to get unfortified flour as it is fortified in South Africa as determined by law. Obligatory fortification of flour and maize meal was introduced in South Africa in 2002 with the result that the sale of unfortified flour in the RSA is against the law and therefore illegal. Notwithstanding that flour was fortified in South Africa, there was still evidence of vitamin A deficiency in South Africa. For these reasons it was decided to go ahead with the study as planned.

Children were examined by the community health nurse at baseline, 3 months, at 6 months of supplementation and again 6 months after supplementation was stopped. Blood was drawn by a paediatric nurse at baseline, 3 and 6 months of intervention and again 6 months after intervention stopped. Plasma was separated from the red blood cells on the crèche site and stored on dry ice to be air-freighted to Cape Town.

\section{Blood Analysis}

Blood could not be analysed for Iron Manganese, Copper or Selenium because the amount of plasma obtained did not allow analysis of these elements. To be able to do these analyses as originally planned, a minimum of $10 \mathrm{ml}$ blood was required, which was seldom obtained. Some children co-operated well whilst others behaved in a very difficult way, which made it almost impossible to get blood from them. Age of the children probably played a role in this. The paediatric nurse was very competent and effective in obtaining blood samples. $\alpha$ - Tocopherol was extracted from plasma and determined by HPLC according to the method as described by Rizzo et al. ${ }^{8}$ Human C-reactive protein (CRP), II-6 and TNF-alpha activity were determined on plasma samples frozen on dry ice. Elisa kits purchased from Millipore (Millipore Cat. No. CYT 298, Cat. No. EZHIL6 and Cat No EZHTNFA respectively) were used for determining CRP, II-6 and TNF-alpha activities in plasma samples.

\section{Statistical analysis}

All statistical analysis was performed using the NCSS statistical analysis package (NCSS 9 Statistical Software (2013) NCSS, LLC. Kaysville, Utah, USA, ncss. com/ software / ncss.). Two sets of analysis were performed, one on the full 'intention to treat' dataset and the 
other on data where only individuals with complete data were included. Generally, the analysis was performed on log-transformed data and then back transformed for illustration purposes to show geometric means and confidence intervals. The $95 \%$ confidence intervals were calculated throughout. To determine whether a transformation was required, descriptive analysis was performed on both untransformed and logtransformed data and the transformation decision based on the results.

For statistical reasons, only those research participants who were present on all four occasions for observations, were included in the analysis. Based on this approach, fortyseven children were present on all four occasions of which twenty-five were from group A and twenty-two were from group B. Overall, sixty-three children were present when the baseline observations were made.

\section{Results}

As blood TNF-alpha levels did not show any change from base-line levels during and after supplementation, they were not included in the results. Because of the amount of blood obtained from the children, not enough blood was available to do any analysis for trace elements such as selenium, iron, zinc, manganese and copper.

\section{Attendance of Pre-schoolers}

The attendance of children on a daily basis was voluntary and determined by factors such as parents' availability, social programmes and holidays of the parents. Although children attended on a regular basis attendance was not obligatory. The pattern of attendance was however dependant on the parent's availability for transporting the child to the crèche, or escorting the child to the crèche, the time the parents had to take leave. Because of these reasons, attendance data was not considered for statistical analysis.

\section{Plasma Tocopherol}

Plasma $\alpha$-Tocopherol increased significantly, in both groups from baseline, at 3 and 5 months during supplementation and 5 months after the end of supplementation. (Figure 1). No differences were observed in the response between the two groups, to supplementation. 
Geometric mean and 95\% CLs for $\alpha$-Tocopherol

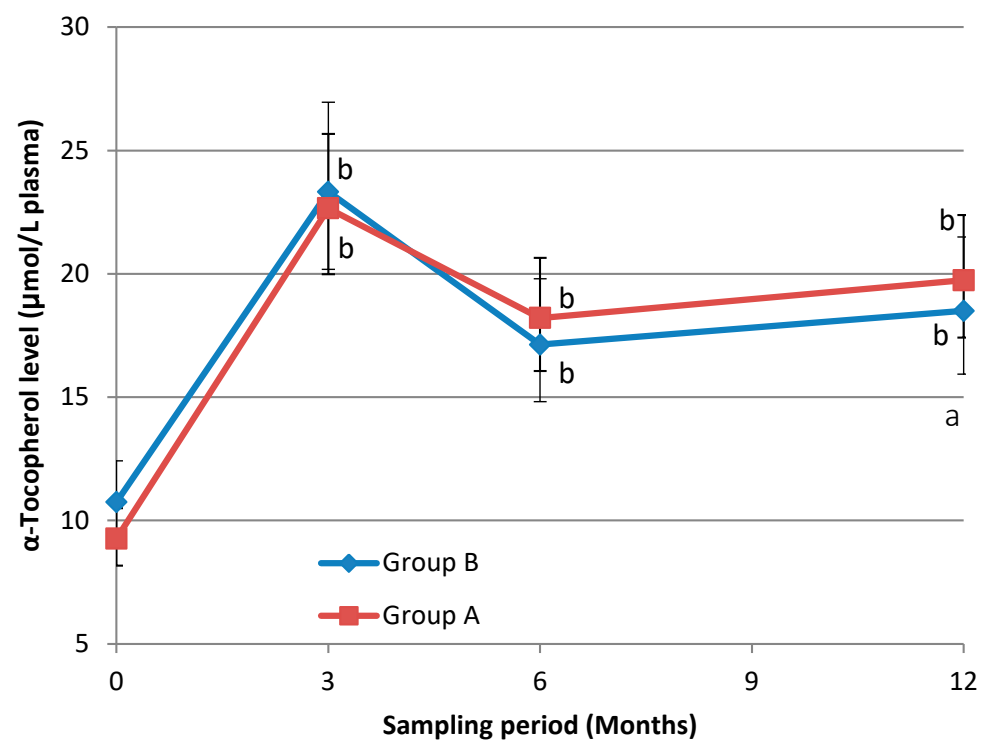

Figure 1: Plasma $\alpha$-Tocopherol levels

$a=$ Not significantly different from baseline at $p=0.05$

$b=$ Significantly different from baseline at $p=0.05$

Table 1 summarizes the mean prevalence of vitamin E deficiency in the two groups. It has been suggested that a desirable plasma concentration of $\geq 30 \mu \mathrm{mol} / \mathrm{L}$ is desirable at which beneficial health effects may occur. ${ }^{9}$ Using, a cut-off value of $\leq 12 \mu \mathrm{mol} / \mathrm{l}$, the deficiency threshold defined by $10 \mathrm{M}^{10}$ the prevalence at baseline was $69 \%$. Using the same cut-off, the prevalence was $10 \%$ at 6 -months intervention and $0 \%$ six months after supplementation ended. Using an arbitrary cut-off of less than $20 \mu \mathrm{mol} / \mathrm{L}$ the respective values were $94.0 \%, 61.1 \%$ and $61.1 .0 \%$ respectively. Supplementation clearly improved the vitamin E status of the participants, which was even evident after supplementation stopped.

Table 1. $\alpha$-Tocopherol cut-off values

\begin{tabular}{ll}
\hline Plasma a-Tocopherol cut-off levels & \\
\hline Baseline & \\
$<12 \mu \mathrm{mol} / \mathrm{L}$ & $69 \%$ \\
$<20 \mu \mathrm{mol} / \mathrm{L}$ & $94.0 \%$ \\
6 months intervention & \\
$<12 \mu \mathrm{mol} / \mathrm{L}$ & $10.0 \%$ \\
$<20 \mu \mathrm{mol} / \mathrm{L}$ & $61.1 \%$ \\
6 months post-intervention & \\
$<12 \mu \mathrm{mol} / \mathrm{L}$ & $0.0 \%$ \\
$<20 \mu \mathrm{mol} / \mathrm{L}$ & $61.1 \%$ \\
\hline
\end{tabular}

Plasma C-Reactive Protein (CRP) 


\section{Article 8}

As CRP did not differ significantly between groups, results were pooled for statistical analysis (figure 5). Plasma levels of CRP declined during supplementation to reach significantly lower levels from baseline $(p=0.05)$ after six months of supplementation. When supplementation was stopped, levels of CRP increased significantly compared to levels observed after six months of supplementation $(p=0.05)$. Mean baseline levels measured, suggest that average baseline values still fall within the normal range. (less than $3.8 \mathrm{mg} / \mathrm{L}$ ). However, using baseline CRP plasma levels of $3.8 \mathrm{mg} / \mathrm{L}$ (Millipore as a cut-off point, it was calculated that $29 \%$ of the children had CRP plasma levels higher than $3.8 \mathrm{mg} / \mathrm{L}$ and could be considered to have high levels of inflammation before intervention.

\section{Geometric Means and 95\% CLs for CRP}

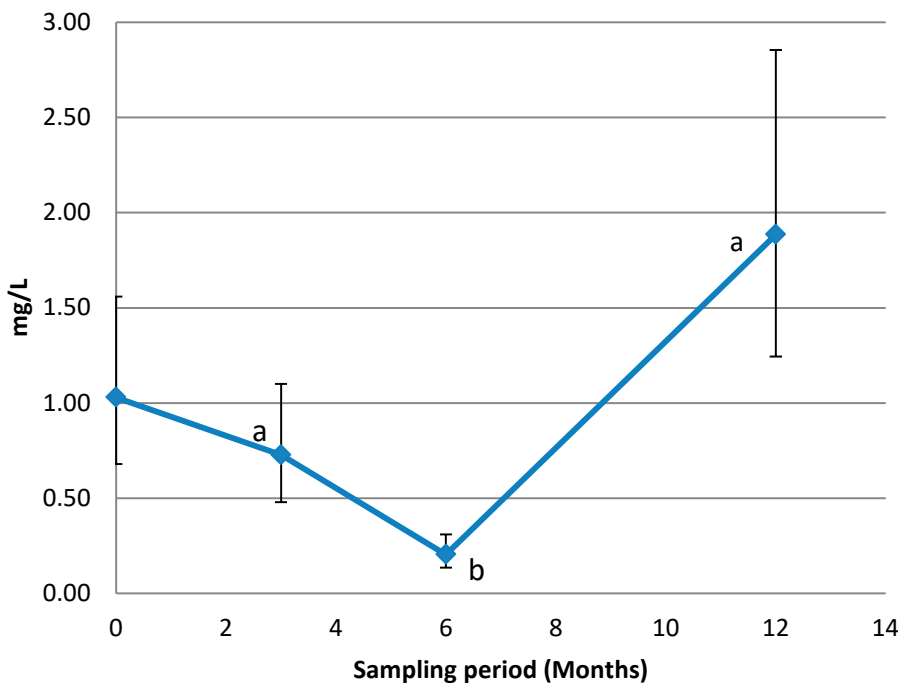

Figure 2

$a=$ Not significantly different from baseline at $p=0.05$

$b=$ Significantly different from baseline at $p=0.05$

Changes observed in the level of CRP during and after supplementation occur within normal values of CRP $(<3.8 \mathrm{mg} / \mathrm{L}$. Millipore Human C-Reactive Protein (CRP)Elisa Kit)

\section{Plasma Interleukin-6 Activity (IL-6)}

Again, as no significant difference was found in the plasma IL- 6 activity between the two groups, results obtained during supplementation were pooled for statistical analysis (Figure 6).

Activity was found to decrease significantly $(p=0.05)$ during supplementation to reach activities significantly lower than baseline at 3 and 6 months of supplementation. During the six months when the children did not receive supplementation, IL-6 increased to reach levels that were higher than those measured at 3 and 6 months during 
supplementation but not significantly different from baseline levels $(p=0.05)$. Again using an arbitrary cut-off level of $4.5 \mathrm{pg} / \mathrm{ml}^{11}$ for baseline values, IL- 6 values showed that $24 \%$ of the children had IL-6 levels above these cut-off levels, which confirms the CRP observations.

\section{IL-6}

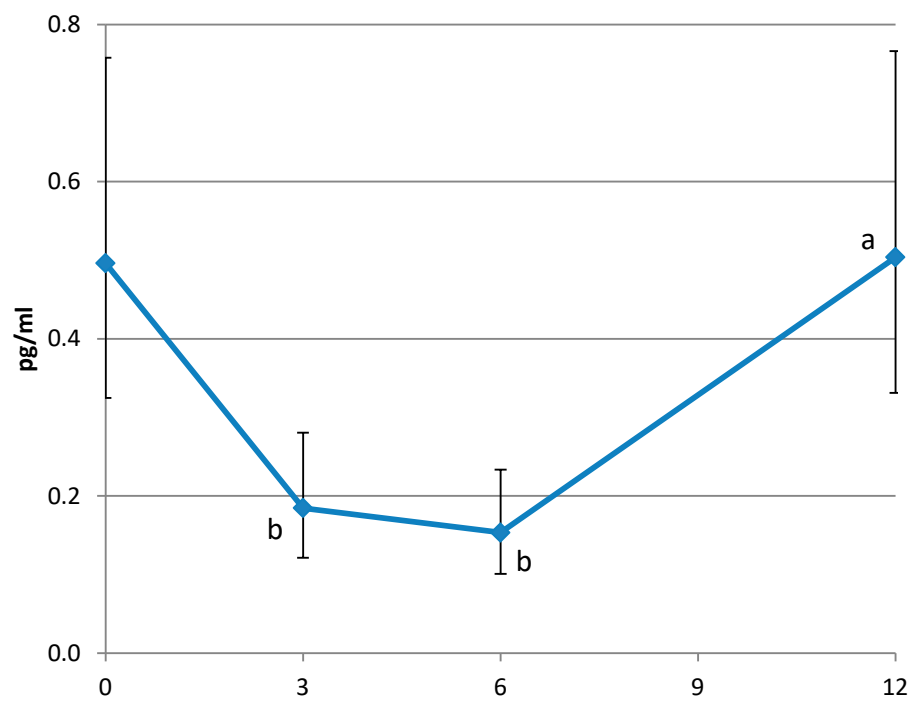

Figure 3

$a=$ Not significantly different from baseline at $p=0.05$

$b=$ Significantly different from baseline at $p=0.05$

Mean changes measured in the level of IL-6 during and after supplementation occur within normal values of IL-6 $(<4.8 \mathrm{pg} / \mathrm{ml})$.

\section{Discussion}

A rather surprising observation of the current study was the observed low vitamin $E$ levels in these children. Mean base-line levels of $\alpha$-Tocopherol were about $11 \mu \mathrm{mol} / \mathrm{L}$. Using a cutoff values of $<12 \mu$ mole $/ L^{10}$ and $<20 \mu$ mole $/ L$, revealed a prevalence rate of $69 \%$ and $94.0 \%$ respectively. After 6 months of supplementation with the biscuits these values declined to $10 \%$ and $61.1 \%$ respectively. Six months after supplementation stopped, the respective values were $0 \%$ and $61.1 \%$. These values clearly showed that palm oil-based shortening had a significant long- term effect on $\alpha$-Tocopherol levels. It is estimated that the amount of $\alpha$-Tocopherol provided by the two biscuits was about $1 \mathrm{mg}$ per day. Two biscuits per day supplied a further3mg of Tocotrienol. These results further suggest that after supplementation was stopped, $\alpha$-Tocopherol accumulated in the body, and continued to provide the metabolic needs (based on the $<12 \mu$ mole/L blood levels). The prevalence 
of vitamin E deficiency in our study, is in line with that reported for children in more or less the same age group in Brazil, Argentina and Mexico ${ }^{12}$, Korea ${ }^{13}$ and Allen et al. Mexico. ${ }^{14}$ The relatively low $\alpha$-Tocopherol values measured in these children at baseline potentially have significant health implications. The relatively elevated biomarkers for inflammation, CRP and IL- 6 at baseline, could potentially have been caused by a combination of different factors of which $\alpha$-Tocopherol could have played a role.

Vitamin $\mathrm{E}$ has many functions in the body, and is best known for its role as an antioxidant. It is the most important chain-breaking, lipid-soluble antioxidant present in body tissues and is considered the first line of defence against lipid per oxidation. It is important for normal function of immune cells. ${ }^{9}$ It was shown that supplementation with vitamin E significantly enhances both cell mediated and humoral immune functions in humans especially in the elderly and animals. ${ }^{15}$ It is also known that even marginal deficiency of vitamin E, impairs the immune response. ${ }^{11,16}$ It is therefore possible that the decline in biomarkers of inflammation with supplementation of biscuits baked with palm oil shortening containing Tocopherols and Tocotrienols, could have been at least partly due to the known effect of vitamin E on immune function. Mean plasma levels of vitamin $E$ at six months of intervention were similar to those measured at six months after supplementation was stopped and yet both inflammatory markers showed a steep increase after supplementation was stopped. This observation questions the role of whether vitamin E played a key role in the decline in the activity levels of inflammatory markers during supplementation.

The relationship between vitamin $\mathrm{E}$ and immune function was also demonstrated in Canadian 3-year olds. ${ }^{17}$ Those with the lowest serum vitamin $E$ had the lowest lymphocyte proliferative responses and serum IgM concentrations.

The implication of low serum/plasma vitamin E levels is far reaching, especially in the light of recent findings from a study published by Mangialasche et al. ${ }^{18}$, which reported that elevated levels of Tocopherol and Tocotrienol forms are associated with reduced risk of cognitive impairment in older adults. Koscik et al. ${ }^{19}$, concluded from a study on cognitive function of children with cystic fibrosis that minimizing the duration of vitamin E deficiency, is associated with better cognitive functioning in children with Cystic Fibrosis. As suggested by Farrel et al. ${ }^{20}$, continued extra-hepatic tissue alpha-Tocopherol depletion put peripheral nerves at risk. Although cognitive function was not measured in these children, it would be reasonable to hypothesize that against existing evidence, the cognitive function of those children with a low plasma vitamin E level was affected negatively and that supplementation with a biscuit baked with palm oil shortening would have improved their cognitive function. Further studies are needed in this regard. It is surprising that improvement of plasma vitamin E levels were observed (in the present study) by an estimated additional intake of between 4-6 mg vitamin E per day of which about 0.8$1.2 \mathrm{mg}$ was alpha-tocopherol. From the low plasma vitamin $\mathrm{E}$ levels measured during the base-line observations, it would appear that vitamin $E$ intake in this group of children was inadequate. ${ }^{21}$ This is in agreement with a conclusion drawn by Oldewage-Theron ${ }^{22}$ that 
the high prevalence of vitamin E deficiency found in low-income South African elderly, was due to the poor dietary intake of vitamin E. Our results also showed that vitamin $E$ deficiency $(<12 \mu \mathrm{mol} / \mathrm{L} \alpha$-tocopherol) can exist in the absence of severe malnutrition. This is in contrast to the findings in malnourished children in India. ${ }^{23}$ The malnutrition prevalence in children participating in the present study can be regarded as very low ${ }^{1}$ and yet a high prevalence of vitamin E was observed (Table 3 ).

Although the effects of consuming a biscuit baked with palm oil on Tocotrienol levels in blood of these children, could not be detected by the study- design used in the current study, it must be borne in mind, that blood was collected about eighteen hours after consuming the two biscuits. Studies on Tocotrienol kinetics showed that Tocotrienols have virtually disappeared from plasma within 8 hours after administration. ${ }^{24}$ Given the kinetic characteristics of Tocotrienol as well as the relatively low content of the biscuit and subsequent intake of Tocotrienol (about 3-5mg) per day and the fact that the children had biscuits at least 24 hours before blood was drawn, the lack of detection of Tocotrienol under these conditions, is not surprising. However, the effect of the relatively low intake of $\alpha$-Tocopherol on blood levels, warrants further investigation.

The significant decline in the level of inflammatory markers from baseline to six months after biscuit supplementation could possibly be attributed to several factors and not to any single one factor. Firstly, plasma alpha-Tocopherol increased significantly in both the $A$ and $B$ groups. This is known to have a beneficial effect on immunity. ${ }^{5,25}$ After Supplementation was stopped, retinol levels declined to baseline levels, whilst $\alpha$ Tocopherol levels remained significantly elevated above baseline levels and did not differ significantly from values measured at three months of intervention. Both $A$ and $B$ groups received biscuits baked with flour containing micronutrients included in the national fortification program. In addition, Zinc, Copper, Manganese and Selenium in their amino complex form was added (50\% NRV) to both biscuits. One could therefore speculate that the improvement seen in inflammatory markers during biscuit supplementation was entirely due to the improvement of vitamin A status in the two groups. It would however be an over-simplification to ascribe the changes observed during biscuit supplementation to any one single factor. The increase in inflammatory markers after supplementation was stopped, suggest that the A and B biscuit contained elements that did affect the level of inflammatory markers in these children. When supplementation was stopped, these elements were lacking and subsequently inflammatory marker levels increased again. The most obvious candidates in this process appear to be Retinol and other trace elements included in both biscuits. Trace elements are indispensable for life and play an important role in essential functions including immune function. Low intakes of micronutrients have been shown to suppress immune function by affecting the innate T-cell mediate immune response and antibody response, which in turn, increases the susceptibility to infections. ${ }^{26}$ It must however be pointed out that the changes observed in the inflammatory markers, occur in levels within relatively low to normal ranges for CRP and IL-6. 


\section{Limitations of the study}

Several aspects of the study need to be considered.

Firstly, the question of the effects of using fortified flour for baking the biscuits must be considered. As fortification of all flour in the RSA is obligatory and non-fortified flour is subsequently not available. As mentioned earlier, the sale of unfortified flour is not permitted by law. We therefore had no choice but to use whatever was available. The reason for going ahead with the project notwithstanding the issue of using fortified flour was that some recent surveys confirmed the existence of vitamin A deficiency in children in the RSA notwithstanding the fortification of staple foods such as maize meal and flour. ${ }^{4}$ However, the results of this study appear to indicate that these children did not consume adequate amounts of fortified foods. This is further confirmed by the sharp increase in the prevalence of vitamin A deficiency six months after the biscuit supplementation was ended.

Secondly, not enough blood could be obtained to do micro-element analysis. Although we employed a competent paediatric nurse for blood collection, collaboration from the children was often poor, with the result that not enough blood could be collected for all the analysis indicated in the original protocol. Because of the limited amount of plasma available for analysis, we had to prioritise for which analysis the plasma will be used to obtain an acceptable number for statistical analysis.

\section{Conclusion}

The role of trace elements and other micronutrients in the response of the two groups, should also be considered. A high prevalence of Vitamin E deficiency was observed in this group of children which could have far reaching consequences. The value of palm oil in addressing vitamin E deficiency should not be under estimated, especially in the light of the world- wide prevalence of low vitamin E levels in plasma as pointed out by Péter et al. ${ }^{9}$

\section{Acknowledgement}

We would like to thank FARR for their logistic support in the field during the execution of the study and MPOB for financially supporting the study.

\section{Conflict of interest}

None 


\section{References}

1. Benade A.J.S., Olivier L., Bukasa L. Nutritional and immune status of pre-school children attending an informal crèche in Bethelsdorp, Eastern Cape. SA J Clin Nutr. (Submitted for publication).

2. Shah M.D., Keramat Ali, Khaleda Adib, et al. Effects of beta-carotene on acute respiratory infection in a girls' school of Dhaka City. Chest and Heart J. 2003; 27: 70-76.

3. Katengua-Thamahane E., Marnewick J.L., Ajuwon O., et al. The combination of red palm oil and rooibos show anti-inflammatory effects in rats. J Inflamm. 2014; 11: 41.

4. Cooper K.A., Adelekan D.A., Esimai A.O., Northrop-Clemens C.A., Thurnham D.L. Lack of influence of red palm oil on severity of malaria infection in pre-school Nigerian children. Trans R Soc Trop Med Hyg. 2002; 96: 216-223.

5. Mahallingam D., Radhakrishnan A.K., Amon Z., Ibrahim N., Neesaretnam K. Effects of supplementation with tocotrienol-rich fraction on immune response to tetanus toxoid immunization in normal healthy volunteers. Eur J Clin Nutr. 2011; 65: 63-69.

6. Ren Z., Pae M., Dao M.C., Smith D., Meydani S.N., Wu D. Dietary supplementation with tocotrienols enhances immune function in C 75 BL/6 mice. J Nutr. 2010; 140: 1335-1341.

7. Benadé A.J.S., Marais C. de W, Lombard C.J. The development, nutritional composition and acceptability of a red palm oil-based micronutrient fortified bread spread for feeding programmes. Proceedings of Food Technology and Nutrition Conference, International Palm Oil Congress, Kuala Lumpur, Malaysia, 2005.

8. Rizzo C., Dionisi-Vici C., D'Ippoliti M, et al. A simple and rapid HPLC method for simultaneous determination of plasma 7-dehidrocholesterol and vitamin E. Clin Chim Acta. 200; 291: 97-102.

9. Péter S., Friedel A., Roos F.F., et al. Systematic Review of Global Alpha Tocopherol Status as Assessed by Nutritional Intake levels and Blood Serum Concentrations. Int.J. Vitam Res. 2016; 1-21. Hogrefe AG, Bern.

10. IOM. Vitamin E. In: Dietary Reference Intakes for Vitamin C, Vitamin E, Selenium, and Carotenoids. Pp 186-283, National Academic Press (US) Washington DC.2000.

11. Todd J., Simpson P., Estis J., Torres V., Wub A.H.B. Reference range and short- and long-term biological variation of interleukin (IL)-6, II-17A and tissue necrosis factor-alpha using high sensitivity assays. Cytokine. 2013; 64: 660-665.

12. Monteiro J.P., Freimanis-Hance L., Faria L.B., et al. Both human deficiency virus-infected and human immunodeficiency virus exposed, uninfected children living in Brazil, Argentina and Mexico have similar rates of low concentrations of retinol, beta-carotene, and vitamin E. NutrRes.2009; 29:716-722.

13. Giraud D.W., Kim Y.N., Cho Y.O., Driskel J.A. Vitamin E inadequacy observed in a group 2-6-year old children living in Kwangju, Republic of Korea. Int J Vitam Nutr Res. 2008; 78: 148-155.

14. Allen L.H., Rosado J.L., Casterline J.E., Martinez H. Lack of haemoglobin response to iron supplementation in anemic Mexican preschoolers with multiple micronutrient deficiencies. Am J Clin Nutr. 2000; 71: 1485-1494.

15. Pekmezci D. Vitamin E and immunity. Vitam Horm. 2011; 86: 179-215.

16. Beharka A., Redican S., Leka L., Meydani S.N. Vitamin E status and immune function. Methods Emzymol 1957; 282: 247-263

17. Vobecky J.S., Vobecky J., Shapcott D. Nutritional influences on humoral and cell-mediatede immunity in healthy infants. J Am College Nutr. 1984; 3: 265.

18. Mangialasche F., Solomon A., Kareholt I., et al. Serum levels of vitamin E forms and risk of cognitive impairment in a Finnish cohort of older adults. Exp Gerontol.2013; 48: 1428-1435.

19. Koscik R.L., Farrell P.M., Kosorok M.R., et al. Cognitive Function of Children with Cystic Fibrosis: Deleterious Effect of Early Malnutrition. Pediatrics. 2004; 113: 1549-1558.

20. Farrell P.M., Bieri J.G., Fratantoni J.F., Wood R.E., di Sant'Agnese P.A. The occurrence and effects of human vitamin E deficiency: a study in patients with cystic fibrosis. J Clin Invest. 1977; 60: 233-241.

21. Traber M.G. Vitamin E Inadequacy in Humans: Causes and Consequences. Adv Nutr.2014; 5: 503-514. 


\section{Article 8}

22. Oldewage-Theron W.H., Folake O.S., Djoulde R.D. Serum concentration and dietary intake of vitamins A and $\mathrm{E}$ in low-income South African elderly. Clin Nutr.2010; 29: 119-123.

23. Kalra V., Grover J., Ahuja G.K., Rathi S., Khurana D.S. Vitamin E deficiency and associated neurological deficits in children with protein-energy malnutrition. J Trop Pediatr. 1998; 44: 291-295.

24. Fairus S., Nor R.M., Cheng H.M., Sundram K. Alpha-tocotrienol is the most abundant tocotrienol isomer circulated in plasma and lipoproteins after postprandial tocotrienol-rich vitamin E supplementation. Nutrition Journal doi:10. 1186/1475-2891-11-5.2002.

25. Calder P.C., Jackson A.A. Undernutrition, infection and immune function. Nutr Res Rev. 2000; $13:$ 3-20.

26. Wintergerst E.S., Maggini S., Hornig D.A. Contribution of selected vitamins and trace elements to immune function. Ann Nutr Metab. 2007; 51: 301- 323. 


\section{Summary (English) Samevatting (Afrikaans) Valorization Acknowledgements Curriculum Vitae}





\section{Summary}

\section{The Current Scenario}

The FASD journey in South Africa has just begun. The wealth of information available about the condition, the international and South African research findings and lessons learnt from 20 years of community engagements, provided enough information to start this exploratory journey. It is now imperative to evaluate some of these interventions as to create appropriate and effective programmes for FASD awareness, prevention and management. In doing so, sound theoretical and evidence based programmes, that relate to the specific needs of the different cultural groups and clients in urban and rural communities, should be developed. That being said, it is evident that the solution does not lie in one generic intervention, but rather in a flexible programme that could be revised as the needs of the clients and their environment change. Proper planning of health promotion programs, using approaches like Intervention Mapping, should provide the necessary empirical baseline to develop scientifically sound interventions.

To date the role of the woman has received most of the attention. Some have raised the concern that by placing the burden of responsibility and blame on women, society might come close to violating the rights of women in making informed decisions about their own health and the well-being their off-springs. Health promotional messages, and media reports advocate that no alcohol is safe during pregnancy. It calls on pregnant women to be responsible and good mothers by abstaining from alcohol use as 'FASD is $100 \%$ preventable'. By doing so, society continues to put all the pressure and responsibility on pregnant women and women of childbearing age. It implies that women who are using alcohol during pregnancy are perceived as bad and irresponsible mothers. Determinants such as confusing, and often contradicting, messages provided by health providers, limited access to education, as well as pressure from family and friends are not adequately acknowledged.

In South African studies, researchers have consistently reported on the defenceless-

ness of women as so many are unemployed, unmarried and stressed. Family planning services are not optimally utilized, often resulting in unplanned pregnancies. Many children are raised by maternal headed households and fathers are frequently absent due to work circumstances, failed relationships or death. The burden placed on women, in often dire circumstances, is significant. As this is a regular occurrence, it seems as if 
some communities have accepted it as the norm. Although men are regularly being blamed for being absent, one wonders how these communities would define responsible fatherhood.

Environmental and cultural factors, for example poverty, family practices, cultural beliefs, limited access to health and substance abuse facilities, further disadvantage women of childbearing age. Breaking the cycle of poverty and high-risk behaviour require more than mere health promotion messages. The need to be socially acceptable and to socialise are often stated as reasons why pregnant women continued to use alcohol. Despite of this, very few interventions focus on the role of the family and friends in terms of FASD prevention. The African proverb "It takes a village to raise a child" should encourage actions to appeal to the community's sense of responsibility and accountability in supporting pregnant women in their prenatal alcohol-free months.

Scientist have reported on the importance of maternal nutrition and concern has been raised about the increased vulnerability of women with low Body Mass Indexes. Various South African reports alert to the high prevalence of malnutrition and stunting in women of childbearing age. Coupled with high levels of alcohol abuse, especially binge drinking, these women are especially at risk of having children with FASD. Despite of this, little is known about the role of vitamins and micro-nutrient which might be crucial determinants in providing some protection against severe prenatal damage.

Late confirmation of pregnancy leaves fetuses exceptionally vulnerable, especially during the first trimester. This is often an indication of poor access or attendance of antenatal services, but also raises the concern about possible stigmatisation. At present there is no policy or guidelines on the management of pregnant women who are abusing alcohol in the Department of Health. By reporting her risky behaviour, a pregnant woman might run the risk of receiving a reprimand and a reminder about the harm that she is doing to her unborn child. It is highly unlikely that she will receive a referral for substance abuse counselling and support. In communities where there is an emerging awareness of FASD, but little collective responsibility in terms of prevention and support, the pregnant woman might even be ostracized and stigmatized. Being already in a compromising position, it might be easier for her not to disclose her prenatal alcohol use.

Raising a child with FASD in South Africa is a lonely journey. With little resources and adequately trained professionals, it is highly unlikely that the affected child will receive a diagnosis, let alone an early diagnosis, which is vital for early intervention. Even if the child receives a correct diagnosis there are very few resources available with limited accessibility to therapeutic interventions such as occupational, physio and behavioural therapy. Due to the country's inclusive education policy, it is compulsory for children to be enrolled for school at the age of seven. Children with learning disabilities, might be identified as they progress through school, and if severely affected, might be referred to schools for children with special needs. In some provinces access to appropriate educational services is less problematic than in others. Support to those who are affected 
with FASD and their families are in general non-existent, leaving families spending their already limited resources on seeking services and assistance.

\section{Moving forward}

As stated, the FASD journey in South Africa has just begun. The aforementioned might provide a bleak and dooming picture, but there is enough information and experience available in South Africa to enable the country to acknowledge the problem and to take action. Knowing the challenges, enables one to address it. Factors for consideration in this process include the following:

\section{Research questions}

Reviewing the existing research findings in the country, as well as international research reports, raise a myriad of questions about determinants such as the impact of maternal malnutrition and low Body Mass Index, especially in terms of vulnerability. Would food fortification be beneficial in providing some protection to exposed fetuses, especially in this country where so many women are malnourished?

The same question applies to children with FASD. Infant malnutrition is common in South Africa. The effect on children's immunity, cognitive development and overall performance has been described. Food fortification, with the relevant vitamins and micro-nutrients, might enable a child with FASD to reach his full, albeit limited, potential, thereby improving his quality of life and ultimate functioning within the community.

The impact of paternal alcohol abuse is currently being researched and might provide interesting information which has the potential to decrease the blame and shame burden from women.

\section{Political will}

In a developing country like South Africa health and social problems are competing to gain acknowledgement and access to scarce resources. The HIV/AIDS denialism in 1999 - 2008 is a good example of how a country's ability to progressively address a problem can be derailed. The fear is that a lack of political recognition regarding South Africa's FASD problem might lead to a delayed action which is going to cost the country dearly. FASD is but a symptom of a much bigger problem, namely alcohol abuse. The country's draft Liquor Bill is currently being reviewed and addresses the main challenges such as marketing, distribution, liquor trading and outlets, under-age drinking, selling of alcohol to pregnant women, litigation and accountability. The Department of Social Development's Substance Abuse Programme provides a framework and guidance for service delivery. Unfortunately, these services are lacking in many communities, especially in 
rural areas. Of great concern is the numerous missed opportunities within the Department of Health, due to a lack of policy and guidelines for the management of pregnant women at risk and diagnostic services for FASD.

\section{Service delivery}

The FASD diagnostic criteria currently used in South Africa is complex and expensive. Given the limitation on resources, it is imperative to develop practical and reliable methods and tools to increase the accessibility to diagnosis. At present highly skilled and trained medical specialists and psychologists/psychometrists are responsible for these assessments. Maternal interviews are fortunately already done by trained community workers. Increased availability and affordability would require the training of new cadres of workers. Options such as surveillance systems or brief-screening methods will have to be explored.

Training of professionals is essential. National policy and guidelines on the management of FASD will steer and focus limited resources and alleviate possible duplication and wastage of means.

Support groups providing information and guidance to people living with FASD, parents and caregivers will capacitate those who are facing the multitude of challenges on a daily basis. Networking and good infrastructures will alleviate the pressure on limited service resources, freeing the latter up for more pressing needs and enable better service delivery.

\section{Awareness and prevention}

Implementation of the above-mentioned is however, no guarantee for a reduction in the country's FASD prevalence rates. If the person at risk is not ready and prepared to accept the message and to change the harmful behaviour, there will be no positive impact on the problem. A concerted effort should be made to identify interventions needed by communities and parents at risk to actively engage them and to bring about behaviour change.

Pressure is put on women to protect their children, but in order for them to change their behaviour, they have to be willing to act in a certain way and have the necessary knowledge and skills to perform the required behaviour. People will only do so if they believe that their current behaviour is harmful and if they see the advantages of the new behaviour. Given the quest for social acceptability and support, it is important to receive support and positive encouragement from peers and family to implement and maintain the changed behaviour. High levels of self-efficacy and a positive self-esteem, coupled with a believe that one is capable to perform the behaviour, provide the necessary assertion needed for sustained behaviour change. 
In true African spirit the country not only needs the proverbial village to raise a child, but it also needs the village to support the individual with FASD, his family, educators and other service providers. FASD can only be optimally addressed and combatted through concerted and collaborative action and by the implementation of a clear vision with the child's best interest at heart. 



\section{Samevatting}

(in Afrikaans, the author's first language)

\section{Die huidige senario}

Die FASA (Fetale Alkohol Spektrum Afwykings) reis in Suid Afrika het maar so pas begin. Die skatkis van inligting wat tans oor die toestand beskikbaar is, die internasionale en Suid-Afrikaanse navorsingsbevindinge en die lesse wat gedurende die afgelope 20 jaar oor gemeenskapskakeling geleer is, verskaf genoeg inligting om hierdie ontdekkingsreis te begin. Ten einde toepaslike FASA bewusmaking-, voorkoming- en hanteringsprogramme te kan ontwikkel, is dit gebiedend noodsaaklik om sommige van hierdie intervensies te evalueer. Sodoende kan betroubare teoretiese en bewys-gedrewe programme ontwikkel word. Toepaslik programme moet spreek tot die spesifieke behoeftes van die verskillende kulturele groepe en kliënte in stedelike en landelike gemeenskappe. Daar moet egter aggeslaan word daarop dat ' $n$ enkele generiese program nie noodwending die antwoord gaan bied nie. 'n Buigsame program wat volgens die kliënte se behoeftes en hul omgewing aangepas kan word, is meer toepaslik. Noukeurige beplanning van gesondheidsbevorderingsprogramme, met die gebruik van benaderings soos Intervensiekartering, behoort die nodige empiriese basis te verskaf om programme op 'n wetenskaplike manier te ontwikkel.

Tot op datum het die rol van die vrou die meeste aandag geniet. Kommer is al uitgespreek oor die gemeenskapsdruk en blaam op vroue. Sommige meen dit grens aan ' $n$ skending van vroue se regte om ingeligte besluite rakende hul eie gesondheid en die van hul kinders te maak. Gesondheidsbevorderingsboodskappe en mediaverslae, propageer dat dit nie veilig is om alkohol tydens swangerskap te gebruik nie. Daar word ' $n$ beroep op swanger vroue gedoen om verantwoordelike en goeie moeders te wees deur hul van voorgeboortelike alkoholgebruik te weerhou, want 'FASA is $100 \%$ voorkombaar'. Sodoende plaas die gemeenskap meer druk op swanger vroue en vroue van kinderbarende ouderdom. Dit impliseer ook dat vroue wat alkohol tydens swangerskap gebruik, slegte en onverantwoordelik moeders is. Faktore soos verwarrende, en dikwels teenstrydige, boodskappe wat deur gesondheidswerkers verskaf word, beperkte toegang tot opvoeding, asook druk van familie en vriende, word nie genoegsaam erken nie. 
Navorsers in Suid-Afrikaanse studies, rapporteer deurlopend oor die weerloosheid van vroue, aangesien baie van hulle werkloos, ongetroud en gespanne is. Gesinsbeplanningsdienste word nie optimaal benut nie en dit lei dikwels tot onbeplande swangerskappe. Baie kinders word deur huishoudings grootgemaak waar vroue aan die hoof is en vaders dikwels afwesig is as gevolg van werksomstandighede, gefaalde verhoudings of die dood. Die las op vroue, wat hul dikwels in haglike omstandighede bevind, is beduidend. Aangesien dit so ' $n$ algemene verskynsel is, het baie gemeenskappe dit reeds as die norm aanvaar. Alhoewel mans gereeld vir hul afwesigheid geblameer word, is dit ' $n$ ope vraag hoe hierdie gemeenskappe verantwoordelike vaderskap sou definieër.

Omgewings- en kulturele faktore, soos armoede, familiegebruike, kulturele tradisies, gebrekkige toegang tot gesondheid- en middelafhanklikheidsfasiliteite, benadeel vroue van kinderbarende ouderdom nog verder. Om die siklus van armoede en hoë-risiko gedrag te verbreek, vereis meer as net blote gesondheidsbevorderingsboodskappe. Die behoefte om sosiaal-aanvaarbaar te wees en om te sosialiseer word dikwels as redes aangevoer waarom swanger vroue voortgaan om alkohol te gebruik. Ten spyte hiervan fokus baie min intervensies op die rol van die familie en vriende in die voorkoming van FASA. Die Afrika-gesegde 'dit vereis ' $n$ dorp om ' $n$ kind groot te maak' behoort as aanmoediging te dien om ' $n$ beroep te maak op die gemeenskap se sin vir verantwoordelikheid en aanspreeklikheid ter ondersteuning van swanger vroue in hul voorgeboortelike alkoholvrye maande.

Wetenskaplikes wys op die belang van moederlike voeding en kommer is reeds uitgespreek oor die verhoogde weerloosheid van vroue met lae Liggaamsmassa-indekse. Verskeie Suid-Afrikaanse verslae waarsku oor die hoë voorkoms van wanvoeding en groeivertraging in vroue van kinderbarende ouderdom. Tesame met die hoë vlakke van alkoholmisbruik, veral fuifdrinkery, is hierdie vroue onder groter risiko om kinders met FASA te baar. Ten spyte hiervan is min bekend oor die rol van vitamiene en spoorelemente wat dalk kritiese bepalende faktore mag wees in die beskerming teen erge voorgeboortelike skade.

Laat bevestiging van swangerskappe laat fetusse uitermate weerloos, veral gedurende die eerste trimester. Dit is dikwels ' $n$ aanduiding van swak beskikbaarheid of bywoning van voorgeboortedienste, maar dit wek ook kommer oor moontlike stigmatisering. Tans is daar geen beleid of riglyne in die Departement van Gesondheid vir die hantering van swanger vroue wat alkohol gebruik, nie. As sy haar risiko gedrag sou bekendmaak, loop die swanger vrou die risiko om 'n teregwysing te ontvang en daaraan herinner te word dat sy haar ongebore baba beskadig. Dit is hoogs onwaarskynlik dat sy 'n verwysing vir berading en ondersteuning vir haar middelafhanklikheid sal ontvang. In gemeenskappe waar daar ' $\mathrm{n}$ ontluikende bewussyn van FASA is, maar min kollektiewe verantwoordelikheid ten opsigte van voorkoming en ondersteuning, mag swanger vroue selfs verwerp en gestigmatiseer word. Siende dat sy haarself reeds in 'n netelige posisie bevind, mag dit vir haar makliker wees om nie haar alkoholmisbruik bekend te maak nie. 
Om ' $n$ kind met FASA in Suid-Afrika groot te maak is ' $n$ eensame tog. Met min hulpbronne en ' $n$ gebrek aan toepaslik opgeleide professionele persone, is dit hoogs onwaarskynlik dat die geaffekteerde kind gediagnoseer gaan word, wat nog te sê van 'n vroeë diagnosering, wat so belangrik vir vroeë intervensie is. Selfs al sou die kind die korrekte diagnose ontvang is daar beperkte hulpbronne beskikbaar met min toegang tot terapeutiese intervensies soos arbeidsterapie, fisioterapie en gedragsterapie. As gevolg van die land se ingeslote opvoedkundige beleid, is kinders teen sewejarige ouderdom skoolpligtig. Kinders met leergestremdhede mag dalk geidentifiseer word soos hulle deur hul skoolloopbane vorder, en kinders met erge gestremhede, sal dalk na skole vir kinders met spesiale behoeftes verwys word. In sommige provinsies is toegang tot toepaslike opvoedkundige dienste minder problematies as in ander provinsies. Ondersteuning aan diegene met FASA en hul gesinne, is meestal afwesig en dit noodsaak die gesinne om hul alreeds beperkte bronne in die soektog na dienste en ondersteuning te spandeer.

\section{Die pad vorentoe}

Soos genoem, het die FASA reis in Suid-Afrika maar so pas begin. Die voorafgaande verskaf dalk ' $n$ triestige en verdoemende prentjie, maar daar is genoeg inligting en ondervinding beskikbaar in Suid-Afrika om die land in staat te stel om die probleem te erken en tot aksie oor te gaan. Faktore wat tydens hierdie proses in ag geneem moet word, sluit die volgende in:

\section{Navorsingsvrae}

' $n$ Hersiening van die beskikbare navorsingsbevindinge in die land, asook internasionale navorsingsverslae, opper ' $n$ legio vrae rakende die oorsakende faktore soos moederlike voeding en lae Liggaamsmassa-indeks, veral in terme van weerloosheid. Sal voedingsverryking voordelig wees in die beskerming van blootgestelde fetusse, veral in hierdie land waar soveel vroue wangevoed is?

Dieselfde vraag is op toepassing van kinders met FASA. Kinderwanvoeding is algemeen in Suid-Afrika. Die effek op die kinders se immuniteit, kognitiewe ontwikkeling en algehele prestasie is reeds beskryf. Voedselverryking, met die toepaslike vitamiene en spoorelemente, mag dalk die kind met FASA in staat stel om sy volle, alhoewel beperkte, potensiaal te ontwikkel en sodoende sy lewenskwaliteit en uiteindelike funksionering in die gemeenskap te verhoog.

Die impak van vaderlike alkoholmisbruik word tans nagevors en mag dalk interessante inligting verskaf. Dit het die potensiaal om die las van skande en blaam op vroue te verlig. 


\section{Politieke wil}

In 'n ontwikkelende land soos Suid-Afrika kompeteer gesondheids- en sosiale probleme om erkenning en toegang tot beperkte hulpbronne. Die MIV/VIGS ontkenning in $1999-$ 2008 is ' $n$ goeie voorbeeld van hoe ' $n$ land se vermoë om progressiewe aksie te neem, ontspoor kan word. Die vrees bestaan dat ' $n$ gebrek aan politieke erkenning rakende Suid-Afrika se FASA probleem kan lei tot vertraagde aksie wat die land duur te staan gaan kom. FASA is in werklikheid net nog ' $n$ simptoom van die veel groter probleem, naamlik alkoholmisbruik. Die land se konsep Drankwet word tans hersien en spreek die hoof uitdagings soos bemarking, verspreiding, drankhandel en afsetpunte, alkoholgebruik op ' $n$ te jong ouderdom, verkoop van alkohol aan swanger vroue, vervolging en verantwoordelikheid aan. Die Departement van Maatskaplike Ontwikkeling se Middelafhanklikheidsprogram verskaf ' $\mathrm{n}$ raamwerk en riglyne vir diensverskaffing. Ongelukkig skiet hierdie dienste in baie gemeenskappe te kort, veral in landelike areas. Kommerwekkend is die verspeelde geleenthede binne die Department van Gesondheid, wat toegeskryf kan word aan ' $n$ gebrek aan ' $n$ beleid en riglyne vir die hantering van hoë risiko swanger vroue en diagnostiese dienste vir FASA.

\section{Diensverskaffing}

Die FASA diagnostiese kriteria wat tans in Suid-Afrika gebruik word is kompleks en duur. Gegewe die beperkte hulpbronne, is dit gebiedende noodsaaklik om praktiese en betroubare metodes en meetinstrumente te ontwikkel om die toeganklikheid tot ' $n$ diagnose te verhoog. Tans is hoogs opgeleide en vaardige mediese spesialiste en sielkundiges/psigometriste verantwoordelik vir hierdie ondersoeke. Moederlike onderhoude word gelukkig alreeds deur opgeleide gemeenskapswerkers gedoen. Verhoogde beskikbaarheid en bekostigbaarheid sal die opleiding van ' $n$ nuwe kader werkers noodsaak. Moontlikhede soos siftingsprogramme of blits-assesseringsmetodes moet ondersoek word.

Opleiding van professionele werkers is noodsaaklik. Nasionale beleid en riglyne rakende die hantering van FASA sal die beperkte hulpbronne kan rig en bestuur om sodoende duplisering en vermorsing te bekamp.

Ondersteuningsgroepe wat inligting en leiding aan persone met FASA, ouers en versorgers verskaf, sal hul beter bemagtig om hul magdom daaglikse uitdagings te trotseer. Skakeling en goeie infrastruktuur sal die druk op beperkte diensbronne verlig, dit in staat stel om op dringender behoeftes te fokus en sodoende beter dienslewering bewerkstellig. 


\section{Bewusmaking en voorkoming}

Implementering van bogenoemde is egter geen waarborg tot ' $n$ daling in die land se FASA voorkomssyfers nie. Indien 'n risiko-persoon nie gereed en ontvanklik vir die boodskap is nie, en nie bereid is tot gedragsverandering nie, sal daar geen positiewe impak op die probleem wees nie. 'n Daadwerklike poging behoort aangewend te word om intervensies te identifiseer wat gemeenskappe en risiko-ouers aktief sal betrek en tot gedragsverandering sal lei.

Die druk is op vroue van kinderbarende jare om hul kinders te beskerm. Ten einde gedragsverandering teweeg te bring, moet hulle bereid wees om hul gedrag te verander en oor die nodige kennis en vaardighede beskik om op die verlangde manier op te tree. Mense sal dit slegs doen as hulle glo dat hul huidige gedrag skadelik is en hulle aan die voordele van die nuwe gedrag glo. Gegewe die behoefte aan sosiale aanvaarding en ondersteuning, is dit noodsaaklik dat die portuurgroep en familie die nodige ondersteuning en positiewe aanmoediging gee om die implementering en volhouding van die nuwe gedrag aan te moedig. Volhoubare gedragsverandering vereis hoë vlakke van selfhandhawing, 'n positiewe selfbeeld, asook die vertroue in jou eie vermoêns.

In tipiese Afrika-gees benodig die land nie net die spreekwoordelike dorp om die kind groot te maak nie, maar dit vereis ook dat die dorp die persoon met FASA, sy familie, opvoeders en ander diensverskaffers ondersteun. FASA sal slegs optimaal aangespreek en bekamp kan word met behulp van daadwerklike en samewerkende aksie en deur die implementering van 'n duidelike visie wat die kind se beste belange vooropstel. 



\section{Valorization}

Eleven Fetal Alcohol Spectrum Disorders (FASD) prevalence studies in 4 of the 9 provinces in South Africa have reported rates ranging between 27 to 282 per 1000 of the population. Global meta-analyses and systematic reviews indicate that the country has the highest reported FASD rate in the world. No FASD studies have been done in the remaining 5 provinces, therefore the extent of the problem in these areas and the FASD rate for the country are still unknown. In a developing country with limited resource, it is essential to collect empirical data as this can be used to guide government on policy formulation, resource allocation (especially to high-risk areas) and to lobby for appropriate services.

FASD is a complex condition with multi-factoral causes, closely linked to historical, psycho-social, economical and a multitude of other determinants. In order to plan and implement effective awareness and prevention programmes, there needs to be an understanding of the core drivers of the condition. Research focussing on these aspects not only highlights the causative factors, but also identifies the needs of community members and makes recommendations for appropriate interventions. Existing services, delivered by government and civil society, need to be adapted to take on these responsibilities, but can only do so if clear guidelines, derived from empirical research findings, are provided. By developing evidence based models for implementation examples for practical implementation can be provided (such as the Healthy Mother Healthy Baby Programme).

Limited knowledge and expertise regarding FASD lead to underdiagnosis and reporting. Research results and findings have led to the development of training courses whereby health practitioners, social workers, psychologists and educators receive not only information on FASD, but also on the prevention and management of the condition.

Since the condition is caused by prenatal alcohol exposure, stigmatization of mothers of individuals with FASD is a reality. Health promotion on the risks pertaining to alcohol use, especially by women of childbearing age and their partners, is essential to raise the awareness, encourage help-seeking behaviour and to reduce the number of alcohol exposed pregnancies. By using research findings, more appropriate and relevant health promotion messages and campaigns can be developed. Research studies focussing on the reasons for prenatal alcohol use, identified the important influence of part- 
ners, family and friends on pregnant women's behaviour and decision making processes. Using this information does not only improve health promotion interventions, but also strengthens support to pregnant women and their families and it lessens stigma.

People affected by FASD face a myriad of challenges throught life. Many of these problems still need to be identified and properly described. Diagnostic tools are refined through research which will lead to improved diagnosis, appropriate recommendations and improved management, service delivery and support.

All of the above-mentioned research results and recommendations are already used to lobby for increase acknowledgement of the condition, development and/or adaption of policies and service delivery models, training of professionals and ultimately the allocation of appropriate resources to combat and address this preventable condition. 


\section{Acknowledgements}

Reflecting on the journey preceding this thesis highlights many remarkable events and people.

Being affected with Fetal Alcohol Spectrum Disorders in South Africa poses numerous challenges for clients, families and communities. Most sincere gratitude and respect is therefore expressed for the willingness of these participants to avail themselves to participate in the studies undertaken by the author and Research Group.

My promotors and supervisors, Prof. dr. Leopold Curfs, Prof. dr. Denis Viljoen and Prof. dr. Gerjo Kok were key role-players in my academic growth and provided the necessary guidance and support to bring me to this point. I am most grateful to Prof. dr. Curfs who offered me the opportunity to do my PhD at Maastricht University. I am immensely thankful for the honour and opportunity to study at this prestigious establishment. Introducing me to Intervention Mapping, Prof. dr. Kok not only broadened my insights into the importance of the scientific planning of health promotion programmes, but also re-emphasised the complexities and challenges pertaining to behaviour change. Prof. dr. Viljoen has been my highly respected professional, academic and spiritual mentor for many years, often believing in my abilities when I faltered. Over the years he always encouraged me to to take the road less travelled and applauded me along the way.

Drs Sylvia Roozen was a constant beacon of light and support, especially during the finalization of the thesis for publications and the arrangements at Maastricht University. Together we made it so much 'easier'.

A wide range of professionals and colleagues taught me, guided my work and supported me during my professional career. Special mention needs to be made of my dedicated and loyal colleagues at the Foundation for Alcohol Related Research, as well as our very supportive Board of Directors, other co-workers and sponsors. These colleagues are always willing to embark on often unexplored routes and are constantly prepared to take on the proverbial extra mile. Together we have conquered so much and still have plenti more to do.

My husband, Tinie, and our sons, Carlo and Anro are my constant inspiration and motivation, not only in my studies, but also in my daily work and life. Respecting my passion 
for life and the task at hand, they have themselves contributed greatly to my journey and the management of Fetal Alcohol Spectrum Disorders in South Africa.

I salute the Heavenly Father and everybody for bestowing me with the opportunities I have enjoyed during my life, and especially in doing this PhD. I undertake to continue to dedicate myself to the prevention and management of Fetal Alcohol Spectrum Disorders and to serve those who are in need.

To all I am saying: Thank you, Veel dank en Baie dankie! 


\section{Curriculum Vitae}

Leana Olivier was born in Cape Town and grew up on a farm in the Stellenbosch district, in the heartland of the virticulture area. After completing her school career at the Bloemhof Girl School, she enrolled for a B Cur Nursing Degree at the University of Stellenbosch. At the completion of this degree in General Nursing, Midwifery and Psychiatry, she continued her studies at the University of South Africa (UNISA) as a part-time student. At UNISA she obtained another B Cur Nursing Degree in Community Health, Nursing Education and Management Administration. Continuing her part-time studies, she obtained an Honnors Degree in Psychology at the University of the Western Cape (UWC).

Whilst studying, she started her nursing career at Tygerberg Hospital (the Provincial Hospital for the Western Cape Province) where she soon took up the position as Intensive Care Unit Manager. Following unto this, she spent a short period in the private sector as an Operating Theatre Manager, but soon found her niche when she started working in a Primary Health Care Unit (Department of Health) in the community. Her interest in training and development brought her to the Training Unit of the Department of Health and from there she became the Provincial Manager of the Maternal, Child and Women's Health (MCWH) Division in the Western Cape Province. One of the programmes in the MCWH Division was the Human Genetic Programme where she met Prof dr Denis Viljoen who was also founder of the Foundation for Alcohol Related Research (FARR). Through her work and liaison with Prof Viljoen, she became aware and interested in Fetal Alcohol Spectrum Disorders (FASD). She was a key role-player in the liaison between the Department of Health and the principal investigators of the first three FASD studies in South Africa (funded by the NIH and NIAAA).

During her time in the Department of Health she developed and implemented a number of health programmes and was also involved in a variety of task and advisory teams for the National Department of Health and other government departments. In 2006 she left the Department to take up the management of FARR. Under her leadership FARR has grown from a small non-governmental organization (NGO) with three employees to a vibrant flourishing organization with research, awareness, prevention and training programmes in 4 provinces, 10 offices and community centres, 43 full time employees, as well as a number of post graduate students and volunteers. 
Over and above her passion for FASD, she also has a keen interest in people and organizational development. She has done consultancy work on a wide range of aspects such as organizational development, script writing for plays, radio drama and educational DVD series for private corporates and government departments. She has also done consultancy work for the Faculty of Health Sciences, University of Stellenbosch where she holds a Research Fellowship position. It has always been her dream to continue her studies. This became a reality when she met Prof Curfs at an EUFASD conference and through a partnership between FARR and the Governor Kremers Centre at Maastricht University and was given the opportunity to persue her doctoral studies. 
Addendum

\section{Informed Consent Form for FASD Prevalence Study}




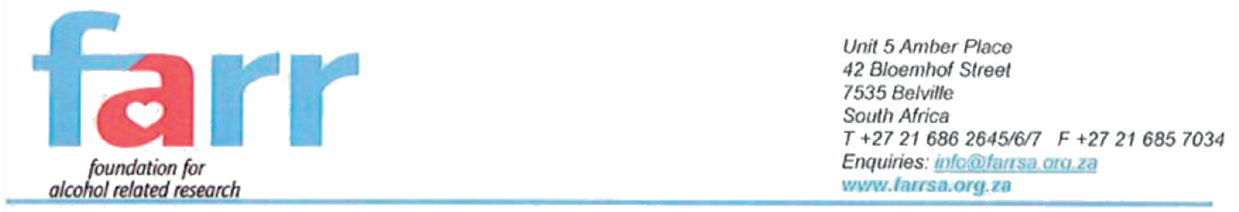

PARTNERSHIP between the

Foundation for Alcohol Related Research (FARR), University of Stellenbosch: Faculty of Medicine and Health Sciences and the Department of Education

Study: Epidemiological screening for Fetal Alcohol Syndrome and Fetal Alcohol Spectrum Disorder

REFERENCE NUMBER: N13/01/008

VERSION 2

PRINICIPAL INVESTIGATOR: Prof Denis Viljoen

Contact Number: 021-686 2646

Informed Consent Form: Parent/Guardian

The Department of Education has given permission that we do a study involving Grade 1 learners in the schools in your area. We therefore want to invite your child to participate in the study, but we need your permission.

Your child is being invited to take part in the research project. Please take some time to read the information presented here, which will explain the details of this project. In addition, study staff will hold a meeting at the school to give more information - we encourage you to attend this meeting and to ask any questions you may have. Your child's participation is voluntary and you can at any stage of the study withdraw your child from further involvement or participation. You are not under any obligation to let your child participate in the study. Your child will not be punished if he/she does not participate.

This study has been approved by the Health Research Ethics Committee at Stellenbosch University and will be conducted according to the ethical guidelines and principles of the international Declaration of Helsinki, South African Guidelines for Good Clinical Practice and the Medical Research Council (MRC) Ethical Guidelines for Research.

\section{Purpose of the Study}

FARR and the University of Stellenbosch Faculty of Medicine and Health Sciences are conducting a study among Grade 1 children in your area to assess how common are problems affecting child development, including fetal alcohol syndrome (FAS).

The study will help us to understand how common FAS and other causes of learning difficulty are in your area. This will help planning of services by agencies such as the Departments of Social Development, Education and Health. It may also assist educators to provide support for children with learning difficulties.

\section{Procedure}

For all children with consent, we will conduct assessments to assess their health and development, and to detect the cause of any health or development problems. The assessments include some simple measurements (height, weight and head measurements) in all children, and in some children further assessment by: a medical check-up (by a doctor), and a detailed assessment of their

\begin{tabular}{|c|c|}
\hline \multicolumn{2}{|c|}{ Foundation for Alcohol Related Research } \\
\hline $\begin{array}{l}\text { Associaton incorporated under Section } 21 \\
\text { Registration Number. } 19970019000\end{array}$ & $\begin{array}{l}\text { NPO Reference No: } 069 \cdot 368 \\
\text { VAT Registration: } 4610166615\end{array}$ \\
\hline $\begin{array}{l}\text { HWSeta Accredtation: HWS9IPA101109I } \\
\text { PBO. } 18 / 11 / 135356\end{array}$ & BBQEE: BRSE004022 \\
\hline
\end{tabular}


development (by a specialist in child development), an interview with a parent/guardian. Based on the information we gather, we will assess if a child has a learning problem and try to find the cause. Please note that some participants will receive more assessments than others - this does not necessarily mean that they have more health or development problems than others.

We will inform you of the date on which we will visit your school. You are welcome to come to the school on that day or phone us if there is anything more that you want to know (Tel: 021-686 2646 or send a 'please call me' to 083275 0202).

\section{Possible risks and benefits for your child}

The study procedures (measurements, medical check-up, assessment of development) will not hold any health risks for your child and do not include any blood tests or painful procedures. We will inform you of the results if we have any concerns about your child's health or development. If we detect a health problem, we will ensure that your child is referred to an appropriate public health care or social service centre. These are not part of the research, and there you should know that while social services are provided free, health services may entail a cost (at a standard rate).

We will inform you if we detect any significant learning difficulty (including fetal alcohol syndrome) in your child. If we find a learning difficulty, we can arrange a referral for further support within the Department of Education's Learner Support System, which does not entail an extra cost.

\section{Confidentiality}

We recognise that finding a developmental problem such as FAS can be beneficial (e.g. by allowing the child to get better support for learning) but can possibly also lead to stigma or discrimination. Therefore, all information regarding the examination of your child will be kept confidential (a secret). We will not publish the name of your child at all, and will only inform the school if we have your permission to do so. It is only in the case of child abuse that we are legally required to report it to the authorities.

The Ethical Committee of the University of Stellenbosch will protect the rights of you and your child in this study.

\section{Costs}

There will be no costs involved for you, if your child does take part. Parents who need to attend the interview and feedback sessions (which take a bit of time) will receive a gift voucher to the total of R80 to cover their time and expenses - this will be provided at the feedback session.

For any further information or questions please contact:

Leana Olivier / Prof Denis Viljoen

FARR

Unit 5, Amber Place

42 Bloemhof street

Bellville, 7535

Tel: 021-686-2646

You can contact the Health Research Ethics Committee at 021-9389207 if you have any concerns or complaints that have not been adequately addressed by your study doctor. You will also receive a copyofthis information sheet and consent form foryour own records.

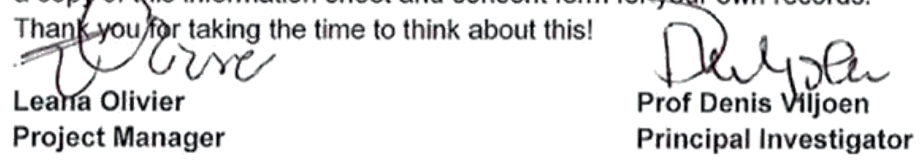




\section{PARENTS' VOLUNTARY PERMISSION FOR CHILD TO PARTICIPATE}

By signing below $\mathrm{I}$, the parent/guardian of (name of child) agree that my child may take part in a research study entitled: 'Epidemiological screening for Fetal Alcohol Syndrome and Fetal Alcohol Spectrum Disorder'.

I hereby say that:

- I have read or had somebody read to me this information and consent form and it is written in a language that I understand.

- If needed, I have had a chance to ask questions and I am satisfied with the answers to all my questions.

- I understand that participation in this study is voluntary and I have not been pressurised to have my child take part.

- I understand that my child may leave the study at any time and will not be penalised or prejudiced in any way.

- I understand that all information about my child will be kept confidential unless I give permission for it to be shared

I understand that by signing this consent form, I give permission for the following:

- Simple measurements can be taken on my child

- A brief medical check-up can be conducted on my child (if required)

- A developmental assessment can be conducted with my child (if required)

- An interview can be conducted with me or someone else who attends in my place (if required)

Signed at:

(name of your town) on (date) $20 \ldots$ 


\section{Declaration by investigator}

I (name) ..................................................... declare that:

- I explained the information in this document to

- I encouraged him/her to ask questions and took adequate time to answer them.

- I am satisfied that he/she adequately understands all aspects of the research, as discussed above

- I did/did not use an interpreter. (If an interpreter is used then the interpreter must sign the declaration below.

on (date)

$20 \ldots . .$.

\section{Declaration by interpreter}

I (name) declare that:

- I assisted the investigator (name) to explain the information in this document to (name of participant) using the language medium of Afrikaans/Xhosa.

- We encouraged him/her to ask questions and took adequate time to answer them.

- I conveyed a factually correct version of what was related to me.

- I am satisfied that the participant fully understands the content of this informed consent document and has had all his/her question satisfactorily answered. 

Addendum

Dysmorphology Checklist 


\section{tarr

Name:

Study number:

School's Name:

Date of Examination: dd/ mm / yyyy

D.O.B.: $\mathrm{dd} / \mathrm{mm} / \mathrm{yyyy}$
Sex:

Examiner:

Age:



$\mathrm{Ht}$

$\mathrm{Ht} \%$

$\mathrm{Wt}=\quad \mathrm{Wt} \%$

$\mathrm{Wt} \%$

OFC



OFC $\%$

PFL

PFL \%

$\overline{\overline{ }}$

Upper Lip Length

Mental status/behavior

Neurological

Cranium

Face: General

Ears

Eyes

Nose

Mouth
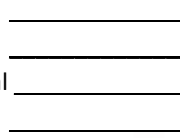

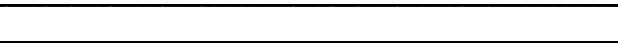

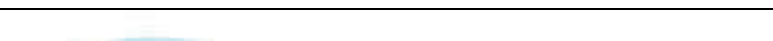

Neck

Thorax

Heart

Arms

Hands: General

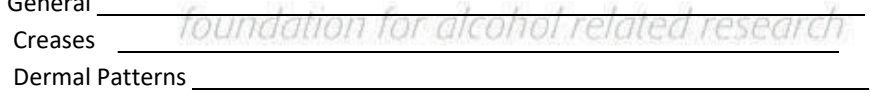

Legs:

Feet:

Skin:

Hair:

Clarren:

Other/Comments

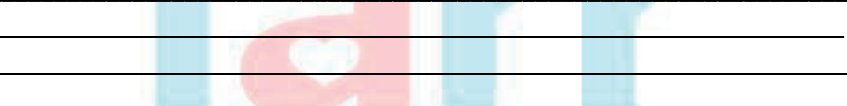

Creases

ermal Patterns

Other/Comment

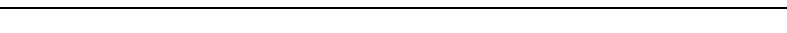

Mother's Name
Encircle scores if positive:

$\mathrm{HT}$

(1)

WT

OFC

PFL

(3)

HYPERACT

FINEMOTR (3)

+ GROSS MOTR

HYPOFACE(2)

RREARS(2)

STRABISM(2)

PTOSIS(3)

EPICANTH(1)

NALSBRDG(1)

ANTENARE(1)

LONGPHIL(3)

SMTHPHIL(3)

NRRWRML (3)

PROGNATH (2)

HEARTMUR (3)

SUPINATE(3)

CLINDACT (1)

CAMPDACT (2)

PALMCR(1)

HYPRTRIC(2) 


\section{farr \\ alcohol related research}

DIAGNOSIS

Abnormalities compatible with FASD (check ALL that apply)

$\square$ 1. Growth deficiency

․ Structural abnormality

3. Cognitive/behavioural abnormalities

$\square$ 4. No abnormalities compatible with FAS observed

$\square_{5 \text {. No significant abnormalities of any kind observed Does }}$ the child have FAS or FASD?

1. No

2. Yes

3. High Dysmor phology Score

$\square$ 1. No

$\square$ 2. Yes (please specify)
a)
b)
c)
d)

Is special follow-up or testing recommended?

$\square$ 1. No

2. Yes

Nutrition

$\square$ Social worker

प Maternal interview and Neurodevelopmental assessment

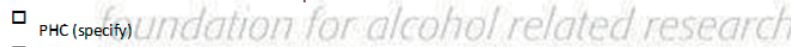

$\square$ Other (specify)

Notes:

Foundation for Alcohol Related Research (C)

Tel: +27 (0)21-686 2646 Email: info@farrsa.org.za Website: www.farrsa.org.za

Updated: September 2014 



\section{Addendum}

Cape Argus, 5 April 2016 


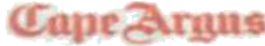

TUESDAY APRIL 52016

\section{Alcohol syndrome high in Saldanha}

Warda Meyer

POLITICAL WRITER

warda.meyer@inl.co.za

HIGH levels of foetal alcohol syndrome (FAS) have been found in the fishing community of Saldanha Bay along the West Coast, where about 6 percent of children are born with the disorder.

The findings are contained in a three-year study commissioned by the Western Cape Department of Social Development in partnership with the Foundation for Alcohol Related Research.

Addressing a media briefing in the city yesterday, social development MEC Albert Fritz said although the figures were concerning, the study had provided the department with the necessary information to fight the problem more effectively.

"The prevalence of foetal alcohol spectrum disorder (FASD) on the West Coast was found to be 64 . children per 1000 affected, which is 6.42 percent," he said.

Fritz said in total 1452 of 1535 Grade one pupils in the area were seen in the first phase of the study.

He said the department hoped to develop more programmes to target specifically the youth because it had become clear that the average age of mothers with FASD babies had dropped and teenagers were more affected.

Foundation for Alcohol Related Research chief executive Leana Olivier said the study, the first of its kind in a fishing community, showed a surprisingly high prevalence rate and indicated a serious problem in the area.
Olivier said rural communities were far more vulnerable because they did not have access to information, but said communities in urban areas were also battling.

"Khayelitsha and other areas on the Cape Flats are our neglected communities. Very. littie has been done in the Metro area."

Olivier said most of the work done around FAS had been completed in the rural areas, leaving urban areas neglected. She said another problem was the higherand middle-income groups who thought they were not at risk and it was merely a poor man's problem. "Whether you drink champagne orbeer it is the alcohol that damages the baby."

Zooming in on the controversial dop system, Olivier said the department's research indicated that the problem was no longer as prevalent. She said the real threat in the Western Cape was shebeens, which have been mushrooming throughout communities.

Olivier said as part of the study the department also worked with 200 mothers through the Healthy Mother Healthy Baby Programme.

She said that during the course of the three years, none of the mothers involved in the project gave birth to children with FASD.

"What was phenomenal was that of all the women who participated in our healthy mother healthy baby programme, none had children with foetal alcohol syndrome."

She said they found that the community was hungry for information about the syndrome. ${ }^{\circ}$ They knew vaguely that alcohol could harm their babies, but not the extent of the damage. Once they heard about the damage they were shocked."

Olivier said the buddy system was a good way to keep pregnant women from drinking. "You need a buddy just to take your hand and help you through the pregnancy and not to drink, because it is very lonely if you are the only person at a party who is not drinking." 
Healthy Mother Healthy Baby Programme: Audit Screening Tool 


$\begin{array}{ll}\text { Score 1-7: } & \text { Group 1 } \\ \text { Score 8-15: } & \text { Group 2 } \\ \text { Score 16-19: } & \text { Group 3 } \\ \text { Score 20-40: } & \text { Group 4 }\end{array}$

INITIALS: ADDRESS:

\begin{tabular}{|l|l|l|l|}
\hline (mark with X) & User & Stopped usage & Never used (Abstain) \\
\hline Tabacco & & & \\
\hline Alcohol & & & \\
\hline Drugs/other methods & & & \\
\hline
\end{tabular}

\begin{tabular}{|c|c|}
\hline $\begin{array}{l}\text { Use of Audit } \\
\text { Read the questions exactly as it is stated below. } \\
\text { am now going to ask you questions about your } \\
\text { interest of your baby to provide me with honest } \\
\text { the correct number of the answer above the line }\end{array}$ & $\begin{array}{l}\text { cord the answers. Start the AUDIT by saying: "I } \\
\text { hol usage during the past year. It is in the best } \\
\text { wers." Explain what a "standard drink" is. Write } \\
\text { vided for each question. }\end{array}$ \\
\hline $\begin{array}{l}\text { 1. How oftue do you drink alcohol? } \\
\text { (0) Never (qo directly to Questions } 9-10 \text { ) } \\
\text { (1) Monthly or less } \\
\text { (2) } 2-4 \text { times per month } \\
\text { (3) } 2-\text {-times per week } \\
\text { (4) } 4 \text { times or more per week } \\
\text { Score: }\end{array}$ & $\begin{array}{l}\text { 6. How often during the past year did you had to take a } \\
\text { reamaker. ('fix) in the mornings after a heavv drinking } \\
\text { session? } \\
\text { (0) Never } \\
\text { (1) Less than monthly } \\
\text { (2) Monthly } \\
\text { (3) Weekly } \\
\text { (4) Daily or nearly every day } \\
\text { Score: }\end{array}$ \\
\hline $\begin{array}{l}\text { 2. How many drinks of alcohol do you usually drink per } \\
\text { session? } \\
\text { (0) } 1 \text { or } 2 \\
\text { (1) } 3 \text { or } 4 \\
\text { (2) } 5 \text { or } 6 \\
\text { (3) } 7,8 \text {, or } 9 \\
\text { (4) } 10 \text { or more } \\
\text { Score: } \\
\end{array}$ & $\begin{array}{l}\text { 7. How many times during the past year did your regret or } \\
\text { were you sorry that you have used alcohol? } \\
\text { (0) Never } \\
\text { (1) Less than monthly } \\
\text { (2) Monthly } \\
\text { (3) Weekly } \\
\text { (4) Daily or nearly every day } \\
\text { Score: }\end{array}$ \\
\hline $\begin{array}{l}\text { 3. How often do you drink more than six drinks at a time? } \\
\text { (0) Never } \\
\text { (1) Less than monthly } \\
\text { (2) Monthly }\end{array}$ & $\begin{array}{l}\text { 8. How often during the past year were you unable to recall } \\
\text { what happended the previous evening ,because you have } \\
\text { used alcohol? } \\
\text { (0) Never }\end{array}$ \\
\hline 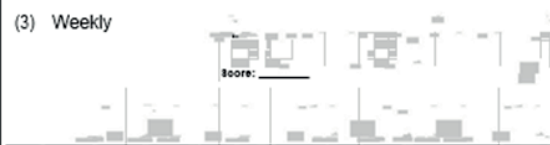 & $\begin{array}{l}\text { (1) Less than monthly } \\
\text { Weekty } \\
\text { (4) Daily or nearly every day }\end{array}$ \\
\hline $\begin{array}{l}\text { you could not stop drinking once you have started? } \\
\text { (0) Never } \\
\text { (1) Less than monthly } \\
\text { (2) Monthly } \\
\text { (3) Weekly } \\
\text { (4) Daily or nearly every day } \\
\text { Score: }\end{array}$ & $\begin{array}{l}\text { (0) No } \\
\text { (2) Yes, but not durina the past vear } \\
\text { (4 Yes, during the past year }\end{array}$ \\
\hline $\begin{array}{l}\text { 5. How often during the past year did you neglect your work } \\
\text { due to your alcohol usage? } \\
\text { (0) Never } \\
\text { (1) Less than monthly } \\
\text { (2) Monthly } \\
\text { (3) Weekly } \\
\text { (4) Daily or nearly every day } \\
\text { Score: }\end{array}$ & $\begin{array}{l}\text { 10. Was a family member, doctor, friend or health worker ever } \\
\text { worried about your alcohol use and suggested that you drink } \\
\text { less? } \\
\text { (0) No } \\
\text { (1) Yes, but not during the past year } \\
\text { (2) Yes, during the past year }\end{array}$ \\
\hline S1 & \\
\hline Scoring dor & Evaluated by: \\
\hline
\end{tabular}

Healthy Mother Healthy Baby@ Programme

Foundation for Alcohol Related Research

2017 

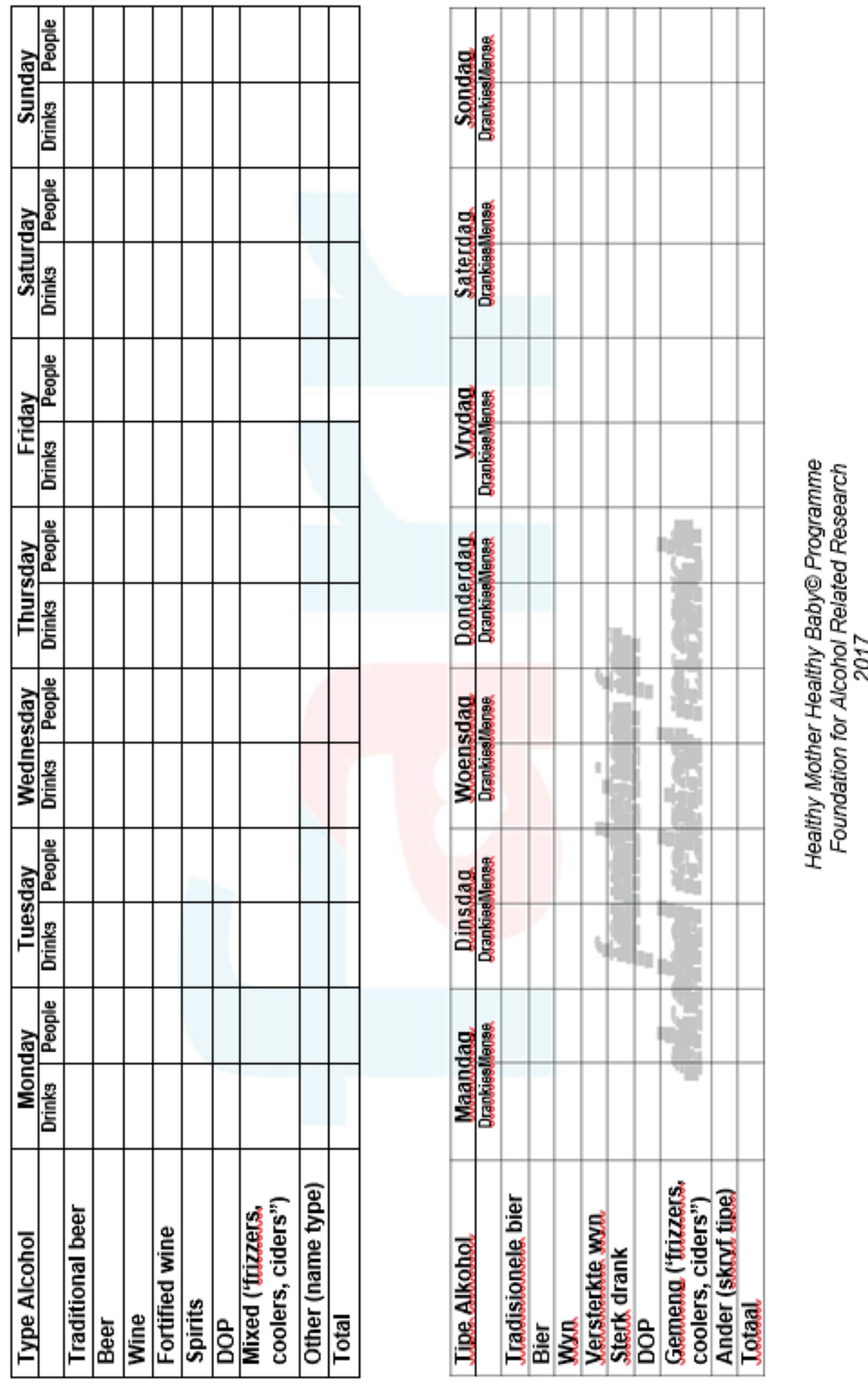



\section{Addendum}

Healthy Mother Healthy Baby Programme:

My Special Booklet 



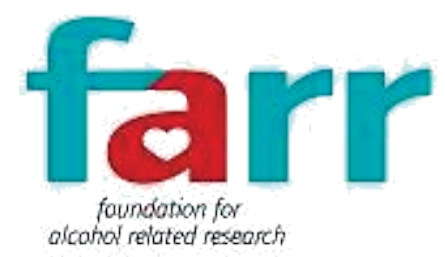

\title{
HEALTHY MOTHER HEALTHY BABYC PROGRAMME
}

\author{
My Special Pregnancy Booklet
}

Healthy habits for the pregnant mother to ensure that she gives life to a healthier baby
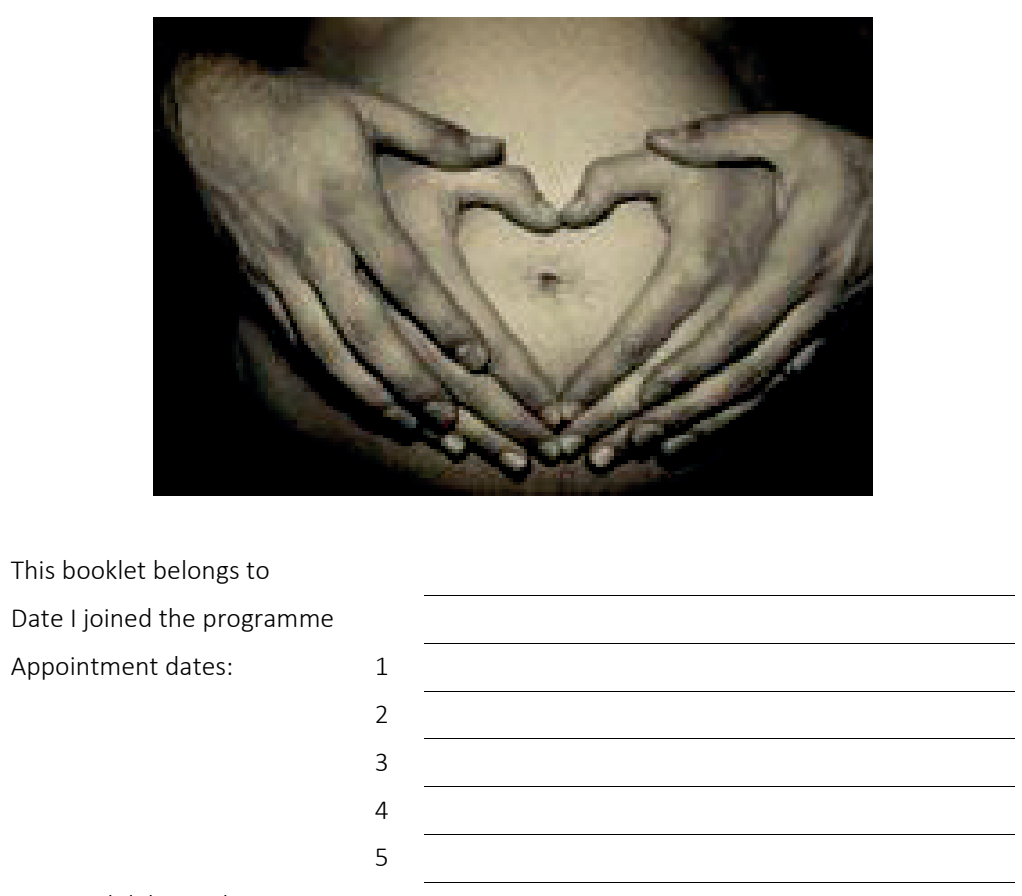

Expected delivery date 


\section{Addendum 5}

\section{Content}

1. Pregnant - now what?

2. How will you feel during your pregnancy?

3. Development of the unborn baby

4. How many weeks are you pregnant?

5. Visits to the antenatal clinic

6. Minor aches or health problems during pregnancy

7. What should I eat during my pregnancy?

7.1. What is healthy food?

7.2. Should you eat for two?

8. Exercising during pregnancy

8.1. What type of exercise should I do during pregnancy?

9. No smoking or tobacco

10. Avoid alcohol

10.1. What causes FAS?

10.2. What is Fetal Alcohol Syndrome (FAS)?

10.3. What does a child with FAS look like?

10.4. What are the symptoms/problems of a child with FAS?

10.5. Other problems that children with FAS may be born with

10.6. What can I do?

11. The FASD knot

12. Drugs

13. Will your baby be normal?

14. Concerns regarding childbirth

15. Labour

15.1. What do I need to take with me to the Labour Ward?

15.2. What happens in the Labour Ward?

16. How will you feed your baby?

16.1. Why is breastfeeding healthy for your baby?

16.2. Why is breastfeeding good for you?

16.3. Until what age should I be breastfeeding?

17. Follow-up appointments after delivery

17.1. When are follow-up appointments necessary?

17.2. Why are these examinations necessary?

18. Warnings after delivery

18.1. Postnatal depression

19. The baby's visits to the clinic:

20. How do I stimulate my baby?

21. Family planning

21.1. The pill 
21.2. Intrauterine device

21.3. Injection

21.4. Sterilisation

21.5. Emergency contraceptive

21.6. Condoms

22. Pap smear

23. Breast examination

List of figures

Figure 1: What mommy does....baby does (Johnson \& Johnson)

Figure 2: The development of the unborn baby (fetus) 


\section{Pregnant - now what?}

The FARR staff would like to congratulate you on your pregnancy and we would like to help you have a healthy pregnancy and healthy baby. We hope that this will be a happy time for you. If this is your first pregnancy, you might have many questions. You are welcome to ask us anything. We will try our best to help where we can; even if this is not your first pregnancy. Every pregnancy is different! During this time, you may experience many changes physically, as well as emotionally. If the pregnancy was planned, you are probably very excited about having this baby. However, an unplanned pregnancy can mean that this is a difficult time for you. We understand that everyone's circumstances are different. If you would like to talk to someone about your situation, you are more than welcome to come to any of us at FARR. Everything you tell us is confidential and we will not discuss it with anyone else.

\section{How will you feel during your pregnancy?}

A woman is usually pregnant for 9 months. The pregnant woman is often excited about the baby, but at the same time worried about everything that's coming; like whether the child will be healthy and if she'll be able to take care of the child. During these 9 months your hormones will change and this may cause you to feel sad and emotional. You may feel like you get angry very quickly or that you are more forgetful. Don't think you are alone in this, as many pregnant women feel the same way. It may help you to talk to your husband; partner; a friend or one of us about this. It often helps to simply talk to someone about how you feel.

During these 9 months it is important that your lifestyle is as healthy as possible, to ensure that you do whatever you can to help your baby develop normally.

Many women feel nauseous and tired in the morning, especially in the first 3 months of pregnancy. Make sure that you get enough rest and take time to relax; maybe try to take naps in the afternoon if possible.

\section{Development of the unborn baby}

A baby grows and develops in the pregnant woman's womb. When you are not pregnant, your uterus is about the size of your fist. This means that the uterus needs to stretch a lot to make space for the growing baby. This is one of the reasons why your body will feel so strange at times and why so many changes need to happen in you body, during the months before your baby is born.

A woman is usually pregnant for 40 weeks or "nine months", as we often say. During this time the baby grows from a group of cells the size of a pinprick, to a healthy boy or 
girl; weighing about $3.4 \mathrm{~kg}$. Each of us are different /unique. Therefore, each of you will feel differently about your pregnancy and your body will respond differently to the baby growing inside you. Some of you may not experience any problems at all; while others may get tired quickly. Some may gain a bit more weight and some may have higher bloodpressure, but we will give you information to help you stay as healthy as possible while you are pregnant.

Here is a picture to show you where the baby grows and how food reaches the baby.

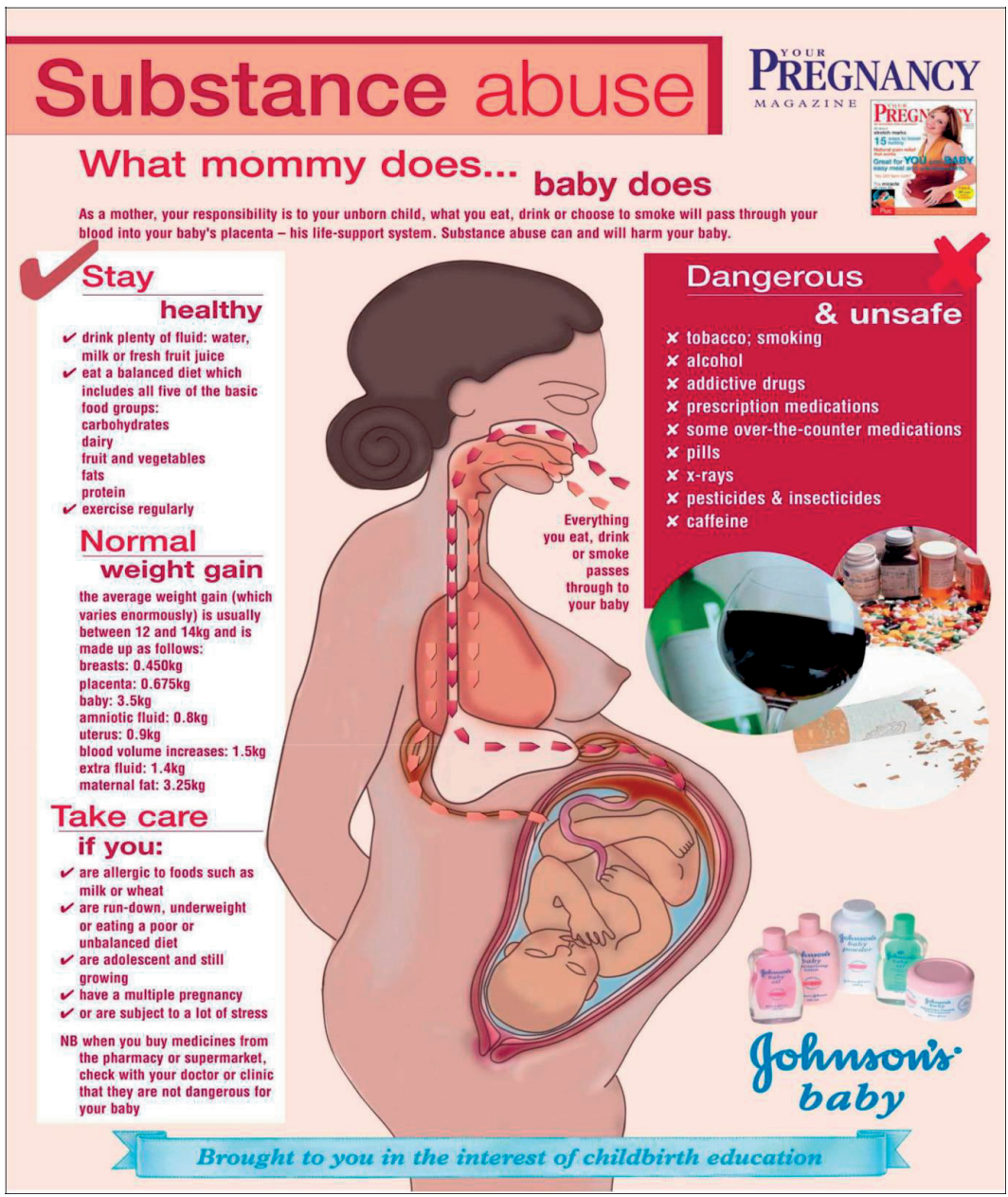

Figure 1: What mommy does .... baby does (Johnson \& Johnson)

\section{How many weeks are you pregnant?}

(Take a look at "The Development of the Unborn Baby" on next page) 


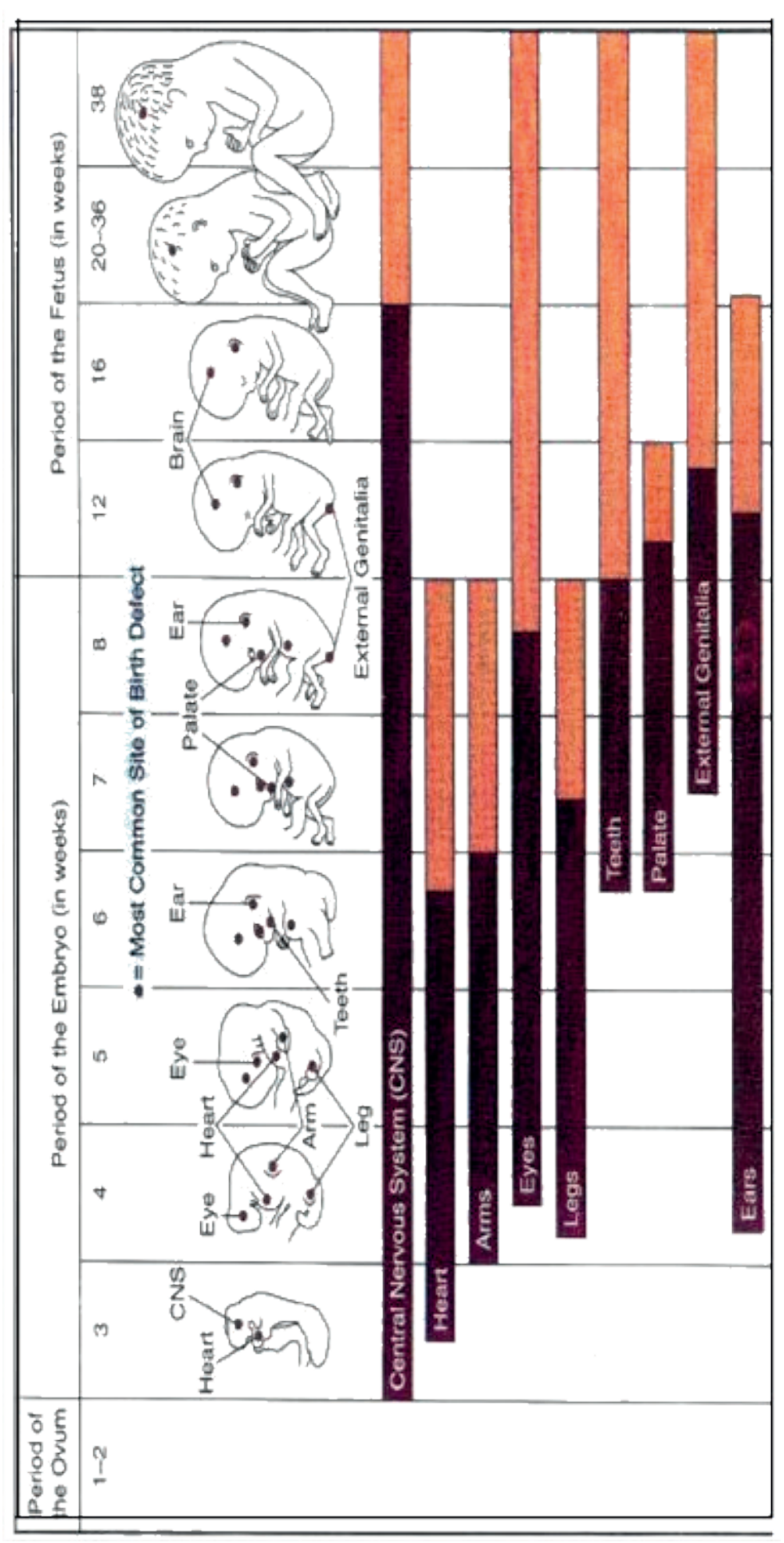

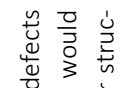

웜항

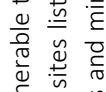

독 雚

तᄎ 든



变先

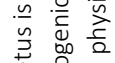

4 눈

焉

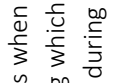

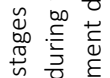

艺

产 है

० 눙

焉



들 을

co



苾

产苍

Do है

는

ลิ

苋这这



造

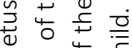

茫范

ते

동 흥

웓

告 \&

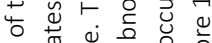

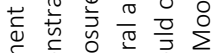

है



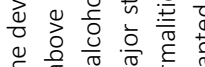

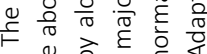

ن $\frac{0}{0}$ 文

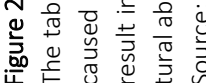


By the time that you are 20 weeks ( 5 months) pregnant, your baby is already starting to look like a little person with hands, legs, feet, eyes, ears and all the internal organs developing. The doctor may even have told you - if a sonar has been done - whether it is a boy or a girl. The picture below shows you clearly how your baby grows and develops from 3 weeks to 38 weeks. You'll see that the baby's brain and organs are developing throughout this time.

Do you think the baby would want to drink alcohol, smoke or use drugs? If you don't look after yourself during this time, especially if you smoke, drink or use other drugs, the baby can be damaged. You should even be careful about using home remedies or medication that has not been prescribed for you personally by the doctor, hospital or clinic. Remember, whatever the woman eats or drinks, the baby eats or drinks as well.

This Healthy Mother Healthy Baby (C) Programme has been developed with the purpose of - if necessary - helping you change your lifestyle, improving your diet and exercising regularly during your pregnancy, to ensure that you and your baby are as healthy as possible.

\section{Visits to the antenatal clinic}

We can't emphasise enough how important it is that you attend the antenatal clinic during your pregnancy. Regular examinations at the clinic will ensure that any problems are identified early enough by the clinic nurse. Even if you feel that everything is fine, it is still better to have an examination done by the clinic nurse. A woman should go to the clinic as soon as she suspects she's pregnant and should continue to attend the clinic for examinations.

During these antenatal examinations, you are welcome to ask the nurse any questions about your pregnancy, as well as your and your baby's health.

\section{Why are all the examinations during the first visit to the clinic necessary?}

To confirm your pregnancy as early as possible. This will ensure that any health problems you or your baby might have are identified as soon as possible.

Your blood pressure is measured, because if your blood pressure is high, you and your baby may experience problems.

The nurse examines you to:

o Measure the baby's growth and development, to determine your expected date of delivery and maybe to do a sonar examination.

o Feel how the baby is positioned.

o Listen to the baby's heartbeat. 


\section{Addendum 5}

You are weighed to check whether you are gaining enough / too little weight and to make sure you are not retaining water.

Tests:

o Finger prick to test your blood's iron levels.

o Blood is taken to determine your blood type, whether you have infections such as syphilis, HIV, etc. and to offer you treatment where necessary.

o Urine tests to determine whether diabetes, infections or other problems are present.

If you became pregnant as a result of rape (even if you didn't report it to the police), it's important to discuss this with the nurse at the clinic. She will be sure to take special care of you and address all the risks associated with rape.

\section{It is important to visit the clinic at:}

12 weeks (3 months)

20 weeks (5 months)

28 weeks (7 months)

34 weeks ( $8 \frac{1}{2}$ months)

If you experience any problems in between these times, make sure to go back to the clinic.

If you have any other health problems such as diabetes, asthma, epilepsy, heart problems or high blood pressure, the nurse will ask you to attend clinic more regularly.

If your HIV test is negative, it is important that you remain negative! You must only have safe sex (by using condoms), as this is in the best interest of you and your baby. If you become HIV positive during your pregnancy, it is very likely that your baby may also become positive.

\section{Don't become HIV positive during your pregnancy or while breastfeeding.}

If you are HIV positive, you must receive special treatment for yourself and your baby.

\section{Mother}

o The treatment will be determined by your CD4 count. If your CD4 count is very low, you will receive ARV medication to lower the virus levels in your blood. This will reduce the chance of passing the infection to your baby.

Baby

- You will receive information and medication to help keep your baby negative

- PMTCT (Prevention of Mother to Child Transmission) programme is focused on preventing the virus from being passed from the mother to her baby. 
o Feeding of the baby will also be discussed.

Medication for the pregnant woman:

Iron, to make the blood strong.

Folic acid, to make sure the brain and nervous system develops correctly. Vitamins, etc.

This medication is very important for you and your baby, even if it is free. Don't use your own medication or other home remedies, as this could be harmful to you and your baby.

All these examinations will help you to have a happy, relaxed pregnancy.

Important! Make sure you have your antenatal care booklet with you at all times!

\section{Minor aches or health problems during pregnancy}

For most women it is normal to experience certain problems such as constipation, back pain, thrush and heartburn during pregnancy. This is normal, HOWEVER if you feel uncomfortable or uncertain about anything, it's better to discuss it with the nurse at the clinic.

Immediately go back to the clinic if you experience any of the following:

Itchy or smelly vaginal discharge,

Bladder infection (painful bladder or burning urine). Complaints such as:

o Severe constipation, o Severe heartburn,

o Headaches with flashes, o Severe vomiting,

o Any vaginal bleeding,

- If your baby suddenly moves more / less, o If your water breaks,

o If you experience cramps that start in your back and move toward your stomach (with frequent pauses).

Fortunately, most of these problems can be prevented or treated. It is important that you stay fit and healthy by eating healthy and getting enough exercise. This might mean that you need to make some changes to your current lifestyle and/or diet. It is important to remember that a pregnant woman should get enough exercise and should not use any alcohol or tobacco. 


\section{What should I eat during my pregnancy?}

It is very important that you eat healthy food during your pregnancy. This will also help your baby to be healthier and grow well.

\subsection{What is healthy food?}

The food you eat gets used by your body to provide the baby with the food he/she needs in order to grow and develop; while at the same time, making sure your body stays strong and healthy. It is therefore very important that you eat as healthily as possible, by following these guidelines:

Variety: Food has been divided into different food groups. Each group is necessary for healthy growth and development. You should try to eat food from all the different food groups.

Starchy foods: Starch (bread, pap / porridge, rice, potatoes, pasta) forms the basis of most meals. Starchy foods provide the body with energy. Rather choose whole grains like oats and brown bread, as these prevent constipation and are sources of Vitamin B, which helps you and your baby have healthy hair, eyes, skin and nails.

Protein: Meat, fish, chicken, milk, eggs, soybeans and beans, should be eaten every day. This food group is very important, because your body needs it to produce extra blood and cells for you and your baby. This food group is also a good source of Vitamin B6 and B12. Meat also provides you with iron, which is essential for producing blood. Milk and milk products provide calcium which is important for the development of bones and teeth.

Fruit and vegetables: You must eat enough fruit and vegetables, because they contain vitamins and minerals which strengthen your immune system and help your body fight illnesses and infections like colds and flu. Choose green, leafy vegetables (spinach, broccoli, cabbage), as these are a good source of folate, which is essential for the development of the nervous system. Also include orange and yellow fruits and vegetables as these are a good source of Vitamin A, which is important for healthy eyes.

Fats: Try not to eat too many fatty foods, as this may cause you to gain too much weight. A high fat diet is also harmful to you heart.

Salt: Use very little salt. Some women develop high blood pressure during pregnancy, referred to as Pre-eclampsia. Don't add a lot of salt to your food and try to keep foods such as chips, biltong, droë wors and savoury biscuits to a minimum.

Sugar: Use very little sugar. Too much sugar, especially sweets and cooldrinks, can make you fat. Women who are overweigth before pregnancy should stay away from sweets. 
Fluids: Drink enough clean water, like tap water. Water from a dam or river may carry illnesses that can make you and your baby very sick. If you are not sure about the safety of the water, it's better to boil it before you drink it. This will ensure that the germs are killed.

Many pregnant women complain about nausea and other problems:

\section{If you feel nauseous}

Don't eat fatty or deep fried foods.

Eat smaller meals, more regularly - eat slowly.

Eat dry crackers before you get up in the morning. Drink rooibos tea rather than coffee.

\section{If you experience heartburn}

Eat 6 smaller meals per day.

Don't eat fatty or deep fried foods.

Don't drink coffee or sodas and don't eat chocolates. Don't eat spicy food.

Peppermint and smoke may worsen the heartburn.

Don't wear clothes that are tight against your stomach.

\section{If you are constipated}

Eat fibre (unpeeled fruit and vegetables, lentils, whole grain bread, oats, beans). Drink enough water ( 6 to 8 glasses per day).

Do not replace water with coffee or tea. Get enough exercise.

\subsection{Should you eat for two?}

You may notice that you feel hungrier, especially in the middle of your pregnancy. It is very important to eat breakfast every morning! You should not skip any meals. Eat a healthy snack, or drink a glass of milk. If you don't have enough food at home, you are welcome to come talk to one of us or the clinic nurse.

\section{Exercising during pregnancy}

Being pregnant for 40 weeks is not easy on your body. If you are fit, you'll not only feel better during your pregnancy, but the delivery may be easier as well. Also, being fit means you'll have more energy to take care of your baby after birth. Pregnancy is not an illness, so it's not necessary for you to sit or lie down all day. You should rest when you are tired, but make sure you get enough exercise. If you are fortunate enough to start your own 'pregnancy garden', it will help to keep you fit and busy. 


\subsection{What type of exercise should I do during pregnancy?}

The best rule to follow is to continue with your regular routine, like you had before pregnancy, but to listen to your body. If you feel tired, make sure you get enough rest. Examples of exercises that are ideal during pregnancy; are walking, swimming, dancing or light stretching exercises. Remember to do 'squeezing exercises' (pelvic floor exercises) and breast exercises. Ask the clinic nurse or the FARR staff to tell you more about this.

\section{No smoking or tobacco}

Take another look at the picture on page 4, which shows you that everything the mother eats, drinks or inhales, will eventually reach the baby as well.

Smoking is not only harmful to the mother's health, but also damages the unborn baby. Tobacco in any form contains many harmful elements which will prevent your placenta from growing the way it should; which means your baby will not receive sufficient nutrients from your body. That way, your baby will be smaller than normal at birth and may not be as clever as he would have been if you did not smoke. Smoking may also lead to miscarriages or cause a baby to die at birth (stillborn).

\section{Avoid alcohol}

Fetal Alcohol Syndrome is $100 \%$ PREVENTABLE!
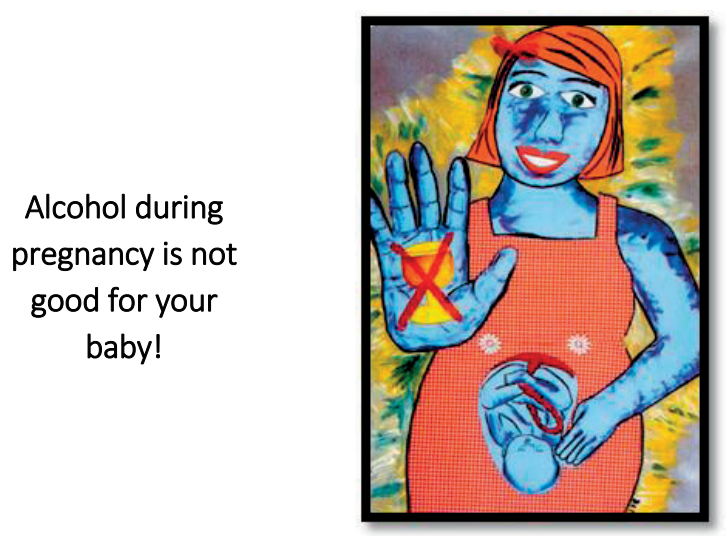

\author{
When the \\ pregnant \\ woman drinks, \\ her baby \\ drinks too!
}




\subsection{What causes FAS?}

During pregnancy, the unborn baby (fetus) grows in the mother's uterus. The baby is fed from the mother's body: everything the mother inhales, eats or drinks during pregnancy, feeds the baby.

The pregnant woman's body can digest the alcohol she drinks, however, the developing baby (fetus) cannot do this yet. Alcohol causes permanent damage to baby: the brain gets damaged and the growth of the baby is hindered; which means the baby is very small at birth and will remain smaller than other children his age, throughout his life. A baby will only be born with FAS if his mother used alcohol during pregnancy.

\subsection{What is Fetal Alcohol Syndrome (FAS)?}

Fetal Alcohol Syndrome (FAS) is found in children whose mothers drank alcohol during their pregnancy. These children's brains and other organs are damaged by the alcohol, because the alcohol acts as a poison to the unborn baby's developing cells. Children with FAS have permanent brain damage which can not be fixed/cured with medication or an operation. These children have learning and behavioural problems throughout their lives.

A child will not have FAS if his mother did not drink during pregnancy.

\section{A child with FAS has brain damage, learning and behavioural problems.}

\subsection{What does a child with FAS look like?}

A child with FAS is usually smaller than other children and may have certain facial features. Some children with FAS do not have these features and look completely normal. It is not possible to know whether someone has FAS just by looking at him. To know whether a child has FAS, he must be examined and tested by a specialised doctor and other specialists.

\subsection{What are the symptoms/problems of a child with FAS?}

Children with FAS may experience some or all of the following problems:

Brain damage (intellectual disability), Heart problems,

Problems with other organs, like the kidneys,

Baby is much smaller than other babies at birth,

Child remains smaller than other children their age, Hearing difficulties,

Learning problems - struggling to focus in class and progressing at school, Forgetful (poor memory),

Poor concentration, 


\section{Addendum 5}

Struggle with easy tasks, Poor behaviour,

Do not get along with other children (peers), Poor appetite,

Sleep problems.

10.5. Other problems that children with FAS may be born with

Spina Bifida (open spine), Cleft lip and/or palate.

10.6. What can I do?

Do not drink any alcohol during your pregnancy.

$\rightarrow$ If you do use alcohol, make sure you do not fall pregnant by using an effective contraceptive such as the pill or the injection.



Any amount of alcohol can damage the baby. Even small amounts of alcohol can cause brain- and/or physical damage in the unborn baby. It is not ONLY heavy drinking that damages the unborn baby. The use of alcohol may also lead to miscarriages.

REMEMBER: Any amount of alcohol during pregnancy can damage the growing baby. It is best for baby not to drink ANY alcohol!

Even if you only drink on occasion at parties or with friends, the alcohol can still affect your baby.

\section{The FASD knot}

Alcohol during pregnancy causes Fetal Alcohol Syndrome (FAS). You may know the red AIDS-ribbon everybody wears on AIDS-day. We have a similar symbol for FAS-day, but we use a cord with a knot in the place of a ribbon. This is called the FAS-knot. The FASknot, shown here in the picture, is used across the world as a reminder NOT to drink alcohol while pregnant. 


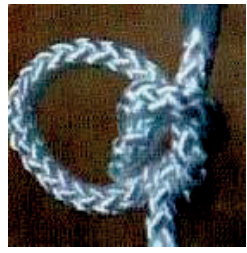

The community worker will give you a FAS-knot to wear or keep at home where you can see it everyday. Let it remind you not to drink alcohol while you are pregnant.

\section{Drugs}

Any drug such as marijuana, cocaine, amphetamines, hallucinogens, ecstasy, TIK as well as some prescription medication can harm your unborn baby. It is very important that you are honest and discuss it openly with the doctor, nurse or community worker if you use drugs. Some people also become addicted to drugs prescribed by the doctor or clinic such as cough syrup, headache pills or other pain medication. Please discuss any drugs you may use with us so that we can work together to protect your baby.

\section{Will your baby be normal?}

During the 9 months of pregnancy, every expectant parent will wonder whether something might be wrong with their baby. Talk to the clinic nurse about this, especially if there are illnesses or disabilities that run in your family.

Women will often be worried about their unborn babies' health, because they feel responsible for them. If something is wrong with the baby, the mother is also more likely to feel like it is her fault. By following the advice in this booklet, as well as the advice you receive from FARR and the clinic, you can be assured that you are doing your best to have a healthy, normal baby.

\section{Concerns regarding childbirth}

When a woman is pregnant for the first time, there is no way for her to know what to expect from the birth. Many women are worried about the birthing pains and whether they will be able to cope with it. No one can describe contractions (birthing pains) to you - although some women will try! Women who have had difficult deliveries previously may be worried about the next baby's birth, but remember that all pregnancies are different.

If this is your first pregnancy, try getting as much information as possible, read up on it and discuss the delivery process with the nurse or doctor. Don't be afraid to ask as many questions as you want. 


\section{Addendum 5}

\section{Labour}

\subsection{What do I need to take with me to the Labour Ward?}

You should have your suitcase packed when you are seven months pregnant. Remember to include the following items:

For the Mother

- Toiletries such as a washcloth, soap, toothpaste, toothbrush, deodorant, etc.

- Comb, towel.

- Pajamas and dressing gown.

- Slippers or comfortable, open shoes.

- Underwear (2 bras and 4 panties).

- Sanitary pads.

o Clothes for when you go home.

For the baby

- 2 babygrows and socks.

o 2 vests.

- 2 nappies and safety pins or disposable nappies.

- 2 thin blankets (receiving blankets).

- 1 thick blanket.

o 2 washcloths.

\subsection{What happens in the Labour Ward?}

Remember that you can take a special friend with you for support. The father of the baby may also be with you.

\section{.... For the pain}

Do some relaxation and breathing exercises.

Let your husband, partner or friend gently massage your back to help reduce the pain.

\section{... During delivery}

Keep moving and walk around, it will help you to dilate (deliver) faster and reduce the pain

Have a small snack and something to drink so that you have enough energy for the delivery

You will be examined regularly to check how the delivery is progressing Talk to the nurse if you are worried about anything 


\section{How will you feed your baby?}

Even before the baby is born, you should decide how you are going to feed your baby.

Breast is best!

Your body already starts producing milk during your pregnancy. Breast milk will always be the best nourishment for your baby; even if your baby should be born early (prematurely). Up to six months of age, breast milk will be the only food your baby needs. Between 6 and 12 months breast milk will still be the main source of nourishment your baby needs, even if you start feeding him/her solid food as well.

\section{Do not use any alcohol while you are breastfeeding, because the breast milk will also contain alcohol!}

The first breast milk will have a yellow colour (colostrum) and this contains many essential vitamins and minerals. This milk is very good for:

The growth and development of the baby.

Protection of the baby's intestines and helps with digestion of food.

Protecting the baby against common illnesses.

The milk that comes after the colostrum will have more of a bluish colour, but will be just as nourishing. The colour of the milk may differ between women, so do not worry about this.

Breast milk is fresh, at just the right temperature to be used immediately and is always ready. You don't even have to warm up any bottles! The body produces enough milk for all the baby's needs and there will always be enough for each feed. The more milk the baby drinks, the more milk will be produced by the body. A woman's breast milk will never be too strong or too weak for the baby.

\subsection{Why is breastfeeding healthy for your baby?}

Breast milk has all the nourishment a baby needs to grow and develop.

Breast milk has antibodies that protect the baby agains germs and illnesses such as diarrhea, chest- and ear infections.

It is a good way to calm the baby when he/she gets upset (almost like a "dummy"). It helps develop a close bond between mother and baby.

Breast milk is easier to digest than other types of milk (cow milk or powdered milk).

It helps with the healthy development of the baby's teeth.

Breast milk contains fat that is important for brain development.

Breast milk is clean and is always available at exactly the right temperature. 


\section{Addendum 5}

\subsection{Why is breastfeeding good for you?}

There is no preparation needed for breast milk, it is always available.

Breast milk is free, you don't have to pay for it.

Breastfeeding gives you some time to relax.

Breastfeeding is an opportunity to spend some alone-time with your baby and give him/her special attention.

Your menstural cycle (periods) get postponed while you breast feed.

Breastfeeding shrinks your uterus more quickly, helping it to return to its original size.

Breastfeeding may help you lose some of the extra weight you gained during pregnancy.

Breastfeeding reduces your risk of developing breast and ovarian cancer during menopause.

\subsection{Until what age should I be breastfeeding?}

Until they are 6 months old, babies must ONLY be fed breast milk. Breast milk contains all the nutrients the baby needs until that age and the baby's intestines have not matured enough to be able to digest other foods. From 6 months of age you can start feeding your baby solid food. Between 6 and 8 months the baby should first receive breast milk, followed by solid food. After 8 months of age the baby can be fed solid food first, followed by breast milk. Continue to breastfeed even after the baby has started eating solid food. If at all possible, babies should be breastfed until they are at least 2 years old.

\section{Follow-up appointments after delivery}

\subsection{When are follow-up appointments necessary?}

Within 3- 6 days after delivery, 6 weeks after delivery, If you or the baby are experiencing any problems.

\subsection{Why are these examinations necessary?}

To treat any infections, you or your baby might have,

To make sure you and the baby are both healthy, For advice and support,

To start with family planning again, For sex education, if necessary, To discuss breastfeeding,

Caring for your baby, e.g. fingernails and bottom. 


\section{Warnings after delivery}

Immediately go back to the clinic if you experience any of the following:

Headaches or dizziness, Fever,

Abnormal bleeding,

Smelly vaginal discharge, Leg pain or cramping,

Stomach pain,

Painful or swollen breasts,

Struggling with breastfeeding, Painful or cracked nipples,

If you feel sad, tired or depressed.

\subsection{Postnatal depression}

\section{How will I know whether I have postnatal depression?}

Struggling to sleep,

Blaming yourself when things go wrong,

You feel anxious, scared and overwhelmed by all your responsibilities, you lose interest in your baby,

You feel sad all the time.

GO TO THE CLINIC IMMEDIATELY!!! (even if you only have 3 of the symptoms)

\section{The baby's visits to the clinic:}

Take your baby to the clinic $3-6$ days after birth,

After that he/she needs to visit the clinic once a week until 6 weeks to be weighed,

After that once a month until the baby is 2 years (24 months) old, In between these visits, the baby should receive immunisations at:

6 weeks after birth

10 weeks after birth

14 weeks after birth

9 months of age

18 months of age

These appointments are very important, to prevent illnesses. The following will be done at baby clinic appointments:

Immunisations,

Vitamin A supplements, Deworming, 


\section{Addendum 5}

Weighing of the baby (to monitor growth and development), Check how your baby is developing.

\section{Immediately take your baby to the clinic if the baby:}

Has severe diarrhea that does not improve, Vomits,

Does not want to feed,

Does not want to drink breast milk, Has very few dirty nappies,

Has blood in the stool (poo) or urine, Develops a fever,

Just gets sicker,

Develops a yellow colour, Has dull eyes.

Do not wait until your baby is VERY sick before you go to the clinic. Rather go sooner than later!

When your baby has diarrhea you can give him/her a small measure of the following mixture, every time he has loose stool:

\section{8 teaspoons of sugar \\ $1 / 2$ teaspoon of salt \\ Dissolved in 1 litre of clean water}

Wash your hands with soap and clean water, Wash all the necessary kitchen utensils,

Make the mixture by following the recipe exactly. Be careful not to add too much salt. (The mixture should not taste saltier than your tears),

If the baby struggles to drink it, feed him/her a few teaspoons at a time.

\section{How do I stimulate my baby?}

Your baby already started developing during your pregnancy, when you stimulated him/her by talking, singing and playing music.

Talk and sing to your baby when baby is awake. Massage / stroke your baby.

Let your baby lie on his/her tummy when he/she is awake.

Make eye contact with your baby when you're busy feeding him/her or whenever the baby is awake.

Always cuddle your baby close to your body to make him/her feel safe.

\section{Family planning}

\subsection{The pill}

The pill must be used everyday, at the same time. 
Antibiotics, laxatives and diet pills counteract the effectiveness of the pill and could cause you to fall pregnant again. It is therefore important that you don't drink just any medicine, but that you ask the nurse at the clinic, doctor or pharmacist to give you medicine that is safe to use along with your family planning medication.

\subsection{Intrauterine device}

This device is inserted into the uterus. It is effective for years and can be removed when you want to plan a pregnancy. It is a very safe method of contraception, as you do not have to remember to take anything. If you tend to develop vaginal infections, the clinic may decide against this device for you.

\subsection{Injection}

You have a choice between a 2 month or a 3-month injection. This is also a reliable method of centreception and you don't have to remember to take a pill every day. However, you must remember to have the injection on time to prevent unplanned pregnancies.

\subsection{Sterilisation}

If you already have the number of children you want or can afford, it is a good idea to consider sterilisation for you or your husband/partner.

\subsection{Emergency contraceptive}

Emergency contraceptives are available at the clinic and should be taken within 72 hours ( 3 days) after having unprotected sex. An intrauterine device can be used for emergency contraception for up to 5 days.

\subsection{Condoms}

Condoms protect you agains unplanned pregnancies, as well as sexually transmitted diseases.

\section{Pap smear}

This is a quick procedure that can be done by the nurse at the clinic or by a doctor, to ensure that the uterus is healthy. Cells are collected from the uterus and sent to the laboratory to detect uterine cancer. Remember to return to the clinic for the results. 


\section{Addendum 5}

\section{Breast examination}

It is important to examine your breasts for lumps or any other abnormalities. You can get more information on how to do a breast examination from the nurse.

List of attachments

Figure 1 Johnson \& Johnson poster

Figure 2 Growth of the embryo (baby) 


\section{Healthy Mother Healthy Baby@ Programme}

Compiled by staff from the Foundation for Alcohol Related Research (FARR):

Leana Olivier, Leigh-Anne Davies, Zelia Gomes, Chanelle Lombard, Lian-Marie Drotsky, Marica du Toit and Yolandé Posthumus

Special thanks for the following contributions to the development of this booklet:

Ms Mariette Eckhard, Department of Health Northern Cape (De Aar)

Department of Health Western Cape, You and your baby are precious, February 2011 Departement van Gesondheid Wes-Kaap, Jy en jou baba is kosbaar, Februarie 2011

The development of this material was funded by Anglo American and Wesbank in collaboration with the

Foundation for Alcohol Related Research



(D) AngloAmerican

Healthy Mother Healthy Baby@ Programme

Foundation for Alcohol Related Research

16 November 2016 



\section{Addendum}

\section{Do yo have 3 minutes? \\ Card for Health Professional}




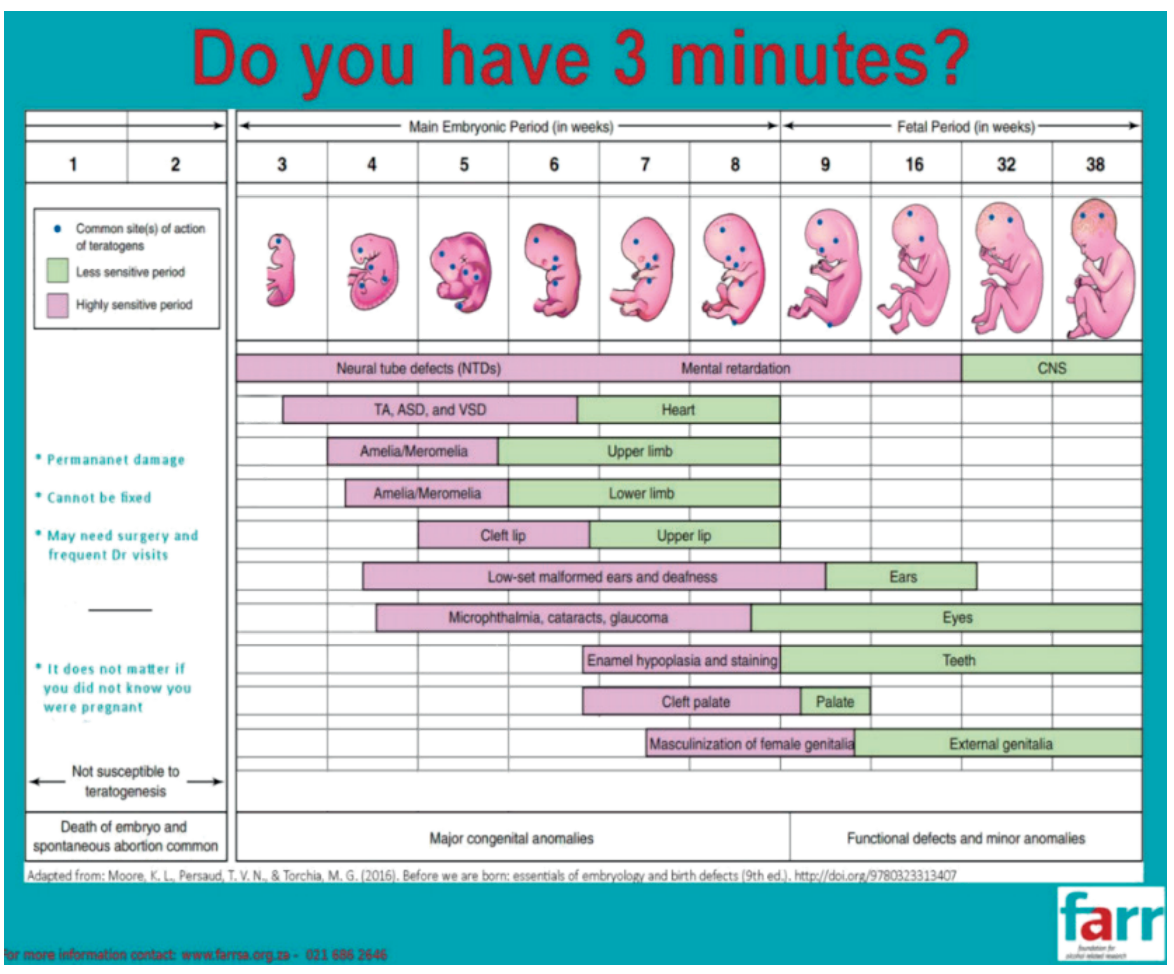

Do You Have 3 minutes?

Minute 1: Recognise the pregnancy postively. Congratulate the mom on her pregnancy, or if you feel that would be inappropriate, speak to her about the wonderful opportunity to bring a new life into the world, or how rewarding the relationship with one's child can be.

\section{Minute 2: Explain the dangers of drinking during pregnancy.|}

Using the fetal development chart on this card, explain that there is no safe time during pregnancy to drink, and that there is no safe amount one can drink during pregnancy. If she is drinking she must stop immediately to reduce the harm done to her baby.

Minute 3: Ask the mother to reflect on her own behaviour.

Ask the mother to reflect on her own drinking. Stress that she doesn't have to share it with you, but if she answers yes to two or more of the following questions she should consider getting assistance with her drinking behaviour.

1. Have you ever felt you should cut down on your drinking?

2. Have people annoyed you by criticizing your drinking?

3. Have you ever felt bad or guilty about your drinking?

4. Have you ever had a drink first thing in the morning to steady your nerves or to get rid of a hangover (eye-opener)

Should a mother indicate she may have a problem and wants help, please refer as appropriate.

FASD is a permanent disability, but it is $100 \%$ preventable 
Addendum

Do you have 3 minutes?

Card for Educators 


\section{Do you have 3 minutes?}



Visual Learing

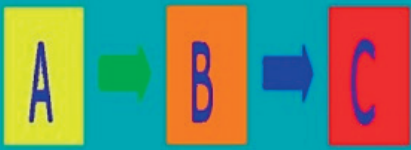

Structured Tasks

\section{9 \\ Small Chunks of \\ Information}

Do You Have 3 minutes?

Minute 1: I want to talk to you aाjout Fetal| a pregnant woman drinks alcohol, the alcohol can damage the unborn baby, and the damage caused will last a lifetime. It does not matter at what time during pregnancy she drinks, how much she drinks, or what kind of drink she drinks, any alcohol can put the fetus at risk! The baby takes in everything that the mother eats and drinks and alcohol is like poison to a baby.

Minute 2: How does FASD impact children in the classroom?

Problems with attention, working memory and inhibition:

Focusing attention, maintaining attention and shifting attention.

Deficits in working memory $\rightarrow$ cannot take in and process a lot of information at once:

Especially verbal instructions. Children will lose track easily.

Lack of inhibition can lead to inappropriate behaviour:

Acting out \& conflict with peers.

Behaviour may be linked to disability rather than disobedience

Minute 3: How can I assist an FASD child in the classroom?

Benefit if instructions are kept short:

Break tasks down and give instructions for each part separately;

Use visual aids when giving a lesson or instructions;

Give clear breaks between the end of one tasks and the beginning of the next. Have a consistent routine so that they can anticipate what happen next Give the child a break to move around when focus is lost.

Use positive reinforcement of good behaviour rather than punishment.

FASD is a permanent disability, but it is $100 \%$ preventable 


\section{Addendum}

\section{Do you have 3 minutes?}

Card for Community Workers 


\section{Do you have 3 minutes?}

For more information:

www.farrsa.org.za

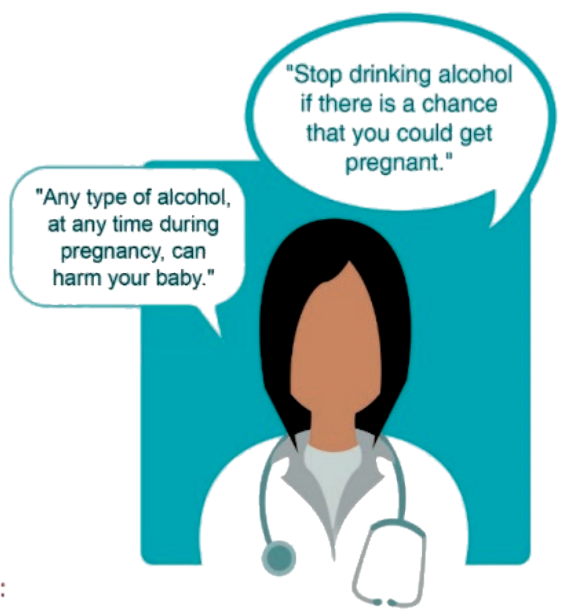

Tel: 0216862646

\section{Do You Have 3 minutes?}

Minute 1: I want to talk to you about Fetal Alcohol Spectrum Disorder (FASD). When a pregnant woman drinks alcohol, the alcohol can damage the unborn baby, and the damage caused will last a lifetime. It does not matter at what time during pregnancy she drinks or how much she drinks, any alcohol can put the baby at risk! The baby takes in everything that the mother eats and drinks and alcohol is poison to a baby

Minute 2: What happens when a child has FASD?

Permanent brain damage that cannot be fixed

Struggle in school

Struggle to follow instructions and obey rules

Struggle to learn from experience

Do the same things wrong over and over

Physical disabilities

Problems with their hearts, eyes, ears and other organs.

May need a doctor more often than other children

Minute 3: What can be done to prevent FASD?

Women must STOP drinking when they plan on getting pregnant.

Pregnant women must ABSTAIN from drinking for the whole 9 molnths

If a mother does not drink during pregnancy, she CANNOT have a child with FASD

FASD is a permanent disability, but it is $100 \%$ preventable 


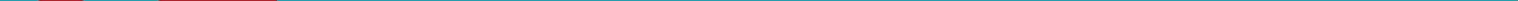

